Portland State University

PDXScholar

Spring 7-1-2016

\title{
(Re)Presenting Peoples and Storied Lands: Public Presentation of Archaeology and Representation of Native Americans in Selected Western U.S. Protected Areas
}

Cerinda Survant

Portland State University

Follow this and additional works at: https://pdxscholar.library.pdx.edu/open_access_etds

Part of the Anthropology Commons, and the Cultural History Commons Let us know how access to this document benefits you.

\section{Recommended Citation}

Survant, Cerinda, "(Re)Presenting Peoples and Storied Lands: Public Presentation of Archaeology and Representation of Native Americans in Selected Western U.S. Protected Areas" (2016). Dissertations and Theses. Paper 3032.

https://doi.org/10.15760/etd.3027

This Thesis is brought to you for free and open access. It has been accepted for inclusion in Dissertations and Theses by an authorized administrator of PDXScholar. Please contact us if we can make this document more accessible: pdxscholar@pdx.edu. 
(Re)Presenting Peoples and Storied Lands:

Public Presentation of Archaeology and

Representation of Native Americans

in Selected Western U.S. Protected Areas

by

Cerinda Survant

A thesis submitted in partial fulfillment of the requirements for the degree of

\author{
Master of Science \\ in \\ Anthropology
}

Thesis Committee:

Jeremy Spoon, Chair

Katrine Barber

Virginia Butler

Douglas Wilson

Portland State University

2016 
(C) Cerinda Survant 2016

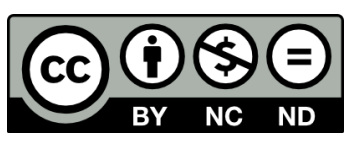

(Re)Presenting Peoples and Storied Lands: Public Presentation of Archaeology and Representation of Native Americans in Selected Western U.S. Protected Areas by Cerinda Survant is licensed under a Creative Commons Attribution-NonCommercialNoDerivatives 4.0 International License. 


\begin{abstract}
Every year, hundreds of thousands of people visit the Native American ancestral lands in the western United States developed for tourism and recreation. The stewards of these lands seek to engage visitors and enrich their experience, and simultaneously to protect the lands' natural and cultural resources. To achieve their mission, protected areas regularly use interpretation -- materials and experiences that aim to educate visitors about resources and see them as personally meaningful. However, there is little literature on interpretive content in protected areas, few qualitative studies of interpretation as constructed by visitors and interpreters, and little literature on the representation of Native Americans in museums and protected areas.

I consider the public presentation of archaeology at exemplary protected areas in the U.S. Southwest and Great Basin within a theoretical framework of governmentality and representation. Within a mixed-method research design, this project used participantobservation at thirteen protected area locales to identify interpretive content and representational strategies, and semi-structured interviews with 31 individuals to elicit staff and visitors' understandings of interpretation and display. This research found three types of narratives in the interpretation sampled-- scientific narratives, cultural narratives, and management messages. In general, scientific narratives appeared more frequently than cultural narratives and both appeared more frequently than management messages. Archaeology dominated scientific narratives, cultural continuity dominated cultural narratives, and orientation dominated management messages. In general, archaeology appeared with greater relative frequency than any other component of interpretive
\end{abstract}


content. This study also found that interpretation predominantly adopted a third-person omniscient point of view and represented people predominantly in the ancient past.

This study has both academic and applied outcomes. The work aims to contribute to the scant body of literature on interpretive content in protected areas stewarding natural and cultural resources, the few qualitative studies of interpretation as constructed by visitors and interpreters, and the existing literature on the representation of Native Americans in museums and protected areas as well as informing future interpretive practice. These findings inform a report on contemporary interpretive practice and recommendations for the public presentation of archaeology delivered to the US Fish and Wildlife Service in December 2013. 
Dedication

For David, as ever 


\section{Acknowledgements}

I deeply appreciate the guidance and support my advisor, Dr. Jeremy Spoon, has offered from the very earliest days of this project. Drs. Katy Barber, Virginia Butler, and Doug Wilson also offered encouragement, time, and energy. Anan Raymond of the U.S. Fish and Wildlife Service was instrumental in creating and funding the project. Angie Jabine provided editorial assistance.

Richard Arnold of the Pahrump Paiute Tribe, members of the Nuwuvi Working Group, individual citizens of the Nuwuvi (Southern Paiute) Nation, and Annjanette Bagozzi, Kevin Des Roberts, Amy LaVoi, and Wendy Smith of the U.S. Fish \& Wildlife Service made key contributions to the applied portion of this project. I owe much to the individual visitors who participated in interviews and acknowledge the assistance of staff at the Anasazi Heritage Center, Bandelier National Monument, Canyons of the Ancients National Monument, the Makah Resource and Cultural Center, Mesa Verde National Park, Petroglyph National Monument, the State Museum of Nevada, and Bureau of Land Management staff in Caliente and Carson City. Colleagues in the Office of Applied Anthropological Research, particularly Rachel Lahoff and Kendra Wendel, provided friendship and encouragement.

Finally, I acknowledge the understanding and support of family, extended family, and friends, notably David Kaplin, Gwendolyn Kaplin, Jonathan Survant Kaplin, Benjamin Vulpes, and Kara Fern Vulpes 
This research was made possible by funding provided by the Lincoln County Archaeology Initiative (LCAI) funded by the Southern Nevada Public Lands Management Act (SNPLMA). 


\section{Table of Contents}

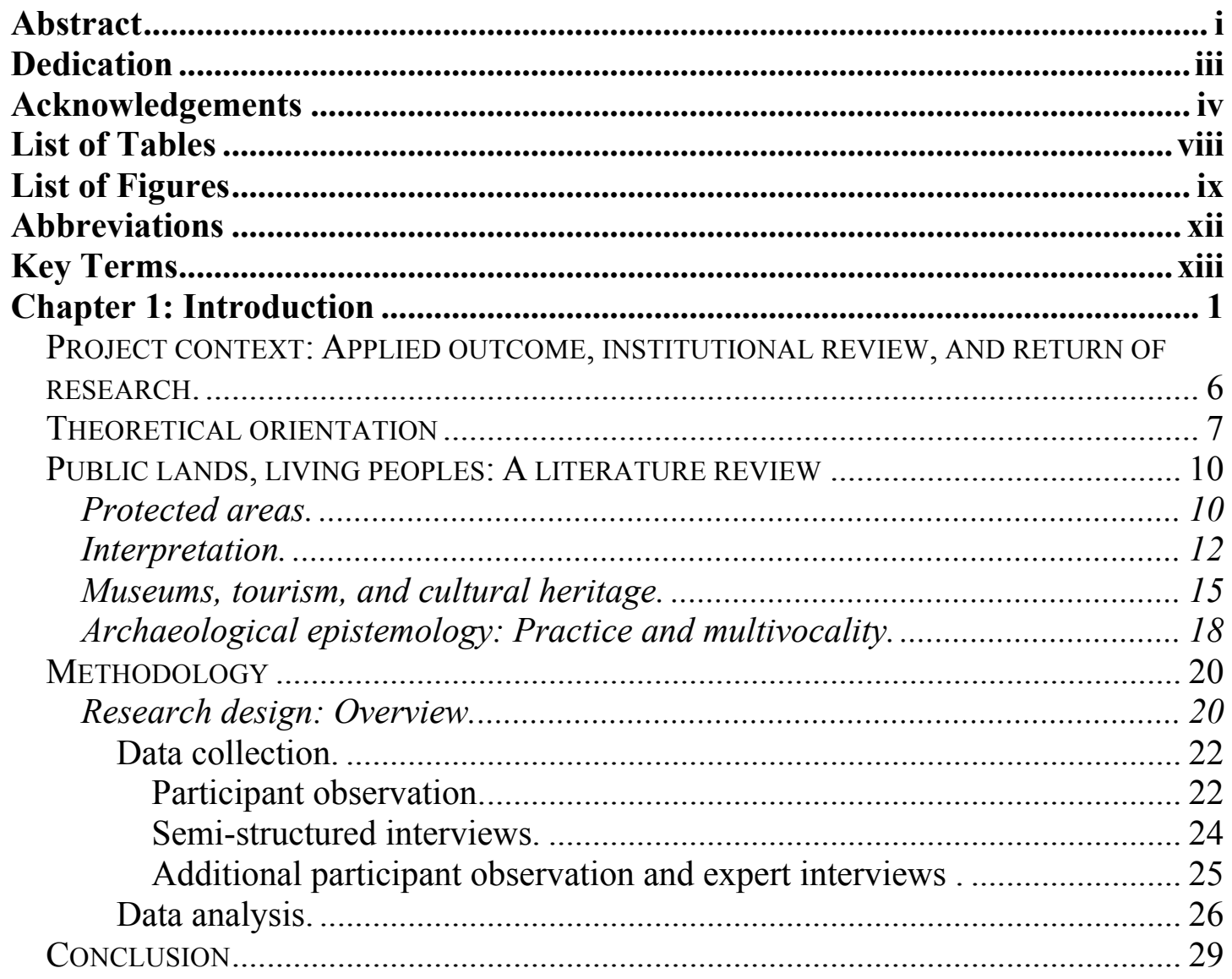

Chapter 2: Context ............................................................................................ 30

Petroglyph National Monument, Albuquerque, New Mexico.................... 31

Bandelier National Monument, Los Alamos, New Mexico. ......................... 34

Mesa Verde National Park, Mesa Verde, Colorado. ................................... 37

Anasazi Heritage Center and Canyons of the Ancients National Monument,

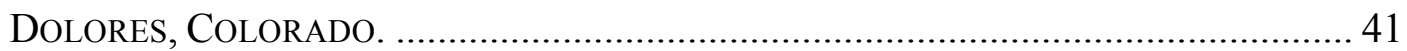

Nevada Petroglyph Sites: Churchill And Lincoln Counties....................... 45

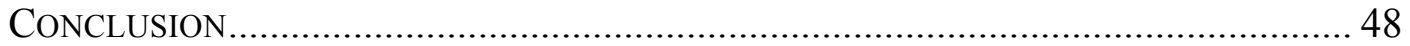

Chapter 3: The what of Interpretation: Narrative content ................................51

SCIENTIFIC NARRATIVES: THE PHYSICAL SCIENCES, PROCESSUAL ARCHAEOLOGY AND

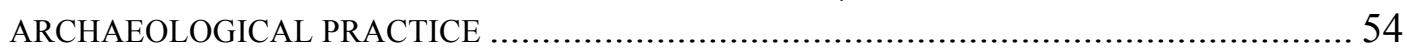

MANAGEMENT MESSAGES: ORIENTATION, CONSERVATION/PRESERVATION, AND MISSION

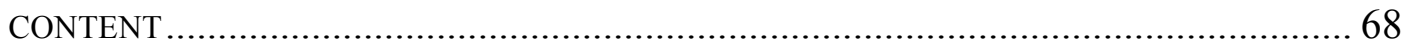

CUlTURAL NARRATIVES: NONINDIGENOUS HISTORY, CONNECTION TO PLACE, CULTURAL

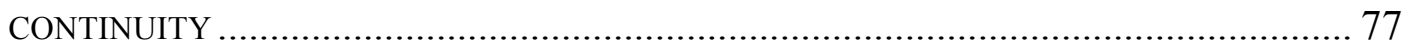




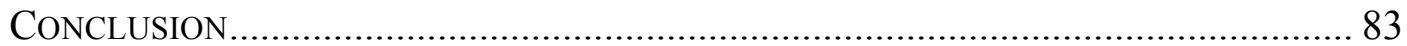

Chapter 4: Peoples' stories: Unpacking Cultural Narratives ............................... 85

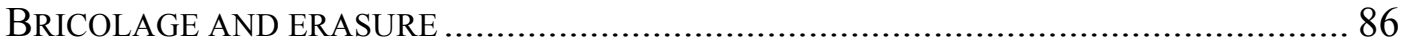

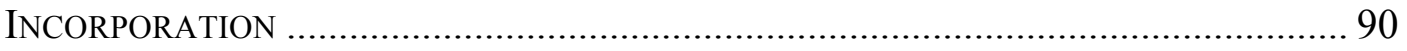

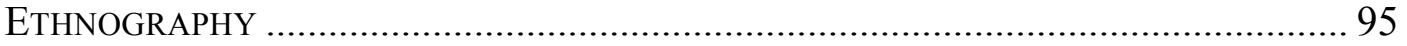

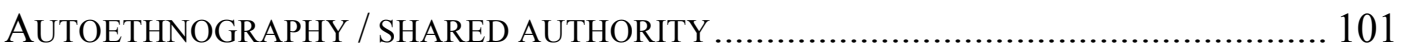

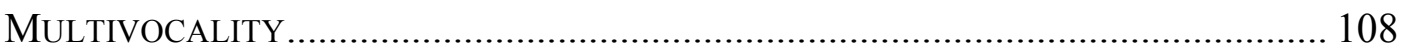

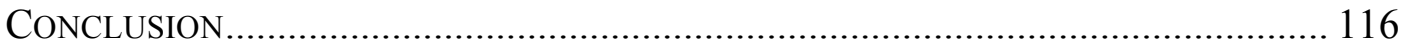

Chapter 5: Who, Where, When, How: Voice, Time, and Representation ......... 118

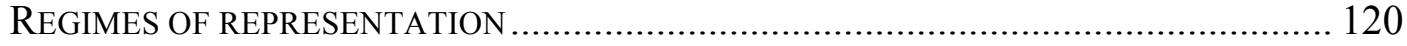

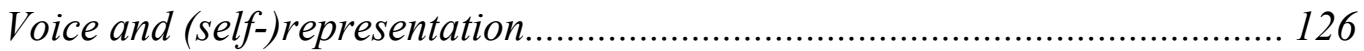

Native voice. .................................................................................. 126

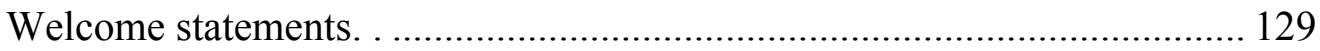

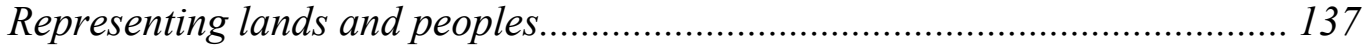

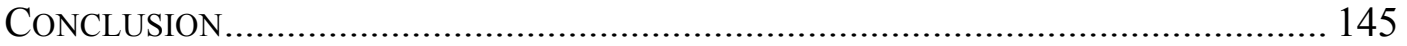

Chapter 6: Conclusion ................................................................................................ 146

META-ANALYSIS OF NARRATIVE CONTENT ..................................................... 146

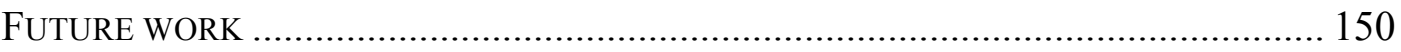

References ....................................................................................................................... 155

Appendix A: Recommendations and Lessons Learned ........................................ 170

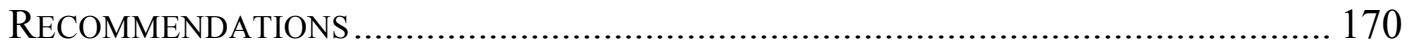

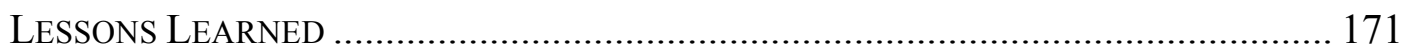

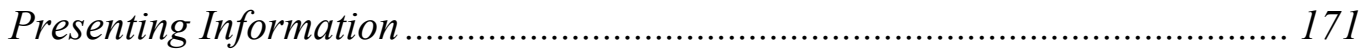

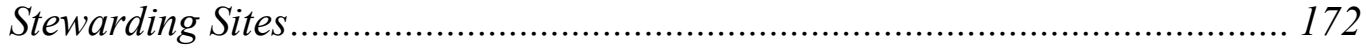

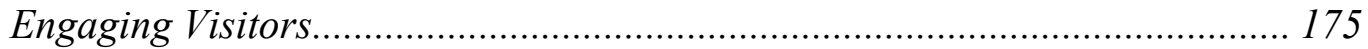

Representing Visually .................................................................. 178

Ending Erasure and Resituating Archaeology ........................................ 180

Appendix B: Sample Questions .................................................................................... 184

Appendix C: Codebook ........................................................................................................ 186

Appendix D: Informed Consent ............................................................................ 188

Appendix E: Demographic statistics ............................................................................. 190

Appendix F: NPS Permits ............................................................................................. 191 


\section{List of Tables}

Table 1. Summary of research sites, locales, data...... 28

Table 2. Selected natural and cultural resources, Petroglyph National Monument .. 32

Table 3. Interpretive infrastructure, Petroglyph National Monument ...................... 33

Table 4. Selected natural and cultural resources, Bandelier National Monument .... 35

Table 5. Interpretive infrastructure, Bandelier National Monument ....................... 36

Table 6. Selected natural and cultural resources, Mesa Verde National Park .......... 38

Table 7. Interpretive infrastructure, Mesa Verde National Park ............................ 39

Table 8. Selected natural and cultural resources, Anasazi Heritage Center / Canyons of the Ancients National Monument ................................................................ 43

Table 9. Interpretive infrastructure, Anasazi Heritage Center / Canyons of the Ancients National Monument ........................................................................ 43

Table 10. Selected natural and cultural resources, Churchill and Lincoln County sites, Nevada 47

Table 11. Interpretive infrastructure, Churchill and Lincoln County Sites, Nevada . 47

Table 12. Relative presence of selected language constructions: Narrative point of view 121

Table 13. Relative presence of narrative timeframes 123 


\section{List of Figures}

Figure 1. Client site and research sites. Following page 20

Figure 2. Petroglyph National Monument, Boca Negra interpretive trail. 31

Figure 3. Bandelier National Monument, Tyuonyi Overlook trail. 34

Figure 5. Anasazi Heritage Center / Canyons of the Ancients National Monument, excavated and backfilled Sand Canyon Pueblo.

Figure 6. Anasazi Heritage Center / Canyons of the Ancients National Monument. 42

Figure 7. Grimes Point Archaeological Area, Churchill County, Nevada. 45

Figure 8. Ash Springs petroglyphs, Lincoln County, Nevada. 46

Figure 9. Petroglyph National Monument, Piedras Marcadas wayside sign incorporating management messages, archaeological narratives 51

Figure 10. Petroglyph National Monument, Boca Negra wayside sign incorporating geologic narrative, archaeological narrative, cultural narrative, and management messages. 52

Figure 11. Relative presence of scientific narratives, management messages, and cultural narratives in selected protected area Interpretation. 53

Figure 12. Petroglyph National Monument, Boca Negra Canyon trail, worn interpretive key sign. 54

Figure 13. Bandelier museum display juxtaposing scientific and cultural narratives. 55

Figure 14. Relative presence of scientific narratives in selected protected area Interpretation.

Figure 15. Mesa Verde pithouse interpretive sign. 57

Figure 17. Anasazi Heritage Center / Canyons of the Ancients National Monument, display of Puebloan material culture over time. 62

Figure 18. Anasazi Heritage Center / Canyons of the Ancients National Monument, portion of Discovery Room. 63

Figure 19. Anasazi Heritage Center / Canyons of the Ancients National Monument, display of Pueblo cultures over ancestral time. 
Figure 20. Relative presence of management messages in selected protected area Interpretation.

Figure 21. Ash Springs sign, Lincoln County, Nevada. 70

Figure 22. Grimes Point Archaeological Area sign, Churchill County, Nevada. 70

Figure 23. Mesa Verde Visitor and Research Center, display presenting management message with mission content. 73

Figure 24. Mesa Verde Visitor and Research Center, entrance plaza. 74

Figure 25. Relative presence of cultural narratives in selected protected area Interpretation. 78

Figure 26. Mesa Verde Visitor and Research Center, first display alcove. 79

Figure 27. Petroglyph National Monument, Mesa Point Trail sign incorporating management message, archaeological content, and multiple cultural narratives.

Figure 28. Anasazi Heritage Center / Canyons of the Ancients National Monument, display of kiva mural fragment. 83

Figure 29. Anasazi Heritage Center / Canyons of the Ancients National Monument, historic and contemporary era timeline. 85

Figure 30. Component cultural content: combined Nevada sites. 86

Figure 31. Component cultural content: Mesa Verde National Park. 91

Figure 32. Mesa Verde Visitor and Research Center, first display alcove, detail of Figure 26. 93

Figure 33. Component cultural content: Petroglyph National Monument. 96

Figure 34. Petroglyph National Monument, central visitor center exhibit. 98

Figure 35. Component cultural content: Bandelier National Monument. 102

Figure 36. Bandelier museum Oral Tradition panel. 104

Figure 37. Component cultural content: Anasazi Heritage Center / Canyons of the Ancients National Monument. 110

Figure 38. Anasazi Heritage Center / Canyons of the Ancients National Monument, Escalante Pueblo Trail introductory interpretive panel. 111 
Figure 39. Anasazi Heritage Center / Canyons of the Ancients National Monument, Lowry Pueblo Ancestral Knowledge display.

Figure 40. Anasazi Heritage Center / Canyons of the Ancients National Monument Sand Canyon Pueblo trail minimal interpretive panel. 118

Figure 41. Mesa Verde Visitor and Research Center, satellite map detail.. 139

Figure 42. Bandelier museum geologic map.. 140

Figure 43. Bandelier museum Rio Grande Coalition Period map. 141

Figure 44. Bandelier museum migration map. 142

Figure 46. Anasazi Heritage Center / Canyons of the Ancients National Monument, cultural continuity map. 144 


\section{List of Abbreviations}

ADA: Americans with Disabilities Act (1990)

AHC: Anasazi Heritage Center (BLM)

AIRFA: American Indian Religious Freedom Act (1978)

BAND: Bandelier National Monument (NPS)

BLM: Bureau of Land Management, Department of the Interior

CANM: Canyons of the Ancients National Monument (BLM)

CCC: Civilian Conservation Corps

FWS: U.S. Fish and Wildlife Service, Department of Agriculture

MEVE: Mesa Verde National Park (NPS)

NAGPRA: Native American Graves Protection and Repatriation Act (1990)

NHPA: National Historic Preservation Act (1966)

NMAI: National Museum of the American Indian (Smithsonian Institution)

NPS: National Park Service, Department of the Interior

PETR: Petroglyph National Monument (NPS)

UNESCO: United Nations Educational, Scientific, and Cultural Organization

VRC: Mesa Verde National Park Visitor and Research Center

WPA: Work Projects Administration 


\section{List of Key Terms}

Degree of Development

- Minimally developed: parking, trails, limited signage

- Developed: parking, trails, signage, restrooms, shade, seating; most have water

- Fully developed for tourism: parking, trails, signage, restrooms, shade, seating, water, camping or lodging, visitor center and/or museum; most have retail

Interpretation: The "educational activity that aims to reveal meanings about our cultural and natural resources" (Beck \& Cable, 2011, p. xviii). In order to avoid confusion with archaeological interpretation, I use it as a proper noun.

Interpretive programming: the full range of interpretive efforts — signage, brochures, videos, guided tours and their electronic stand-ins, exhibits in visitor centers, museums, and on the land.

Interpretive signage

- Key sign: typically 4-8 inches wide, 1-3 feet high; usually identifies flora or bears a number corresponding to particular trail guide text; may display regulations or minimal interpretive content, e.g. Figure 2, Figure 8.

- Minimal sign: typically a single rectangular panel, 1-4 feet per side; typically placed waist-high and angled; displays interpretive content without blocking view of surrounding landscape, e.g. Figure 3, Figure 5. Minimalist refers to design.

- Wayside sign: the largest and most informative type of sign; typically displays site orientation, maps, management directives, and interpretive content; usually placed at parking areas and trailheads, e.g. Figure 9.

Interpretive print media

- Site brochure, site bulletin: branded, multi-fold brochure; often lavishly illustrated and in color; protected area's signature

- Site newspaper, visitor guide: as above, but reprinted seasonally or more often; may resemble glossy magazine, tabloid newspaper, single color multi-fold brochure, or simple flyer

- Trail guide, brochure: printed material available at or near trailhead; copies to borrow or purchase for minimal or no cost; form and style vary widely

Voice (grammar): a category which distinguishes between constructions (verb phrases, clauses, sentences) which present a situation as active or passive (Oxford Dictionary of English Grammar, Aarts, 2014).

- Active voice: the grammatical subject is the actor of the action expressed by the verb, e.g. John loved Mary.

- Passive voice: the grammatical subject undergoes the action expressed by the verb, e.g. Mary was loved by John. The agent appears in the by-clause, 
equivalent to the Latinate dative. True passive constructions have active equivalents.

- Agentless passive: a passive construction that expresses no agent. The agent may be unknown, unimportant, or patently obvious e.g. Eisenhower was elected in 1952. The agent may be concealed for rhetorical purposes, e.g. The constitution has been interpreted as outlawing federal land ownership.

- Pseudo-passive or statal passive: A construction resembling the passive but lacking an active equivalent, permitting no agent, and expressing a state of affairs, e.g. It was finished (opposed to a passive in a progressive verbal construction, e.g. It was finished when he arrived at noon).

Verb tense (Oxford Dictionary of English Grammar, Aarts, 2014)

- Perfect: the verb tense indicating action completed before another-stated or implied - time; contrasts with progressive and simple tenses; may express past, present, or future action.

- Unmarked present tense: present tense used to express quintessential reality or timeless truth e.g. The moon orbits the earth.

Bricolage: Construction using a range of materials or sources; an object or idea thus created; a miscellany, often composed of found objects (OED Online, "Bricolage, n.," 2015). From the French for "tinkering" or "do it yourself," bricolage is constrained by materials ready to hand (Dictionary of Critical Theory, 2016). Makeshift handiwork; similar to collage (Oxford Dictionary of Literary Terms, 2015). Unlike collage, which implies conscious, even critical, selection from available material, bricolage suggests that available material determines what the maker --a handyman or jack-of-all tradesconstructs.

Incorporation: Action of incorporating one thing into another; of forming into a community, especially of the formation of a body politic (OED Online, "Incorporation, n.," 2015). The assimilation of groups into larger collectivities (Dictionary of the Social Sciences, Calhoun, 2002). 
(Re)Presenting peoples and storied lands

\section{Chapter 1: Introduction}

Contemporary perceptions of Native Americans in the western United States are largely limited and inaccurate. Stereotypes and misinformation in the media and museums (and museum-like institutions) generally characterize Native Americans as unchanged and unchanging; most de-emphasize the vitality and diversity of contemporary Native cultures. In one study of visitors to three Smithsonian museums, for example, respondents talked about Native Americans primarily in an idealized precontact past; they underestimated the overall American Indian population, overestimated the reservation population, and considered traditional Native culture critically endangered by urbanization and reservation conditions (Doering, DiGiacomo, \& Pekarik, 1999, pp. 147-148). There is little social science research on the general public's attitudes toward Native Americans; in light of the number of institutions that display Native American material culture to the public, there is a particular dearth of literature on museum or protected area visitors' attitudes toward Native Americans (Doering et al., 1999, p. 149).

A study undertaken to inform exhibit development at the National Museum of the Native American (NMAI), found "only a cursory familiarity with Native philosophy, history, or current conditions" among a representative sample of museum-goers (Doering et al., 1999, p. 148). The authors report that more than $75 \%$ of their respondents encountered Native culture and communities via exhibitions of Native culture in natural history, history, and other museums; only $25 \%$ had personal contact with Native Americans at work, school, or through family connections (Doering et al., 1999, pp. 146147). Some respondents (10\%) explicitly cited movies, television, and news coverage as 
the source of their knowledge of Native American cultures and some of them (5\%) expressed skepticism about media content (Doering et al., 1999, p. 144). The authors identified five key challenges facing the development of the new museum: 1) the necessity to "bridge the chasm" between visitors' idealized images of Native Americans in the past and negative perceptions of descendant communities in the present; 2) to foster recognition of Indian culture in the contemporary U.S.; 3) to emphasize the cultural meanings of material culture; 4) to convey both Native American cultural change and continuity simultaneously; and 5) to show visitors the commonalities between Native American cultures and their own (Doering et al., 1999, pp. 147-148).

Every year, more than half a million people visit Mesa Verde National Park, the National Park Service's flagship park dedicated to "preserving the works of Man" (**cite website). Visitors to other protected areas on Native American ancestral lands in the western United States seek historical and cultural experiences in them as well (White, Virden, \& Cahill, 2005, pp. 71-72) ${ }^{1}$. Generally, western US protected areas steward natural and cultural resources, and the majority of them offer the visitor Interpretation of both. Little academic literature examines interpretive content in protected areas, the stories and themes presented to visitors to sites stewarding natural and cultural resources

${ }^{1}$ The authors constructed the analytic component "cultural and historical learning" by combining the survey responses: "to learn about Native American traditions," "to develop my knowledge of history," "to develop a knowledge of prehistoric cultures," "to experience a connection with Native American cultures," "to learn about archaeology," and "to have an authentic experience of past cultures." 
(Carr, 2004, pp. 434-436; Staiff, Bushell, \& Kennedy, 2002, p. 98). This project seeks to address the following research questions:

- What narratives constitute Interpretation in selected U.S. Southwest protected areas?

- How is archaeology presented to the public in these protected areas?

- How are peoples and cultures represented in these protected areas' Interpretation?

One exceptional study of protected area Interpretation, White et al., **undertaken to inform the development of National Park Service (NPS) General Management Plans for two protected areas stewarding Native American cultural resources, found visitors more motivated by "cultural and historical learning" than "nature contemplation," or "escape and socializing. The authors noted that this particular interpretive planning project displayed a certain tension between what staff thought visitors should know, and what visitors wanted to know, as evidenced in the research. The authors situated key challenges facing the project's interpretive planners within the larger sociopolitical context:

There remain questions about the structure, tone, and plurality of the narratives to be presented and which voices are presented and thus privileged. These choices have real implications for residents of communities near the parks and for affected social groups, such as modern affiliated American Indian tribes. . . This choice and subsequent decisions about the stories and themes for cultural sites often go unexamined. (2005, pp. 79-80)

This thesis queries the structure, tone, and plurality of the narratives presented in selected western U.S. protected area Interpretation, the stories and themes presented to the public, and examines "which voices" are presented, represented, and privileged in the public presentation of archaeology. This thesis aims to contribute to an anthropological understanding of Interpretation by examining the content of stories told to visitors in protected areas and how interpreters understand their practice. 
Within a mixed-method research design, I used participant observation to generate my core component and semi-structured interviews to generate my supplemental component (Morse \& Niehaus, 2009, pp. 28-32) at the thirteen exemplary western protected areas. ${ }^{2}$ In order to study interpretive programming, I focused on topical or thematic units in signs, text-driven exhibits, and printed trail guides $(\mathrm{n}=531)$. In order to access individuals' understandings of Interpretation, I conducted semi-structured interviews with sixteen protected area staff and volunteers and fifteen visitors $(\mathrm{n}=15$ and $\mathrm{n}=8$ respectively; see Table 1).

I argue that the observed protected area Interpretation disproportionately features scientific narratives over cultural narratives. Furthermore, I maintain that each protected area's Interpretation embodies the differential privilege protected area management accords to the practices, perspectives, and knowledge of land managers, archaeologists, anthropologists, and other disciplinary specialists over the practices, perspectives, and knowledge of local residents and of Native Americans who identify protected areas as ancestral lands. Additionally, I identify these protected areas' interpretive signatures, and argue that each site uses characteristic rhetorical strategies that reflect a particular balance of and attitude toward emic and etic knowledge (Pike, 1967). This work aims to

2 Two protected areas, The Anasazi Heritage Center and Canyons of the Ancients, are collocated but not coextensive, and share a management regime; I regularly collapse the distinction between them in analysis but often highlight it in discussion. The eight least-developed protected areas share a management regime, and are located in two counties in the state of Nevada: I consider them together. Therefore, thirteen protected areas comprise five research sites: the combined Anasazi Heritage Center and Canyons of the Ancient National Monument (AHC/CANM), the NV sites (NV), Bandelier National Monument (BAND), Petroglyph National Monument (PETR), and Mesa Verde National Park (MEVE). 
contribute to the literature on interpretive content in protected areas, qualitative studies of the attitudes of producers and consumers of protected area Interpretation, and the representation of Native Americans in museums and protected areas; this work also aims to inform future interpretive development.

The remainder of Chapter 1 describes the project and the methods chosen to address my research questions. Chapter 2 establishes the context of the research by presenting the thirteen geographic locales that comprise the five research sites. Chapter 3 examines plurality, comparing the relative presence of three types of interpretive content: scientific narratives, cultural narratives, and management messages. I argue that sampled protected area Interpretation generally privileges scientific narratives of the past over cultural ones and occasionally perpetuates the nature/culture dichotomy by disproportionally featuring management messages. Chapter 4 queries structure and tone, presenting the components of each research site's cultural narratives, and argues that each site's Interpretation reflects a particular attitude toward etic and emic (outsider and insider) knowledge characteristic of that site. Chapter 5 focuses on key interpretive displays in situ to consider voice, and frames representational strategies in terms of the who, where, when, and how of the stories told to visitors. I argue that the rhetorical strategies employed -most notably who speaks and who is spoken for-- correlate with the attitudes toward insider and outsider knowledge discussed in Chapter 4. Chapter 6 reviews my argument and explores some of the implications of this work. Interested readers will find Lessons Learned and Recommendations in Appendix A. 
(Re)Presenting peoples and storied lands

PROJECT CONTEXT: APPLIED OUTCOME, INSTITUTIONAL REVIEW, AND RETURN OF RESEARCH.

This work has both applied and academic outcomes. The research was undertaken as part of the Interpretive and Public Site Use Site Plan for the Black Canyon Archaeological District (Spoon, Melham, \& Arnold, 2015) for the U.S. Fish and Wildlife Service (FWS). Expert knowledge holders among the Black Canyon project participants selected the research sites for the applied project and the thesis.

The Interpretive and Public Site Use Site Plan for the Black Canyon Archaeological District, Pahranagat National Wildlife Refuge, Desert National Wildlife Refuge Complex (Spoon, Melham, et al., 2015) incorporated a report of my research findings as the Comparative Study of Similar Sites (Survant \& Spoon, 2015). The FWS used information from the report in two successful agency proposals for funding under the Lincoln County Archaeological Initiative (LCAI) and the Southern Nevada Public Land Management Act (SNPLMA).

In accordance with protocols authorized by Portland State University's Institutional Review Board and the terms of National Park Service (NPS) research permits, ${ }^{3}$ I collected no identifying information from interviewees, only basic demographic information from which to create descriptive statistics, and have filed interim research reports with the NPS. Upon completion of this degree, I will provide protected area, museum, and cultural center staff with executive summaries and permanent URLs to the finished thesis.

\footnotetext{
${ }^{3}$ NPS research permits, informed consent for staff, a sample script for use with visitors, sample interview questions, an acknowledgment of visitor participation, and demographic statistics will be found in Appendices B - F.
} 
(Re)Presenting peoples and storied lands

\section{THEORETICAL ORIENTATION}

Following Foucault $(1970,1994)$, I consider the public presentation of archaeology and the representation of Native Americans in these protected areas as an episteme: a discursive apparatus "always inscribed in a play of power...linked to certain coordinates of knowledge which issue from it but, to an equal degree, condition it" (Foucault, 1980, pp. 196-197). The literature on protected area Interpretation generally focuses on environmental education, managing visitor behavior, achieving management objectives, and maximizing revenue. Therefore I turn to recent scholarship in museology, cultural heritage, and alternative archaeology (e.g. Habu, Fawcett, \& Matsunaga, 2008; Peers \& Brown, 2003; L. Smith, 2004) to illuminate the many museum-like qualities of protected area Interpretation of cultural resources. Like museum display, protected area Interpretation is highly epistemic: protected areas repair, update, and renovate Interpretation as resources allow; museums regularly practice rotation and curation. Because of these disciplinary practices, the study of a museum is necessarily an act of archaeology (Bennett, 1995, 2004; Foucault, 1970); I suggest the study of Interpretation is as well. Historically, both archaeology and the museum have reinforced nationalist and colonialist projects; in turn, nationalist and colonialist projects have reinforced archaeology and the museum (Bennett, 1995, 2004; Boast, 2011; Rose, 1999; Trigger, 1984).

I query the degree to which archaeology and the museum continue to determine the terms of interpretive discourse as well as the degree to which Native American assertion of sovereignty reshapes it. All five research sites display Native American material culture to the public and so situate themselves within this problematic 
genealogy. Some sites construct this heritage as a monument to human creativity and innovation; some as national patrimony; and some as public lands to which some Americans have prior claims or special affinities.

Recent scholarship generally associates shifts in relations of power/knowledge within North American anthropology and the museum to a number of factors (Barber, 2013, pp. 27-29; Lonetree, 2012, pp. 2-26). Postmodernist thought has encouraged disciplinary reflexivity and cultural relativism across archaeology, anthropology, and museology (Lawlor, 2006, pp. 4-6; Peers, 2007, pp. xvii-xix; Phillips, 2003, pp. 158160). International human rights discourse has reshaped North American discussions of indigeneity and indigenous rights (Lawlor, 2006, pp. 162-185; Phillips, 2003, pp. 158160). Both have contributed to the development of indigenous archaeology. The gradual institutionalization of NAGPRA and NHPA has, in some cases, fostered durable working relationships among federal agency personnel, archaeologists practicing in cultural resources management, academic archaeologists, individual Native Americans, and Native American nations (Fine-Dare, 2002, pp. 6-9). Finally, the rise of the Red Power movement in the 1970s not only brought Native American concerns into the larger public discourse, but also influenced (and continues to influence) contemporary Native American assertions of sovereignty and the right to self-determination, both of which influence the interpretation and the Interpretation of Native American material culture. Archaeology is one way of knowing the past, and traditional knowledge is another. But in general, neither the general public nor the academy accord traditional knowledge - indigenous perspectives on time, space, and culture - the same authority as 
western science (Colwell-Chanthaphonh \& Ferguson, 2010, pp. 337-338). Museological convention mirrors shifts in knowledge/power over time (Bennett, 2004). The technologies of display $-19^{\text {th }}$ and early $20^{\text {th }}$ century taxidermy, dioramas, and reconstructions, midcentury displays of archaeological excavations in situ, lavish videos - change over time but continue to reflect the privilege science enjoys.

Following Hall (Hall, Critcher, Jefferson, Clarke, \& Roberts, 1978; Hall, Held, \& McGrew, 1992; Hall \& Gieben, 1992), I consider the repertoire of imagery, language, and visual effects in exemplary protected area interpretive practice as a regime of representation. Hall (1999) notes that heritage is doubly inscribed: "We come to know its meaning partly through the objects and artifacts which have been made to stand for and symbolize its essential values. Its meaning is constructed within, not above or outside of representation" (Hall, 1999, p. 5, italics in original). This thesis queries how Interpretation works to represent archaeologists, Native Americans, science, and tradition.

One might, following Boast (2011), Clifford (Clifford, 1997, 2001, 2004), or Pratt (1991), question the degree to which peoples' self-representation is possible within the power relations of the museum or, by extension, protected area. I suggest that protected area Interpretation is a key arena for the assertion of Native American sovereignty and remains insufficiently studied and theorized. Lyons (2000) defines rhetorical imperialism as "the ability of dominant powers to assert control of others by setting the terms of debate" (2000, p. 452), and rhetorical sovereignty as "the inherent right of peoples to determine their own communicative needs and desires in this pursuit [of self- 
determination, i.e., political sovereignty], to decide for themselves the goals, modes, styles, and languages of public discourse" (2000, pp. 449-450, italics in original). I follow the example of scholars using the lens of rhetorical sovereignty to examine and critique visual representations (Raheja, 2007, 2011), museum practice (King, 2011), and Interpretation (Lahoff, 2013).

PUBlic LANDS, LIVING PEOPLES: A LITERATURE REVIEW

This project occupies the intersection of tourist experience, archaeology, and the interpretive programming developed by and for protected areas and draws upon literature across a range of disciplines.

\section{Protected areas.}

In general, protected areas reflect the dominant construction of humans' relationship to the environment: that nature is out there, a distinct system best understood and managed within the epistemology of Western science and best served, conserved, and preserved in the absence of humans (Cronon, 1996, pp. 9-14; Escobar, 1999, pp. 6-7; Lane, 2010, pp. 662-663). Starting with the establishment of U.S. national parks in the late 19th and early 20th century, the dominant worldwide paradigm for the establishment and governance of protected areas has been the "Yellowstone Model" (Spence, 1999, pp. 4-8; Stevens, 2014, pp. 36-40). Generally, the model erases both the history of land use and Native Americans themselves (West \& Brockington, 2006, citing Meyer, 1996). This construction of protected areas assumes that these areas are best established, governed, and managed by the state to preserve nature in the absence of human occupation and resource use. In many cases, force is justified to remove residents and protect resources. 
(Re)Presenting peoples and storied lands

In the US, protected areas managed by the NPS focus on preservation and recreation; those managed by the BLM, on multiple use. Unlike the model, neither agency's mandate is limited to the protection of biodiversity. The NPS "preserves unimpaired the natural and cultural resources and values of the National Park System for the enjoyment, education, and inspiration of this and future generations" (National Park Service, n.d.-b). The BLM "sustain[s] the health, diversity, and productivity of the public lands for the use and enjoyment of present and future generations" (Bureau of Land Management, 2012). Both agencies' missions mandate balancing the interests of current and future generations, no small feat, but the NPS' mission emphasizes the preservation of resources and the BLM's stresses productivity and protection.

Archaeological or spiritual significance complicates the recreational use of public lands. Different stakeholder groups often value the same land, landscape, or feature for quite different reasons: Devil's Tower, for example, is a holy place, a rock-climbing site, and a tourist draw (Dustin, Schneider, Mcavoy, \& Frakt, 2002, pp. 80-82); desert springs may be both loci of spiritual practice and water sources for livestock and crops (Spoon, Arnold, \& Nuwuvi Working Group, 2011, pp. 10, 12, 53, 2014, pp. 12, 19-20, 22, 26, 36; Wendel, 2014, pp. 34, 37-39). Petroglyph sites, too, attract multiple constructions of meaning (Dickinson, 2012, pp. 118-121; Spoon et al., 2014, pp. 49-59). Protected areas' historical exclusion of indigenous peoples from the conserved wilderness is changing. Indigenous input into Interpretation and management at protected areas is increasing (Hibbard, Lane, \& Rasmussen, 2008, pp. 144-146; Spoon \& Arnold, 2012, pp. 491-495; Stevens, 2014, pp. 15-83, 283-311), but remains exceptional. 
(Re)Presenting peoples and storied lands

\section{Interpretation.}

Historically, Interpretation was the province of the naturalist and the nature guide; he interpreted natural resources—quite distinct from cultural resources—-for the interested visitor. As John Muir wrote in an often-cited 1871 journal, "I'll interpret the rocks, learn the language of flood, storm and the avalanche. I'll acquaint myself with the glaciers and wild gardens, and get as near to the heart of the world as I can." Enos Mills' 1920 Adventures of a Nature Guide and Freeman Tilden's 1957 Interpreting Our Heritage remain the practice's foundational texts (Benton, 2009, p. 10). Mills' focus on nature, particularly on nature as an environment apart from human influence, still underpins the practice today, although interpreters practice a variety of settings. Tilden's six principles of interpretation construct the practice as being relevant, transcending mere information, a teachable art, holistic, developmentally appropriate, and aiming to provoke affect and cognition (Tilden, 2007, pp. 34-35), and remain highly influential in current professional practice.

Ham (1992) identifies four qualities that distinguish Interpretation from other forms of communication: it is pleasurable, relevant, organized, and structured thematically (1992, p. 8). Interpretation crosses media. It may be personal — tours, talks, lectures, walks, storytelling, demonstrations, performances—or nonpersonal —exhibit panels, object displays and labels, waysides and other signs, websites, interactive technologies, self-guided tours, newspapers, magazines, books, brochures, etc. (National Park Service, 2007, n.d.-c). Both types share aims, applications, and theoretical orientation, but nonpersonal interpretation reaches almost three times as many visitors as 
(Re)Presenting peoples and storied lands

the archetypal face-to-face interaction of visitor with uniformed (or costumed) staff (National Park Service, 2007, p. 6).

Scholars generally emphasize the interpenetrability of education and Interpretation (Farmer \& Knapp, 2008, pp. 340-341). Theoretically, the practice of Interpretation is constructivist, (i.e. posits that knowledge is socially constructed) and draws upon recent research in cognitive and behavioral psychology (Ham, 2009, pp. 5154). Hunter (2012) identifies a lack of ethnographic fieldwork and cultural analysis in the professional literature, a gap this research aims to fill by asking interpreters about their professional practice (2012, p. 5). Additionally, the author cites the absence of qualitative studies as evidence of the disciplinary privilege of cognitive and social psychology in the study of Interpretation (2012, pp. 49-52).

Recent conceptualizations of Interpretation extend more widely and emphasize visitors' meaning-making. Interpretation is "a mission-based communication process that forges emotional and intellectual connections between the interests of the audience and the meanings inherent in the resource" (National Association for Interpretation, n.d.). Alternatively, it is "an informational and inspirational process," the "educational activity that aims to reveal meanings about our cultural and natural resources" (Beck \& Cable, 2011, p. xviii). Across the discipline, both literature and practitioners use the phrase "connecting the visitor to the resource" widely and take its meaning to be self-evident. Empirical studies of Interpretation are relatively new and few in number. One recent model, Benton's Four Conceptions of Interpretation (2009) considers the practice in terms of four sets of definitive goals that have accreted over time: the foundational 
(Re)Presenting peoples and storied lands

goal of connecting visitors to resources; conveying agency mission and influencing visitor behavior (1950s); encouraging environmental literacy (1960s); and promoting tourism outcomes (1980s) (2009, pp. 8-10). Skibins, Powell, and Stern (2012) found much of the existing work focuses on measuring change in visitor learning, and to a lesser extent, visitor attitudes and satisfaction (2012, p.5). Additionally, a significant body of professional literature is devoted to the development and evaluation of Interpretation and to the training and certification of guides, interpreters, and planners. There is also a significant body of academic literature exploring the economic implications of visitor experience and visitor choice at cultural heritage sites (e.g. Strickland-Munro \& Moore, 2013). That literature is beyond the scope of the current study.

Few studies of Interpretation address the actual content of Interpretation (Carr, 2004, pp. 434-436; Staiff et al., 2002, p. 98). Much of the literature of Interpretation asserts that Interpretation increases visitors' knowledge and shapes behavior (Duncan \& Martin, 2002, pp. 23-24; Ham, 2009, pp. 52-53; Littlefair \& Buckley, 2008, pp. 340341; Powell \& Ham, 2008, pp. 477-485). However, persuasive empirical investigations suggest that Interpretation correlates more highly with visitors' emotional connection to resources than with their stated intention of adopting pro-conservation or propreservation behaviors (Benton, 2009, pp. 20, 26-27; Hughes \& Saunders, 2005, pp. $620-623)$.

In general, Interpretation conflates material culture and culture; it may objectify indigenous people as well. Even respected professionals and scholars in the field continue 
to use the phrase "interpretation of Native Americans" or "interpretation of indigenous people" (e.g. NAI 2013 conference materials, Benton, 2011, p. 84). Given that the field's accepted usage of Interpretation links visitors to resources, I resist the established usage; in this research, I use the terms representation and self-representation of Native Americans instead.

Museums, tourism, and cultural heritage.

The museum is an institution of governmentality, a site in which the state and the population mutually constitute each other (Bennett, 2004, pp. 12-35; Bennett, Dibley, \& Harrison, 2014, pp. 138-140). In the 19th and early 20th centuries, museums developed disciplinary practices (uses of space, conventions of representation and display) to operationalize the museum's goal of civilizing, educating, and managing its public (Bennett, 2004, pp. 160-186). In general, these museum practices continue to shape the ways the protected areas sampled in this research present archaeology to the public. In 21 st-century North America, concern with bias, preconceptions, power, discourse, and representation shapes museum practice (Phillips, 2005, pp. 84-88). Collaborative ethnography in museum practice today is widely considered in terms of which partner holds authority over the content of the display: Who determines the conceptual structure of the exhibit? Who establishes the exhibit's themes? Who selects objects? Who determines the audience to be addressed (Ames, 2003, pp. 170-173; Conaty, 2003, pp. 227-228; Phillips, 2003, pp. 155-160)?

The central trope for most discussions of the 21st-century museum's socially inclusive practice remains the museum as contact zone (Boast, 2011; Clifford, 1997; 
Pratt, 1991). Scholars generally acknowledge that despite museums' stated

commitment to inclusion, colonial relations of power still obtain: the museum remains a place of coercion, outright conflict and enduring inequality. Minimally, protected area policy requires the involvement of affiliated Native American communities in interpretive development: ${ }^{4}$ potentially, Interpretation is also a contact zone. Museum studies literature generally describes the making of collaborative exhibits as a spectrum of practices that can result in community-curated exhibits as well as conventionally authoritative and didactic ones. A genuinely collaborative practice demands a significant shift in power relations between institutions and source communities. Such a shift may only be nominally possible, as Boast (2011, pp. 57-59, 64-67) and Clifford (1997, pp. 212-215) emphasize.

According to Phillips (2003, pp. 163-164), the current practice of collaboration between museums and indigenous peoples validates and disseminates multiple social constructions of reality; collaboration may also undermine the messages the usual funders and sponsors of museums and exhibits seek to perpetuate, and instead offer avenues for indigenous self-representation. In contrast, Boast (2011, p. 66) suggests that despite the new museology's emphasis on education, engagement, and multivocality, the mainstream museum remains a neocolonial institution and instrument of governmentality: indigenous people are given more room to maneuver and more access to resources when they agree

\footnotetext{
${ }^{4}$ NPS and BLM policy requires the involvement of descendent communities in interpretation (Bureau of Land Management, 2004; National Park Service, 2006). Federal law, i.e. NEPA, NHPA, and NAGPRA, governs consultation. The former is policy driven; the latter, legally mandated.
} 
to accept institutional control. Following Clifford (1997, p. 214), Boast questions the status accorded to state museums and tribal museums / local cultural centers, emphasizing their differential access to funding, loan systems, and media attention. Selfrepresentation comes at a price. Potentially, different Native nations negotiate this network of opportunity and constraint in very different ways.

Historically, the primary venues for Native American self-representation have been limited to casinos, powwows, tribal museums, and cultural centers (Lawlor, 2006, p. 2). Recent interpretive projects involving collaboration between Native Americans and protected area staff suggest that it is mutually beneficial to shift representational authority from land managers, anthropologists, and archaeologists to the descendant community itself. Collaborative ethnographic research can provide land managers and interpreters with thematic content that reflects both emic and etic perspectives (Spoon, 2014; Spoon, Arnold, \& Nuwuvi Working Group, 2012; Spoon et al., 2014; Spoon, Jeremy, 2013). Such community-based ethnography often embodies a view of humans and their environment as inextricably linked, and offers a complement to conventional Western science that is potentially relevant to land management as well as Interpretation (Spoon \& Arnold, 2012, p. 480). Recent projects open the possibility that indigenous representation may reach members of the dominant culture, increase knowledge of Native American cultural practice, and enrich understanding of Native American culture, as well as contributing to the transmission of Native American cultural knowledge (Spoon et al., 2011, p. 72). 
The works of Graburn (1983), MacCannell (1973, 1976, 2001), and Urry (Larsen \& Urry, 2011; Urry, 1992, 2003) remain foundational in the literature of tourism and cultural heritage. Graburn emphasizes the liminality of the tourist experience; MacCannell and Urry emphasize production and consumption respectively. Urry (2003, pp. 3-6) develops his foundational notion of the tourist gaze (1992, pp. 174-180) by emphasizing the corporeality of tourism, the necessity to be there oneself. Seeing with one's own eyes is central. However, the tourist also moves back and forth between his or her own direct and total sense experience of the external world and sensescapes that are constructed and discursively mediated. Furthermore, media and tourism experts- - tour operators, guides, service workers who act as hosts whether or not they are localsconstruct and regulate the embodied tourist gaze. Following Goffman and others, Larson and Urry (2011, pp. 1112-1119) note that tourist places and the embodied actions of tourist, hosts, and locals are scripted and performed, and both produce and reproduce dynamic relations of power. I would suggest that, in protected areas, Interpretation provides scripts for visitors: where to go, what to look at, what to discuss with fellow visitors; occasionally, even what photos to take. While heritage work carries significant political implications and inevitably responds to capitalist economics, it also constructs and reconstructs meaning at multiple levels (Clifford, 2004, p. 9).

Archaeological epistemology: Practice and multivocality.

Archaeologists and anthropologists actively construct their understandings of the discipline and the field (Colwell-Chanthaphonh \& Ferguson, 2006, pp. 148-150, 159; Darvill, 2007, pp. 444, 450). Relations of power enmesh archaeology; social and political 
(Re)Presenting peoples and storied lands

context shape and condition archaeological knowledge (Trigger, 2006, pp. 360, 363). In turn, archaeological practice and archaeological epistemology have wide-ranging social and political ramifications, particularly as they contribute to the domination or erasure of subject populations (Trigger, 2006, p. 363). Trigger advocates reflexive rigor and developing "a deeper awareness of why archaeologists ask the questions and seek the kinds of knowledge they do" (2006, pp. 368-369). Hodder (1999) advocates the practice of "diversity, fluidity, and reflexivity" in archaeological practice (1999, p. 148), and furthermore maintains that disciplinary ethics mandate the participation of interested individuals and communities.

Following Trigger and Hodder, a large and growing body of literature approaches multivocality as a means of cultivating innovative and alternative archaeological interpretations that acknowledge the authority of individuals and communities over their own history (e.g. Atalay, 2012; Colwell-Chanthaphonh \& Ferguson, 2006; Habu et al., 2008; Watkins, 2011). Potentially, multivocality offers archaeology “a broader anthropological approach," decenters colonialist thinking, and acknowledges the constructedness of all narratives of the past (Colwell-Chanthaphonh \& Ferguson, 2006, p. 159). Scholars generally consider multivocality the participation of uncredentialed, underrepresented, or marginalized individuals and communities in the production of competing, even conflicting, archaeological interpretations of the past (Fawcett, Habu, \& Matsunaga, 2008, pp. 2-3). However, as Atalay (2008, pp. 33-35), Hodder (2008, pp. 196-197), and Silberman (2008, p. 138) note, the inclusion of multiple voices or multiple points of view in Interpretation may merely serve hegemonic interests: alternative 
interpretations may be rendered "superfluous" or reduced to local color (Atalay, 2006, p. 34, 2012, p. 168). In the absence of input into the design of research, the development of research questions and field methods, funding, publication, alternative means of knowledge transmission, and heritage management, multivocality risks being "no more than a ploy to achieve incorporation and agreement" (Hodder, 2008, p. 197).

\section{METHODOLOGY}

Research design: Overview.

In order to assess the current state of the public presentation of archaeology in western U.S. protected areas, I worked with experts in archaeology, Interpretation, protected area management, and Native American culture to choose research sites that

Figure 1 (following page). Client site: Black Canyon Archaeological District, Pahranagat National Wildlife Refuge, Alamo NV. Research sites: Petroglyph National Monument, Albuquerque, New Mexico; Bandelier National Monument, Los Alamos, New Mexico; Mesa Verde National Park, Mesa Verde, Colorado; Anasazi Heritage Center and Canyons of the Ancients National Monument, Dolores, Colorado; Grimes Point Archaeological Area, Fallon, west central Nevada, and Ash Springs Rock Art Site, Crystal Wash Rock Art Site (Entrance Site and Main Site), Mount Irish Rock Art and Archeological District, Rainbow Canyon Archeological Site, Shooting Gallery Game Drive District, and White River Narrows Archaeological District, Lincoln County, east southeast Nevada. Map courtesy of Michael Henry Meyers. 


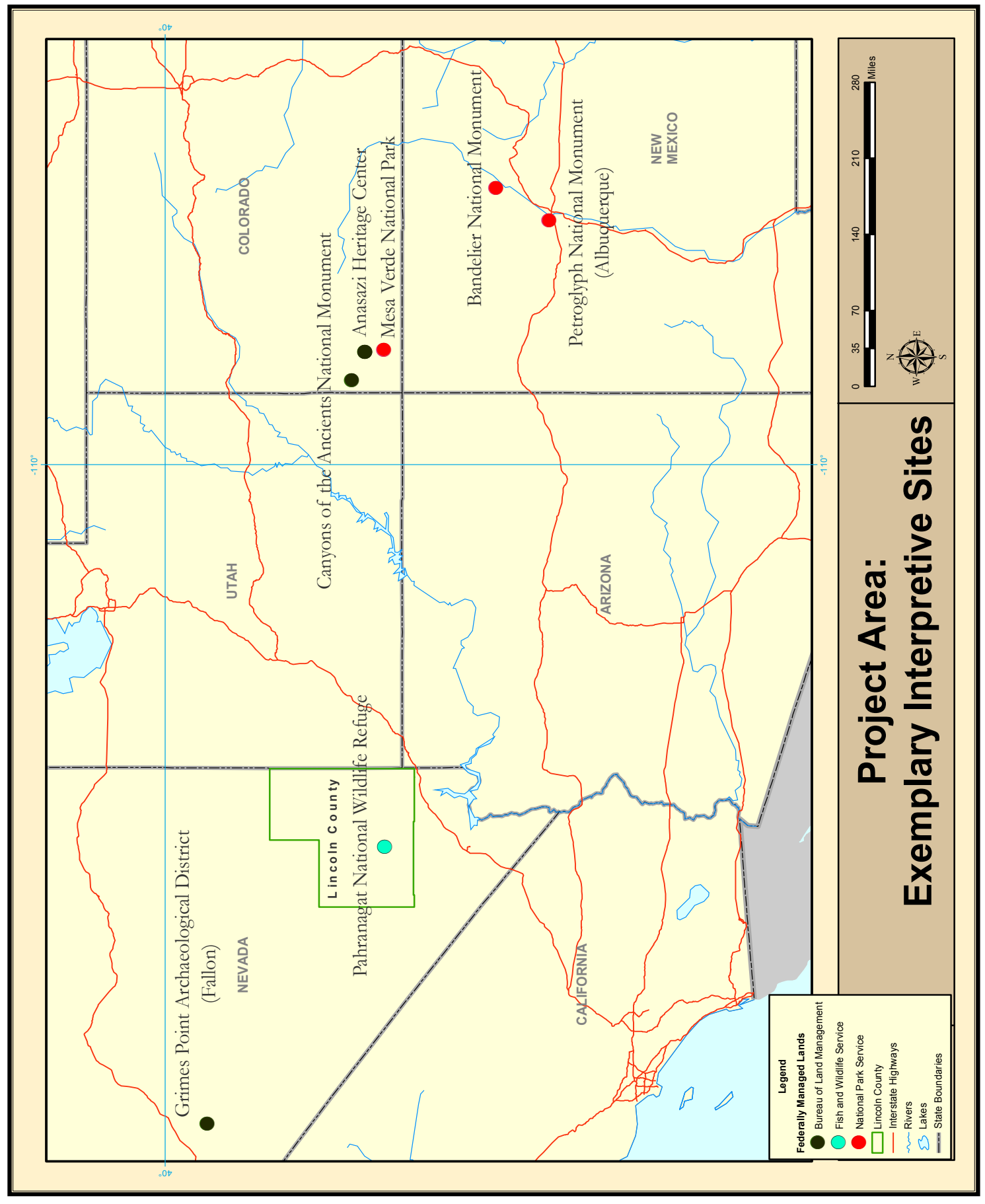


would be both relevant and feasible within the scope of this thesis: Petroglyph National Monument, Bandelier National Monument, Mesa Verde National Park, Anasazi Heritage Center / Canyons of the Ancients National Monument, and sites in Lincoln County, Nevada (Figure 1). To examine different aspects of the same complex phenomenon, namely the public presentation of archaeology, I used grounded theory (Bryman, 2012, p. 387) to analyze both the data generated by participant observation (i.e., my qualitatively driven core component) and the data produced in semi-structured interviews (i.e., my simultaneous qualitative supplemental component). Because the interviews (the supplemental component) contained data participant observation (the core component) could not access, I coded the two components separately, then brought the two sets together to formulate the codes for the primary analysis of the core component. Therefore, this research used a mixed-method design comprising an inductive approach to a qualitatively driven core component and a simultaneous qualitative supplemental component (a QUAL + qual design in the sense of Morse \& Niehaus, 2009, pp. 28-32). I designed this research to be both rigorous and replicable within the context of a single observer.

Data collection.

Participant observation.

The core component comprised two phases of participant observation, the first weighted toward participation and the second toward observation; in practice, the two often overlapped. At each site, participant observation began with an orientation of onehalf to two days; I rode shuttles, toured visitor centers and museums, collected literature, 
joined informal groups gathered around roving rangers, joined ranger- and volunteerguided walks, followed printed trail guides and driving tours, hiked trails, and purchased tour tickets. I conceived of this orientation as a reasonable proxy for a visitor's experience (Batten, 2005; Duval \& Smith, 2013); written and digital audio fieldnotes and a limited number of photographs stand in for a visitor's snapshots and travel journal. ${ }^{5}$ Participant observation captured data including sites' offerings, the ways visitors use sites, and the attracting and holding power of media, displays, and resources: protected area tourist scripts and visitors' performance of scripted tourism.

To begin the documentation phase, participant observation, I introduced myself and my research to protected area staff who were interacting with visitors, and verified that their policy permitted photographing and drawing displays and installations (in some cases, the necessity for collecting NPS Research Permits from management upon arrival made the introduction unnecessary).

In order to study interpretive programming at the five research sites, I focused on documenting nonpersonal interpretation, the media that reach the most visitors. To capture interpretive content, I focused on signs, text-based exhibits (distinct from labeled object displays), and printed trail guides in visitors centers, museums, and on the landscape; all were readily available to even a casual visitor and independent of the availability or presence of protected area staff.

${ }^{5}$ I structured this participant observation of tourist experience following Batten 2005 and Duval \& Smith 2013. This two-phase model followed Duval \& Smith but consciously eschewed subterfuge: twice visitors queried me when we were the only people at a site, and I immediately disclosed myself and my research. 
I conducted fieldwork for eight weeks of the summer of 2013 at protected areas in New Mexico, Colorado, and Nevada. I documented fieldwork in sketches and photographs, and hand-wrote, word-processed, and dictated digitally recorded notes (using Nikon3100D digital and iPhone5 cameras, a Sony IC digital recorder, iPhone5 running DragonDictatation, and a MacbookPro running Aperture, Word, Evernote, and Excel software). The photo archive for the core component exceeds 2,700 digital images. The images capture cultural resources and archaeological sites and associated Interpretation — waysides, museum and visitor center displays, trail signs, and tours. The audio archive runs over 22 hours.

Semi-structured interviews.

The project's supplemental component comprised two sets of semi-structured interviews designed to elicit the attitudes of people who produce the public presentation of archaeology — land managers, archaeologists, interpreters, volunteers - and those who consume it—visitors. I conducted fifteen interviews with a purposive sample (Bernard, 2011, p. 145) of sixteen protected area staff and volunteers who regularly engaged in Interpretation and/or archaeology, and eight interviews with a convenience sample (Bernard, 2011, p. 147) of fifteen visitors ( $\mathrm{n}=15$ and $\mathrm{n}=8$ respectively; see summary in Table 1). At National Park Service sites, land managers suggested interviewees and released them from duty to participate in 50-minute interviews; the terms of the NPS Research Permits limited my solicitation of visitors to those I observed engaging in interpretive activities and those with whom I shared interpretive activities. At other sites, 
I sought staff interviewees in advance by phone and email and solicited visitor interviews in museums and visitor centers, at parking lots, trailheads, ramadas, and on trails. $^{6}$

Interviews aimed to capture people's varying constructions of Interpretation and archaeology. Staff interviews focused on interviewees' regular interpretive activities, their ideas about successful Interpretation, and the relevance of archaeology; visitor interviews focused on interviewees' activities, what they particularly enjoyed, what they would like more of, and their reasons for visiting the protected area (see Appendix B for sample questions). Nine interviews with ten staff and volunteers were digitally recorded and fully transcribed. Four staff members at one site declined to be recorded: one interview was captured in hand-written notes; three via laptop. During one interview, both digital recording devices failed, and the interview was reconstructed immediately afterwards from hand-written notes. I digitally recorded and fully transcribed seven interviews with fourteen visitors; I recorded and partially transcribed one additional interview, over 120 minutes long.

Additional participant observation and expert interviews .

In addition to the core and supplemental data sets, I constructed a secondary data component. In order to open the research universe, I sought an alternative example, a case of the Interpretation of archaeology in a Native American tribal institution. In December 2014, I undertook additional research at the Makah Cultural and Research

\footnotetext{
${ }^{6}$ I solicited visitors who appeared to be over 18 and included children only at the suggestion of their parents/guardians.
} 
Center (MCRC) in Neah Bay, Washington. The Makah control research at the MCRC consciously and closely. The tribal council gave me permission to study the exhibits, but not to draw or photograph them. Without documentation of the display, I excluded the MCRC from the case studies, but my on-site content analysis of the MCRC interpretive displays added dimension to this research. A report to the Makah tribe, including a requested typescript of interpretive text, digital audio, transcripts edited in collaboration with interviewees, recommendations for updating exhibit text panels, and print and digital copies of the final thesis, will be delivered upon completion of my degree.

During the eight weeks of fieldwork in the summer of 2013 I conducted four additional interviews and documented one additional interpreted archaeological site and one museum installation in response to interviewees' suggestions, "You should really talk to X," and their responses when I asked, "What's an archaeological site you think is well interpreted, really exemplary?" I partially transcribed those interviews. This peripheral sampling — particularly the State Museum of Nevada in Carson City and Baker Archaeological Site in Baker, Nevada—provided valuable contrasting and comparative information (Miles \& Huberman, 1994, p. 34).

Data analysis.

Following established professional practice in Interpretation, I conceived of the core component's unit of analysis as the interpretive theme or topic (Beck \& Cable, 2002; Ham, 1992; National Park Service, n.d.-c). In signage and display, the unit of analysis nearly always corresponded to the panel; in trailguides, the unit of analysis generally corresponded to a stop on the scripted tour. I identified emergent themes in each analytic 
(Re)Presenting peoples and storied lands

unit, enumerated the themes, sought patterns, and selected themes to use as potential codes.

I conducted a preliminary data analysis of the core component for my applied project. While I engaged in and observed the full range of interpretive programming at all the sites, the research universe for the initial content analysis of the core component comprised only the nonpersonal interpretive media common to all, namely signage and trail guides. In the content analysis of the supplemental qualitative component, staff and visitor interviews ( $\mathrm{n}=15$ and $\mathrm{n}=8$ respectively), I identified emergent themes, sought patterns, and selected themes to use as potential codes. I then combined interview and participant observation data, and compared the two sets of potential codes. I aggregated and disaggregated some, and chose 19 to use as codes in the primary analysis. I grouped the 19 codes as: 1) Management Messages; 2) Scientific Narratives; 3) Cultural Narratives; 4) Third-person Narrative Point of View; 5) First-person Narrative Point of View; 6) Ancient Time; 7) Historic Era; and 8) Contemporary Time. Then I formed the three analytic categories - Narrative Content, Narrative Voice, and Narrative Timeframe-used in the next iteration (Miles \& Huberman, 1994, pp. 55-66). The codebook will be found in Appendix C.

In the primary data analysis of the core component, I coded and enumerated the entire sample of interpretive programming $(\mathrm{n}=531)$ in light of these concepts and categories. I quantified the sample, entering each item into an Excel spreadsheet, identifying each analytic unit in each item (generally 1:1), and noting the presence of each of the 19 codes in each of the analytic units (For example, a Bandelier panel entitled 
“The Art of Dry Farming,” was coded as archaeological practice, archaeology, natural history, third-person omniscient, first-person corporate, and contemporary time). The unit of analysis remained the interpretive theme or topic: in displays, the unit of analysis nearly always corresponded to the panel; in trailguides, the unit of analysis generally corresponded to a stop on the scripted tour. Multiple codes were found in virtually every unit of analysis. The core component thus generated the results in Figures 11, 14, 20, and 25, and Tables 12 and 13 in Chapters 3-5.

Table 1. Summary of research sites, locales, data

\begin{tabular}{|c|c|c|c|c|}
\hline \multirow[t]{3}{*}{$\begin{array}{l}\text { Research } \\
\text { Site }\end{array}$} & \multirow[t]{3}{*}{ Locale } & \multirow{2}{*}{$\begin{array}{c}\text { Core } \\
\text { Component } \\
\begin{array}{c}\text { Participant } \\
\text { observation }\end{array} \\
\end{array}$} & \multirow{2}{*}{\multicolumn{2}{|c|}{$\begin{array}{c}\begin{array}{c}\text { Supplemental } \\
\text { Component }\end{array} \\
\text { Semi } \\
\text { structured } \\
\text { interviews }\end{array}$}} \\
\hline & & & & \\
\hline & & $\begin{array}{l}\text { Units of } \\
\text { Analysis }\end{array}$ & Staff & Visitors \\
\hline PETR & $\begin{array}{l}\text { Petroglyph National Monument } \\
\text { Albuquerque NM }\end{array}$ & 80 & 5 & 2 \\
\hline BAND & $\begin{array}{l}\text { Bandelier National Monument } \\
\text { Los Alamos NM }\end{array}$ & 111 & 3 & $\begin{array}{c}3 \\
(4)^{*}\end{array}$ \\
\hline 'MEVE & $\begin{array}{l}\text { Mesa Verde National Park } \\
\text { Mesa Verde CO }\end{array}$ & 129 & $\begin{array}{c}4 \\
(5)^{*}\end{array}$ & $\begin{array}{c}2 \\
(4)^{*}\end{array}$ \\
\hline \multirow[t]{2}{*}{$\begin{array}{l}\text { AHC/ } \\
\text { CANM }\end{array}$} & $\begin{array}{l}\text { Anasazi Heritage Center } \\
\text { Dolores CO }\end{array}$ & \multirow{2}{*}{115} & \multirow{2}{*}{2} & \multirow{2}{*}{$\begin{array}{c}1 \\
(5)^{*}\end{array}$} \\
\hline & $\begin{array}{l}\text { Canyons of the Ancients National Monument } \\
\text { Dolores CO }\end{array}$ & & & \\
\hline \multirow[t]{2}{*}{ NV } & $\begin{array}{l}\text { Grimes Point Archaeological District } \\
\text { Fallon, Churchill County NV }\end{array}$ & \multirow[b]{2}{*}{96} & \multirow[b]{2}{*}{1} & \\
\hline & $\begin{array}{l}\text { Ash Springs Rock Art Site, Crystal Wash Rock } \\
\text { Art Site (Entrance Site and Main Site), Mount } \\
\text { Irish Rock Art and Archeological District, } \\
\text { Rainbow Canyon Archeological Site, Shooting } \\
\text { Gallery Game Drive District, and White River } \\
\text { Narrows Archaeological District } \\
\text { Lincoln County NV }\end{array}$ & & & \\
\hline 5 & 13 & 531 & 15 & 8 \\
\hline
\end{tabular}

${ }^{*}$ Numbers in parentheses indicate total number of interviewees: some interviewees solicited members of their family or social group to join us 


\section{CONCLUSION}

In the next chapter, I examine some of the key factors in the episteme of Interpretation in these protected areas. In Chapter 3, I present the analysis of the Interpretation sampled across all five sites in terms of the first analytic category, Narrative Content. I examine the stories Interpretation tells to visitors in terms of the relative presence of three large analytic themes - Scientific Narratives, Cultural Narratives, and Management Messages. I argue that the disproportionate frequency of scientific narratives over management messages and cultural narratives in the Interpretation sampled reflects a limited conception of the lands protected areas steward. Chapter 4 presents a more fine-grained analysis of Cultural Narratives, analyzing the actual components of the cultural narratives sampled at each of the five sites. Chapter 5 presents results in the second and third analytic categories, Narrative Timeframe and Narrative Voice: I analyze narrative timeframe in terms of the relative presence of ancient, historic, and contemporary eras in the Interpretation sampled across all five sites; and I examine narrative voice in terms of the relative presence of first-person and thirdperson narratives in the Interpretation sampled across all five sites. 


\section{Chapter 2: Context}

This research aims to capture current practice in protected areas' public presentation of archaeology — the state of the art, the state of the knowledge, the episteme. I emphasize that these research sites are exemplary ones chosen by experts. What may appear as a focus on Southwest archaeology is, rather, an artefact of the history of American archaeology, historic preservation, and of the development of tourism across the West. The scale and preservation of many Southwest sites attracted first Spanish and American adventurers, then anthropologists and archaeologists, entrepreneurs and developers (Colwell-Chanthaphonh, 2010). Tourism quickly followed conquest (Dilworth, 1996). Southwestern archaeology remains highly influential in the subdiscipline, often anticipating disciplinary shifts and catalyzing conflict (Longacre, 2000, pp. 288, 290-296). Many of the same sites draw tourists today. The NPS reports $34,247,008$ recreation visits (2014) to parks and monuments in Arizona, Colorado, New Mexico and Utah alone, nearly all of which feature Interpretation of ancient and historic cultures (compiled from “National Park Service Visitor Use Statistics,” 2016). 
Petroglyph national Monument, Albuquerque, New Mexico.

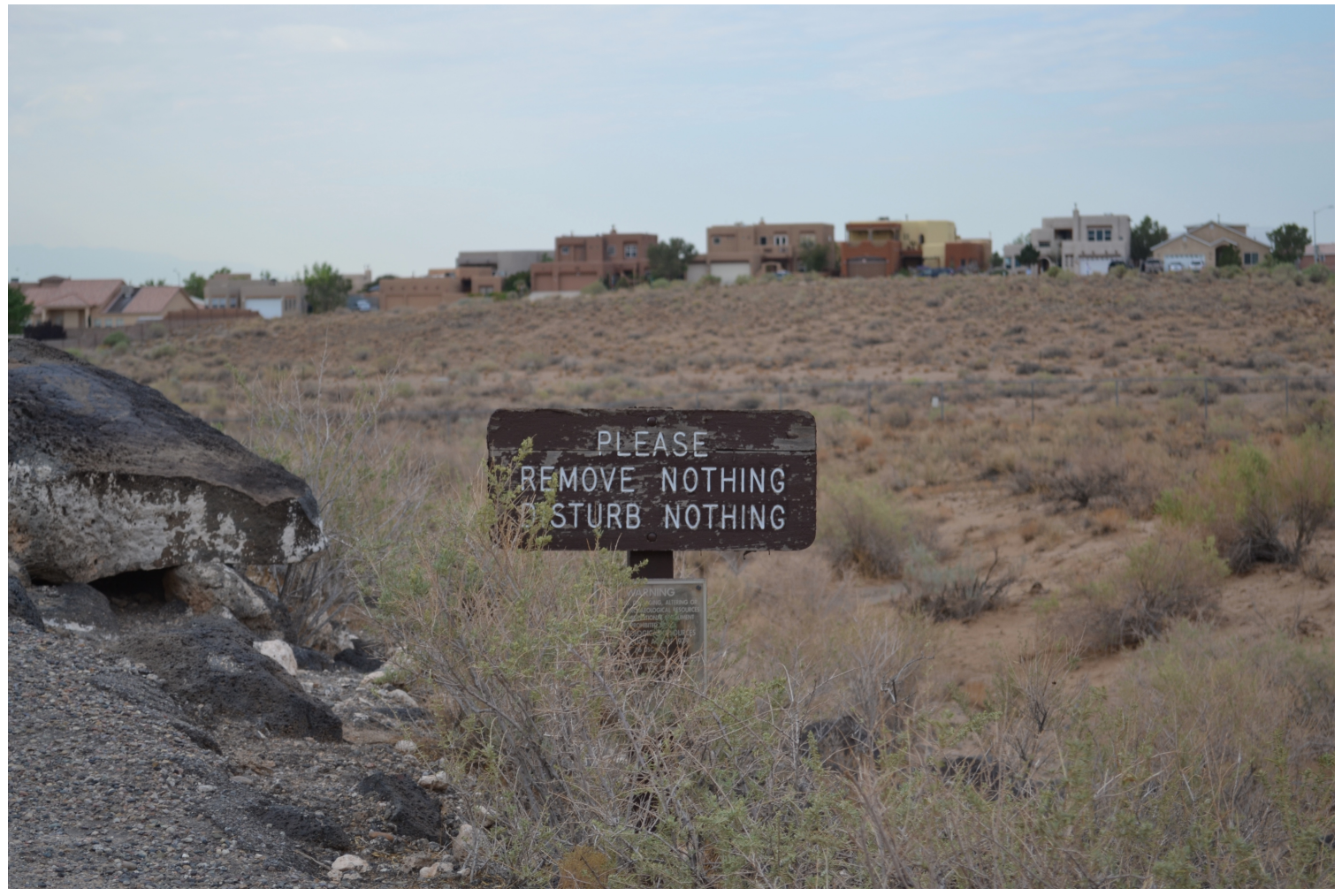

Figure 2. Petroglyph National Monument, Boca Negra interpretive trail. Note the fence along the monument boundary, left background, behind the vintage regulatory sign.

Petroglyph National Monument in Albuquerque, New Mexico, emphasizes landscape-level individual and small-group exploration. Managed jointly by the NPS and the City of Albuquerque, the monument was established in 1990 for "the specific purpose of protecting, preserving, and interpreting prehistoric and historic rock art" (16 USC 41). The park contains some 7,236 acres and four miles of designated trails in three discontinuous parcels on the city's developing west side. The monument stewards more than 24,000 ancient and historic petroglyphs and 350 archaeological sites, including ancient and historic trails and roads, historic sheepherding and ranching sites, and 20th- 
century dump and weapons testing sites. Local residents use the monument widely and freely during daylight hours, and most visitors are children from metropolitan schools: social trails, neighbors' encroachment on the monument boundary, and unauthorized recreational use pose particular management challenges. The NPS reports 2014 recreation visitorship of 115,859 ("National Park Service Visitor Use Statistics,”2016).

Table 2. Selected natural and cultural resources, Petroglyph National Monument

\begin{tabular}{|l|l|}
\hline $\begin{array}{l}\text { Resource } \\
\text { Type }\end{array}$ & Resource Characteristics \\
\hline Ecological zones & $\begin{array}{l}\text { High Desert; flora includes jimsonweed, prickly ear, rice-grass, saltbush, } \\
\text { rabbitbrush, cane cholla, snakeweed, aster, and sagebrush }\end{array}$ \\
\hline Animal species & $\begin{array}{l}\text { millipedes, lizards, rabbits, rats, mice, squirrels, coyote, snakes, hawks, } \\
\text { turkey vultures }\end{array}$ \\
\hline $\begin{array}{l}\text { Archaeological } \\
\text { sites }\end{array}$ & $\begin{array}{l}\text { 17-mile volcanic escarpment bearing ancient and historic era } \\
\text { petroglyphs; ancient and historic trails; historic sheepherding, ranching, } \\
\text { and weapons testing sites }\end{array}$ \\
\hline Historical sites & historic mid-20th century building \\
\hline Material culture & $\begin{array}{l}\text { petroglyphs in situ; single display case curated by volunteers, material } \\
\text { used by regular cultural demonstrators }\end{array}$ \\
\hline
\end{tabular}

Not only has Petroglyph a unique hybrid management regime now, it began as a 1970s state park, and traces of the original development and interpretive programming remain. Like Mesa Verde, Bandelier, and AHC/CANM, Petroglyph interprets Ancient Puebloan culture, but Petroglyph also interprets Spanish and Mexican heritage and is located in an urban, culturally diverse landscape. The monument's location in the midst of a rapidly developing section of a growing urban area (See Figure 2, Figure 9) shapes interpretive activities: interpretive efforts focus on school groups and community outreach. Finally, Petroglyph is the sole national monument set aside specifically for the preservation and enjoyment of petroglyphs. 
(Re)Presenting peoples and storied lands

Table 3. Interpretive infrastructure, Petroglyph National Monument

\begin{tabular}{|c|c|c|}
\hline Infrastructure & $\begin{array}{l}\text { Infrastructure } \\
\text { Characteristics }\end{array}$ & Additional Details \\
\hline Website & Virtual tour & $\begin{array}{l}\text { Features text, imagery, and content found in situ } \\
\text { in orientation video, on interpretive signage, } \\
\text { cellphone tours, and in printed trail guides; } \\
\text { reinforces thematic Interpretation on site } \\
\text { Incorporates park orientation video (2008), a 13- } \\
\text { minute NPS/New Mexico Museum of Natural } \\
\text { History and Science collaboration on local } \\
\text { volcanism (2003), and a } 2 \text { minute video by } \\
\text { monument staff on the making and meanings of } \\
\text { the petroglyphs (ND) in their entirety } \\
\text { Additional information for teachers and students } \\
\text { Limited location information }\end{array}$ \\
\hline Visitor center & $\begin{array}{l}\text { Information desk } \\
\text { Video (ADA } \\
\text { compliant) } \\
\text { Wall-hung relief map }\end{array}$ & See Website, above \\
\hline Tours & Ranger-led & By arrangement \\
\hline Print & $\begin{array}{l}\text { Site bulletin (4) } \\
\text { Trail guide (3) } \\
\text { Info sheets }\end{array}$ & \\
\hline Signage & $\begin{array}{l}\text { Waysides at entry } \\
\text { and trailheads, key } \\
\text { signs }\end{array}$ & $\begin{array}{l}\text { Minimal, minimalist. Key signs display interpretive } \\
\text { text and smartphone cues on trail. }\end{array}$ \\
\hline $\begin{array}{l}\text { Programs and } \\
\text { events }\end{array}$ & $\begin{array}{l}\text { Extensive community } \\
\text { outreach and special } \\
\text { programming }\end{array}$ & Regular flint-knapping, occasional drum-making \\
\hline Tourist facilities & $\begin{array}{l}\text { Water, toilets, } \\
\text { ramadas } \\
\text { Toilets, ramadas } \\
\text { Retail }\end{array}$ & $\begin{array}{l}\text { Visitor center, Boca Negra } \\
\text { Rinconada Canyon } \\
\text { Visitor center }\end{array}$ \\
\hline
\end{tabular}




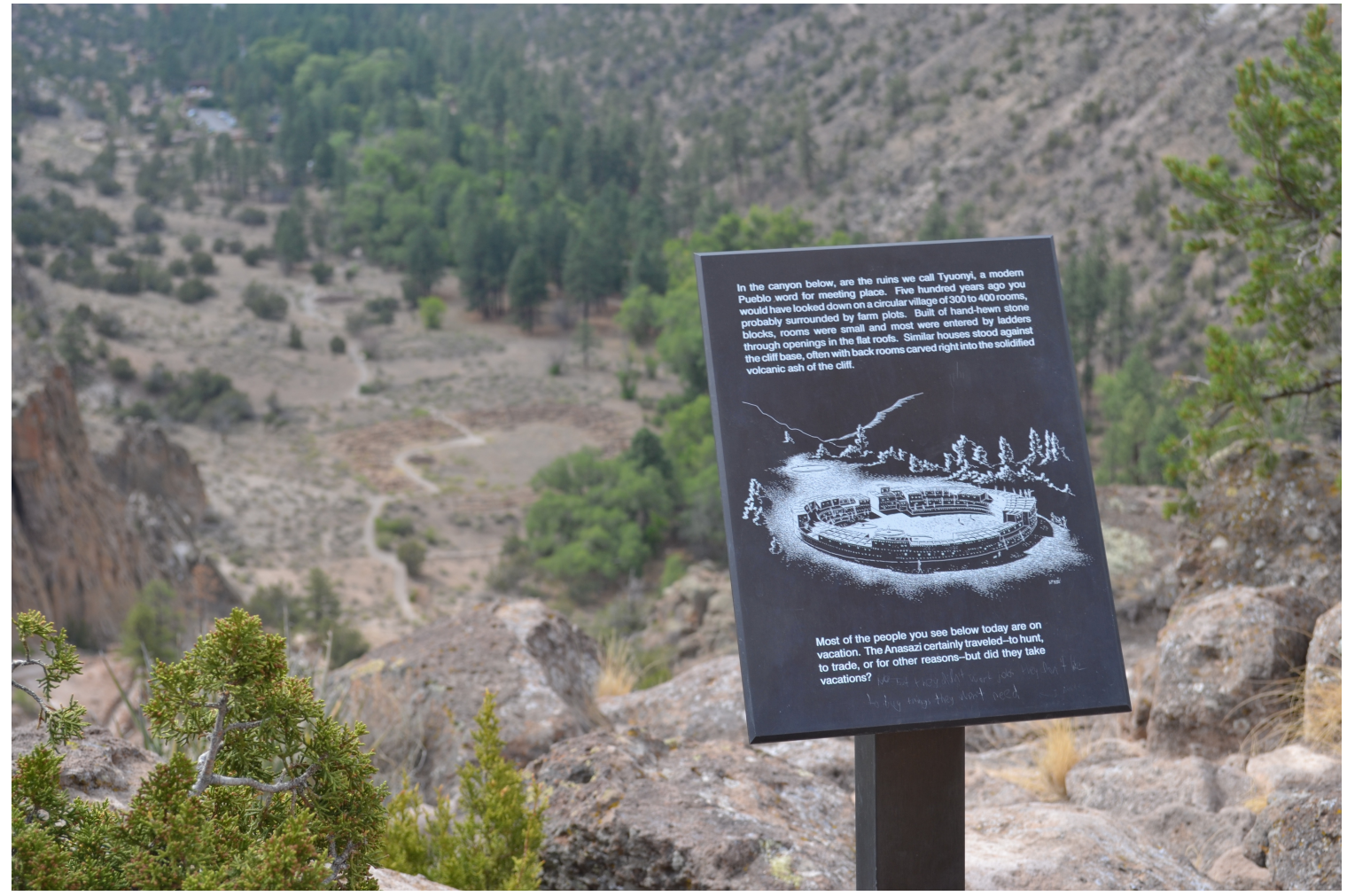

Figure 3. Bandelier National Monument, Tyuonyi Overlook trail. Minimal sign is weathered and damaged.

The museum at Bandelier National Monument was redesigned in 2010 and retains a limited number of earlier interpretive displays. Bandelier, in central Northern New Mexico, was created in 1916 to preserve archaeological resources and was transferred from the U.S. Forest Service to NPS management in 1932. The NPS reports 2014 recreation visitorship of 130,106 ("National Park Service Visitor Use Statistics," 2016). Bandelier's cultural resources include residential sites of Ancestral Puebloan Peoples, ancient and historic trails, early 20th-century historic buildings housing a visitor center and museum, and agricultural and archaeological sites on the surrounding plateau. Altogether, the Monument now encompasses some 33,750 acres and 70 miles of trails. Natural and cultural resources in the backcountry are accessible by a permit readily 
obtained at the visitor center. An extensive concentration of petroglyphs is located in one iconic village; others, in residential and backcountry sites. Backcountry sacred sites no longer figure in interpretive programming.

Table 4. Selected natural and cultural resources, Bandelier National Monument

\begin{tabular}{|c|c|}
\hline Resource Type & Resource Characteristics \\
\hline Ecological zones & $\begin{array}{l}\text { Piňon-juniper woodland, ponderosa forest, aspen groves, high mountain } \\
\text { conifers, montane grasslands, delta wetlands, canyon riparian zones }\end{array}$ \\
\hline Animal species & $\begin{array}{l}\text { Ravens, mule deer, butterflies, pika, coyote, red-tailed hawks, } \\
\text { hummingbirds, hermit thrush, sandhill crane, rattlesnakes, bobcats, } \\
\text { squirrels }\end{array}$ \\
\hline $\begin{array}{l}\text { Archaeological } \\
\text { sites }\end{array}$ & $\begin{array}{l}\text { Residential sites include rock rings, excavated and stabilized villages, } \\
\text { reconstructed cliff dwellings in canyon, residential and agricultural sites } \\
\text { on plateau }\end{array}$ \\
\hline Historical sites & CCC-era buildings designated National Historic Landmark \\
\hline Material culture & $\begin{array}{l}\text { Petroglyphs in situ; paintings, photographs, pottery, videos of singing, } \\
\text { dancing, storytelling, and traditional skills; most objects removed from } \\
\text { museum for safekeeping }\end{array}$ \\
\hline
\end{tabular}

A year after its 2010 opening, the Las Conchas fire and resulting flash floods threatened the monument's historic buildings and necessitated removing the bulk of the museum's collection of material culture. Bandelier's museum is therefore uniquely positioned as a museum sans objects: the museum presents archaeology to the public with little recourse to artifacts and emphasizes living descendant communities. 
Table 5. Interpretive infrastructure, Bandelier National Monument

\begin{tabular}{|c|c|c|}
\hline Infrastructure & $\begin{array}{l}\text { Infrastructure } \\
\text { Characteristics }\end{array}$ & Additional Details \\
\hline Website & Virtual tour, visit, hike & $\begin{array}{l}\text { Reiterates text, imagery, and content } \\
\text { found in exhibits, video, printed trail } \\
\text { guides; documents museum collection; } \\
\text { extensive photographs illustrate virtual } \\
\text { trail guide. } \\
\text { Considerable additional information for } \\
\text { teachers and students }\end{array}$ \\
\hline Visitor center & $\begin{array}{l}\text { Shuttle stop } \\
\text { Orientation video } \\
\text { Information desk } \\
\text { Free-standing relief map } \\
\text { Videos, slide displays } \\
\text { Heritage garden } \\
\end{array}$ & $\begin{array}{l}\text { Met by ranger } \\
\text { Backcountry permits, maps } \\
\text { Charismatic species } \\
\text { Ancient resource use } \\
\end{array}$ \\
\hline $\begin{array}{l}\text { Main exhibit hall / } \\
\text { museum }\end{array}$ & $\begin{array}{l}\text { Contemporary painting, } \\
\text { poem. } \\
\\
\text { Motion-activated welcome } \\
\text { with music; taxidermy, full- } \\
\text { size dioramas, scale model } \\
\text { and maquettes of villages; } \\
\text { visitor choice audio and } \\
\text { video }\end{array}$ & $\begin{array}{l}\text { Exhibits interpreting the environment, } \\
\text { lifeways of ancient Native Americans } \\
\text { and Ancestral Pueblo People, the } \\
\text { histories and cultures of contemporary } \\
\text { affiliated Pueblo Peoples, park } \\
\text { management; limited collection of } \\
\text { material culture } \\
\text { Ancient era illustrated with color artist } \\
\text { renderings (1996) and line drawings } \\
\text { (ND). Historic era illustrated with black } \\
\text { and white photos (one original print). } \\
\text { Contemporary era illustrated with color } \\
\text { photos }\end{array}$ \\
\hline Tours & Ranger- and volunteer-led & Loosely scheduled \\
\hline Print & $\begin{array}{l}\text { Site bulletin } \\
\text { Trail guide (3) } \\
\text { Info sheets }\end{array}$ & $\begin{array}{l}\text { Glossy, color } \\
\text { Glossy black and white stapled booklet; } \\
\text { one-color matte folded brochure for } \\
\text { village; one-color mate stapled booklet } \\
\text { for historic } 20 \text { thC buildings } \\
\text { Various topics, backcounrtry: most } 8 \\
1 / 12 " \times 11 \text { " single sheet }\end{array}$ \\
\hline Signage & $\begin{array}{l}\text { Waysides at entry and } \\
\text { trailheads, key signs }\end{array}$ & $\begin{array}{l}\text { Minimal, minimalist on trails. Key signs } \\
\text { display numbers corresponding to } \\
\text { trailguides }\end{array}$ \\
\hline $\begin{array}{l}\text { Programs and } \\
\text { events }\end{array}$ & $\begin{array}{l}\text { Seasonal weekend raptor } \\
\text { demonstrations, pottery } \\
\text { demonstrations }\end{array}$ & $\begin{array}{l}\text { Campground campfire programs; day } \\
\text { camp }\end{array}$ \\
\hline Tourist facilities & $\begin{array}{l}\text { Free shuttle } \\
\text { Water, toilets } \\
\text { Retail }(2) \\
\text { Coffee shop } \\
\text { Campground with water, }\end{array}$ & Multiple locations \\
\hline
\end{tabular}




\begin{tabular}{|l|l|l|}
\hline & toilets & \\
& Backcountry access & Permit and registration at visitor center \\
\hline
\end{tabular}

Mesa Verde National Park, Mesa Verde, Colorado.

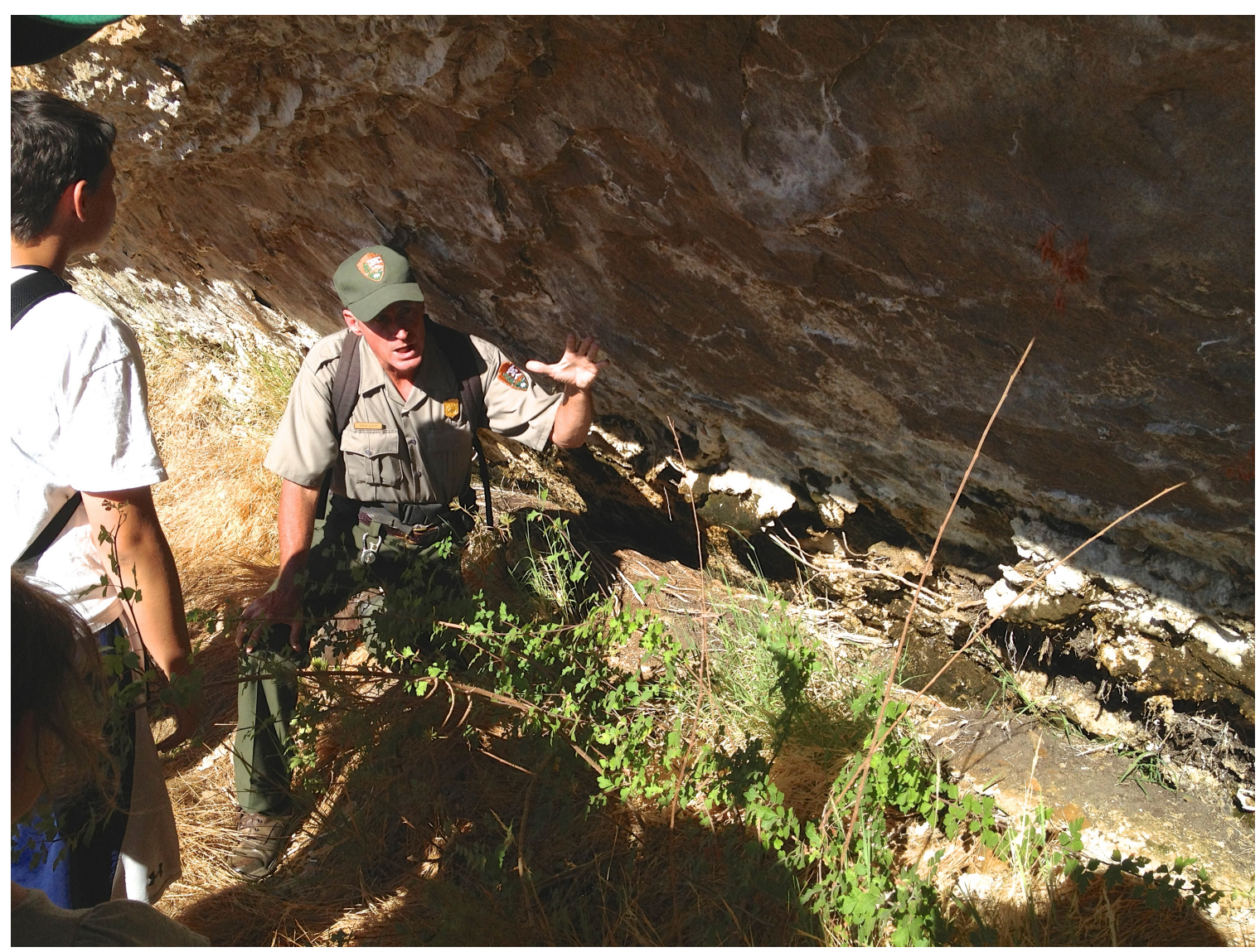

Figure 4. Mesa Verde National Park, ranger-led backcountry tour.

Mesa Verde National Park was created in 1906 as the first US national park dedicated to preserving the works of man [sic]; the park was designated a UNESCO World Heritage site in 1978, and remains the cultural park flagship of the NPS system and a major national and international tourist attraction. The NPS reports 2014 recreation visitorship of 501,563 ("National Park Service Visitor Use Statistics,” 2016). The park stewards almost 5,000 archaeological sites, some 600 cliff dwellings among them. Additionally, Mesa Verde curates more than 3 million objects in the early-20th-century 
Chapin Mesa Archaeological Museum and the Visitor and Research Center opened in 2013. Access to cultural resources is strictly controlled: tourists visit secured iconic cliff dwellings only in the presence of a ranger; visitors walk a limited number of trails connecting overlooks and dispersed mesa top sites, many of which are fenced and roofed as well as gated; and the 52,000-acre park offers only about 19 miles of hiking and walking trails. Petroglyphs and pictographs number among the park's cultural resources, most notably the large panel of rock writing on Petroglyph Point Trail.

Table 6. Selected natural and cultural resources, Mesa Verde National Park

\begin{tabular}{|l|l|}
\hline Resource Type & Resource Characteristics \\
\hline Ecological zones & $\begin{array}{l}\text { Shrub-steppe lands, piñon-juniper woodland, mountain shrub } \\
\text { communities, high mountain conifers. Transition habitat }\end{array}$ \\
\hline Animal species & $\begin{array}{l}\text { Mule deer, Collared Lizard, Spotted Bat, Coyote, Bobcat, elk, butterflies, } \\
\text { Mountain Lion, and Black Bear }\end{array}$ \\
\hline $\begin{array}{l}\text { Archaeological } \\
\text { sites }\end{array}$ & $\begin{array}{l}\text { In excess of 4,500 archaeological sites including pit houses, water } \\
\text { catchment systems, and 600 cliff dwellings. Predominantly excavated } \\
\text { and stabilized; some reconstruction and archaeological display' }\end{array}$ \\
\hline Historical sites & $\begin{array}{l}\text { Early 20thC administrative buildings designated National Historic } \\
\text { Landmark }\end{array}$ \\
\hline Material culture & $\begin{array}{l}\text { Petroglyphs, pictographs in situ; 3 million+ curated objects in Visitor and } \\
\text { Research Center and Chapin Mesa Archaeological Museum; 20th and } \\
\text { 21st C paintings, photographs, sculpture }\end{array}$ \\
\hline
\end{tabular}

Although exhibit space represents only a fraction of the new VRC (approximately one-quarter of the area open to the public), the VRC presentation of archaeology to the public forms an essential case study in this research. When a flagship national park opens a new multimillion-dollar facility that includes, even in a limited way, the public presentation of archaeology, we can reasonably assume that the style and tenor of that presentation represents what the National Park Service considers to be the most current, the very best. 
(Re)Presenting peoples and storied lands

Table 7. Interpretive infrastructure, Mesa Verde National Park

\begin{tabular}{|c|c|c|}
\hline Infrastructure & $\begin{array}{l}\text { Infrastructure } \\
\text { Characteristics }\end{array}$ & Additional Details \\
\hline Website & $\begin{array}{l}\text { Virtual visitor center } \\
\text { Virtual travel agency }\end{array}$ & $\begin{array}{l}\text { Reproduces and reinforces information } \\
\text { in orientation displays and site } \\
\text { publications available at park information } \\
\text { desks } \\
\text { Considerable additional information for } \\
\text { teachers and students } \\
\text { Descriptions of museum and visitor } \\
\text { center and collections; orientation to } \\
\text { selected resources } \\
\text { Information on tickets, prices, schedules, } \\
\text { and tours to cliff dwellings; information } \\
\text { and links for purchasing backcountry } \\
\text { and other special tour and event tickets; } \\
\text { links to concessionaire's services for } \\
\text { tours, lodging, camping, and special } \\
\text { events }\end{array}$ \\
\hline Visitor center & $\begin{array}{l}2013 \\
\text { Entrance plaza, garden } \\
\text { Interior public areas: } \\
\text { Lobby, rotunda, } \\
\text { Display / information } \\
\text { Retail } \\
\text { Ticketing }\end{array}$ & $\begin{array}{l}\text { Visitor and Research Center; } \\
\text { approximately } 80 \% \text { research and } \\
\text { curation } \\
\text { Monumental sculpture, tourist } \\
\text { information } \\
\text { Text panels, cases of iconic black and } \\
\text { white pottery, curation display and } \\
\text { viewing; painting, sculpture } \\
\text { Information desk, cases of material } \\
\text { culture, dioramas and bronze } \\
\text { maquettes, text panels with touchable } \\
\text { replicas, free-standing relief map, audio } \\
\text { kiosk. Ancient era illustrated with line } \\
\text { drawings and color artist renderings } \\
\text { (ND). Historic era illustrated with black } \\
\text { and white photos and facsimile } \\
\text { documents. Contemporary era } \\
\text { illustrated with enhanced satellite map }\end{array}$ \\
\hline Museum & $\begin{array}{l}\text { Information desk } \\
\text { Orientation video } \\
\text { CCC dioramas, scale } \\
\text { models; material culture of } \\
\text { site, region; taxidermy, } \\
\text { geology, and natural history } \\
\text { displays } \\
20^{\text {th }} \text { and } 21^{\text {st }} \mathrm{C} \text { art }\end{array}$ & Temporary exhibit space \\
\hline
\end{tabular}




\begin{tabular}{|l|l|l|}
\hline & Retail & \\
\hline Tours & Ranger-led & $\begin{array}{l}\text { Tickets }(\$ 4 \text { - \$25) required. } \\
\text { Concessionaire motor coach tour } \\
\text { available }\end{array}$ \\
\hline Print & $\begin{array}{l}\text { Site bulletin } \\
\text { Trail guide (3) } \\
\text { Info sheets }\end{array}$ & $\begin{array}{l}\text { Glossy, color } \\
\text { Vary } \\
\text { Vary }\end{array}$ \\
\hline Programs and & $\begin{array}{l}\text { Signature directional } \\
\text { signage }\end{array}$ & $\begin{array}{l}\text { Minimalist signs at archaeological sites, } \\
\text { overlooks, trailheads; minimal and } \\
\text { minimalist signage on trails }\end{array}$ \\
\hline events & $\begin{array}{l}\text { Seasonal school and living } \\
\text { history programs, nightly } \\
\text { campground campfire } \\
\text { programs }\end{array}$ & $\begin{array}{l}\text { Two lecture series, special events } \\
\text { featuring cultural demonstrations and } \\
\text { artists-in-residence }\end{array}$ \\
\hline Tourist facilities & $\begin{array}{l}\text { Lodging } \\
\text { Campground with water, } \\
\text { toilets; adjacent services } \\
\text { include showers, laundry, } \\
\text { market, snack bar, gasoline, } \\
\text { and dump station } \\
\text { Water, toilets } \\
\text { Retail } \\
\text { Food service }\end{array}$ & $\mid \begin{array}{l}\text { Multiple locations } \\
\text { Multiple locations } \\
\text { Multiple locations }\end{array}$ \\
\hline
\end{tabular}


Anasazi Heritage Center and CANyons of the AnCiEnts National MONUMENT, DOLORES, COLORADO.

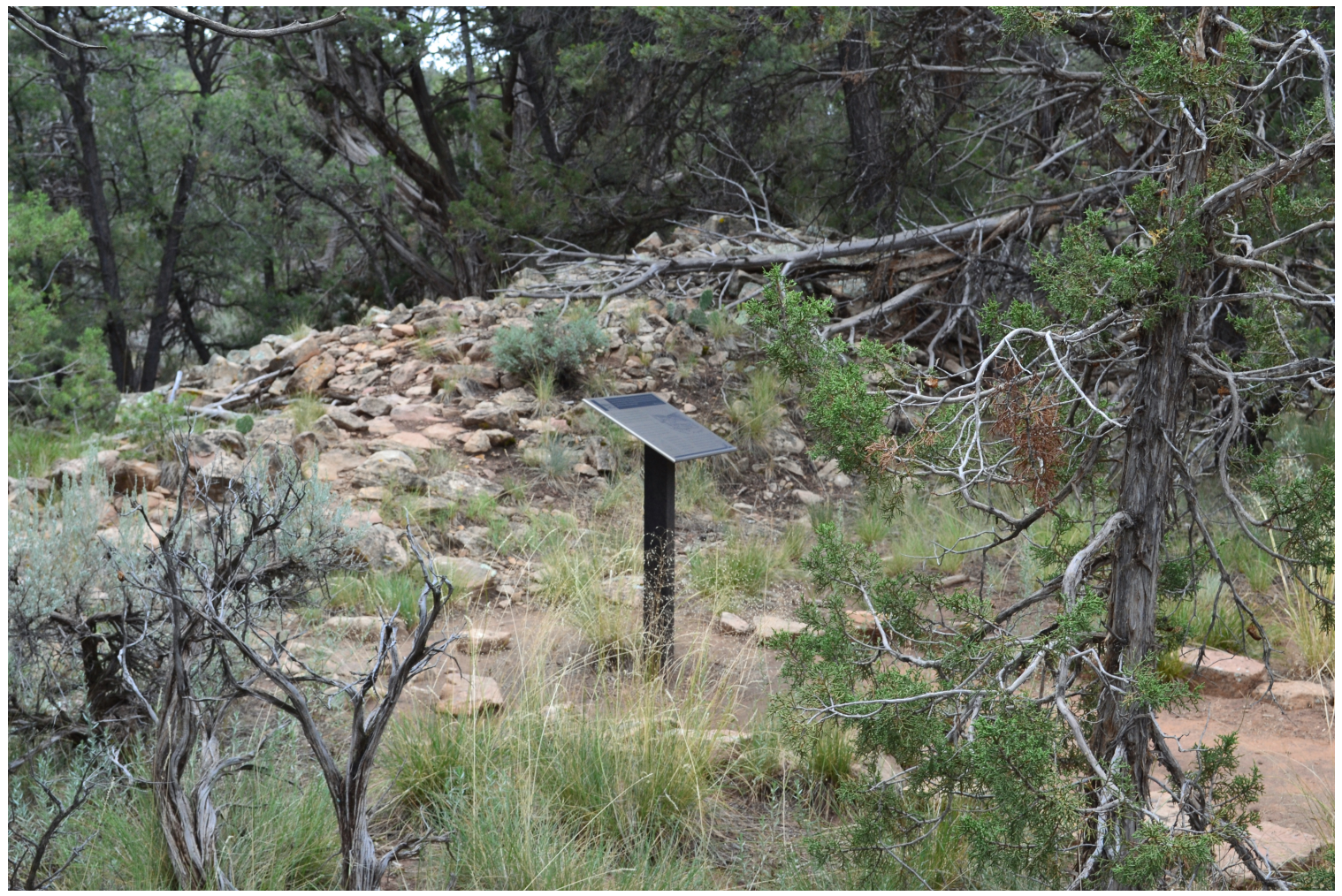

Figure 5. Anasazi Heritage Center / Canyons of the Ancients National Monument, excavated and backfilled Sand Canyon Pueblo. Note minimal interpretive sign emphasizing multiple interpretations.

Both the Anasazi Heritage Center (AHC) and Canyons of the Ancients National Monument (CANM), Dolores, Colorado, date to the late 20th-century (1988 and 2000, respectively) and are managed by the Bureau of Land Management for multiple use. The $\mathrm{AHC}$ was created as a curation facility for salvage archaeology at the nearby McPhee Reservoir and now curates material from excavations across the region (over 3.5 million objects); it houses a museum of archaeology and Ancestral Puebloan material culture, as well as the visitor center for the monument. The monument covers some 175,064 acres and stewards an estimated 20,000 - 30,000 archaeological sites including ancient villages 
and shrines. The vast majority of sites are neither excavated and stabilized nor interpreted; visitors are encouraged to explore the outdoor museum on their own.

Petroglyphs and pictographs do not feature prominently in interpretive programming but are present in backcountry sites.

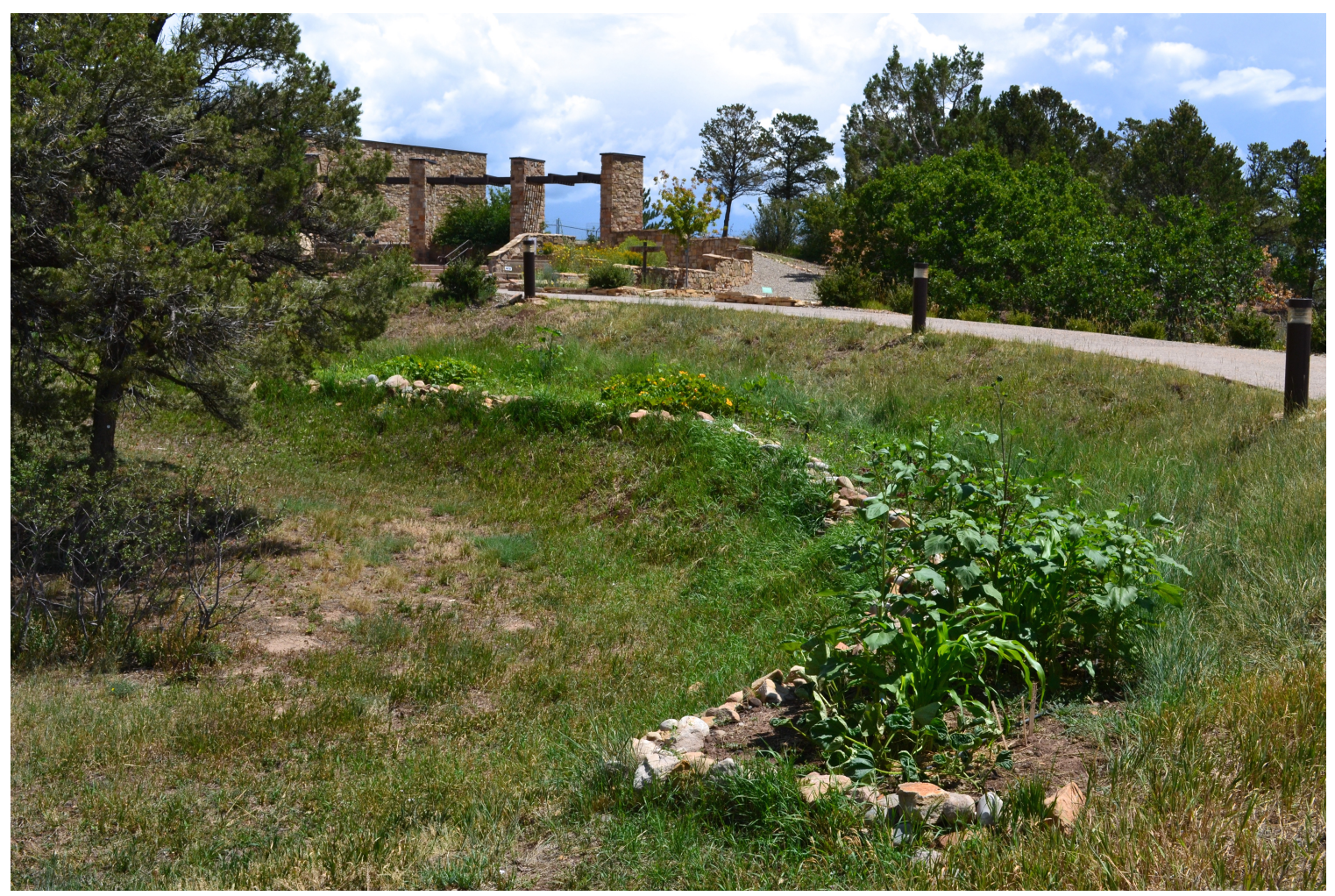

Figure 6. Anasazi Heritage Center / Canyons of the Ancients National Monument. Note excavated and backfilled Dominguez Pueblo, foreground, museum and visitors center, background.

The AHC devotes much of its main exhibit hall to an illustrated history of Southwest archaeology, videos of scientists discussing their work, and participatory and hands-on explorations of archaeological analysis; it places considerably more emphasis on the history and practice of archaeology than either the Mesa Verde VRC or the Bandelier museum. The AHC is located between ancient two pueblos, one excavated and backfilled and one excavated and stabilized; further afield, CANM village sites range 
from relatively untouched backcountry sites to sites that are fully excavated, stabilized, encased in protective structure, and interpreted. More than any other of these exemplary sites, AHC/CANM showcases archaeological practice. Additionally, AHC documents collaboration with Native Americans and exemplifies both the recent museological push for visitor participation and conventional object-driven display.

Table 8. Selected natural and cultural resources, Anasazi Heritage Center / Canyons of the Ancients National Monument

\begin{tabular}{|l|l|}
\hline Resource Type & Resource Characteristics \\
\hline Ecological zones & Piñon-juniper, pine-oak, shrub-steppe, wetland \\
\hline Animal species & Mule deer, rabbit, fox, Coyote, elk, Mountain Lion, Wild Turkey, duck \\
\hline $\begin{array}{l}\text { Archaeological } \\
\text { sites }\end{array}$ & $\begin{array}{l}6,355+\text { recorded archaeological sites including petroglyphs, middens, } \\
\text { water catchment systems, shrines, agricultural sites, pit houses, villages, } \\
\text { and cliff dwellings }\end{array}$ \\
\hline Material culture & 3 million items on display, in research collections, and storage \\
\hline
\end{tabular}

Table 9. Interpretive infrastructure, Anasazi Heritage Center / Canyons of the Ancients National Monument

\begin{tabular}{|c|c|c|}
\hline Infrastructure & $\begin{array}{l}\text { Infrastructure } \\
\text { Characteristics }\end{array}$ & Additional Details \\
\hline Website & Virtual site brochure & $\begin{array}{l}\text { Logistical, cultural, archaeological, and } \\
\text { historical information; features text, imagery, } \\
\text { and orientation content found in site } \\
\text { newspaper; limited location information and } \\
\text { strong encouragement to visitors to come to } \\
\text { the visitor center; highlights ("If you have two } \\
\text { hours..." } \\
\text { Webpages on each major archaeological site, } \\
\text { on the recognition and preservation of } \\
\text { archaeological resources, on the research } \\
\text { collection, management policies. } \\
\text { Hyperlinks to Native American tribes, } \\
\text { universities, non-profits, and other protected } \\
\text { areas } \\
\text { Hyperlinks to "Visit with Respect," video of } \\
\text { contemporary Native Americans visiting and } \\
\text { discussing Ancestral Puebloan sites, and } \\
\text { radio interview with cellist artist-in-residence } \\
\text { Esther Rogers. } \\
\text { Additional information for teachers; details of } \\
\text { existing curricula and onsite activities; contact }\end{array}$ \\
\hline
\end{tabular}




\begin{tabular}{|c|c|c|}
\hline & & $\begin{array}{l}\text { information for customized outreach; } \\
\text { resources and research facilities }\end{array}$ \\
\hline Visitor center & $\begin{array}{l}\text { Information desk } \\
\text { Videos } \\
\text { Free-standing relief map }\end{array}$ & $\begin{array}{l}\text { Display cases of iconic black and white } \\
\text { pottery and other artifacts; photos of noted } \\
\text { archaeological sites and tourist attractions in } \\
\text { nearby states } \\
\text { Theater; see website, above }\end{array}$ \\
\hline $\begin{array}{l}\text { Main exhibit hall / } \\
\text { museum }\end{array}$ & & $\begin{array}{l}\text { Exhibits interpreting the lifeways of ancient } \\
\text { Native Americans and Ancestral Pueblo } \\
\text { People, the history and practice of } \\
\text { archaeology, salvage archaeology and } \\
\text { curation, regional material culture } \\
\text { Participatory exhibits include cabinets of } \\
\text { touchable artifacts and modern specimens/ } \\
\text { replicas, loom, grindstones, microscopes, } \\
\text { audios/videos, and computers }\end{array}$ \\
\hline Tours & Volunteer-led & Weekly tour of curation facility \\
\hline Print & $\begin{array}{l}\text { Site newspaper } \\
\text { Individual site brochures } \\
\text { (5) } \\
\text { Info sheets } \\
\text { Brochure racks }\end{array}$ & $\begin{array}{l}\text { Color tabloid } \\
\text { Dominguez, Escalante, Lowry, Painted Hand, } \\
\text { and Sand Canyon Pueblos } \\
\text { Maps, backcountry information } \\
\text { Regional tourist information }\end{array}$ \\
\hline Signage & $\begin{array}{l}\text { Waysides at trailheads; } \\
\text { onsite interpretive panels }\end{array}$ & Minimal, minimalist \\
\hline $\begin{array}{l}\text { Programs and } \\
\text { events }\end{array}$ & $\begin{array}{l}\text { Lectures, temporary } \\
\text { exhibits }\end{array}$ & \\
\hline Tourist facilities & $\begin{array}{l}\text { Water, toilets, picnic area } \\
\text { Retail } \\
\text { Toilets, picnic area }\end{array}$ & $\begin{array}{l}\text { Visitor center } \\
\text { Lowry Pueblo }\end{array}$ \\
\hline
\end{tabular}


(Re)Presenting peoples and storied lands

Nevada Petroglyph Sites: Churchill And Lincoln Counties

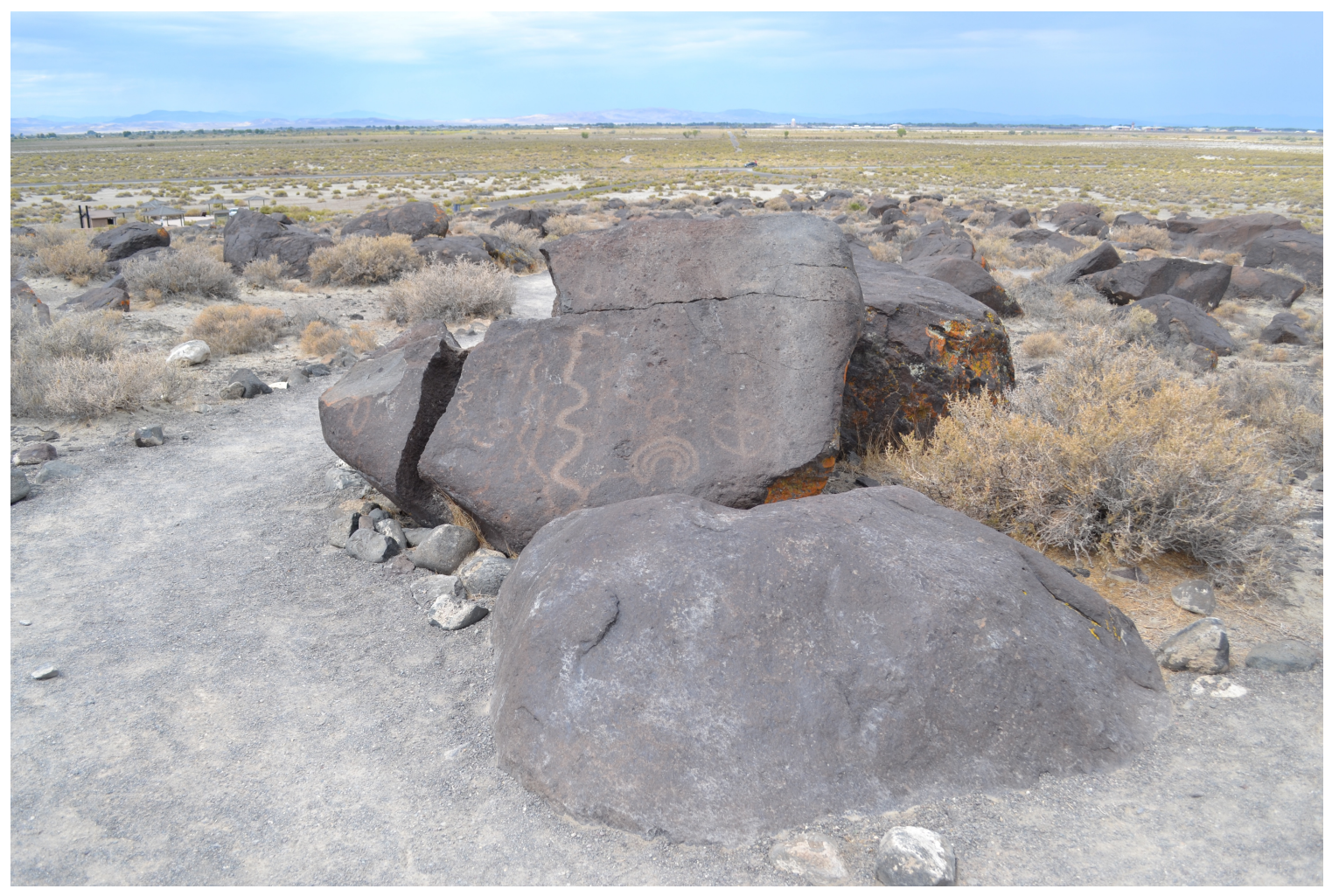

Figure 7. Grimes Point Archaeological Area, Churchill County, Nevada. Note petroglyphs and natural surface trail. Signage, ramadas, and toilets, are located approximately 100 meters away.

This project considers a number of interpreted petroglyph sites In Churchill and Lincoln Counties, Nevada, as a unit: Grimes Point Archaeological District near Fallon, in west central Nevada, and Ash Springs Rock Art Site, Crystal Wash Rock Art Site (Entrance Site and Main Site), Mount Irish Rock Art and Archeological District, Rainbow Canyon Archeological Site, Shooting Gallery Game Drive District, and White River Narrows Archaeological District in Lincoln County, in east southeastern Nevada. All of the sites are located on multiple-use public land managed by two adjoining BLM 
field offices, and at the time of this study, all were either developed or minimally developed. All of the sites steward rock writing and other cultural resources, but only petroglyphs are interpreted for the public. All the sites offer trail guides in metal boxes also housing trail registers. This project considers the sites as offering a baseline of contemporary local practice at the time of the research.

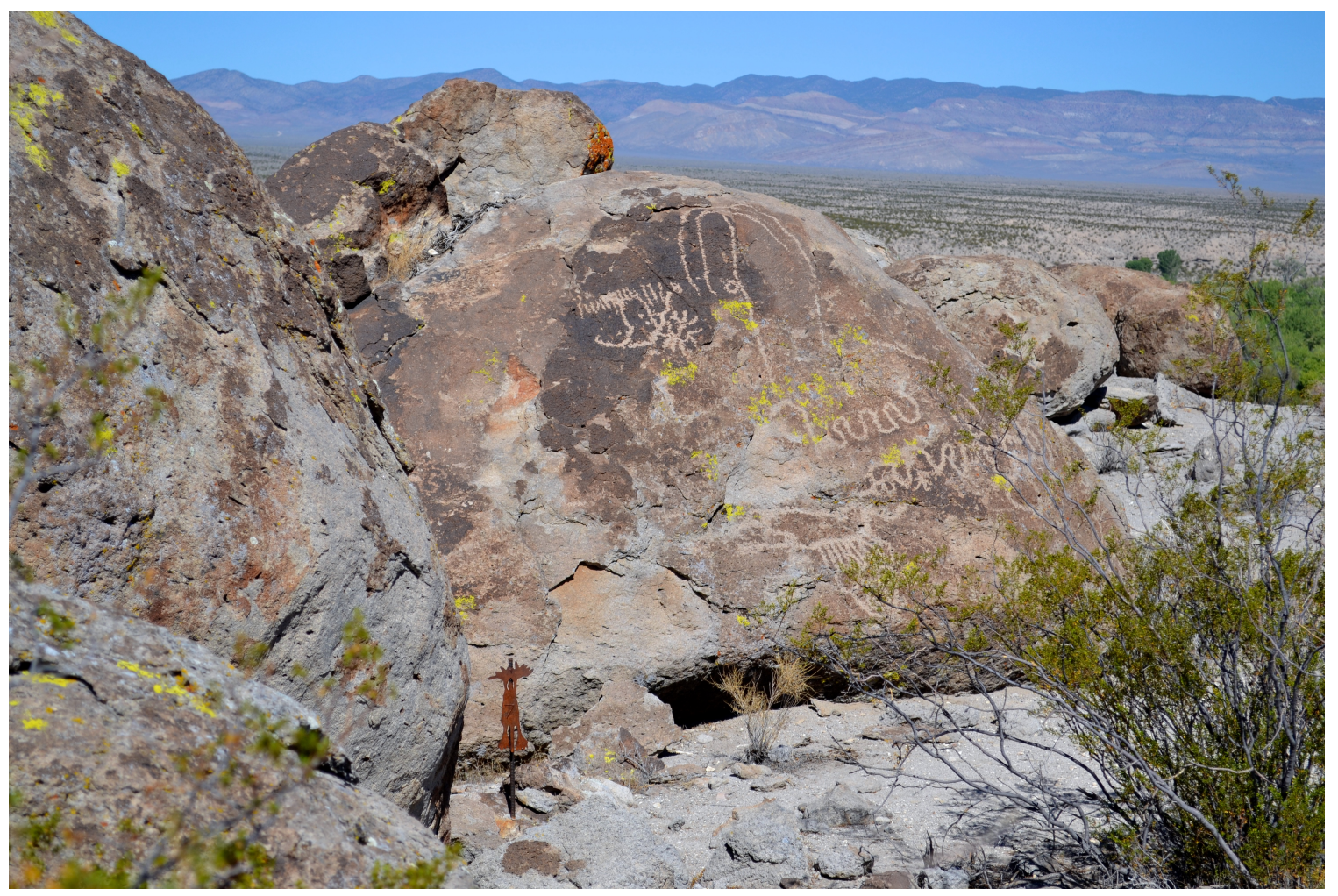

Figure 8. Ash Springs petroglyphs, Lincoln County, Nevada. Note undisturbed lichen (brown and chartreuse, center) and signature key sign, left foreground

Additionally, Grimes Point is an important case study because of its association with Hidden Cave, a foundational site in Great Basin archaeology. Excavations there in the 1940s, 1950s, and 1970s recovered intact basketry, leather, carved wood, seeds, human coprolites, and storage pits in addition to five burials (Thomas, 1985). Material culture and clear stratigraphy illuminate humans' interaction with the environment and 
changing environmental conditions over time. Both sites were listed on the National

Register of Historic Places in 1972 (U.S. Department of the Interior, 2015).

Table 10. Selected natural and cultural resources, Churchill and Lincoln County sites, Nevada

\begin{tabular}{|l|l|}
\hline Resource Type & Resource Characteristics \\
\hline Grimes Point Archaeological Area \\
\hline Ecological zone & Great Basin Desert \\
\hline Animal species & $\begin{array}{l}\text { Pronghorn, coyote, mountain lion, Mule deer, Bighorn sheep, } \\
\text { Rattlesnakes, rabbits, rodents, lizards }\end{array}$ \\
\hline Archaeological sites & Grimes Point and Hidden Cave \\
\hline Material culture & Petroglyphs in situ, rockshelters, pictograph, surface sites \\
\hline Lincoln County Sites \\
\hline Ecological zones & Central Basin and Range \\
\hline Animal species & $\begin{array}{l}\text { Mountain lion, Mule deer, Pronghorn, rabbits, lizards, Rattlesnakes, } \\
\text { Gopher snakes; rarely Bighorn sheep, elk }\end{array}$ \\
\hline Archaeological sites & $\begin{array}{l}\text { Ash Springs Rock Art Site, Crystal Wash Rock Art Site (Entrance } \\
\text { Site, Main Site), Mt. Irish Rock Art and Archaeological District, } \\
\text { Rainbow Canyon Archaeological Site, Shooting Gallery Game Drive } \\
\text { District, White River Narrows Archaeological District }\end{array}$ \\
\hline Material culture & Petroglyphs in situ, surface sites \\
\hline
\end{tabular}

Table 11. Interpretive infrastructure, Churchill and Lincoln County Sites, Nevada

\begin{tabular}{|l|l|l|}
\hline Infrastructure & $\begin{array}{l}\text { Infrastructure } \\
\text { Characteristics }\end{array}$ & Additional Details \\
\hline Grimes Point Archaeological Area \\
\hline Website & Orientation & Text and photos \\
\hline Tours & Volunteer-led & Fortnightly by arrangement \\
\hline Print & Trail guide & Trail register box \\
\hline Signage & $\begin{array}{l}\text { Waysides at entry and } \\
\text { trailhead, minimal and key } \\
\text { signs }\end{array}$ & \\
\hline $\begin{array}{l}\text { Tourist } \\
\text { facilities }\end{array}$ & $\begin{array}{l}\text { Signposted parking area, } \\
\text { gated entrance, toilets, } \\
\text { ramadas }\end{array}$ & $\begin{array}{l}\text { Shaded art installation. When unlocked, } \\
\text { doubles as highway rest stop }\end{array}$ \\
\hline Lincoln County & Sites & \\
\hline Website & No official web presence & $\begin{array}{l}\text { Extensive and variable information on } \\
\text { multiple third-party websites }\end{array}$ \\
\hline Print & $\begin{array}{l}\text { Trailguides } \\
\text { "Lincoln County Nevada get primitive" } \\
\text { brochure available at restaurants, hotels }\end{array}$ \\
\hline Signage & Key signs & Regulations, trailguides \\
\hline Tourist facilities & $\begin{array}{l}\text { Shared orientation wayside } \\
\text { on highway, parking, gated } \\
\text { entrances }\end{array}$ & \\
\hline
\end{tabular}




\section{CONCLUSION}

All five sites steward natural and cultural resources. They present archaeology in situ, representing archaeology and Native American culture (and often their own institutional history) on the land. More developed sites also offer visitors centers, characterized by interviewees as places to help visitors chose what resources to see, or even whether to see anything at all. Visitor centers have a centrifugal force, generally maintain a focus on the land and the landscape, and encourage individual encounter. The sites most fully developed for tourism also offer museums. Museums have a centripetal force, generally focusing on material culture and collections; increasingly, however, they consider visitor participation and the individual construction of knowledge.

Land use captures the protected area's construction of the land and resources it stewards. Mesa Verde is a UNESCO World Heritage Site as well as the first U.S national cultural park preserving "the works of man," and remains the flagship cultural park of the NPS. Visitors view iconic resources in the presence of a uniformed ranger: at iconic sites, there are substantial chain, chain-link, and wire barriers; other resources are gated, enclosed in protective structures, framed from viewpoints. Mesa Verde, perhaps any global heritage site, offers limited opportunities for individual exploration.

Like Mesa Verde, Bandelier was created to steward significant cultural resources, and now encompasses designated wilderness area as well. While much smaller, Bandelier provides more opportunity for individual discovery of the land. Bandelier and $\mathrm{AHC} /$ Canyons of the Ancients place few restrictions on recreational use of backcountry, effectively permitting use 24/7. Both actively encourage independent discovery of natural and cultural resources. 
(Re)Presenting peoples and storied lands

Petroglyph and the Nevada sites are gated and open during daylight hours.

Gates may or may not be closed. Local residents may or may not accept restrictions on their use of the sites. Regulations may or may not be enforced. Independent encounter is the rule.

According to Foucault (1970), any study of the museum is an act of archaeology. The same holds true of the protected area. Historically, protected status resulted from the local and specific intersection of prominent citizens, voluntary organizations, and governments. Stakeholders continue to exert considerable influence today. Law and policy now inscribe federally recognized Native American Nations into the mix.

Disciplinary practices of display -rotation and curation in the museum, stabilization, repair, updating, and development in protected areas' stewardship and Interpretation of cultural resources - create discontinuous layers of constructed knowledge. Very seldom has a protected area enough human and economic capital to render disciplinary shifts and changes in management practices transparent to the visitor. Interpretation is epistemic indeed.

This chapter characterized the project's research sites, in the US Southwest and Great Basin. In the next two Chapters, I present and discuss the results of content analysis of both the research's core data set, derived from participant observation of interpretive programming at the five sites, and the supplemental data set, derived from semistructured interviews with visitors and protected area staff, in terms of narrative content, the actual stories told to visitors in museums, visitor centers, and on the land. I argue that the disproportionate frequency of scientific narratives over management messages and 
(Re)Presenting peoples and storied lands

cultural narratives in the Interpretation sampled reflects a limited conception of the lands protected areas steward. 
Chapter 3: The what of Interpretation: Narrative content

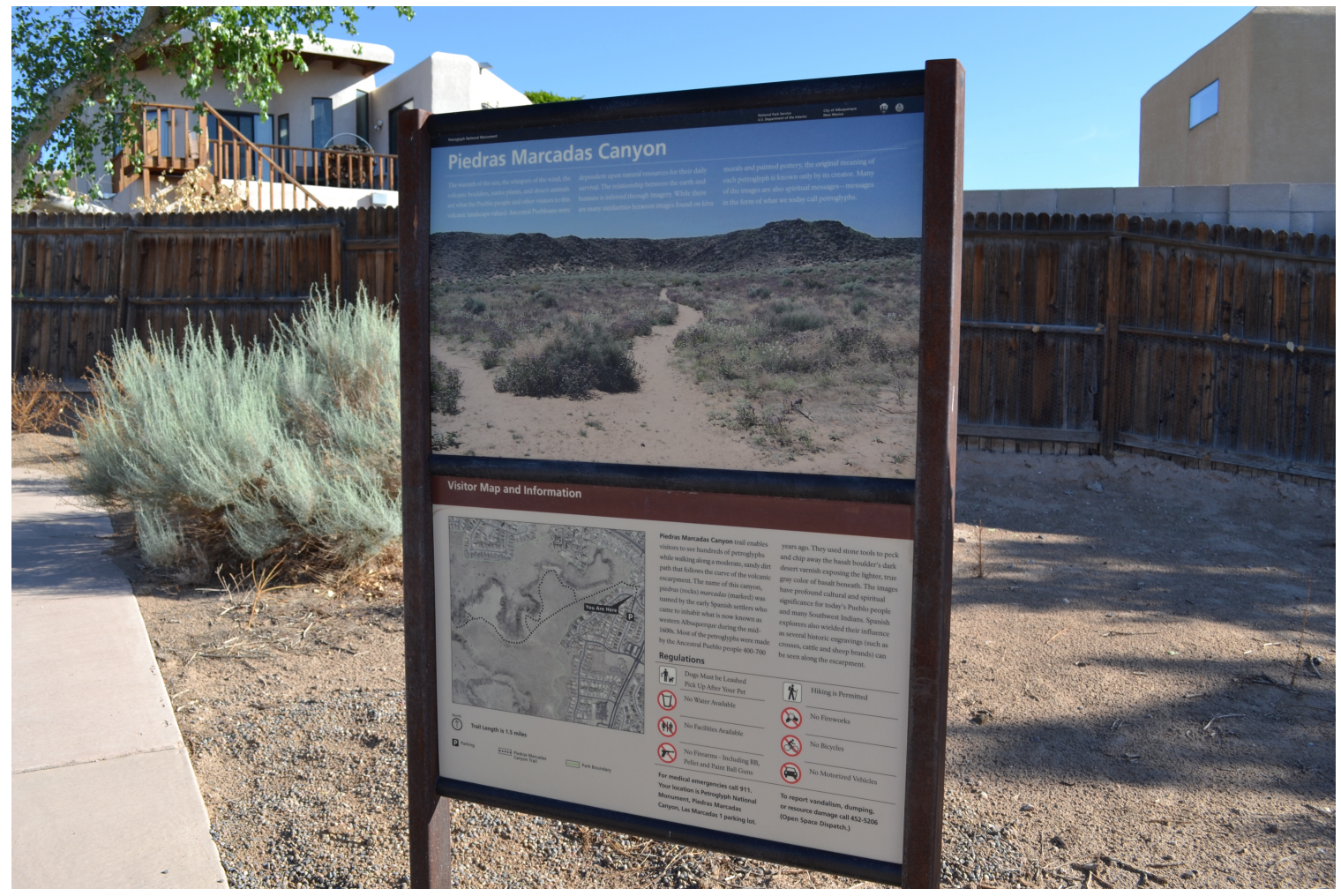

Figure 9. Petroglyph National Monument, Piedras Marcadas wayside sign incorporating management messages, archaeological narratives. Note top panel featuring interpretive text superimposed over landscape photo; lower panel comprising map, key, site regulations, and emergency information as well as additional interpretive text.

The protected area Interpretation observed in this research often presented scientific narratives, management messages, and cultural narratives interwoven within a panel, display, or section of trail guide, as in Figure 9, above. In other interpretive materials, for example the sign below, juxtaposed (but delineated) different types of interpretive content. Scientific narratives reflect the knowledge of natural history, geology, archaeology and archaeological practice. Management messages include park history, agency mission, conservation, and preservation. Cultural narratives focus on Indigenous and non-Indigenous history, cultural practice and continuity (see codebook in 
Appendix C).

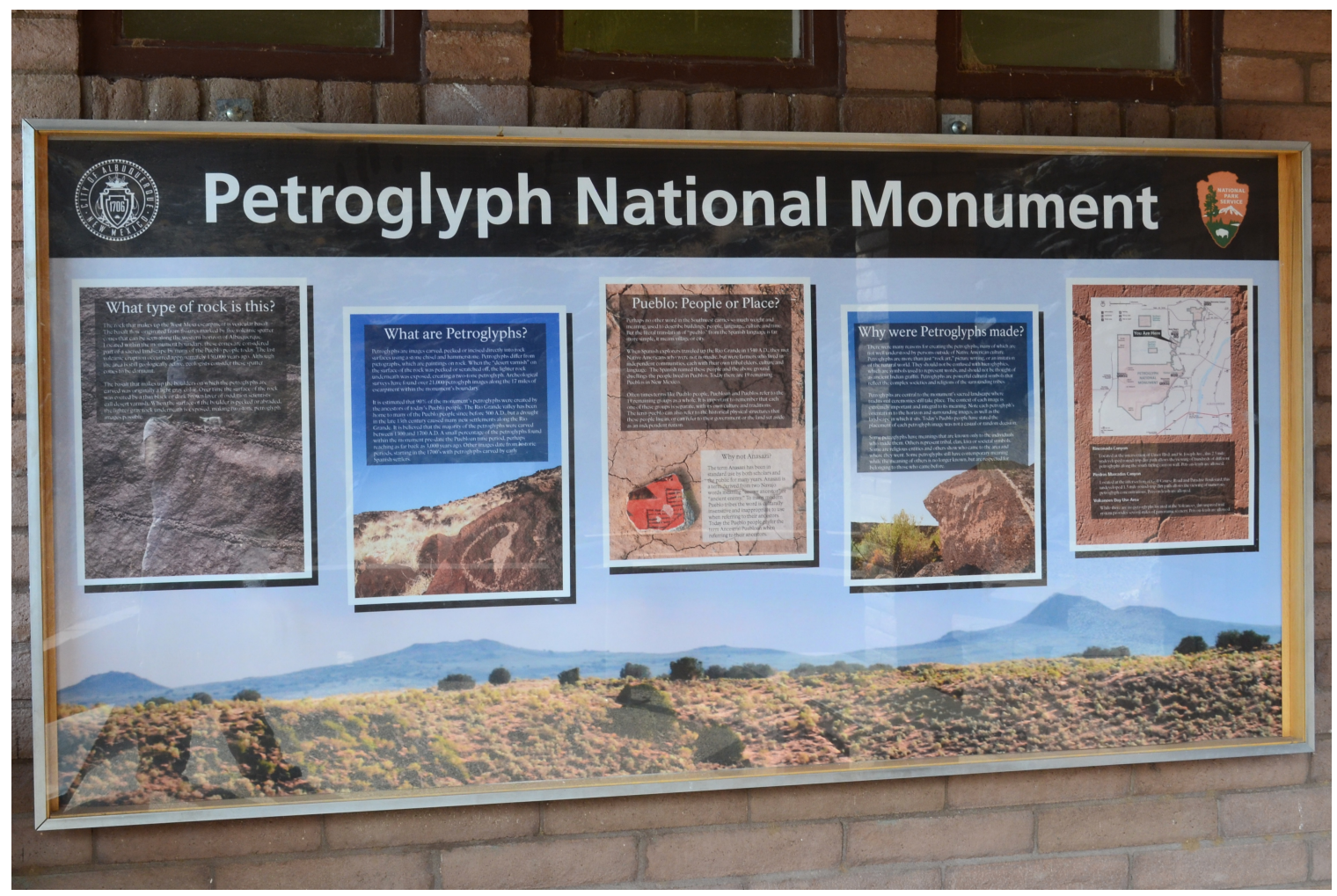

Figure 10. Petroglyph National Monument, Boca Negra wayside sign incorporating geologic narrative, archaeological narrative, cultural narrative, and management messages. Note the five text boxes titled What type of rock is this?, What are Petroglyphs?, Pueblos: People or Place?, and Why not Anasazi?

The five case studies displayed striking similarities in the relative frequencies of scientific, management, and cultural narratives: in general, the Interpretation observed indicated a greater focus on scientific narratives than on management messages, and a greater focus on management messages than on cultural narratives. Additionally, a single type of narrative content appeared most frequently in each narrative category: orientation comprised the largest proportion of management messages, archaeology dominated the scientific narratives, and cultural continuity appeared with the greatest frequency in the cultural narratives. 
Figure 11. Relative Presence of Scientific Narratives, Management Messages, and Cultural Narratives in Selected Protected Area Interpretation ${ }^{7}$

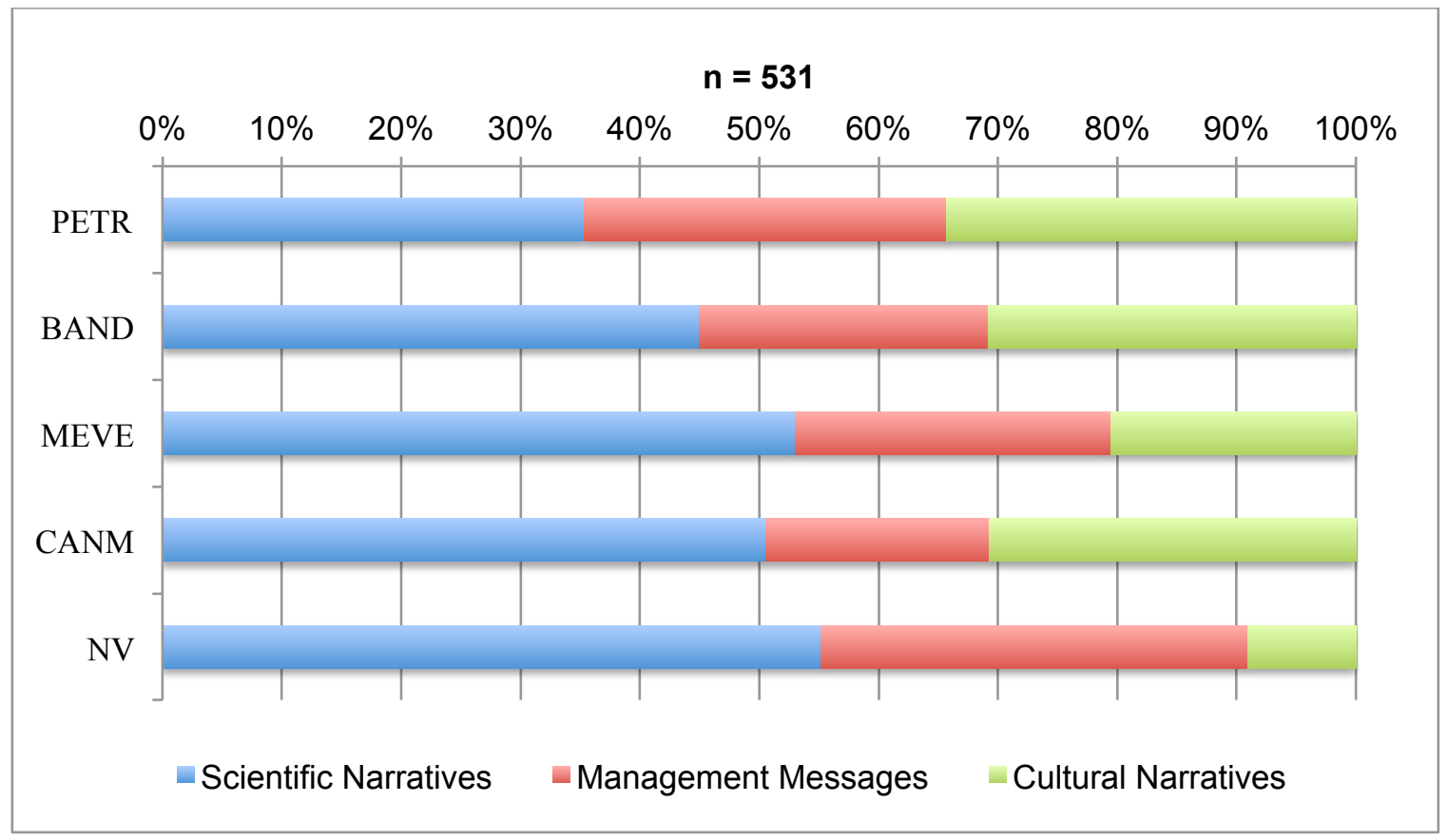

Chapter 3 comprises three sections: the first section focuses on scientific narratives; the second section on management messages; and the third on cultural narratives. In this chapter, I argue that the Interpretation of archaeology in the sampled protected areas disproportionately featured narratives of the past that reflect and privilege EuroAmerican, scientific constructions of nature, land, and nationhood.

${ }^{7}$ Of the Interpretation sampled $(\mathrm{n}=531)$, Petroglyph contributed 80 units of analysis, Bandelier 111 units, Mesa Verde 129 units, AHC/CNM 115, and the combined Nevada sites 96. 
SCIENTIFIC NARRATIVES: THE PHYSICAL SCIENCES, PROCESSUAL ARCHAEOLOGY AND ARCHAEOLOGICAL PRACTICE

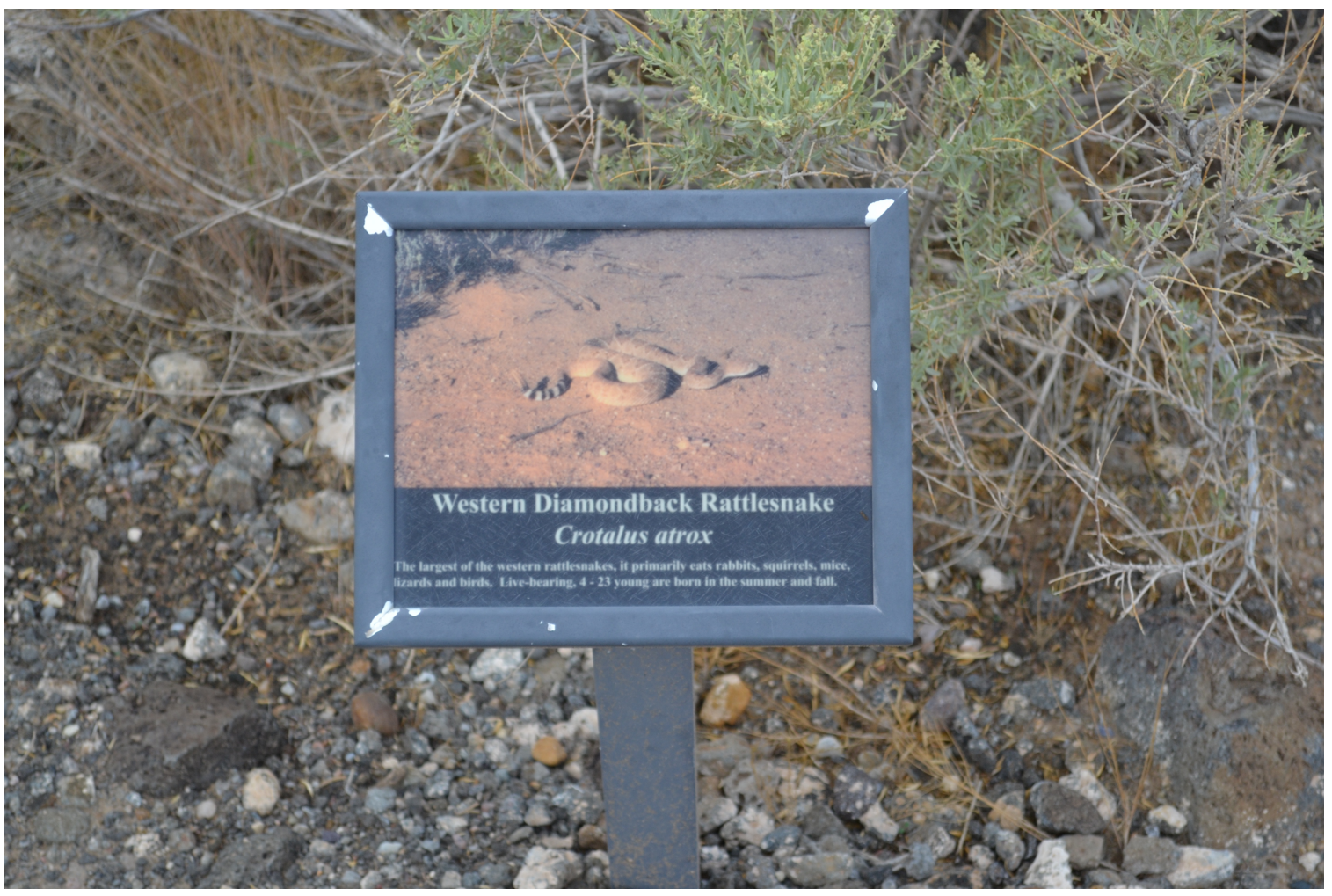

Figure 12. Petroglyph National Monument, Boca Negra Canyon trail, worn interpretive key sign. Note scientific narrative.

The protected area Interpretation observed in this research occasionally presented scientific narratives in the absence of cultural narratives or management messages

(Figure 12); typically, however, the observed Interpretation juxtaposed narrative types (Figure 13). 


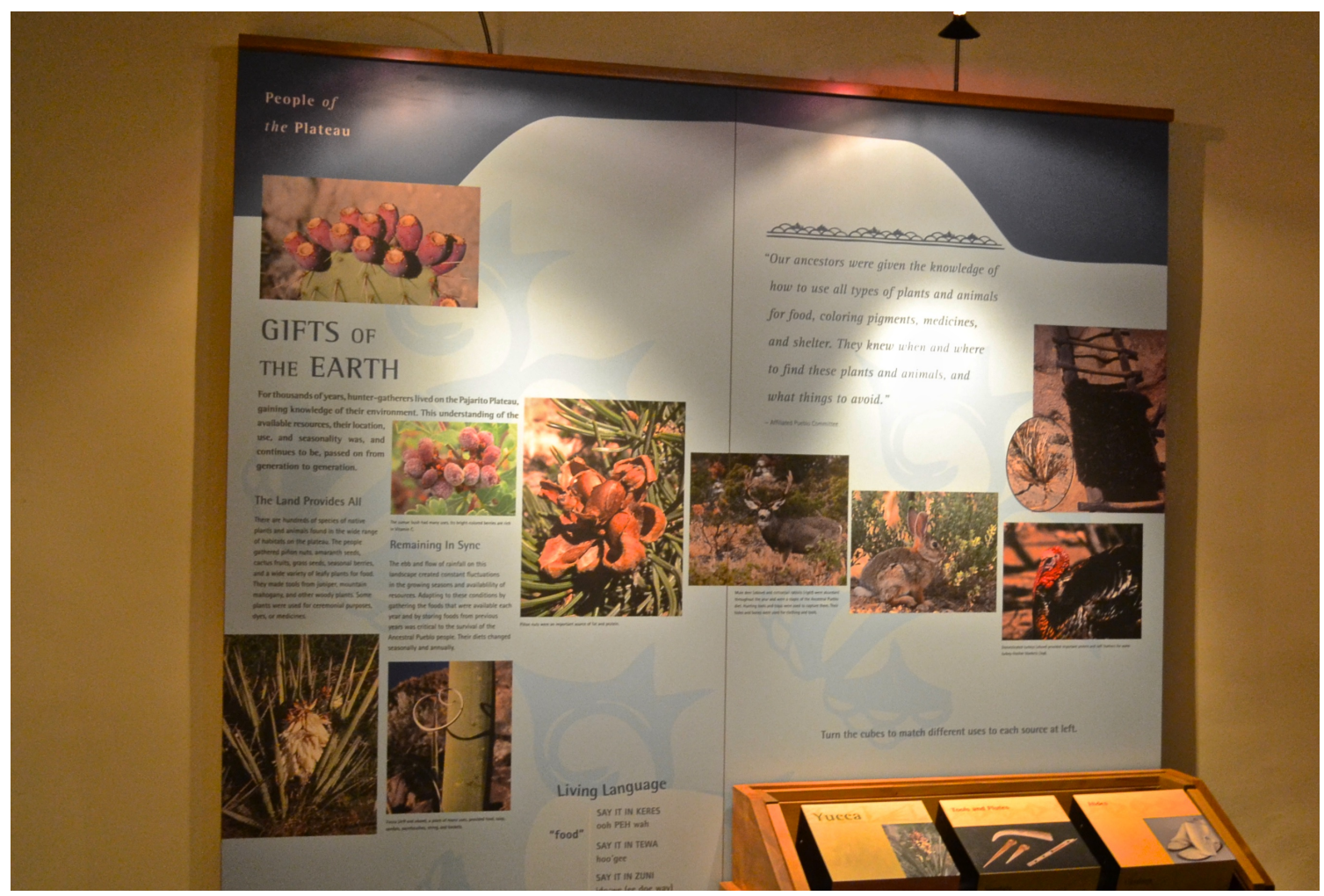

Figure 13. Bandelier museum display juxtaposing scientific and cultural narratives. Note species identification, text detailing resource use over time, and quotation from the Affiliated Pueblo Committee; also note the blending of first-person, third-person inclusive, and third-person omniscient perspectives.

At four of the five NPS and BLM sites observed in this research, archaeological narratives appeared most frequently of any type of content, with a relative presence ranging from $40 \%(\mathrm{MEVE})$ to $73 \%(\mathrm{NV})$; archaeological narratives appeared even more frequently than orientation content, which ranged from 22\% (AHC/CANM) to 45\% (NV). However, at the fifth site, Petroglyph, archaeological narratives appeared in the Interpretation sampled with a relative frequency of $40 \%$ and orientation content with a relative frequency of 49\%. In general, scientific narratives (archaeology, natural history, and geology) appeared with greater relative frequency than management messages or cultural narratives. The scientific narratives observed in this research largely reflect two 
of the four conceptions of Interpretation Benton (2009) identifies: connecting visitors to resources and encouraging environmental literacy. The overwhelming presence of archaeological narratives in this sample of Interpretation confirms the disciplinary privilege of archaeology over other ways of knowing.

Figure 14. Relative presence of scientific narratives in selected protected area Interpretation

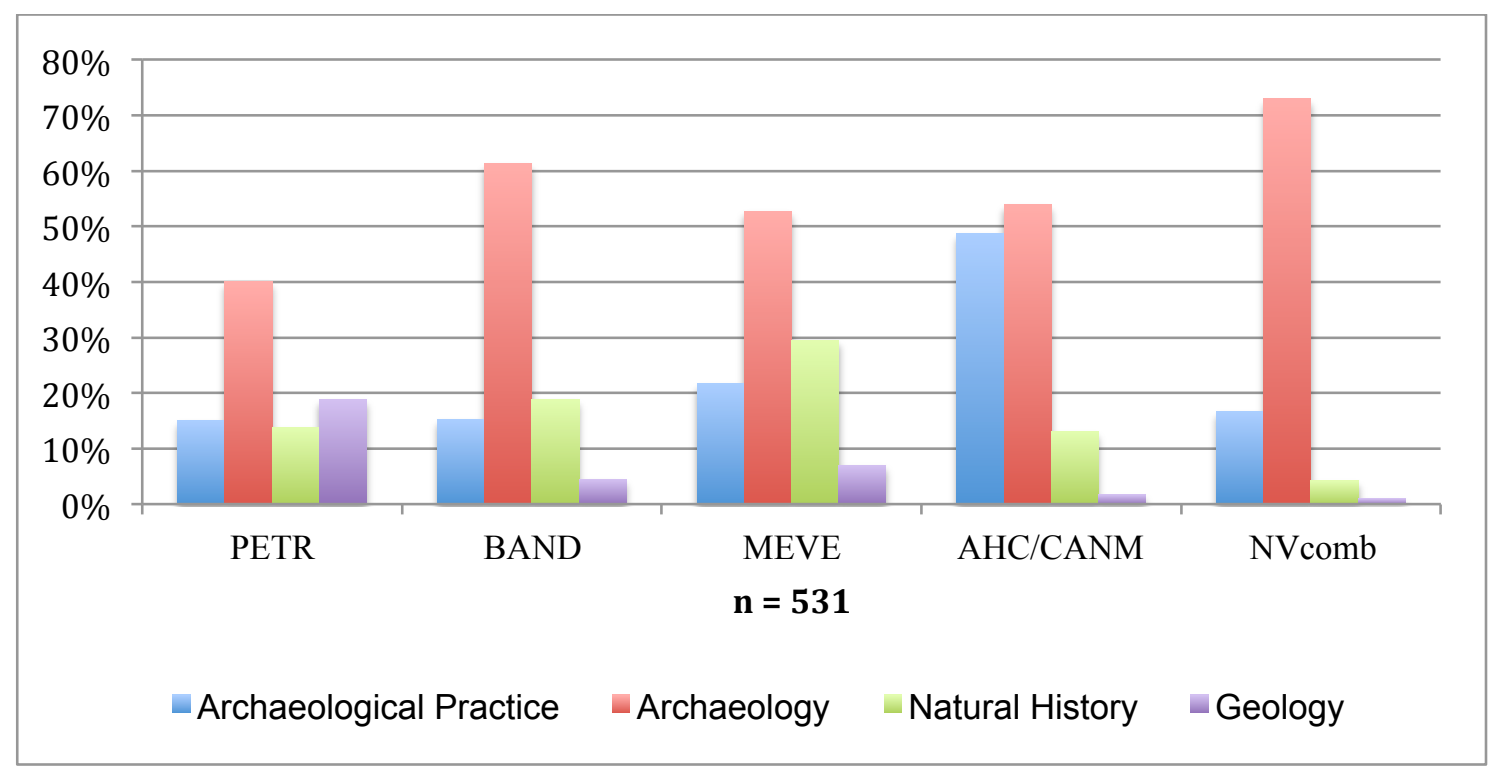

Some protected area Interpretation observed in this research presented knowledge constructed within the disciplines of archaeology and the physical sciences as if it were asynchronic, ahistorical, enduring, objective, and independent of other domains of knowledge (Figure 15). 


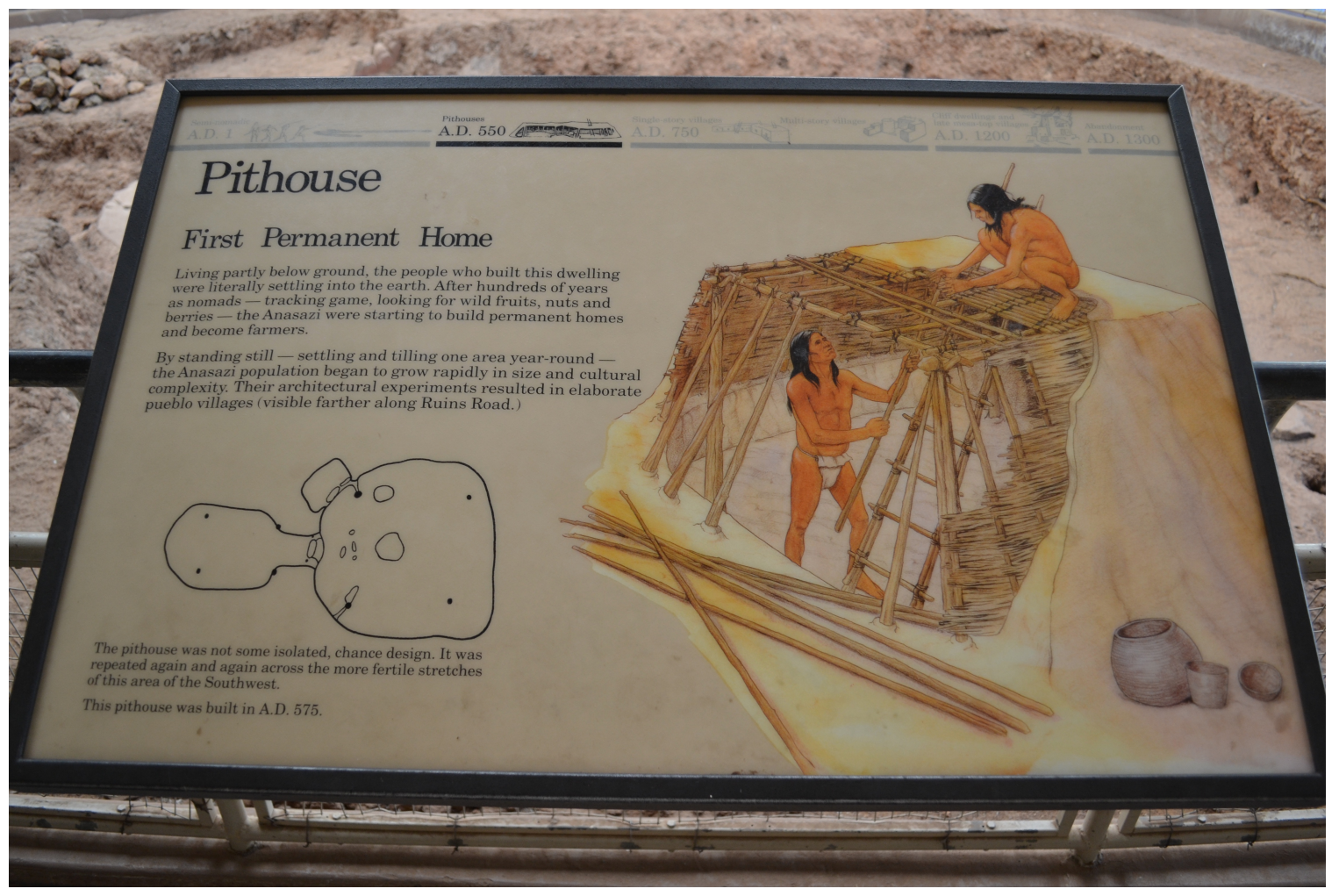

Figure 15. Mesa Verde pithouse interpretive sign. Note archaeological narrative, archaeological site plan, and representational style.

Some Interpretation juxtaposed alternative domains of knowledge without comment, as in the Petroglyph signage pictured above (Figure 9, Figure 10) which illustrates the presence of management messages, scientific narratives, and cultural narratives in a single display. This research also observed some Interpretation that was both multitemporal and multi-voiced, for instance this interpretive panel (Figure 16) from Lowry Pueblo (AHC/CANM) combining an excerpt from the foundational 1936 Field Museum publication, a Santa Clara pueblo visitor's interpretation made "several years ago," current archaeological knowledge, and contemporary cultural practice. 


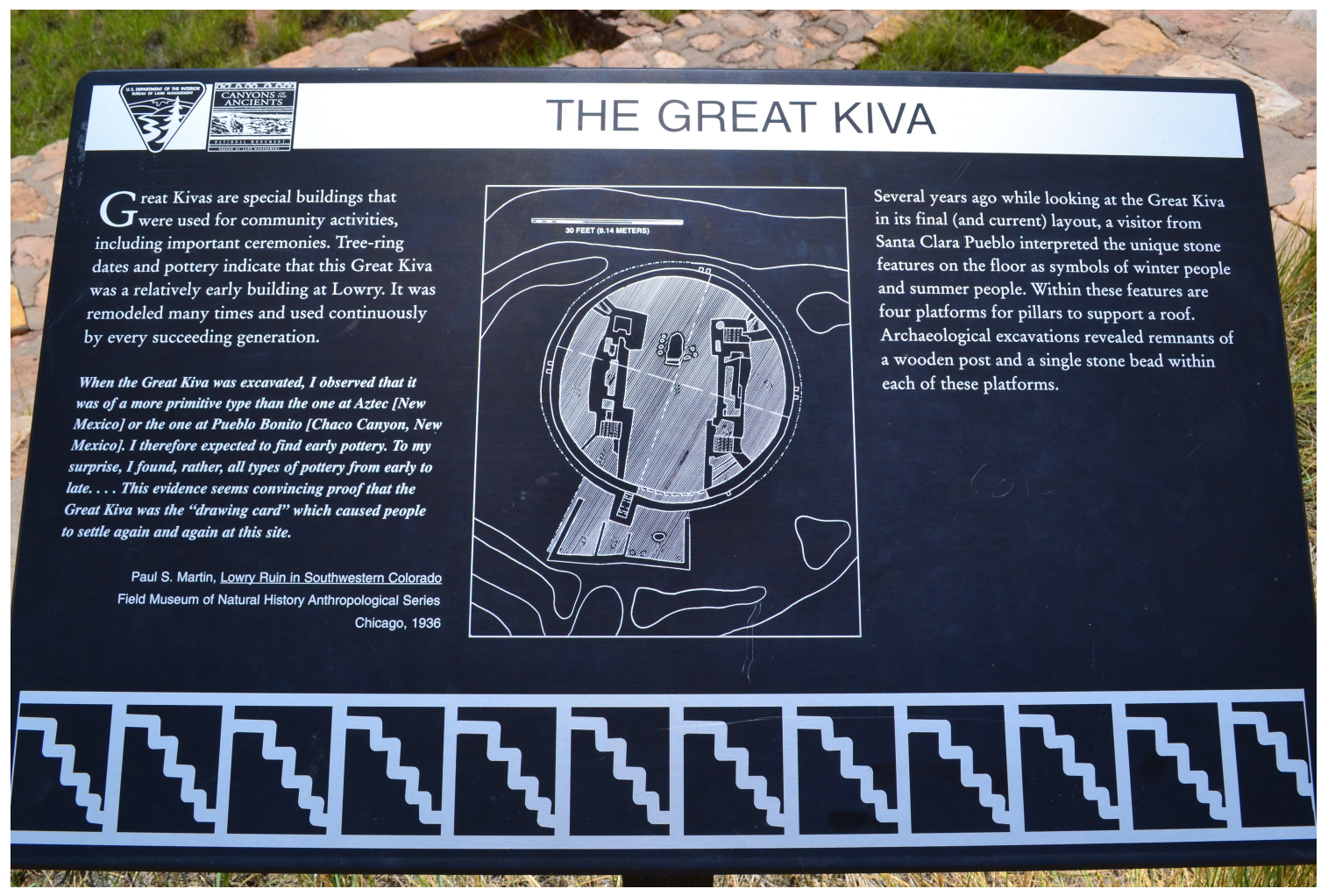

Figure 16. AHC/CANM, Lowry Pueblo Great Kiva interpretive sign incorporating archaeology, archaeological practice, and cultural narratives. Note that archaeological knowledge is situated in two timeframes, the $1960 \mathrm{~s}$ and the (unspecified) present.

Theoretically, Interpretation may use juxtaposition to structure an explicit discussion of the validity of divergent domains of knowledge (Atalay, 2012); however, this research observed no such examples. ${ }^{8}$ Interpretation may- though rarely, and most often in personal Interpretation (i.e. face-to-face encounters between interpreters and visitors) - refuse, revise, or critique the dominant discourse (Fine-Dare, 2002; Peers, 2007). One interpreter interviewed in this research specifically identified as a "skeptic;" another spoke of enjoying "critical interrogation" of sanctioned themes in Interpretation.

${ }^{8}$ I am, however, confident that they exist: readers may be familiar with Here, Now, and Always, at the Museum of Indian Arts and Culture in Santa Fe, New Mexico; see also Lonetree (2012). 
Some visitors and interpreters are well aware that archaeological knowledge is epistemic. They query disciplinary practice and epistemology. Visitors may ask how we know what we know. One visitor to Bandelier (declined to state age), whose young adult son shared her curiosity, put it this way:

One of the things that has intrigued me is just wondering how much more there is. If there was any way a ranger or someone could take you to more areas ... to see the transition between what it looks like on top of the ground to where they excavate the ruins. ... And, how do they know where they [the archaeological sites] are? I'm sure they don't absolutely know where they all are, or how many there are, or how vast they might be. How do we know for sure? We can't absolutely know for sure, but how do we come about believing the information that we have now? What gives it credibility? I'm not doubting [laughter], but I want to know how it came about.

The first time I spoke with these visitors, they were only interested in hiking and socializing with their family; the next day, however, they spoke enthusiastically about the trail-side villages they had seen and were on their way to the visitor center and museum to learn more. The interest of visitors like these argues for the inclusion of archaeological practice in addition to mandated current archaeological and anthropological scholarship (Bureau of Land Management, 2004; National Park Service, 2006).

Some interpreters encourage visitors' interest in epistemology in the public presentation of archaeology: two out of three ranger-led tours observed in this research provoked visitors to ask similar questions. One long-time protected area interpreter interviewed in this research explicitly and consciously focused on epistemology, saying:

Over time we have become a much more skeptical nation. We want to test more the waters and find out more really what's going on. We don't want the surface veneer, no, there's got to be something, there's a story behind this story we're being presented with. ...We are beginning to demand almost: "Well, okay, so how do you know that this place was built in 1165? How do you know this? How do you know that? And so I'm on my guard because I've got to expect that. ... I've got my own skepticism. And so I'm part of that same group that's asking those 
questions. ... I'm sharing the same feelings that those individuals opposite me are feeling; I know what's going on in their minds to a certain degree. ...We are on the same page. We are trying to get the answers together.

This interpreter noted the nearly equal importance of archaeological evidence ("Where did they plant?") and practice (tree ring dating, site reports) in preparing to present archaeology to the public. On this interpreter's tour, participants asked questions, answered questions, and quickly silenced their chatter when the ranger spoke. When one person asked, "What's farther along the trail?", the ranger polled participants and extended the tour. Back at the trailhead, participants were slow to disperse. ${ }^{9}$ Visitors' enthusiastic response, as observed in this research, may also argue for the inclusion of archaeological practice in the public presentation of archaeology.

These two interviews suggest that at least some of the people who produce and consume the Interpretation of archaeology seek an understanding of archaeology as process - the whole process of archaeological data collection, analysis, and inferencerather than product - the knowledge it constructs and presents. The public presentation of archaeology may offer significant opportunities for staff and visitor co-learning as well as bringing the construction of archaeological knowledge to visitors' conscious understanding (Berkes \& Turner, 2006; Spoon, 2014; Spoon \& Arnold, 2012).

${ }^{9}$ Powell \& Stern (2013) measure the success of personal interpretation in terms of visitor response; enthusiastic participation and tour holding power are key metrics. In contrast, this and other interpreters interviewed in this research gauge success in terms of participants' requests for additional information and participants' reluctance to leave at the end of the tour. 
The relative presence of archaeological practice ${ }^{10}$ in the Interpretation sampled varied widely from site to site, ranging from $15 \%$ to $49 \%$ of the Interpretation sampled. The relative proportions of narratives drawn from natural history, geology, archaeology and archaeological practice within each site were generally consistent at Bandelier, Mesa Verde, and Petroglyph. At the Nevada sites, however, archaeology appeared with a relative frequency of $71 \%$, the highest of the five research sites, and natural history appeared with a relative frequency of $1 \%$, the lowest of the five. Potentially, this indicates that Interpretation at the NV sites privileged processual archaeology and culture history to the virtual exclusion of any other domain of knowledge. At AHC/CANM, archaeological practice appeared with a relative frequency of $49 \%$, the highest of the five research sites, and approached the relative frequency of archaeological narratives there, $54 \%$.

Potentially, the relative proportions of narratives drawn from natural history, geology, archaeology and archaeological practice at AHC/CANM indicate the epistemic nature of interpretive display: the Anasazi Heritage Center was developed in 1988 as a museum and curation facility, and Canyons of the Ancients was designated a National Monument in 2000. The AHC allocated nearly all its exhibit hall floor space to the practice of archaeology, the construction of archaeological knowledge, and the display of

10 Archaeological practice emerged distinct from archaeology in coding the supplementary component, the semi structured interviews with staff and visitors. Archaeological practice captures methodology and epistemology; archaeology captures narrative, archaeological inference and interpretation; see Appendix C. 
excavated objects in the style of an art museum (object-heavy display cases with minimalist labels, some with hyperlinks).

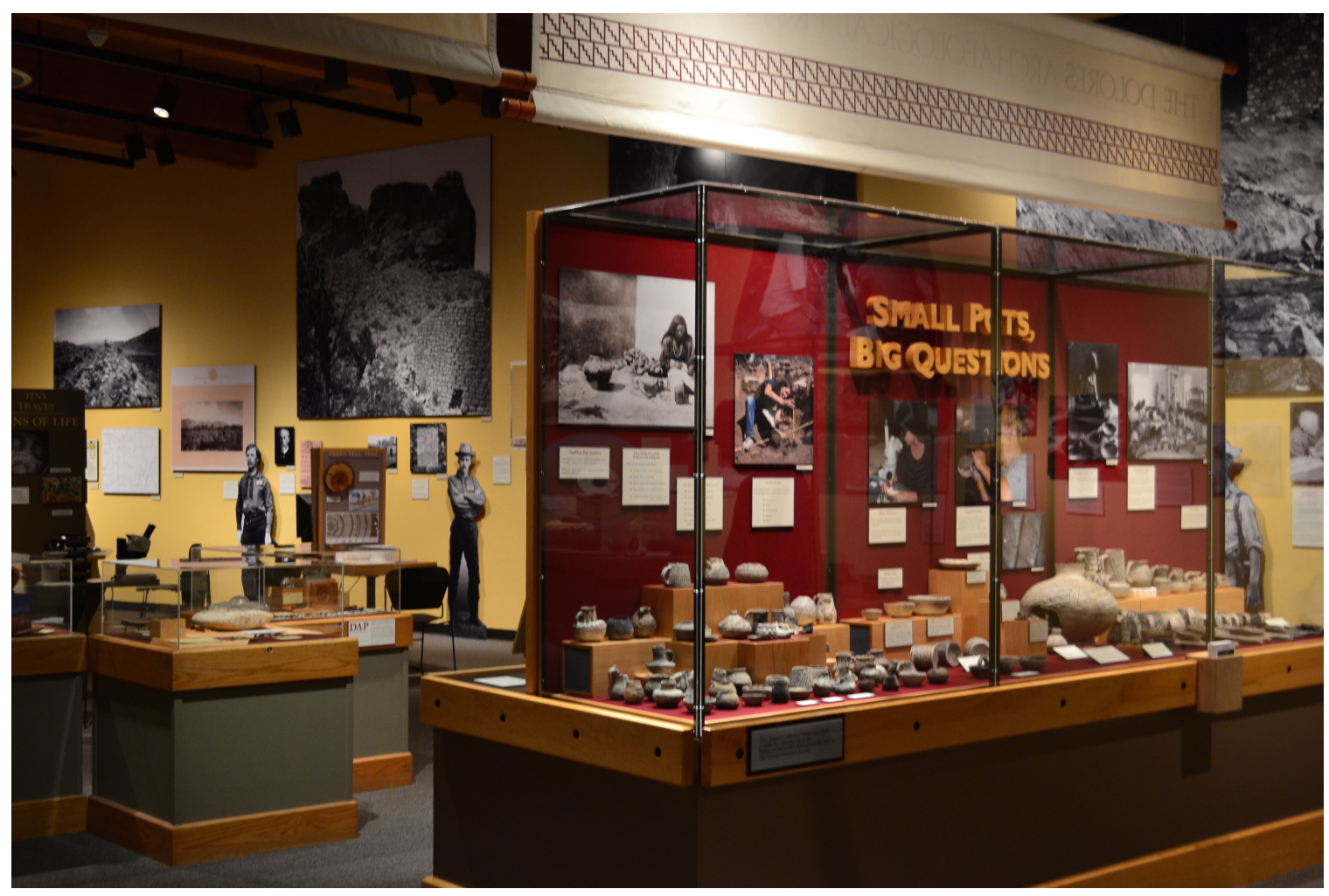

Figure 17. AHC/CANM, display of Puebloan material culture over time. Note archaeological timeline dominated by enlarged black and white photos, background.

While the Mesa Verde VRC, the Petroglyph visitor center, and Bandelier's museum offered a small number of touchable or simple interactive displays, the AHC most closely approximated the participatory museum sensu Simon (2010).

Approximately one-third of the space featured a "Discovery Center" offering interactive exhibits alongside hands-on exploration of activities: a loom and grinding bins; electric microscopes with pottery, pollen and lithic samples at hand, tree-ring samples to match; and computers loaded with an edited curation database, select archaeological reports, virtual reality archaeological sites, and more. 


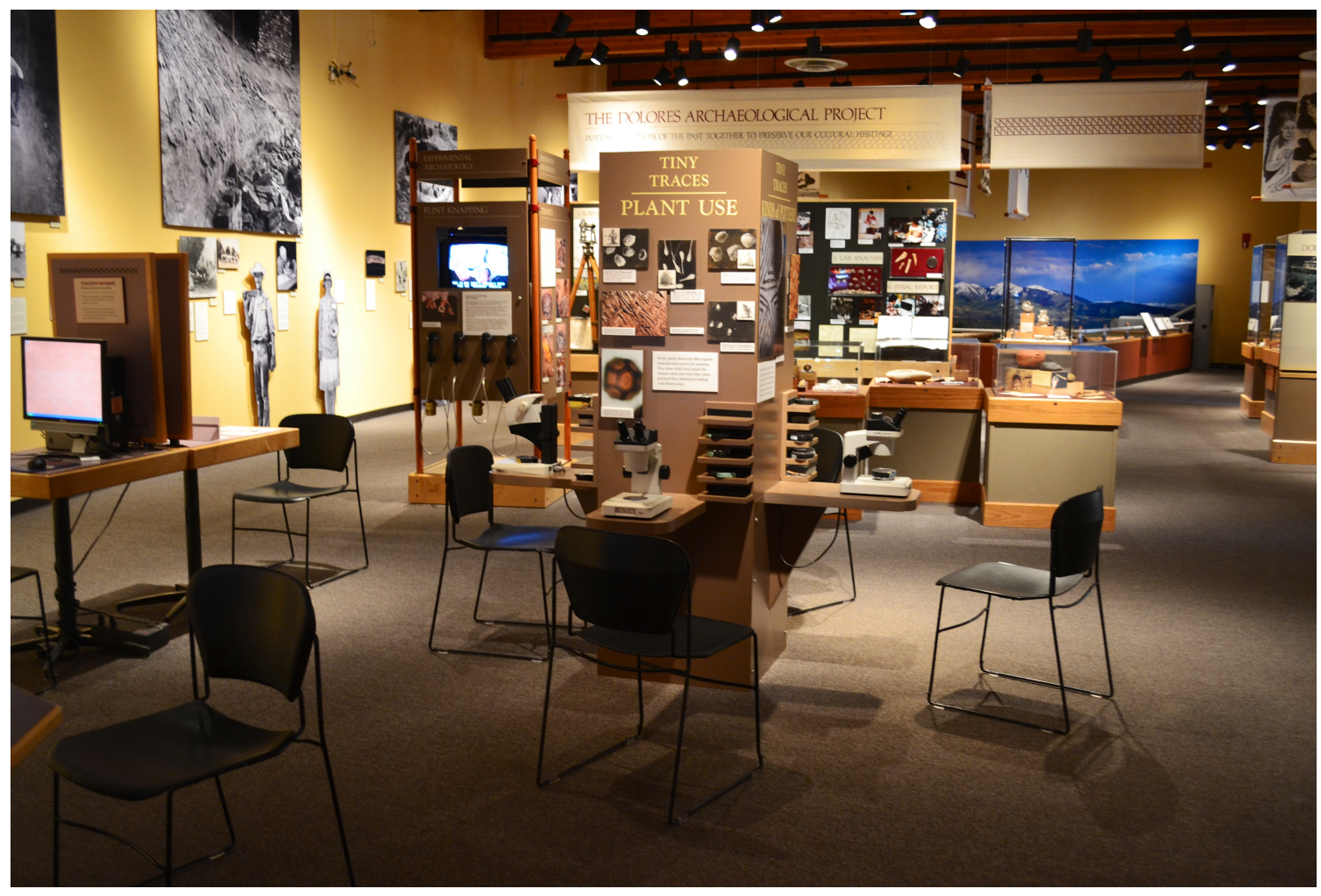

Figure 18. AHC/CANM, portion of Discovery Room. Note microscopes, samples, and experimental archaeology kiosks, center; archaeological timeline, left, and display of archaeological practice partially visible in background.

The exhibit hall perimeter displayed what were essentially two timelines. One wall chronicled the development of Southwestern archaeology through historic photos and text panels (Figure 17, background, Figure 18, left). The opposite wall (Figure 19) chronicled ancient (Paleoindian and Archaic periods), Ancestral (Basketmaker and Pueblo periods), historic, and contemporary Puebloan culture through a display dominated by artifacts and replicas, color photos of charismatic objects and contemporary people, and black and white photos from the historic era. 


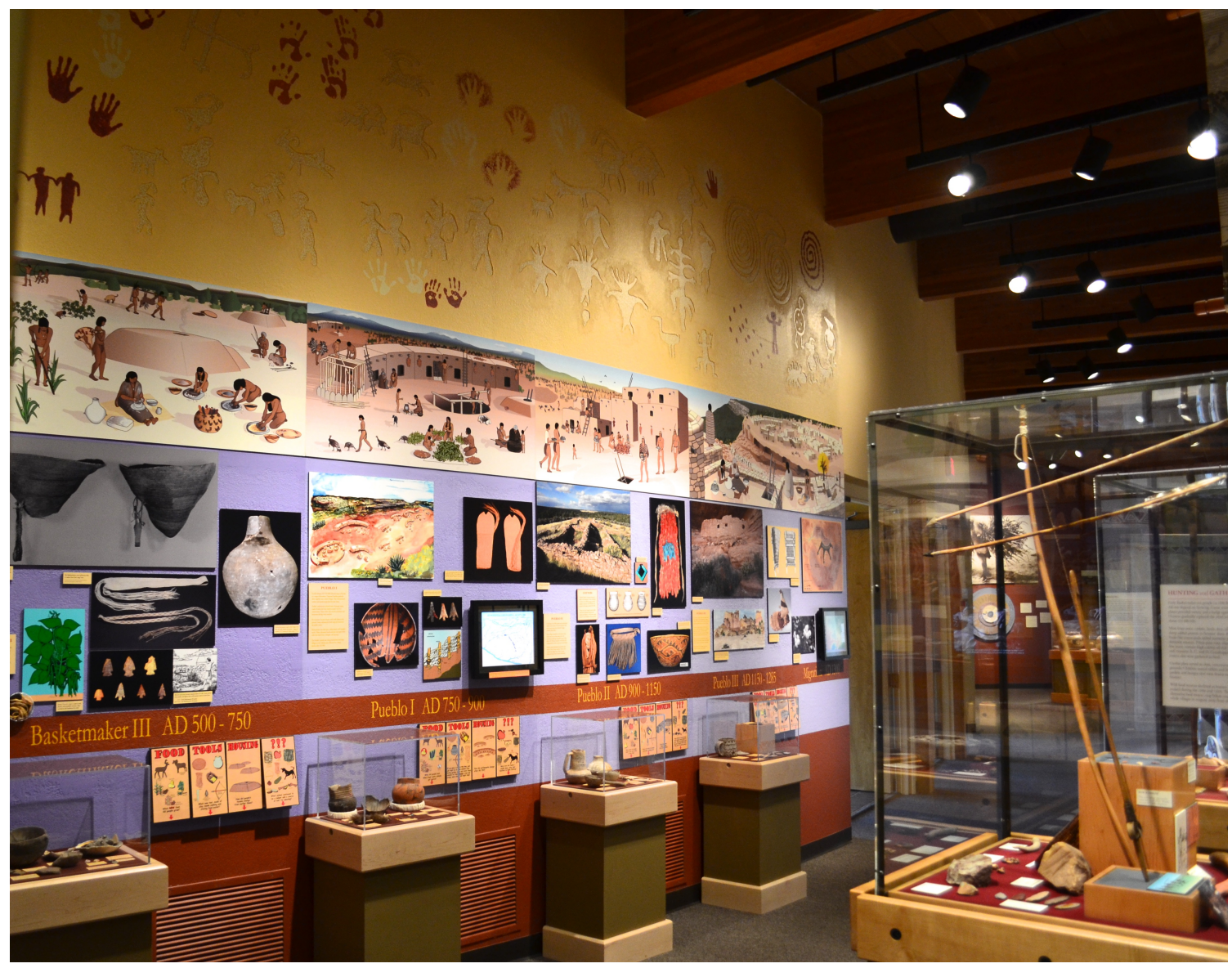

Figure 19. AHC/CANM, display of Pueblo cultures over ancestral time. Note interactive q-and-a flip boards and timeline, bottom; artist's renderings, digital photo frames, and oversized color photos of iconic artifacts, middle; and artist's renderings and painted petroglyphs, top.

A number of outdoor interpretive panels at CANM sites juxtaposed scientific and cultural narratives. Some panels (e.g., Figure 16, Figure 38) employed a multi-voiced, even a multi-temporal approach to the presentation of archaeology. One panel described and depicted inadvertent destruction during excavation. Another contrasted archaeological interpretations of the site made in the 1930s and late 1980s.

At the AHC/CANM, archaeological practice appeared with nearly as great a frequency as archaeology: archaeology and archaeological practice took center stage, often quite literally. Explicit discussion of archaeological practice may well represent a 
conscious strategy on the part of protected area interpretive staff to shift from displaying an ostensibly scientific representation of Native Americans to a more complete, complex, and nuanced disclosure of the workings of archaeological science itself. Such an explanation is consistent with the influence of the reflexive turn in anthropology circa the mid 1980s (Clifford, 1988; Clifford, Marcus, \& Fortun, 2010) . Explicit discussion of archaeological practice may well represent an acknowledgment of the history and the limitations of the discipline and a reluctance to continue to objectify Native Americans. Such an explanation is consistent with increasing presence of indigenous and collaborative practice in the discipline of archaeology itself (Atalay, 2012; Fine-Dare, 2002; Lonetree, 2012; Preucel \& Mrozoski, 2010). Disclosure of practice and epistemology may suggest a move toward decolonizing still-colonial institutions like federal protected areas. Alternatively and most likely, it may represent a conscious strategy to open a space for Native American self-representation in the wake of the institutionalization of NHPA, NAGPRA, and AIRFA as agency policy.

Several themes emerged in interviews with protected area staff that support these possible readings. I asked staff members of protected areas stewarding significant archeological resources to define successful Interpretation. One interviewee connected success (or lack thereof) to the age of the Interpretation: "I'm trying to get those [individual sites] better interpreted. More appropriately done, because they were done in the early ' 80 s and [placed] more emphasis on the interpretive part than the fact part." This interlocutor suggested that the interpretive material in question was dated because it neglected archaeological practice in favor of speculation intended to engage and elicit 
visitors' affect (For example, one trail guide asked the visitor, "Is this a spaceship or a sombrero?").

An interviewee at a different protected area also connected the success of

Interpretation to the presence of current archaeological research:

But one of the things is that we want the park to be a shining example ... And when we see interpretation that we don't think is that magical interpretation, it causes a little bit of heartburn. And so, much of what you've heard for this last hour, is - I don't want to use the word dissatisfaction, because I think that's a little too strong of a word, but I think we... are not doing the best job that we could, presenting the best story we could by incorporating the latest and greatest archaeological research that is being done, just because it's being done 20 miles that way....It bothers me that we are a ignoring a lot of good research because it is new... I don't like that. And so part of what you've heard is my frustration of this park not being the shining star that it should be.

To this speaker, not only was new archaeological knowledge of interest, but also changing archaeological practice and interdisciplinary study elsewhere in the region.

An interviewee at a third protected area spoke at length of how the protected

area's Interpretation changed over time in response to consultation:

The consultations have been so terrific. . We used to talk about things that we now know the Pueblos don't want us to. In those days [agency] people weren't necessarily asking, people weren't necessarily listening. They didn't have the opportunity, period. But when the consultations got going, then everybody learned so much. ... It's like a compact between us. If we're going to ask them to tell us things, we'd better, well, listen and really try. It's one of those things that you're not going to get all this stuff out to visitors, but once in a while you'll get something out that will give them a glimmer, something that gives them an idea that the Pueblo people are very much with us and that it is our job to be respectful to them. We are not just talking about some batch of folks that are not related and are gone. There's a big difference even now. 
This interlocutor specifically connected the effectiveness of officially and explicitly defined interpretive themes, goals, and objectives (National Park Service, n.d.-c) with robust consultation with affiliated Native American nations. ${ }^{11}$

Forces inside and outside of the discipline of archaeology-Native American activism, feminism, Marxism, anthropological reflexivity, post-processualism, and the passage and institutionalization of NHPA, NAGPRA and AIRFA among them-continue to shape increasingly collaborative practices in North American archaeology (Atalay, 2012; Fine-Dare, 2002; "National Register Bulletin: Guidelines for Evaluating and Documenting Traditional Cultural Properties," 1998; Preucel \& Mrozoski, 2010). Scholars across anthropology, archaeology, public history, and museology all discuss collaborative practice as both situated and contested in their respective disciplines; collaboration is highly epistemic. They generally locate specific instances of collaboration somewhere on a spectrum or continuum from pro forma or gestural consultation to community-based participatory research (Atalay, 2012; Barber, 2013; Boast, 2011; Clifford, 2004; Colwell-Chanthaphonh et al., 2010; Colwell-Chanthaphonh, 2008; Lassiter, 2000, 2005; Phillips, 2003; L. Smith, 2004, 2006; L. Smith \& Waterton, 2009; Spoon, 2014; Spoon \& Arnold, 2012). In each phase of an archaeology or museum project — project design, funding, research design, writing, public presentationauthority may rest with the curator, anthropologist or archaeologist, may rest with the community, or be shared.

${ }^{11}$ Other interviewees, however, talked about their professional involvement with affiliated tribes in language that suggested quite limited, even adversarial, relationships. 
(Re)Presenting peoples and storied lands

While mission messages frequently discuss the existence and importance of consultation and collaboration, its actual presence in interpretive material remains somewhat, and perhaps necessarily, opaque (Benton, 2011; Gonzalez, Modzelewski, Panich, \& Schneider, 2006; Little \& Amdur-Clark, 2008). By definition, consultation occurs at the government-to-government level (Biolsi, 2005; Gonzalez et al., 2006; Miller, 2008; Spoon, Arnold, Hambelton, \& Nuwuvi Working Group, 2012); consultation or collaboration is legally mandated in some cases, policy-driven in others. Waysides, exhibits, and brochures are usually produced by staff technicians and outside consultants, i.e. interpretive delegates. The public presentation of archaeology generally tells the visitor about consultation or collaboration more effectively than it shows it. The effect of consultation and collaboration may be suggested by the frequency and kinds of cultural narratives offered in the Interpretation of archaeology for the public, but the process remains somewhat occult (Peers \& Brown, 2003; Spoon, 2014; Spoon \& Arnold, 2012; Spoon, Arnold, Hambelton, et al., 2012).

MANAGEMENT MESSAGES: ORIENTATION, CONSERVATION/PRESERVATION, AND MISSION CONTENT

Within management messages, orientation content—safety information, regulations and penalties, and location information - appeared with greater frequency than conservation and preservation content or mission content. Across the five sites, orientation content ranged from a relative frequency of $22 \%$ (AHC/CANM) to $49 \%$ (PETR) while conservation/preservation content ranged from 11\% (PETR, MEVE, $\mathrm{AHC} / \mathrm{CANM}$ ) to $15 \%(\mathrm{BAND})$ and mission content ranged from $3 \%(\mathrm{NV})$ to $15 \%$ (PETR). In general, the management messages observed in this research reflect three of 
the four conceptions of Interpretation Benton (2009) identifies: conveying agency mission and influencing visitor behavior, encouraging environmental literacy, and, to a lesser extent, promoting tourism outcomes.

Figure 20. Relative presence of management messages in selected protected area Interpretation

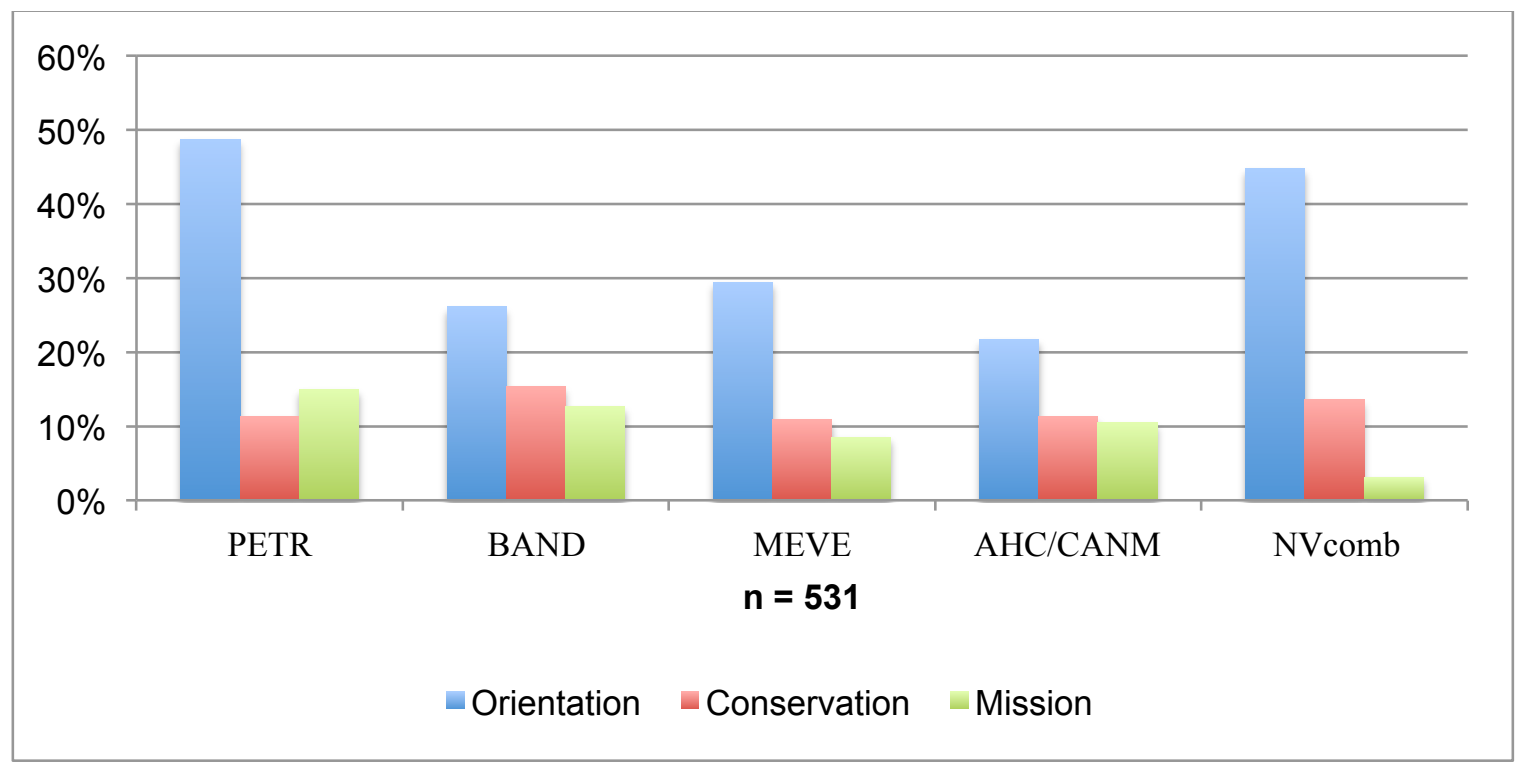

The tone of management messages observed in this research varied, but only rarely did interpretative materials present management messages divorced from other kinds of content. Consistent with established practice in Interpretation, management messages were generally concise. They emphasized the safety of the visitor and the resource over prohibitions. 


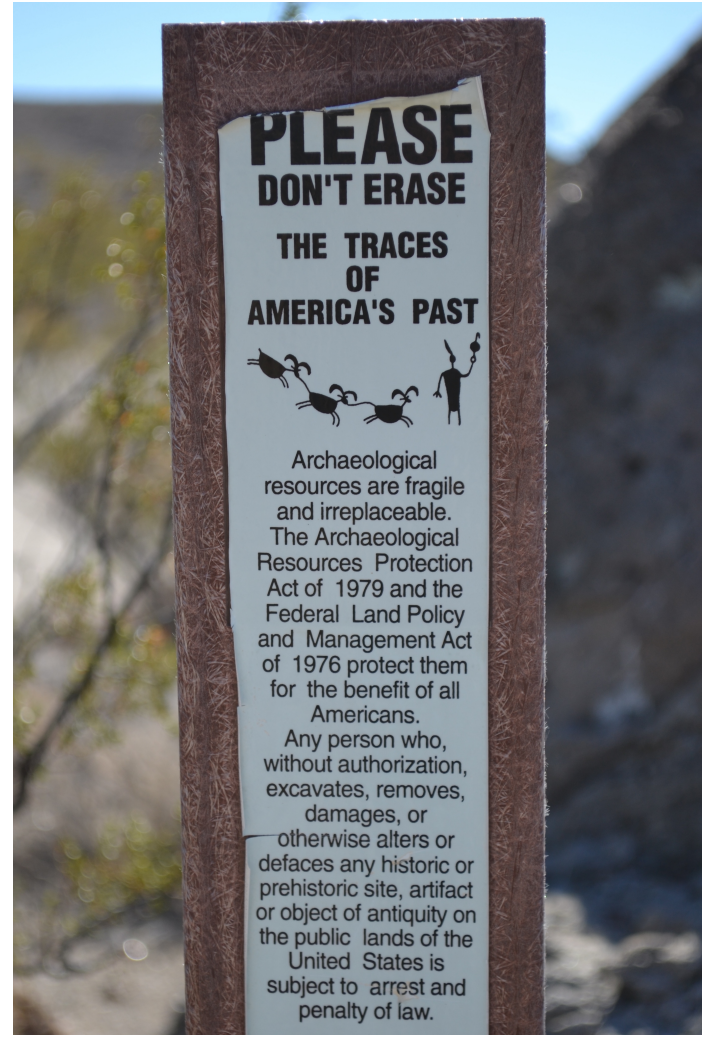

Figure 21. Ash Springs sign, Lincoln County, Nevada. Note management message with orientation content emphasizing regulations and penalties.

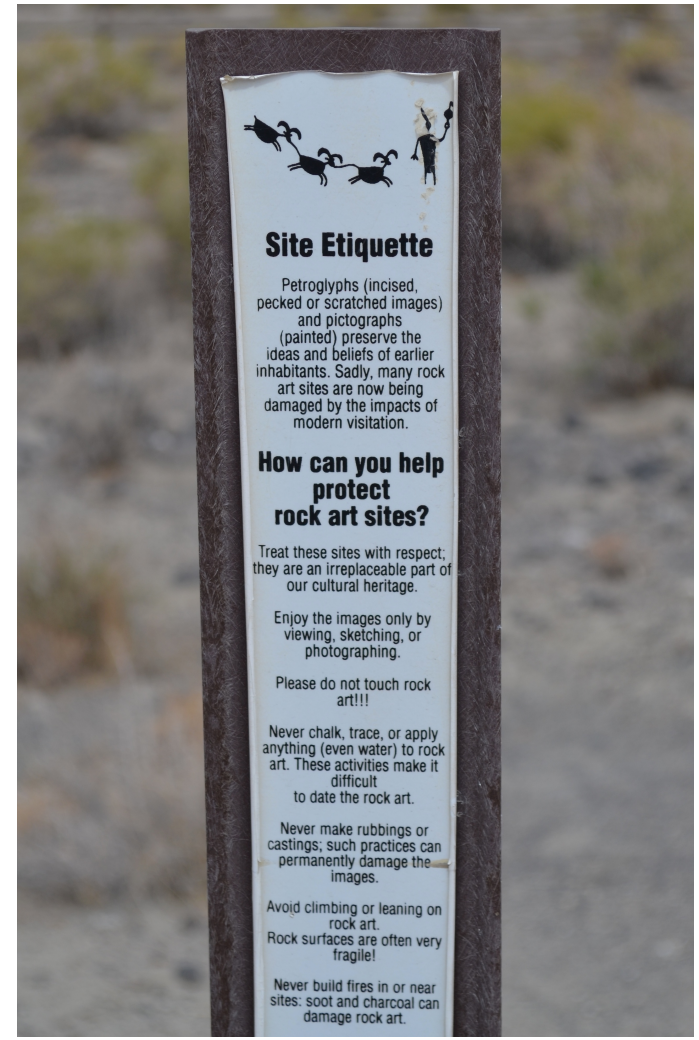

Figure 22. Grimes Point Archaeological Area sign, Churchill County, Nevada. Note admonitory management message incorporating conservation/preservation and limited archaeological narrative.

According to one protected area staff member interviewed in this research, visitor

safety and appropriate behavior dominate face-to-face encounters between staff and

visitors. This interpreter described the daily routine this way:

The last couple of years have been difficult because we've spent so much of our time and energy on just practicality, just getting people on and off the bus, just getting people to not fall off the ladders, just getting people to not float away in the floods.... When you're actually explaining to somebody at the desk, when you have a teachable moment, when you have a chance beyond just explaining to 
them that "The trail goes here and this is what there is on it. Stay on the trail. Go see it." Which is what we do so much of. And that's important-Maslow's hierarchy of needs. If they don't know where the restrooms are, if they don't know where the trail is, nothing else matters.

As this interviewee noted, practicality regularly trumps all other concerns. At both NPS and BLM sites, the relative frequency of orientation messages (ranging from $22 \%$ at AHC/CANM to $49 \%$ at PETR) necessarily reflected the primacy of visitor safety in agency management. As Benton (2009) notes, Skibins, Powell and Stern (2012) detail, and Knudson, Cable \& Beck (2003) exemplify, managing visitor behavior remains a key goal of Interpretation.

Interpretation solicits cooperation: "It is cheaper to guide people than to arrest or deter them" (Knudson et al., 2003, p. 9). Orientation messages also bound space, rendering protected areas as governable spaces (Rose, 1996, 1999). The orientation content observed in this research emphasized the superior knowledge of protected area staff: staff members know the land, the resources, the facilities; visitors do not. Punitive messages and admonitory messages in orientation content reinforced the power/knowledge differential between visitors and protected area staff; such messages frequently threatened surveillance and reprisal. They may encourage visitors to discipline themselves and other visitors (Bennett, 1995; Brady, 2008; Foucault, 1979; B. Lord, 2006). For example, a law enforcement officer at one of the protected areas in this research related an incident of vandalism that occurred earlier that day: two teenaged girls hurled rocks at a still-standing structure and toppled it; one visitor to the heavilyused trail attempted to detain them while others ran in search of staff. Management messages exemplify the cost-effective, relatively invisible, and pervasively diffuse 
workings of power in protected areas. Combined with conservation/preservation messages, they call the visitor into being as a responsible user, subject to the rules governing the protected area (Powell \& Ham, 2008).

Conservation/preservation content appeared less frequently than orientation content and generally stressed the importance of natural and cultural resources and the resources' vulnerability. Conservation/preservation content generally divorced nature and culture, focusing on environmental threats to both humans and cultural resources, on the one hand, and human threats to natural and cultural resources on the other, over any reciprocally reinforcing relationship between humans and environment (Berkes \& Turner, 2006; Turner \& Berkes, 2006).. Human threats to natural resources emphasized resource depletion over time. Environmental threats to humans generally figured more prominently than environmental threats to natural and cultural resources, resonating with protected areas' concern with visitor safety. At Bandelier, for example, conservation/preservation content emphasized the dangers of flash floods; local environmental knowledge, traditional resource use, and agriculture were embedded in cultural narratives (see Chapter 4).

The Interpretation observed primarily constructed humans' threats to cultural resources in terms of looting and vandalism. Interpretation less often constructed threats in terms of development, the wear and tear of visitation, desecration, stabilization, reconstruction, or excavation. Professionals curate and collect; noncompliant visitors loot and vandalize. Professionals stabilize and preserve cultural resources; wind, water, time, and visitors' feet erode and destroy them. 
(Re)Presenting peoples and storied lands

Mission messages often disclosed agency practice. A significant number of the mission messages observed in this research discussed the development of protected areas over time, the passage of land from private to state to federal control, the development of the built environment, and the role of WPA and CCC projects. Mission messages frequently emphasized the protected areas' historic role employing scientists, artists, artisans, and laborers, particularly in protected areas stewarding structures listed on the National Register such as Bandelier and Mesa Verde. Potentially, mission messages such as these illustrate the workings of power/knowledge in protected areas: agents of the state may simultaneously empower and control (Foucault, 1994).

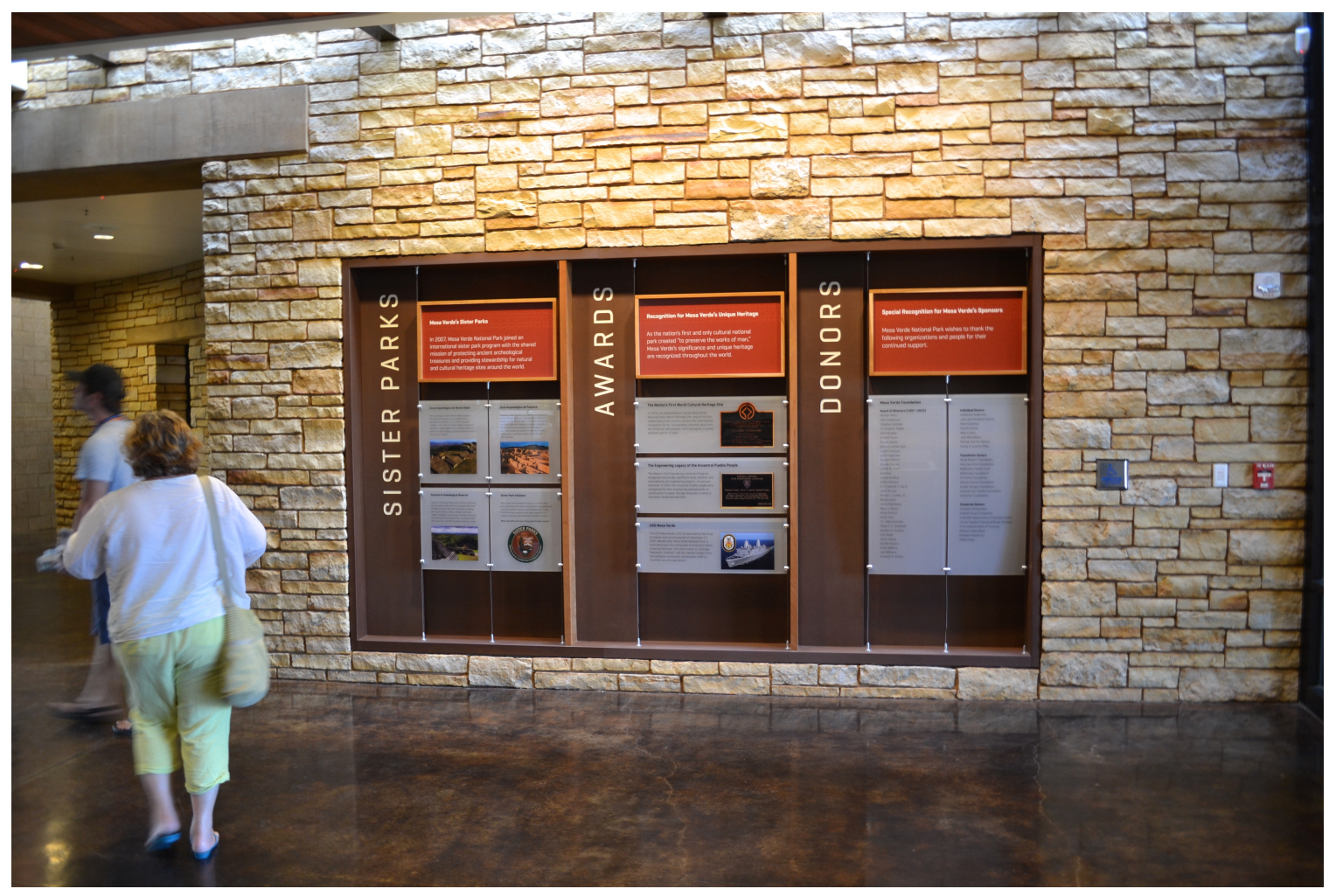

Figure 23. Mesa VRC, display presenting management message with mission content. 
Some mission messages observed in this research noted joint operating agreements, participation in global conservation networks, or acknowledged the participation of individuals and corporate entities, for example, these panels in the entry to Mesa Verde's new VRC (Figure 23). Mission messages also disclosed some of the sanctioned ways in which different people may act upon the protected area and its resources (Li, 2000; Simon, 2010). For example, these panels acknowledged members of Mesa Verde's board of directors, individual donors, and foundation donors. In the monumental entrance plaza, another panel (Figure 24) dedicated the space to "Native American pueblos and tribes" and acknowledged "their continuing support of the park's mission.”

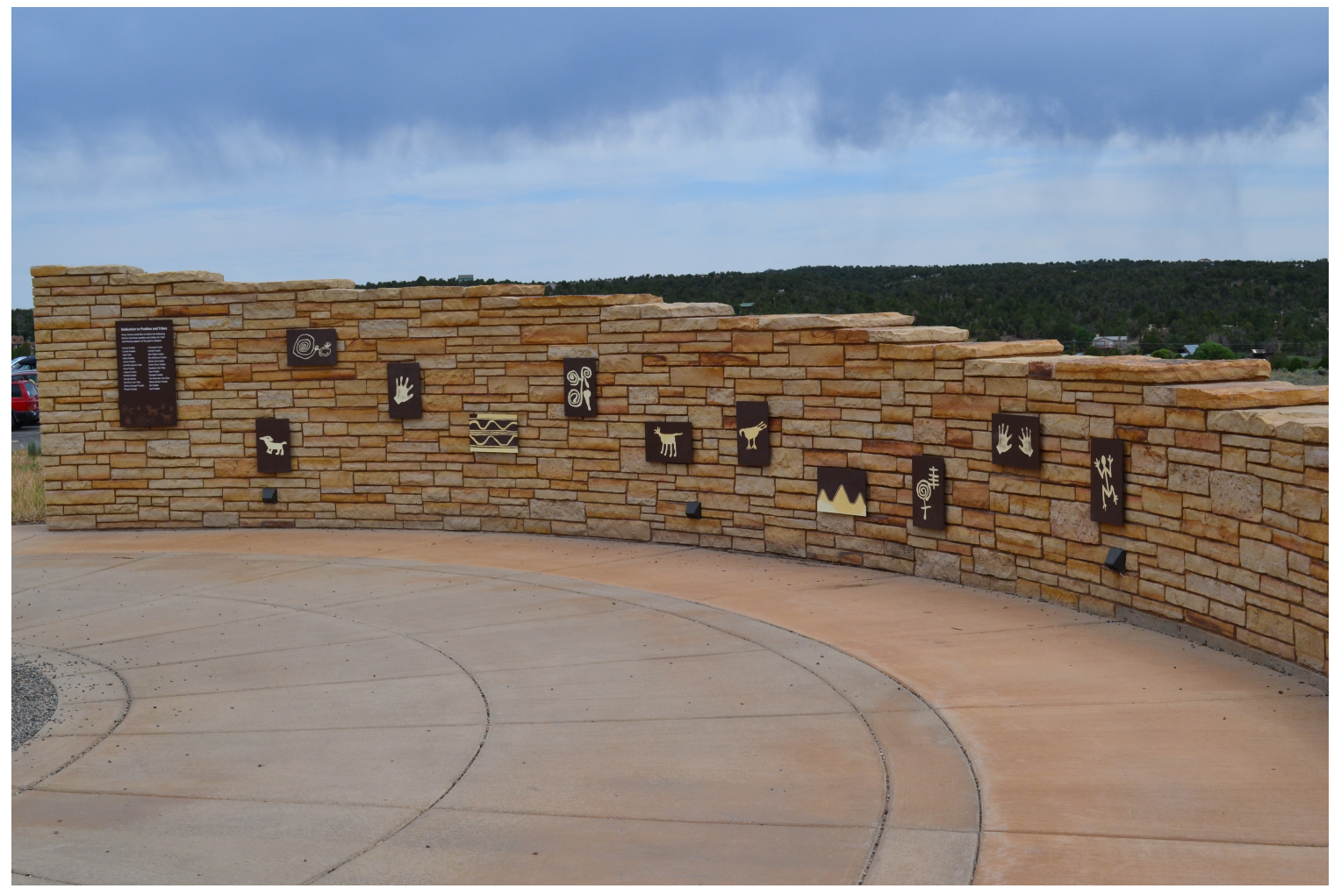

Figure 24. Mesa Verde, VRC Entrance Plaza. Note petroglyphs reproduced as design motifs and acknowledgement panel, far left. 
Making different peoples' social and capital contributions part of the interpretive display potentially reinforced the legitimacy of the institution and encourages visitor support as well as compliance. In some cases mission content also acknowledged the participation of institutions of governmentality that may or may not share the agency's hegemonic interests, e.g., environmental NGOs, panels of Native American consultants, local business associations. Mission content generally legitimized and normalized federal control of land and resources: in the absence of protected area management, people dump garbage (PETR brochure) and criminals hide from the law (BAND brochure).

In general, management messages aim to influence the visitor, guiding access to the resources, encouraging desired behavior, and fostering appreciation for the agency's work (Powell \& Ham, 2008); research indicates that visitors least attend to and retain these messages (Benton, 2009). Management messages generally reflect a limited conception of protected areas' lands. Management messages generally reinforce the construction of these protected areas as sites of recreation, as places for camping, hiking, and informal learning. The management messages observed at these sites seldom acknowledged the distinction between vandalism and looting, on the one hand, and collecting and curation, on the other; such a distinction may be considerably more important to people who construct nature as the integration of the human, the biophysical, and the spiritual (Escobar, 1999) or to some Native Americans (Deloria, 1969; Mihesuah, 1996). 
Only very occasionally did management messages observed at these sites explicitly acknowledge that Native Americans continue to visit them as part of contemporary spiritual and cultural practice. In the absence of public conflict over access to resources, management messages simply admonished visitors to respect the sacredness of the living land and the beliefs of descendant communities. Three interviewees at two sites volunteered information about their protected areas' practice of unrestricted access for Native Americans; in contrast, one interviewee at a third site was equally quick to volunteer information about systematic enforcement of fees and permits for all visitors. This may suggest, first, that different protected areas operationalize the 1978 American Indian Religious Freedom Act (AIRFA) and the 1996 Executive Order $13007^{12}$ differently; and second, that the managers of protected areas in general do not share this aspect of management with the public. This may also reflect the gradual adaptation of the Yellowstone Model to contemporary social, political, and economic reality (Schelhas, 2010).

The relative presence of the three types of management messages was reasonably consistent in this sample despite the difference in management regime, NPS or BLM. In four of the five cases, orientation messages (with a relative frequency ranging from $22 \%$

${ }^{12}$ AIRFA was enacted "to protect and preserve for American Indians their inherent right of freedom to believe, express, and exercise the traditional religions of the American Indian, Eskimo, Aleut, and Native Hawaiians, including but not limited to access to sites, use and possession of sacred objects, and the freedom to worship through ceremonials and traditional rites" (42 USC 1996). Executive Order 13007 directs agencies to "(1) accommodate access to and ceremonial use of Indian sacred sites by Indian religious practitioners and (2) avoid adversely affecting the physical integrity of such sacred sites"(61 F.R. 26771). 
at $\mathrm{AHC} / \mathrm{CANM}$ to $44 \%$ at PETR) appeared more frequently than conservation/ preservation messages (with a relative frequency ranging from $11 \%$ at PETR, MEVE, and $\mathrm{AHC} / \mathrm{CANM}$ to $15 \%$ at $\mathrm{BAND})$. At four of the five sites, conservation/preservation messages appeared more frequently than mission messages (with a relative frequency ranging from $3 \%$ at the NV sites to $13 \%$ at BAND). Only at Petroglyph National Monument did mission messages (15\%) appear with greater frequency than conservation/preservation messages (11\%): only at Petroglyph National Monument does the federal agency share management responsibility with another governmental entity, in this case, the City of Albuquerque's Open Space Division. The monument's relatively recent establishment (1990), its joint operating agreement, urban location, and use of interpretive material to compensate for its relatively small staff may combine to explain the increased frequency of mission messages in Petroglyph's Interpretation.

CULTURAL NARRATIVES: NONINDIGENOUS HISTORY, CONNECTION TO PLACE, CULTURAL CONTINUITY

The desire for cultural and historical learning motivates visitors to visit protected areas' interpreted archaeological sites (White et al., 2005). Research indicates that visitors respond strongly and positively to "the interpretive voices of Native Americans" (Pekarik, Ziebarth, \& Doering, 1996, p. 17). However, this research found cultural narratives generally appeared with a lower relative frequency than scientific narratives and sometimes less frequently than management messages. Because established interpretive practice rests upon site-specific thematic choices (Beck \& Cable, 2011; Ham, 1992; National Park Service, 2006) and sites generally only interpret the resources they steward, this research found conspicuous variation within cultural narratives from site to 
site. Non-Indigenous history appeared in the Interpretation sampled with a relative frequency ranging from 5\% (BAND, MEVE, NV) to 20\% (PETR); connection to place ranged from $3 \%(\mathrm{NV})$ to $20 \%$ (PETR); and cultural continuity from $1 \%(\mathrm{NV})$ to $29 \%$ (BAND). Cultural narratives appeared with the lowest relative frequency at the NV sites and with the greatest at Petroglyph.

Figure 25. Relative presence of cultural narratives in selected protected area Interpretation

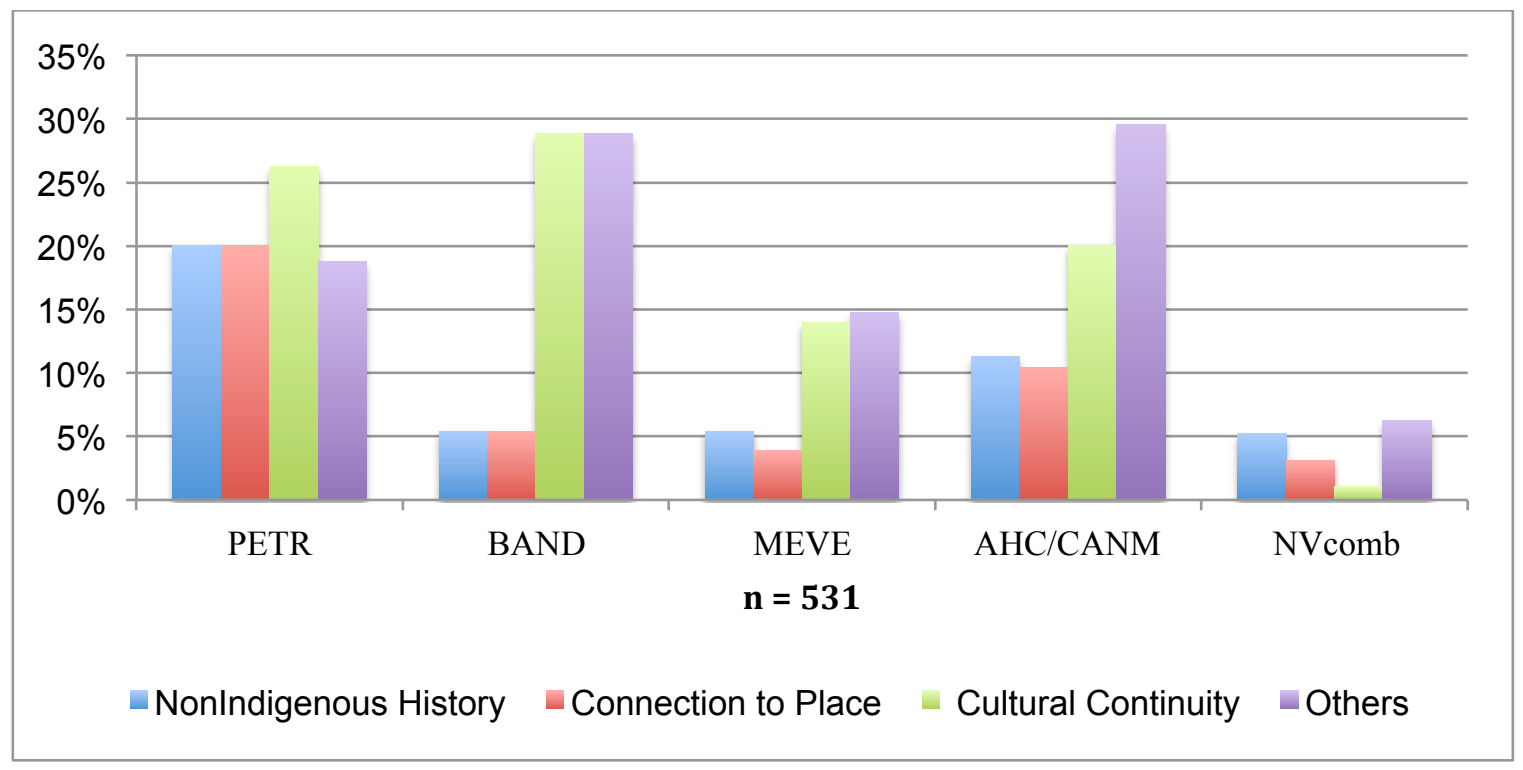

Recurrent content within cultural narratives included cultural continuity, placebased spirituality, and connection to place; contact or entanglement among settlers and indigenous peoples; water and resource use over time; language; the meaning, sacredness, or animate existence of petroglyphs; and the meaning and use of structures and symbols. Some types of cultural narratives - market integration, the hardship of ancient lives, and humans' kinship with the animate and inanimate natural worldappeared a single time at a single site. Cultural continuity appeared with the greatest 
frequency in four of the five sites; and ranged from $1 \%(\mathrm{NV})$ to $29 \%$ (BAND) of the Interpretation sampled across all five.

Much of the Interpretation observed in this research combined scientific and cultural content. Potentially, visitors may be attracted and engaged by one type of content, then encounter material they otherwise would not explore (Pekarik \& Mogel, 2010). Some of the Interpretation observed presented divergent scientific and cultural narratives within a single thematic frame, as in this panel at the Mesa Verde VRC (Figure 26).

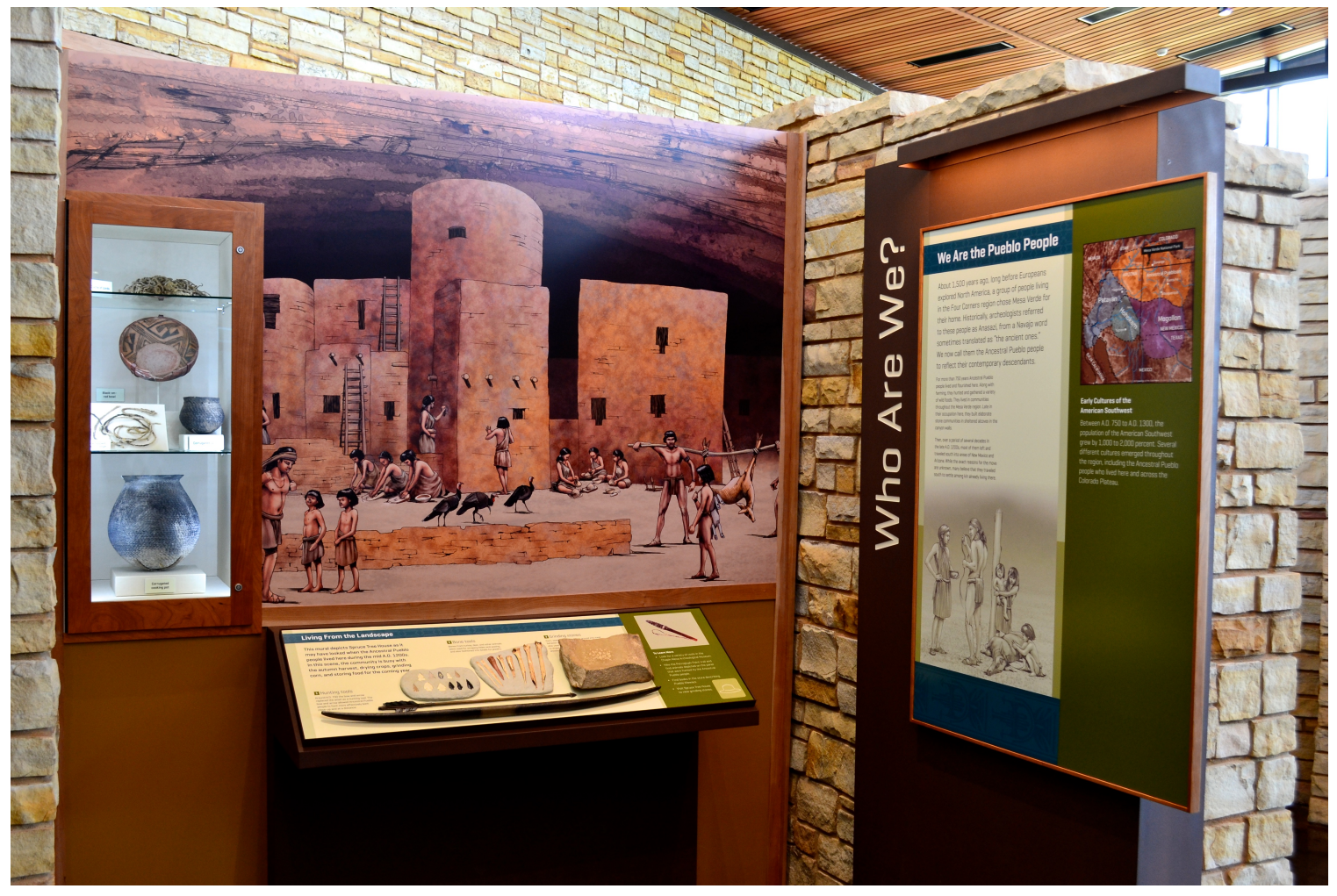

Figure 26. Mesa Verde, VRC, first display alcove, "Who Are We? We Are the Pueblo People. Note two text sections, written from a third-person omniscient point of view, juxtaposing archaeological and cultural perspectives on Ancient Pueblo people. 
Some of the Interpretation observed in this research combined scientific narrative and multiple cultural narratives, for example this minimal, minimalist key sign (Figure 27) detailing Ancestral Pueblo peoples', present day Native peoples', and Spanish settlers' use of protected area resources over time.

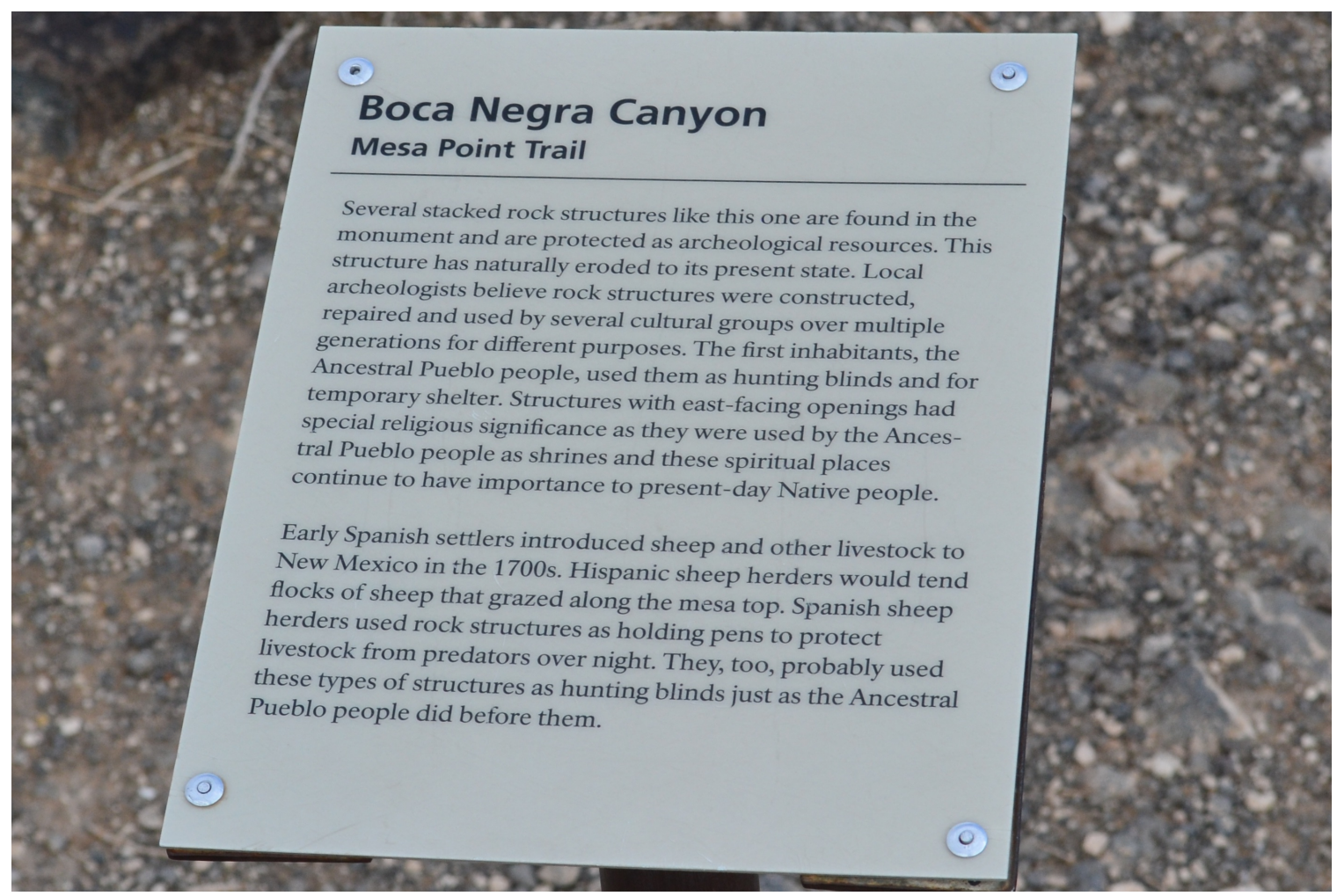

Figure 27. Petroglyph National Monument, Mesa Point Trail sign incorporating management message, archaeological content, and multiple cultural narratives. Note the elision of the years between 1540, the entrada de Coronado, and the 1700s.

Alternatively, some Interpretation observed nested scientific and cultural narratives

within other cultural narratives; for example, the panel in Figure 13 framed resource use over time, ancient subsistence technology, scientific knowledge, and three contemporary languages within ongoing and ancestral knowledge.

Presenting the relative presence of scientific, cultural, and management narratives together emphasizes that multiple narratives coexist in current interpretive practice; 
looking at the relative presence of scientific and cultural narratives together emphasizes that current interpretive practice generally accords the sciences disciplinary privilege over Indigenous history, contemporary cultural practice, spiritual practice, and collaborative or auto-ethnography sensu Pratt (1991). Cultural narratives form a substantial part of what draws visitors to protected areas that steward natural and cultural resources (White et al., 2005). A wide variety of cultural narratives - those that reproduced hegemonic narratives of Euro-American destiny and discovery, those that referenced parts of American history often elided, those that challenged entrenched, reductionist stereotypes, and those that reproduce them—-formed a substantial part of this sample of the public presentation of archaeology.

Some visitors recognized that Interpretation erased Native Americans from their own history; as a 43-year-old female visitor to Petroglyph National Monument remarked:

I love national parks and national monuments. For my own education, I love to learn, and I like to put different things together, put all these different pieces together. ... As I have studied Southwestern history, things have changed. ... For example, Anasazi is no longer politically correct, so they're using the term Ancient Puebloan; Navajo is no longer politically correct, Diné now. As more and more people look at these artifacts and start piecing them together, you learn more. They are doing more: it is wonderful for me to hear and see that they are talking to the Native Puebloan [people] and actually interviewing them, and incorporating them back into the history. ... And of course, as each generation adds to the previous generation, the more and more they learn, the more we all learn.

Like this woman, interviewees from ages 9 to $73^{13}$ spoke of "learning" to characterize what they enjoyed most in their experiences in protected areas; they also spoke of

${ }^{13}$ Pursuant to protocol authorized by Portland State University's Institutional Review Board, I approached only visitors who appeared to be over eighteen but included younger visitors when their parents/guardians suggested it. 
"history" and "archaeology." Some explicitly connected new knowledge of the past with personal utility. One solo visitor said, "Maybe we can learn things not to do, like fighting each other. Living in these ruins you have to be able to get along with each other, and there's so little of that anymore" (73-year-old female). Another, traveling with four family members, connected a ranger's discussion of water, drought, and resource use over time to his own concern about climate change and remarked, "You don't know where you're going if you don't know where you've been. History will repeat itself" [laughter] (40-year-old male). Another solo traveler, the woman quoted above, clearly recognized and appreciated the changes in disciplinary practice reflected in Interpretation.

The frequent observation of Interpretation juxtaposing or combining management, scientific, and cultural narratives in a single display suggests the practice of pedagogical bait-and-switch: of attracting visitors by appealing to their predisposition to seek out and enjoy displays and narratives about "ideas, people, or objects," providing them with an experience that satisfies those expectations, and then "flipping" them toward unaccustomed concepts (Pekarik \& Mogel, 2010, p. 473). 


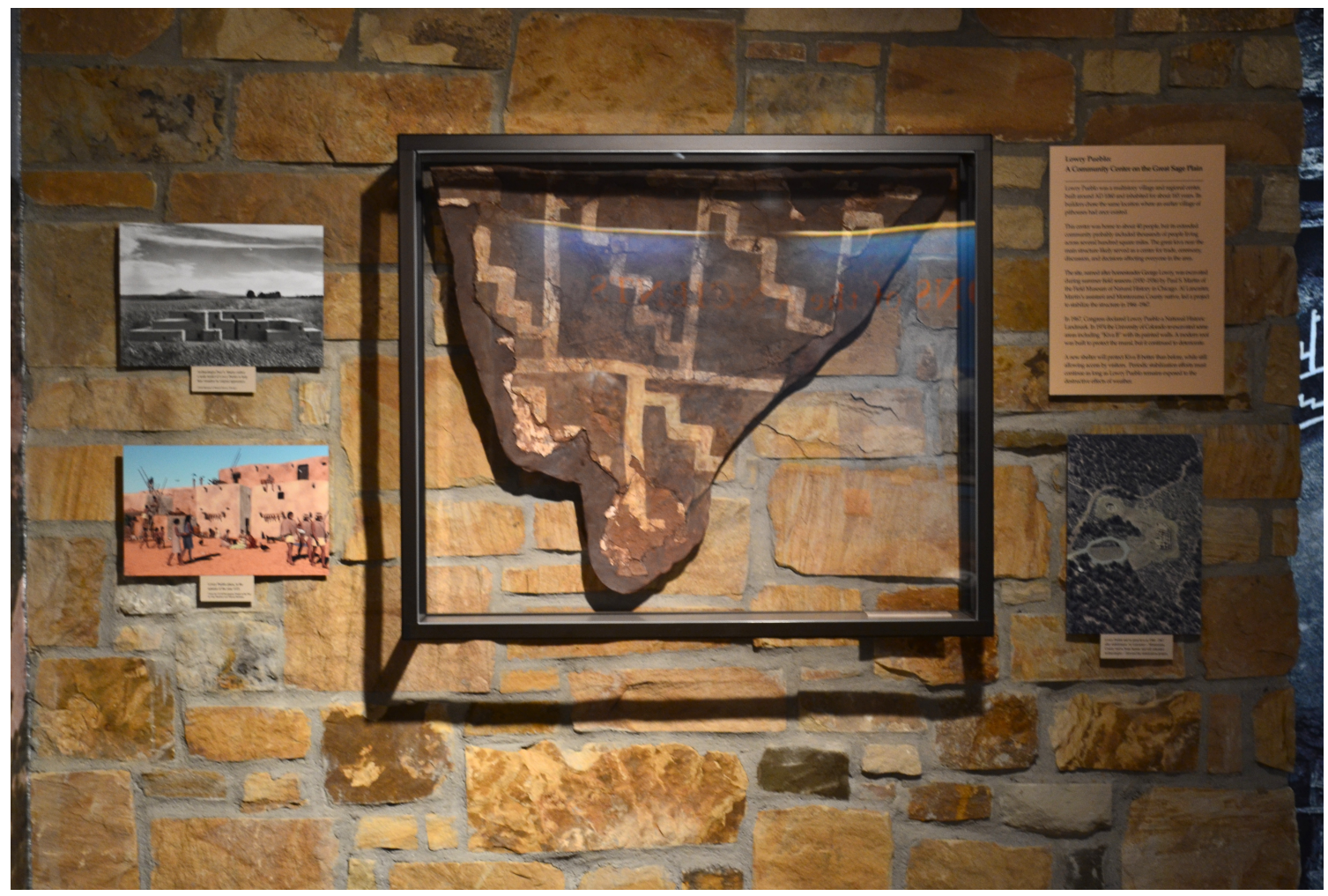

Figure 28. AHC/CANM display of kiva mural fragment. Note photos of scale model and artist's rendering, left, history of archaeological research and aerial photo, right.

For example, the high-traffic portion of the AHC/CANM leading to the theater appeals to all three predispositions: the space features an iconic object - a large fragment of kiva mural destroyed in excavation (Figure 28) — scientific ideas — archaeological site plans, black and white enlargements, drawings — and people - the Native American consultants pictured in Figure 39. Much of the Interpretation observed in this research hooks visitors with authoritative knowledge, generally archaeology, and some does indeed attempt to lure them toward people past and present.

\section{CONCLUSION}

In this chapter I showed that the relative presence of different types of interpretive narratives in protected areas both reflects and reinforces existing relations of power and 
constructions of knowledge. The five case studies displayed striking similarities in the relative frequencies of management, scientific, and cultural narratives: in general, the Interpretation observed indicated a greater focus on scientific narratives than on management messages in all five cases, and a greater focus on cultural narratives than on management messages in three of the five. Additionally, a single type of narrative content appeared most frequently in each category of interpretive content: archaeology dominated the scientific narratives, orientation comprised the largest proportion of management messages, and cultural continuity appeared with the greatest frequency in the cultural narratives. The next chapter continues to examine the cultural narratives, but in terms of each site's component parts. Results further refine the notion of what stories Interpretation tells visitors, and the discussion explores characteristic rhetorical strategies in the representation of emic and etic knowledge. 
Chapter 4: Peoples' stories: Unpacking Cultural Narratives

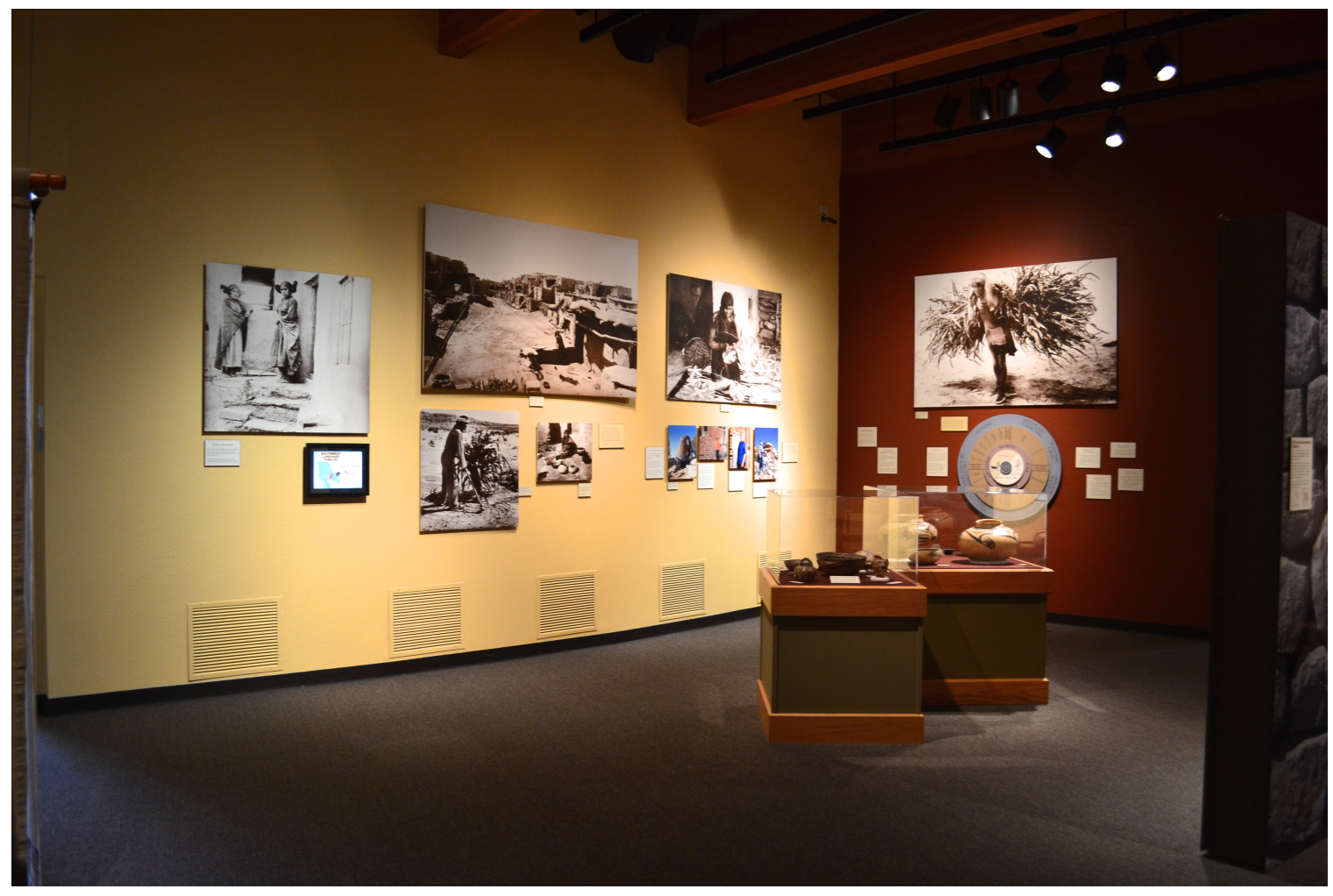

Figure 29. AHC/CANM, historic and contemporary era timeline. Note historic black and white and contemporary color photos, center, and three-dimensional representation of the Pueblo year (after Ortiz, 1969), right, below photo.

Cultural narratives, like this portion of the timelines at the Anasazi Heritage Center (Figure 29), attempt to give voice to constructions of land and culture not exclusively framed in the terms of Western science and the dominant Euro-American culture. The previous chapter argued that variation in the relative presence of scientific narratives, management messages, and cultural narratives at the five sites reflected specific management constraints. This chapter examines each site's profile of component cultural narratives and uses a vocabulary drawn from film theory, literary theory, and cultural studies to identify each site's characteristic rhetorical strategy, its interpretive "signature." I argue that each rhetorical strategy -bricolage, incorporation, ethnography, 
authoethnography, and multivocality--reflects a different relationship between the knowledge of cultural insiders and outside authorities; each rhetorical strategy reflects a different balance of emic and etic constructions of time, history, and peoples. Following the example of Phillips' (2003) representation of collaborative museum development, I range these strategies on a continuum in terms of their engagement with Native voice.

Across four of the five research sites (under both NPS and BLM management) cultural continuity comprised the largest component of cultural narratives in four cases: Petroglyph, Bandelier, Mesa Verde, and AHC/CANM, ranging from 25\% to $39 \%$ of the cultural narratives observed. At three of these four, Petroglyph, Mesa Verde, and AHC/CANM, non-Indigenous history comprised the second-largest component, ranging from $13 \%$ to $21 \%$. In sharp contrast, at the Nevada sites, non-Indigenous history comprised $33 \%$ of the cultural narratives, the largest component; and etic theories about petroglyphs comprised $22 \%$, the second largest component.

\section{BRICOLAGE AND ERASURE}

Bricolage generally refers to an artistic creation from diverse, ready-made material; in art criticism, bricolage, as distinct from collage, takes on additional connotations of being workmanlike and derivative. Bricolage is one rhetorical strategy found in the Interpretation sampled in this research. In general, in its reliance upon late $19^{\text {th }}$ - and $20^{\text {th }}$-century archaeology and salvage ethnography, the Interpretation I characterize as bricolage obscures Native American agency over time and erases Native Americans from the present.

\section{Figure 30. Component cultural content: combined Nevada sites}




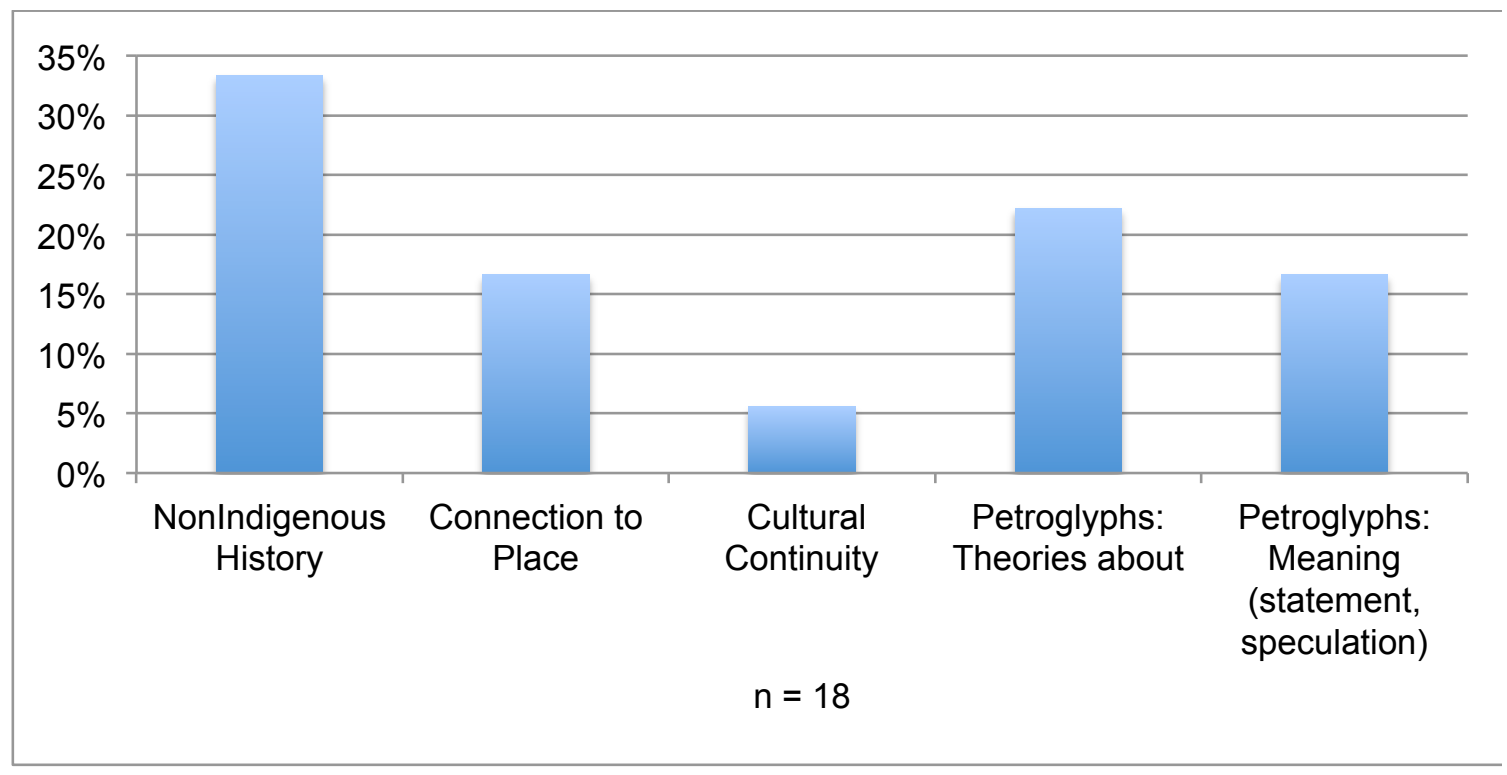

In general, interpretive material at the Nevada sites drew heavily on published academic literature. Printed material frankly disclosed its sources, even providing detailed bibliographic information for the visitor. Archaeological sources outnumbered ethnographic ones (for example, 5:1 in the Grimes Point trail guide and 13:5 in the Ash Springs trail guide). This interpretive material therefore emphasized the construction of the land as an archaeological site rather than a cultural landscape. Following established practice in art criticism and literary criticism (and somewhat counter to Lévi-Strauss's original usage), I consider this use of existing archaeological material in Interpretation a case of bricolage, the craftsmanlike use of material ready-to-hand. Three effects characterize what this research terms the rhetorical strategy of erasure / bricolage: the absence of living descendant communities from Interpretation, the representation of ancient peoples using the passive voice and, as a consequence, a nearly exclusive focus on material culture. 
Non-Indigenous history — mining, prospecting, Euro-American settlementcomprised the largest component, 33\%, of cultural narratives observed across the Nevada sites $(\mathrm{n}=18)$. Interpretive material at the Mt. Irish site, for example, acknowledged Nuwuvi (Southern Paiute) and Euro-American entanglement, lynchings, and resistance, but stopped at AD1890. In general, Interpretation across the Nevada sites downplayed conflict. Other trail guides (Ash Springs, Crystal Wash Main Site) illustrated material culture of the Pahranagat Paiutes — projectile points, basketry, a ceramic vessel, a wickiup — but neither pictured nor disclosed the existence of contemporary Nuwuvi. Native American people and their use of the land, past and present, were generally absent from the Interpretation at these protected areas. Such an emphasis on material culture contributes to an exoticized vision of a vanished people (Dartt-Newton, 2009).

Theories about petroglyphs comprised $22 \%$ of the cultural narratives observed in the Nevada sites. Interpretation variously described petroglyphs as markers of territorial boundaries, game trails, water sources, domestic sites, astronomical alignments, as the expression of "magico-religious practices to insure a successful hunt" (Grimes Point Archaeological Area Petroglyph Trail), or as "doodling during idle time” (Mt. Irish Trail guide). Middle-range theory ${ }^{14}$ or etic knowledge, represented ancient Nuwu and effectively erased the traditional knowledge that continues to exist in descendant communities (Spoon et al., 2014).

${ }^{14}$ Law-like generalizations linking the very "material archaeological record" to its "non-material subject of research," i.e., human behavior (Tschauner, 1996, p. 3). 
Connection to place and the meanings of petroglyphs each comprised $17 \%$ of the cultural narratives across the Nevada sites. Much of the interpretive material characterized connection to place in broad and abstract terms: natural resources "were used by prehistoric populations" and archaeologists study "the clues left by those early visitors" (Grimes Point Archaeological Area trail guide). Some Interpretation referenced particular people while using the past perfect tense, passive voice, and omniscient point of view. For example, sites were "frequented by a culture known as the Pahranagats, one of several known Southern Paiute groups" (Ash Springs, Crystal Wash Main Site, and Crystal Wash Entrance Site brochures) or "served as a camping and activity center for thousands of years" (Mt. Irish). This characteristic syntax, positioning archaeological sites as grammatical subjects and rendering human activity in the passive voice, obscured the human presence in the landscape and appeared to assign agency to the sites themselves. The grammatical focus on natural resources - "Seeds, roots, tubers and berries were collected and small animals were trapped and eaten" (Crystal Wash Main Site brochure) — intensified the symbolic erasure of Nuwuvi (Dartt-Newton, 2009, 2011).

The Nevada sample differed considerably from the other four research sites in every dimension, but especially in the components of cultural narratives presented. While bricolage characterized Interpretation at the Nevada sites, the other four sites proffered at least occasional examples of erasure and passive voice. The Nevada sites, while developed for tourism, lacked the facilities and interpretive infrastructure that 
characterized the others: ${ }^{15}$ the site trail guide dominated interpretive programming. Additionally, the Nevada sites' trail guides lack the concise and forceful text, potent visuals, and tight thematic focus that are standard professional practice (Beck \& Cable, 2002; Ham, 1992) and characterize interpretive material found at the other four sites. The disproportionate importance of trail guides in the Interpretation sampled may, in part, explain the significant differences between the component cultural narratives observed at the combined Nevada sites and the other four sites.

\section{INCORPORATION}

Incorporation is the second rhetorical strategy observed in this research. In the public presentation of archaeology and the representation of Native Americans, identifying the strategy of incorporation foregrounds questions of sovereignty and which body holds the power to determine the terms of discourse.

At Mesa Verde, Interpretation reframed and incorporated Native American cultural knowledge into the larger hegemonic narrative. In contrast to the Nevada sites, at Mesa Verde, cultural continuity, not non-Indigenous history, comprised the largest component, $32 \%)$ of the cultural narratives $(\mathrm{n}=56)$; non-Indigenous history appeared in only $13 \%$ (vs. $33 \%$ in the Nevada sites); and resource use and water in $11 \%$. Park history dominated narratives of non-Indigenous history. In the VRC, historic photos and facsimile documents illustrated panels detailing the looting, excavation, collection, and conservation advocacy that led to the establishment of the park. Key historic-era

${ }^{15}$ Again, I emphasize that interpretation is highly epistemic. Agencies update interpretation as funding permits: the facilities and interpretation observed at the Nevada sites may well have been replaced since I captured and analyzed this particular 'snapshot in time.' 
archaeologists—Fewkes, Nordenskiöld—-figured in multiple brochures; the Chapin Archaeological Museum displayed historic photos of the park's monumental architecture park and construction of the museum's still-popular CCC-era dioramas. Few narratives of cultural continuity appeared in the waysides and interpretive panels at the Mesa Top Sites, the Far View sites, or along the driving tour. At Mesa Verde, with the exception of the Petroglyph Trail Guide and the VRC, 20th- and 21st-century cultural practice (including resource use) generally appeared in interpretive material when it confirmed archaeological knowledge.

Figure 31. Component cultural content: Mesa Verde National Park

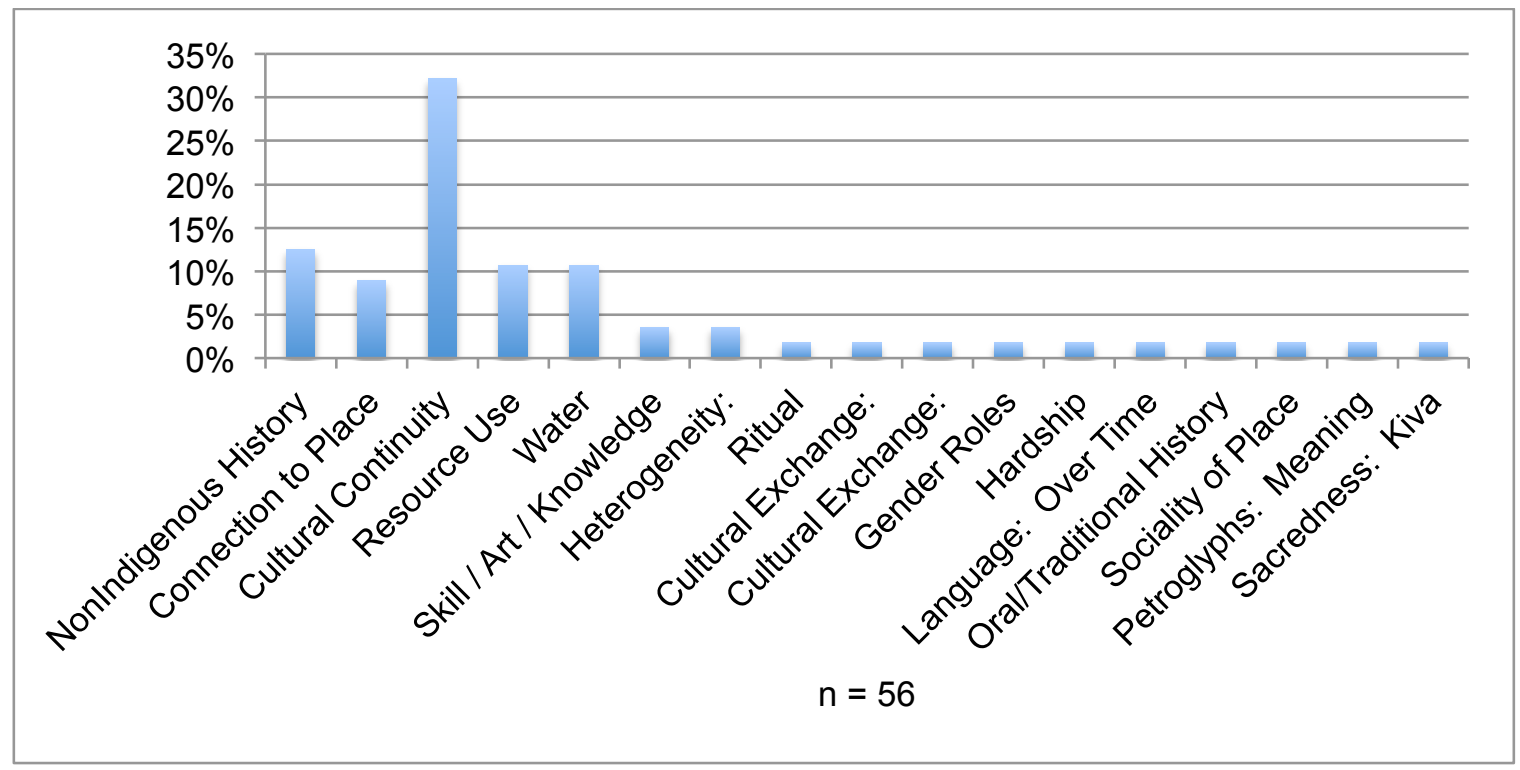

In Mesa Verde's Petroglyph Point trail guide, for example, 31 of 36 units of analysis discussed plant and animal species and ecological homeostasis. The Interpretation cast Petroglyph Trail as a nature trail leading to a cultural resource. This interpretive focus may reflect the practice's roots in nature guiding (Benton, 2009) as well as the emphasis on conservation and preservation in NPS's historic mission. Cultural 
continuity beyond resource use and connection to place appeared only in that section of the trail guide devoted to the meanings of the petroglyph panel.

The 1986 trail guide stated that "These are modern-day Hopi interpretations and may or may not have been the interpretations given them by the 'rock artists' who produced them" and so implied that ambiguity discredits contemporary cultural understanding (Atalay, 2008, p. 38). In Mesa Verde's Interpretation of the petroglyph panels, a knowing narrator interposed between the resource and visitor, revealing --and, to some extent, subtly discrediting-- cultural knowledge by suggesting that continuity demands constancy, unchangingness, and universality. Additionally, Mesa Verde's thirdperson omniscient narrator assumed control of cultural knowledge without acknowledging that it may be closely held, contested, multivalent, or even dangerous (Spoon et al., 2014, pp. 12-13). The third-person omniscient narrator embodied the etic, or outside analyst's, perspective.

Petroglyph Trail and Pictograph Point (a misnomer) may be especially significant to visitor experience because it was one of only nine trails visitors were permitted to use to explore the park on foot and unaccompanied by rangers, a limitation mentioned specifically by two visitors I interviewed. It was also the only one of the nine interpreted.

Rhetorically, the Interpretation sampled at Mesa Verde used framing and incorporation to impart immediacy and legitimacy to the protected area's representation of Native Americans. Of the thematic text panels in the new VRC, four of five displays' titles used first-person in an interrogative construction. Two of the subtitles answered the question in the present tense, and two in the past perfect; overall, they reinforced 


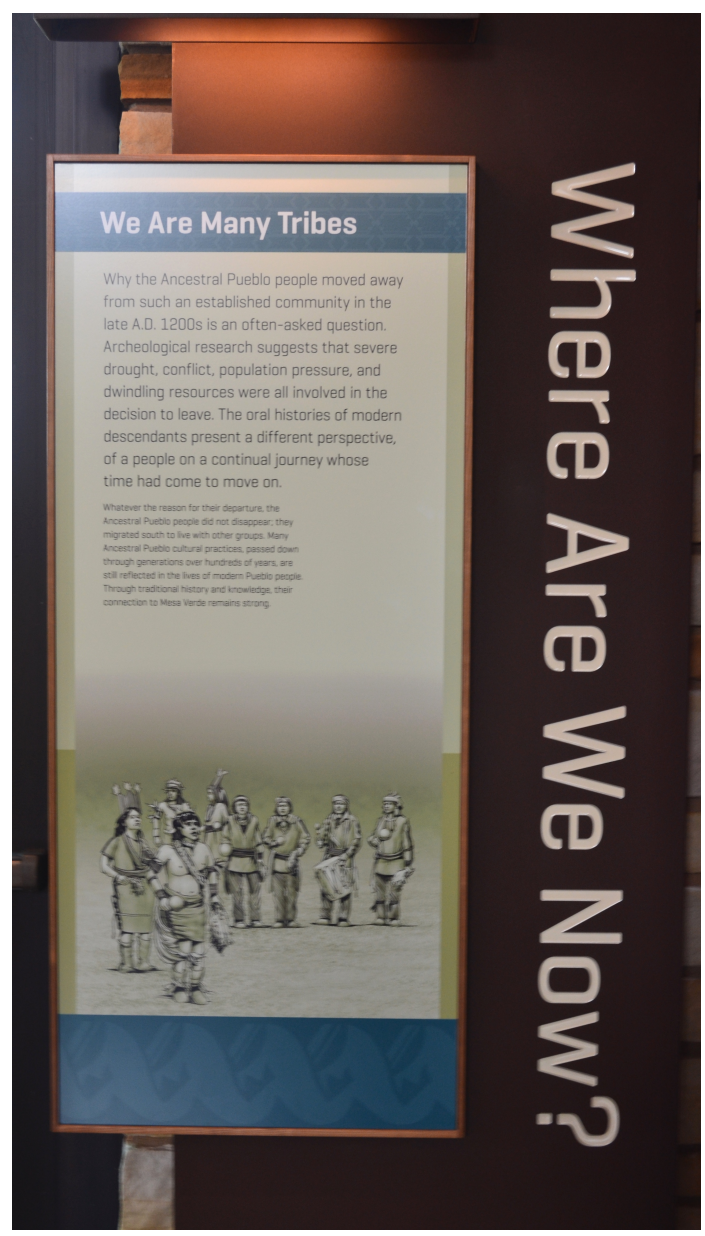

Figure 32. Mesa Verde VRC, first display alcove, detail of Figure 26. Note the use of first-person in titles and third-person in text; compare with Figure 15, Pithouse, above.

continuity while maintaining a focus on the past. The accompanying text, however, was written from a third-person omniscient point of view. Cultural insiders asked a question; professional archaeologists and ethnographers answered it.

The text panels focused on knowledge constructed from the archaeological record ("Historically, archeologists referred to these people as Anasazi," "A new way of living had begun, and the Pueblo culture emerged," "The archeological record at Mesa Verde testifies to their resourcefulness," "Archeological research suggests that...") but noted the 
divergence of the constructions of archaeologists and contemporary Pueblo peoples

("While the exact reasons for the move are unknown, many believe...", "The oral histories of modern descendants present a different perspective...”). This third-person omniscient perspective incorporated cultural practice: for example, "This [growing maize] had a profound effect on the land, skills, and architecture of the Pueblo culture. Today, corn also plays an important role in ceremonies, art, and dance.” The display suggested that interpretive authority rested with social scientists rather than descendant communities.

In contrast, the fifth panel did not query, but told "The Archeological Story: Preserving the Past," detailing late-19th-century looting, collection, and sale of artifacts, and the 1906 passage of the Antiquities Act and establishment of the park. The VRC display emphasized preservation and park stewardship over archeological practice. Practice was represented in a diorama and accompanying text and touch panels.

Rhetorically, the first-person frame conferred immediacy. However, the omniscient point of view created distance, reinforcing the authority of the "contemporary archeological and ethnographic tools" the park uses to "ensure the preservation and protection of important cultural resources" and construct the history of the Pueblo people presented to the park visitor. While narratives of cultural continuity appeared frequently in the Interpretation sampled at Mesa Verde compared to other sites, the Mesa Verde VRC did not focus on the display of cultural practice per se and mediated by cultural practitioners; rather, the visitor center displayed expert understanding of cultural practice. Interpretive material at Mesa Verde did not emphasize descendant communities' cultural 
practice in the landscape; rather, interpretative material emphasized cultural resources' materiality and the centrality of scientific knowledge (Foucault, 1994; L. Smith, 2006).

Constructing cultural resources as material and fragile naturalizes expert control of them (L. Smith \& Waterton, 2009). If their materiality is paramount —and Mesa Verde's monumental and iconic cliff dwellings are certainly material — then the story that matters is the story of Euro-American discovery and preservation. As the first US park dedicated to "preserving the works of man [sic]" (National Park Service, n.d.-a) and a UNESCO World Heritage Site, Mesa Verde represents cultural resources as patrimony at both the national and the global scale. The preservation of Mesa Verde is entrusted to experts, the very experts who constructed and institutionalized global heritage in the first place (L. Smith, 2006; L. Smith \& Waterton, 2009). Expert stewards necessarily control visitor access quite closely (see Chapter 3). At Mesa Verde, the hegemonic narrative generally trumps alternative constructions of the importance of the mesa tops and canyons and justifies management of visitors.

\section{ETHNOGRAPHY}

In this section, I follow Boast (2011, p. 62) and Clifford (Clifford, 1997, p. 213) to argue that not only is ethnography "the systematic study and description of peoples, societies, and cultures" (OED Online, "Ethnography, n.," 2016) and an established textual genre, it is also a rhetorical strategy in the public presentation of archaeology. As a rhetorical strategy, ethnography privileges etic knowledge, but represents living peoples on a culturally constructed landscape and neither trivializes nor homogenizes insider perspectives. At Petroglyph, cultural narratives largely honored emic or insider understandings of the landscape and the entities inhabiting it but emphasized the non- 
Indigenous history of the land. Interpretive material generalized Native American cultural knowledge and emphasized the significance of land and cultural resources over time and across peoples.

Figure 33. Component cultural content: Petroglyph National Monument

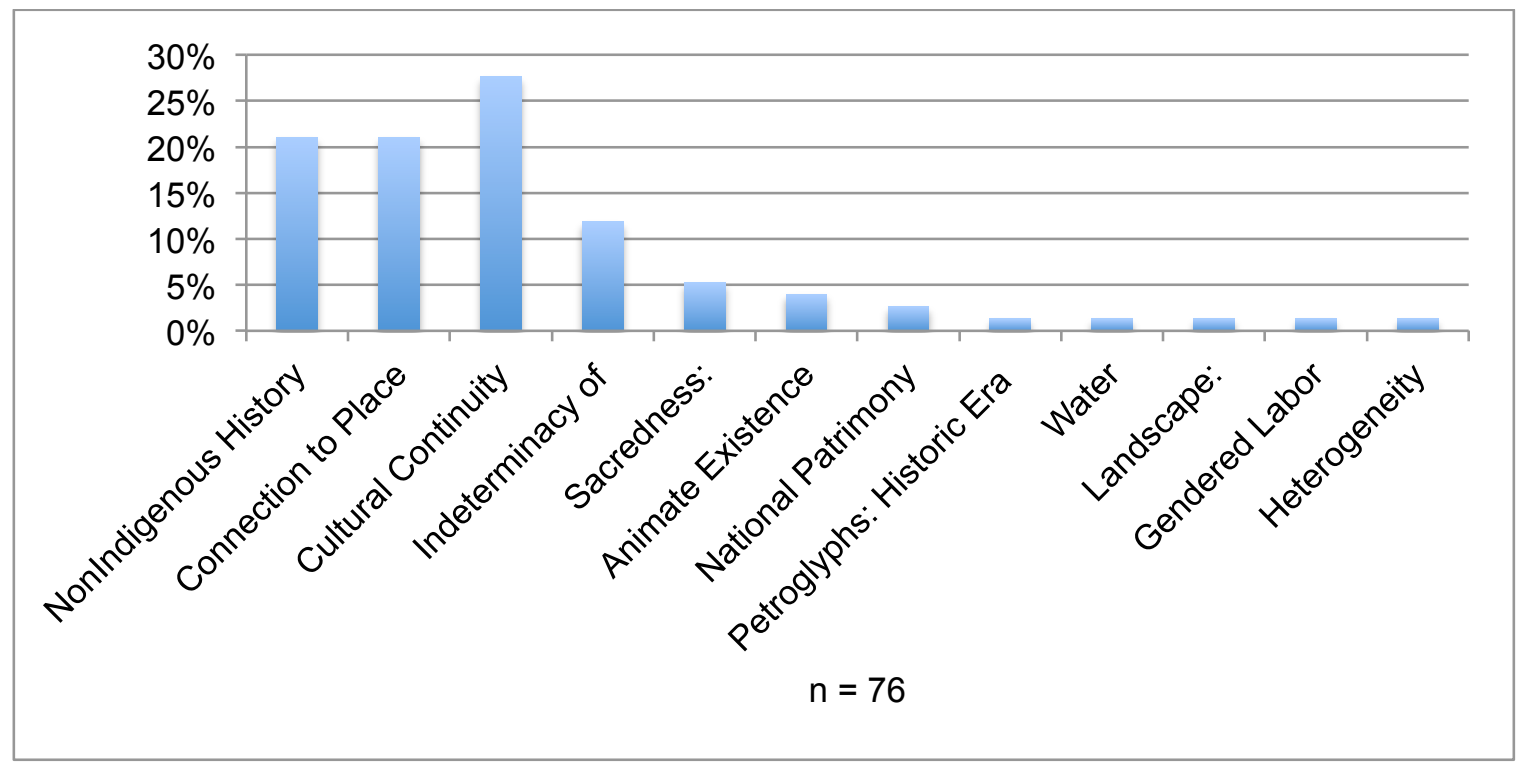

Cultural continuity comprised $28 \%$ of the cultural narratives in the interpretive material sampled at Petroglyph $(\mathrm{n}=76)$. Non-Indigenous history and connection to place were the next-largest components (21\%). Signs, brochures, and trail guides cited the continuing cultural and spiritual significance of the petroglyphs' images to "many Southwest Indians," including "modern Pueblo groups as well as other indigenous people such as the Diné (Navaho) and the Apache." This study found significant Interpretation of the cultural continuity of peoples other than Native Americans at Petroglyph and the Nevada sites.

Petroglyph's Interpretation frequently addressed the meaning of the petroglyphs, but emphasized indeterminacy, a multiplicity of valid meanings (Spoon et al., 2014). 
Interpretation at Petroglyph stressed petroglyphs' sacredness and the sentience of the land and the petroglyphs. Interpretation emphasized that petroglyphs have many meanings, some known only to their makers. Additionally, interpretive material emphasized that some meanings are closely held. Petroglyph's Interpretation seldom shared meaning per se with the public. Rather, Interpretation stated that many meanings are not being shared (Lawlor, 2006, pp. 60-63).

Some signs and brochures used speculative and conditional language to convey possible functionalist explanations of the images (e.g. images "can represent family clan associations. . or may simply communicate a food resource"). In Petroglyph's Interpretation, speculative and conditional language as well as the use of the partitive ("many Southwest Indians," "some Native Americans") made room for multivalence: interpretive material proffered multiple interpretations — by Diné, by ethnographers, by archaeologists, by Atrisco land grant heirs, by Pueblo elders. However, unlike at Mesa Verde or the Nevada sites, Interpretation at Petroglyph largely refrained from privileging etic knowledge or trivializing the emic perspective. 


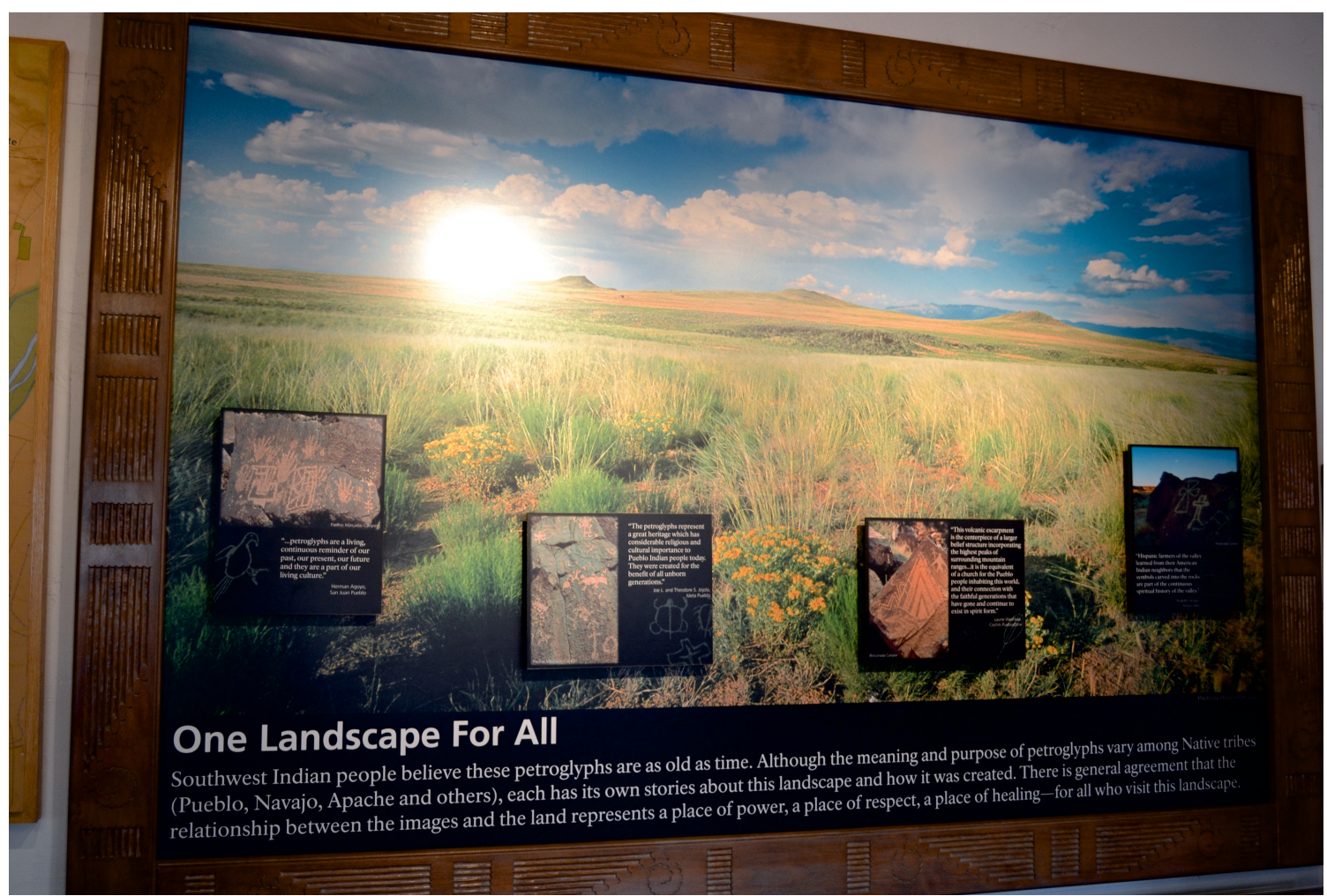

Figure 34. Petroglyph National Monument, central visitor center exhibit. Note inset panels identifying knowledge holders by name and cultural affiliation, one of two such identifications found at the site.

Interpretive material generally quite explicitly deferred to the knowledge and practice of descendant peoples: for example, "Identification of some petroglyphs is based on interpretations by today's Pueblo people" or "Pueblo elders believe the images are as old as time." In general, the interpretive material observed at Petroglyph cited sources for emic knowledge in very broad terms. Petroglyph's Interpretation acknowledged contemporary cultural heterogeneity among Native Americans but emphasized a spiritual connection to the land and symbols common to Native peoples across the region. This research found very few exceptions, notably the central panel in the visitor center, which directly quoted named individuals from San Juan and Isleta Pueblos, the Cochiti Pueblo Diné, and the Atrisco Heirs. 
Petroglyph devoted significant interpretive resources to Spanish and Mexican settlement: at Petroglyph, the frequency of non-Indigenous history equaled that of cultural continuity in the interpretive material sampled; only in the combined Nevada sites did non-Indigenous history constitute a larger fraction of the site sample. At Petroglyph, examples of entanglement included Spanish exploration, occupation, and colonization (including settlement and sheepherding), the land grant era, and the Pueblo Revolt as well as Euro-American settlement and colonization. Colonial practices were acknowledged, though downplayed: "Spanish settlement brought new foods and cooking methods to the region. . . Pueblo men learned to harvest wheat while the women were taught to build hornos." Interpretation recognized pueblo resistance as significant. Interpretive materials emphasizing sacredness may entangle the non-Indigenous visitor in unfamiliar constructions of time and space and agency (Colwell-Chanthaphonh \& Ferguson, 2010, pp. 229-233). For example, the smartphone tour invited visitors "to step back in time;" one brochure emphasized that the spirit and the material are "inseparable," another asserted silent boulders may be "yearning to speak." Interpretation encouraged visitors to believe we "may feel another presence beyond what [we] can see or hear," that the images will choose to reveal themselves to us, and that we will "learn from those who continue to interact and reaffirm their spiritual connection" to this land. By reiterating emic perspectives on the land and the entities that inhabit it across interpretive media, Petroglyph's Interpretation emphasized the validity of divergent constructions of a living land. 
Both staff and interpretive material at Petroglyph urged visitors to engage with the rock writing in situ, to hear, to smell, to see cultural resources (relatively) unmediated by obtrusive signage and lengthy trail guides. Seeing the site/sights is only part of the experience of the tourist body-in-motion (Larsen \& Urry, 2011, p. 1122). Interpretive materials encouraged visitors to engage in individual experience of the landscape, not fashion a simulacrum of Native American cultural and spiritual practice: Interpretation explicitly acknowledged the existence of closely-held knowledge and did not disclose it. Just as definitive meanings of rock writing remain elusive, ambiguous, and multivalent, so do the "beliefs and virtues of [the] makers of the rock writing" and their living relatives.

This interpretive strategy, a kind of patent non-disclosure, a very public privacy, revealed that much is not revealed (Lawlor, 2006, pp. 60-63). Lawlor finds that displayed withholding characterizes many scripted tourist encounters on tribal lands: the guide or the performer emphasizes the right to control access to cultural knowledge. Displayed withholding embodies representational autonomy; it may also be an assertion of rhetorical sovereignty. Displayed withholding potentially illuminates protected areas' Interpretation of archaeology as well. An implied ethnographic authority stood between Petroglyph's generalized, abstracted interpretive sources—-"many Southwest Indians," "some Pueblo groups" - and the visitor. The implied narrator of Petroglyph's brochures and signage screened, shielded, and filtered. This implied narrator represented select cultural knowledge and acknowledged that additional knowledge was withheld. 
(Re)Presenting peoples and storied lands

As a rhetorical strategy for communicating with visitors, ethnography may be circumscribed by anthropological ethics, protected areas' agreements with affiliated Native American tribes and pueblos, sovereign nations' chosen level of involvement, and heterogeneity within and among those sovereign nations. Furthermore, interpretive materials at Petroglyph National Monument cast its natural and cultural resources as the patrimony of all Americans, what one orientation sign termed "our national story and heritage." Despite the sheer volume of references to closely held knowledge in descendant communities and the continuity of their cultural and spiritual practice, the Interpretation observed at Petroglyph generally appropriated emic knowledge.

\section{AUTOETHNOGRAPHY / SHARED AUTHORITY}

Following Pratt (1991) and Boast (2011) and contra Denzin (2005) and Foley (2002), I use autoethnography to characterize both a textual genre and a rhetorical strategy "in which people undertake to describe themselves in ways that engage with representations others have made of them" and often addresses "both metropolitan audiences and the speaker's own community" (Pratt, 1991, p. 35). While autoethnography in protected area Interpretation addresses an audience of visitors, it may also have material consequences for the transmission of cultural knowledge. 


\section{Figure 35. Component cultural content: Bandelier National Monument}

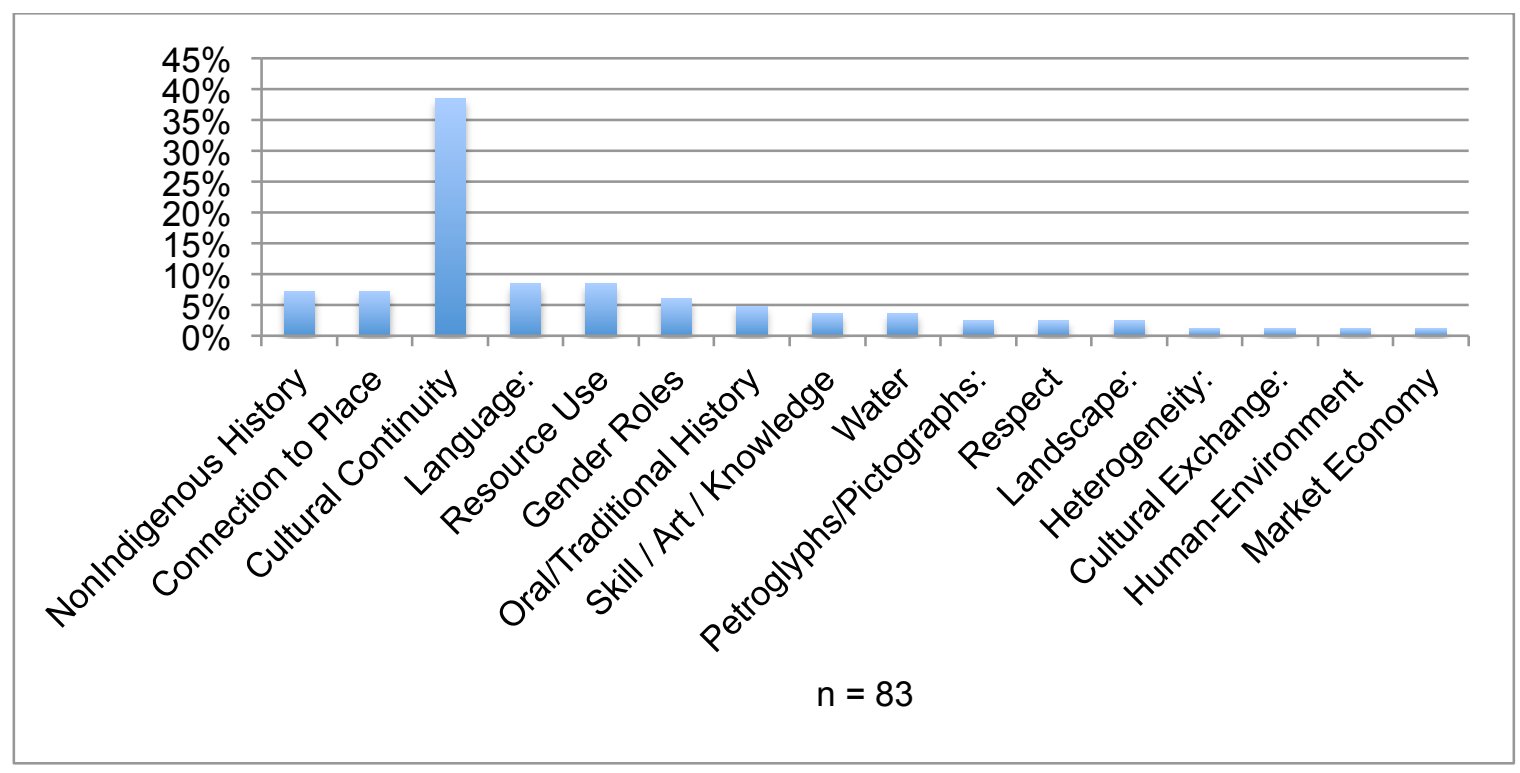

Some protected area Interpretation dispenses with speaking for or about descendant communities. In general, the Interpretation observed at Bandelier National Monument featured real people telling real stories in their own voices. The theme of cultural continuity comprised almost $39 \%$ of the cultural narratives at Bandelier $(n=83)$, more than at Petroglyph (28\%), Mesa Verde (32\%), or the combined Nevada sites $(6 \%)$. In contrast to Petroglyph's, Bandelier's Interpretation of cultural continuity focused nearly exclusively on the affiliated Pueblos and virtually erased Euro-American activity save for the history of park development.

Exhibits and trail guides repeatedly emphasized the six pueblos' continuing spiritual and cultural connection to the places their ancestors lived. ${ }^{16}$ Trail guides

${ }^{16}$ Weathered trail signage, however, emphasized the mysterious disappearance of the Anasazi, a construction explicitly refuted by the site bulletin, trail guides, and museum display. 
explicitly tied management messages about visitor behavior to respect for contemporary Pueblo practice. Text panels in the main exhibit hall included three living languages: "Say it in Keres. . . in Tewa. . . in Zuni" (e.g. Figure 13, bottom center). Natural resource use over time figured in exhibits and trail guides, as well as in the demonstration garden adjoining the visitor center.

Bandelier displayed the acknowledgment of consultation with affiliated Native Americans more prominently than Petroglyph, Mesa Verde, and AHC/CANM, within the exhibit hall itself. Additionally, some Interpretation at Bandelier specifically cited consultation in material juxtaposing mission messages, preservation messages, archaeological practice, and a range of cultural narratives (e.g. "Consultation with San Ildefonso Pueblo has revealed that they prefer the houses and belongings of their ancestors remain untouched," and "the site serves an important role in their spiritual lives and...traditions passed down through generations."). As at Petroglyph, Interpretation did not disclose the specific nature of Pueblo beliefs and traditions. 


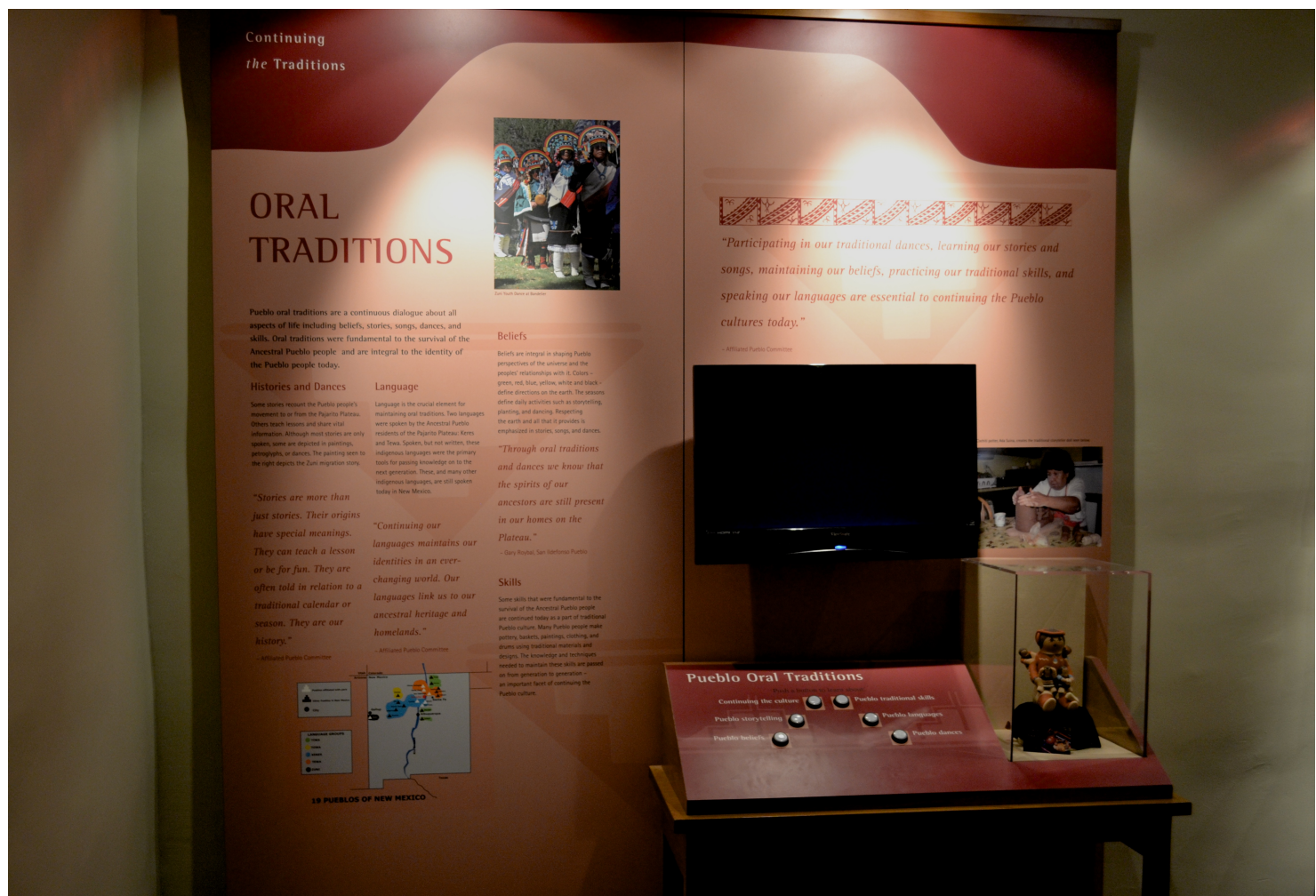

Figure 36. Bandelier museum Oral Tradition panel. Note quotations attributed to the Affiliated Pueblo Committee, bottom left and bottom center of the left-hand panel and top of right-hand panel; note quotation from Gary Roybal, San Ildefonso, retired Bandelier Native American liaison and curator, appears center right of the left-hand panel.

Many of the text panels in the main exhibit hall (upper right in Figure 36 and Figure 13) featured direct quotations from the "Affiliated Pueblo Committee," even among the taxidermy and cast replicas in the section devoted to flora, fauna, and geology. One prominently located panel displayed a poem credited to an individual specifically named as Bandelier ranger and citizen of two Pueblos. Other panels quoted noted artists and influential leaders identified by name and pueblo affiliation. The quotations' themes included ancestral resource use, farming, trade, cultural practice, and art.

Some text panels attributed to the committee referred to ancestral time and used a pseudo-passive (statal passive) grammatical construction in the past tense: "Our ancestors 
were given knowledge of how to use all types of plants and animals for food." In this case, combining pseudo-passive and perfect emphasized temporal ambiguity and the potential multiplicity of the agents. Other panels emphasized continuity over time and used the unmarked present tense: "Farming is the backbone of Pueblo culture and traditions. . . our lifeline. When we farm, we have food; when we farm, we have togetherness." In this case, the unmarked present conveyed enduring truth and timelessness. Individual quotations generally reinforced a living present rooted in tradition: "From the corn we learn to live, we learn the life that is ours. By grinding the corn we learn the footsteps of life" (Sharon Naranjo-Garcia, Santa Clara Pueblo). This use of first-person may make a possibly unfamiliar construction of time and tradition easier for visitors to comprehend.

Interpretive materials in the Bandelier museum voiced emic perspectives with these quotations. Rhetorically, the specificity of the speaker conferred increased credibility, and credibility increased with reiteration, as at Petroglyph. However, at Bandelier authority rested with affiliated Native Americans, not in an implied ethnographic narrator: Native voices addressed the visitor without a patent filter of academic or agency intervention. The museum deemphasized representation in favor of self-representation. Not only was cultural continuity the largest component of cultural narratives across all interpretive media sampled at Bandelier, it was regularly and prominently voiced by cultural insiders. Following Pratt, I characterize this rhetorical strategy as authoethnography (1991, p. 35). 
Only those museum exhibits most closely focused on management messages and archaeology lacked these characteristic first-person and third-person inclusive narratives. Even these displays used voice strategically: one panel placed an excerpt of the 1916 Organic Act, the NPS's enabling legislation, in the same font and layout as the Affiliated Pueblo Committee quotations. Another panel framed a quote from "Rory Gauthier, Bandelier Archaeologist" the same way: "We learn just as much about the Ancestral Pueblo people from their descendants today as we do by looking at the remnants of their lives seen across the Parajito Plateau." Interpretation visually presented the authority of Congress and the disciplinary privilege of the archaeologist in the same way as the statements of interested Native Americans, and suggested that authority may be shared.

The extent of shared authority within a state institution remains problematic. Display is enmeshed in relations of governmentality (Bennett, 2004; Bennett et al., 2014). Government-to-government consultation varies widely: it may be merely gestural (L. Smith, 2004) or check the box consultation (Spoon, Arnold, Hambelton, et al., 2012); however, consultation may also interpenetrate long-standing personal relationships and ongoing projects between tribal citizens and government agency staff. Clifford (1997, p. 200,2004, p. 6) acknowledges the empowering nature of the museum as an instrument of governmentality. As a contact zone, the museum (and, by extension, the protected area) opens the possibility of knowledge/power exerting itself from the bottom up as well as from the top down, a corrective force against misrecognition, misrepresentation, and marginalization. 
(Re)Presenting peoples and storied lands

Protected area museums and visitor centers occupy land that is simultaneously federal property and ancestral territory. Protected area museums and visitor centers continue to participate in (and generally continue to promulgate) the grand narrative of Western progress and reform (Lonetree, 2007; Rose, 1999). In the context of the Bandelier exhibits, shared authority cuts hegemonic discourse two ways. First, Interpretation suggests state control of the land is less monolithic than in the colonial past: Native Americans again occupy this ancestral land and Zuni children dance here (Figure 36. Note color photo, top of left-hand panel). Second, nobody disappeared and the land was never empty or abandoned: Ancestral Pueblo peoples' descendants' voices, images, and words surround the visitor. Note, however, that in the context of this national monument, voice acknowledges cultural sovereignty without specifically referring to political sovereignty.

The use of contemporary Pueblo language on exhibit panels at Bandelier reinforced cultural continuity. Additionally, it functioned as displayed withholding: the visitor is aware she is shown only a part of the picture (Lawlor, 2006). The visitor may learn words, but not the language; concepts, but not the values that link them and create context. In the garden, minimalist panels described plants' functions — in basket making, making weapons, food, medicine, dyes, textiles, etc. - - but not specific details of preparation and application. The visitor may see and hear dancing and storytelling, but not penetrate the back space where lives are lived (Goffman, 1959).

At the Nevada sites, an omniscient narrator told visitors what vanished Native Americans and historic-era Euro-Americans did. At Mesa Verde, how Ancestral Pueblo 
people lived before Euro-American settlement. At Petroglyph, an implied

ethnographic authority told visitors some of what some Native Americans believe about

their land. At Bandelier, specific, named individuals voiced stories within the story of the land.

At Bandelier, these voices were juxtaposed with third-person omniscient narratives, some emic, some etic, others indistinguishable in those terms (Figure 13). Interpretive authority was shared. One might go so far as to argue that, at Bandelier, autoethnography largely silenced archaeology. Potentially, autoethnography denies archaeology sole power to represent cultural knowledge. Quite possibly, even in the absence of explicit discussion of sovereignty, autoethnography is a means of asserting it. As Lyons notes with characteristic irony, "At stake in this discussion are the peoples defined by the writing itself; thus one important tenet of rhetorical sovereignty would be to allow Indians to have some say about the nature of their textual representations" (Lyons, 2000, p. 458).

\section{Multivocality}

The fifth and final strategy I identify in this research is multivocality, the representation of the parity of cultural and scientific knowledge, the emic and etic. Multivocality does more than make room for descendant communities' knowledge alongside or within dominant scientific discourse. For the sake of clarity, in the following discussion, I depart from many scholars' characterization of juxtaposition of multiple viewpoints as multivocality (e.g. Clifford, 2004, p. 11). Atalay's distinction between interpretive and methodological multivocality (Atalay, 2008, pp. 34-39) informs my choice of the term multivoiced interpretation, to characterize juxtaposition of different 
(Re)Presenting peoples and storied lands

constructions of knowledge. Following Atalay (2008, pp. 34-39), Colwell-

Chantaphonh (2010, pp. 128-130), Hodder (2008, pp. 196-198), and Trigger (2008, pp. 189-190), I reserve multivocality for Interpretation that purposefully represents cultural and scientific knowledge as having parity and reflects collaborative research methodology.

At the Anasazi Heritage Center and Canyons of the Ancients National Monument, archaeology and archaeological practice combine to dominate Interpretive discourse. As discussed above (see Figure 14), narratives of archaeological practice appeared with nearly as large a relative frequency as narratives of archaeology (archaeological inference and interpretation) in the scientific narratives at AHC/CANM. At AHC/CANM as at Mesa Verde, Petroglyph, and Bandelier, cultural continuity comprised the largest component, $25 \%$, of cultural narratives $(\mathrm{n}=93)$. Non-Indigenous history comprised $14 \%$, a larger proportion than at Bandelier and Mesa Verde, and a smaller proportion than at Petroglyph and the Nevada sites. Connection to place and resource use each comprised $13 \%$ of the cultural narratives sampled at AHC/CANM. As at Bandelier and Mesa Verde, resource use is the third-largest component of cultural narratives sampled at 
AHC/CANM.

Figure 37. Component cultural content: Anasazi Heritage Center / Canyons of the Ancients National Monument

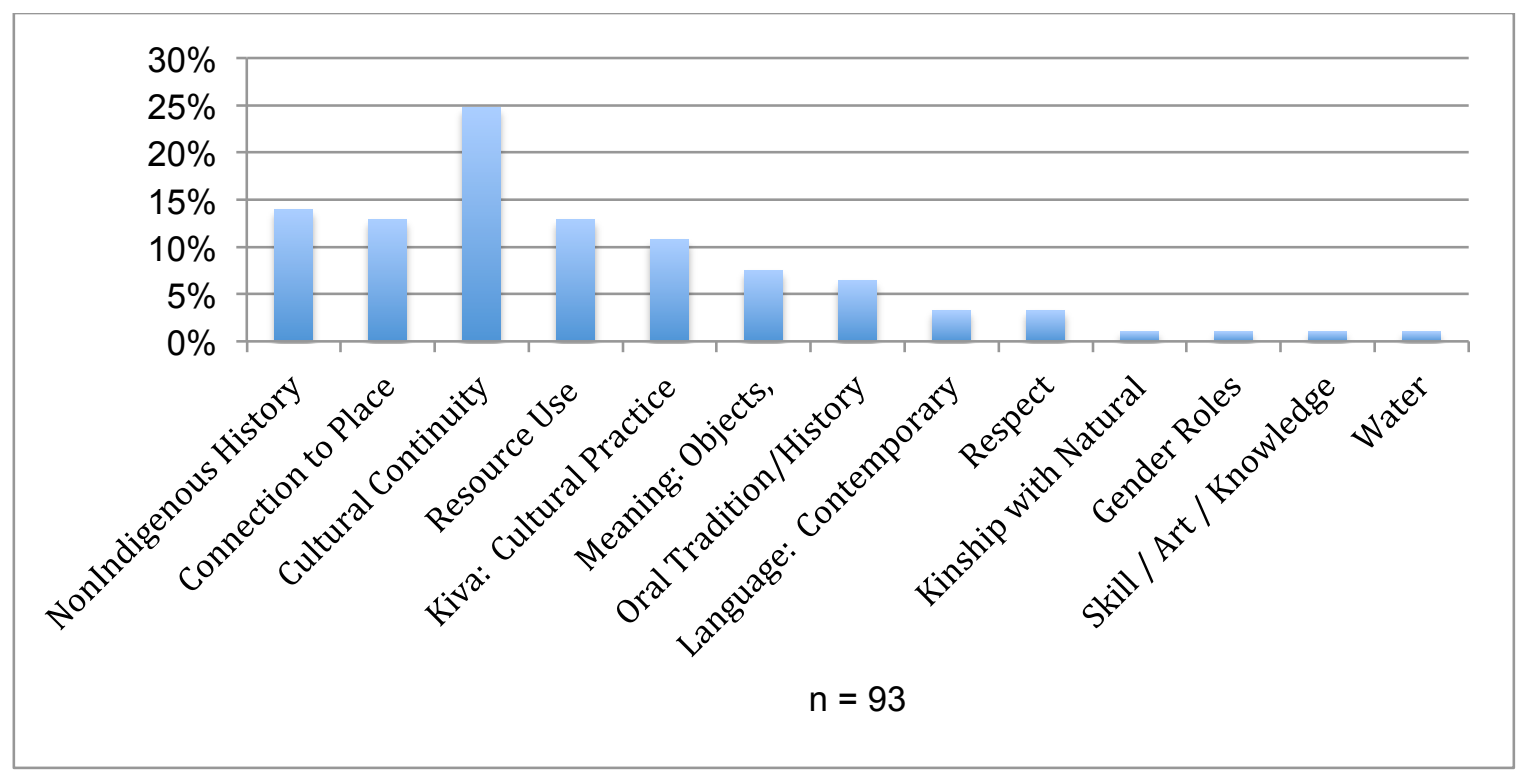

Non-Indigenous history differed considerably at AHC/CANM: the story told here was both multi-voiced and multi-temporal. Interpretive panels on the half-mile nature trail, for example, consistently juxtaposed lifeways and land and resource use of Ancestral Pueblo people, Spanish adventurers, 19th-century Utes and Euro-American settlers, and contemporary ranchers and farmers. The panels' text used a third-person omniscient point of view to frame direct quotations from named individuals with specialized knowledge: the former director of Crow Canyon Archaeological Center, the Spanish Franciscan for whom the trail and pueblo are named, an archaeologist, a naturalist, an historian; citizens of the Diné, Hopi, and San Juan and Jemez Pueblos; a clinical herbalist, a cook, an ethnobotanist. The disciplines of geology, history, and archaeology spoke clearly, but not exclusively. 


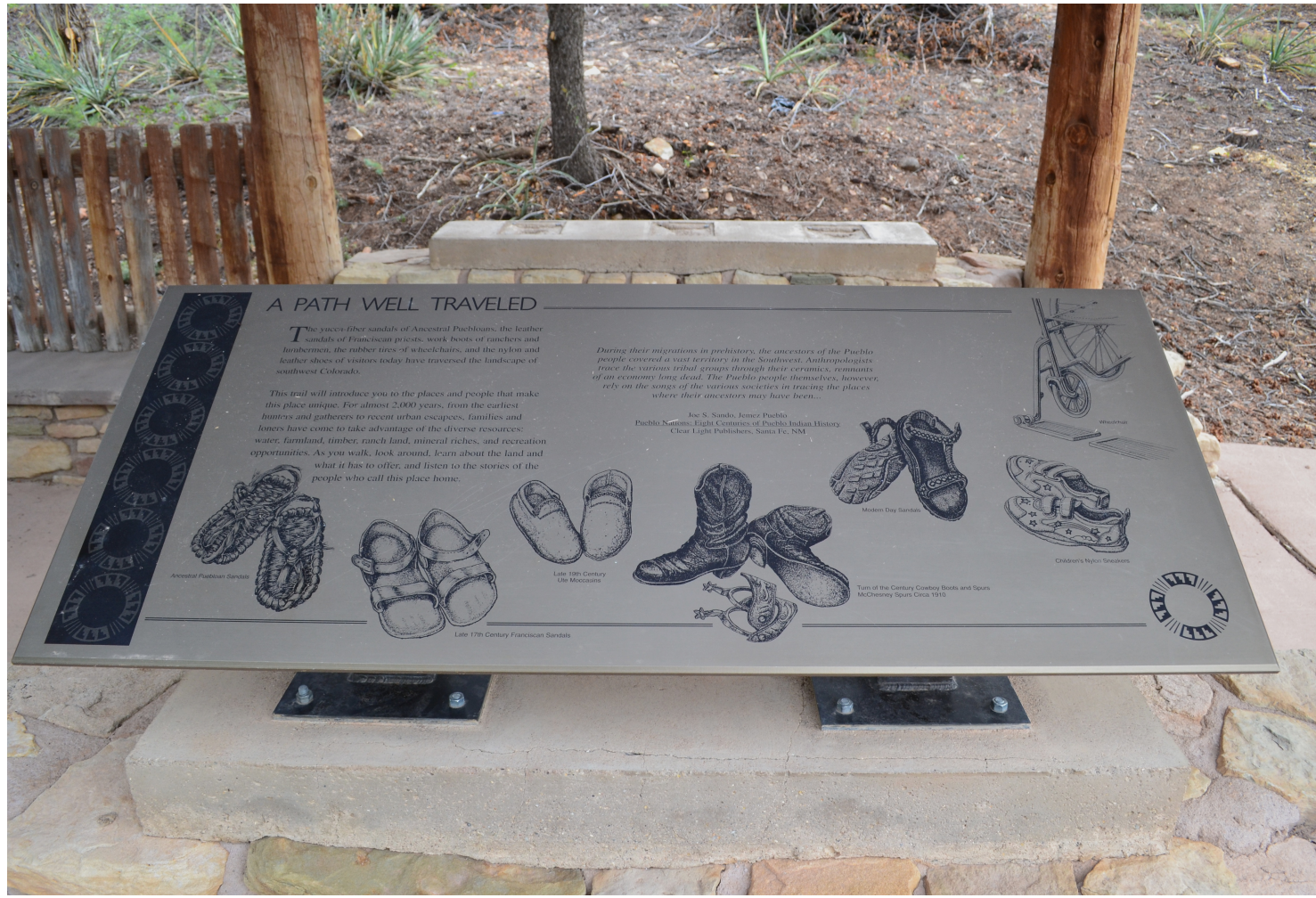

Figure 38. AHC/CANM, Escalante Pueblo Trail introductory interpretive panel. Note iconic footwear of multiple peoples.

Standing on the steps of the closed AHC watching the valley below change colors in the early morning light, another visitor engaged me in casual conversation. Two mornings a week, this middle-aged man from Durango drove "a couple of hours" to walk "an hour or two someplace new." He never read signs, he said, but he did read those on the Escalante Pueblo Trail. "Different. Hmmm," he said walking away, down the steps to his car below. This visitor's response argues for the effectiveness of juxtaposition and the inclusion of voices representing multiple stakeholders' perspectives.

The presentation of Native American cultural continuity at the AHC/CANM also differed from the other research sites. Cultural continuity was not asserted or represented, (as at Mesa Verde and Petroglyph respectively), but displayed. As at Bandelier, cultural 
insiders voiced cultural knowledge. However, in much interpretive material at the AHC/CANM, citizens of affiliated pueblos treated meaning, symbol, and spiritual practice quite explicitly. AHC/CANM Interpretation not only quoted knowledgeholders — archaeologists and Native Americans alike— but pictured and identified them. Different understandings stood side by side.

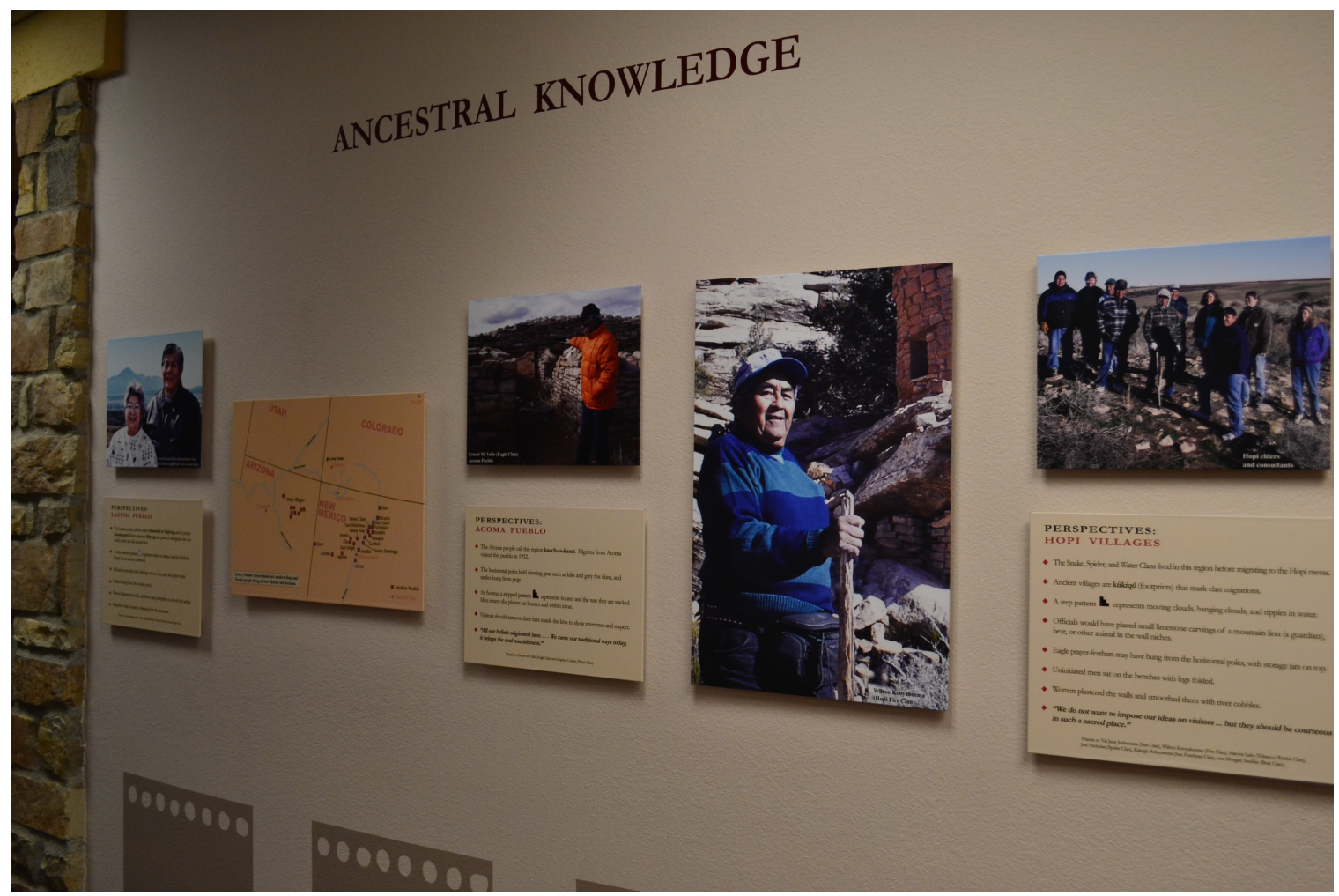

Figure 39. AHC/CANM, Lowry Pueblo Ancestral Knowledge display. Note attributed text describing multiple understandings of place names, symbols, ritual objects, and gender roles related to kiva practice.

The display focused on historic-era and contemporary Pueblo people included iconic 19th-century photos and a display of the traditional Pueblo calendar year drawn 
from the work of San Juan Pueblo scholar Alfonso Ortiz (1969) ${ }^{17}$ as well as color photos of, quotations from, and brief biographies of, eminent contemporary cultural leaders. AHC/CANM included text panels that explicitly defined AIRFA and NAGPRA and situated tribal archaeology in the context of cultural continuity (e.g. "Native Views, Native Voices: More than any other group, Native American recognize deep historical, emotional, and spiritual connections to Southwestern archaeological sites. Native American consultants assist archaeologists in planning research and interpreting the findings. Many tribes manage their own cultural preservation and archaeological research programs.") The process by which "consultants assist archaeologists" remained unclear, but its intended product - multivocal research design and archaeological interpretation sensu Hodder and Atalay—was explicit.

Additionally, multivocality operated at the educational/interpretive level as well. Exhibits presented visitors with credible, creditable multiple understandings of shared cultural meaning, and different constructions of knowledge — archaeological and cultural—coexisted in the display space. Consultants had names and faces, specific tribal affiliations, professions. At AHC/CANM, the emic perspective was embodied rather than erased as at the Nevada sites, incorporated as at Mesa Verde, or appropriated as at Petroglyph. At both Bandelier and AHC/CANM, conventions of display (attribution, type style, layout) emphasized Native Americans' self-representation. However, at AHC/CANM color photos evoked their physical presence in the exhibit space.

${ }^{17}$ While I recognize that some may construct Ortiz' scholarship and activism as rhetorical sovereignty and some as authoethnography, that discussion is beyond the scope of this discussion. 
Additionally, while all five sites are mandated by law and required by policy to practice consultation and recognize tribal sovereignty, only AHC/CANM represented sovereignty and consultation in display.

This research found that the presence of an embodied emic, however great its rhetorical weight, may unsettle—but not actually unseat—hegemonic discourse. Viewing the two long walls of the main exhibit hall as complementary timelines (as one museum staff member explicitly suggested) illustrated the persistence of the hegemonic. First of all, a timeline constructs time as a linear process, a decidedly Euro-American construction of history (Nabokov, 2002): the AHC/CANM represented Pueblo time as a single, small (1 meter diameter) panel within such a chronology. Second, the timeline representing the development of regional archaeology from 1776 to 1988 was longer than the one representing the entire longue durée of Pueblo people. ${ }^{18}$ On the other hand, the display rendered the Puebloan peoples' timeline in saturated color, showcased material culture, and exploited many of the techniques/technologies of the participatory museum (Simon, 2010); the archaeological timeline was comparatively drab and text-heavy (see Figure 17, Figure 18).

Engaged activities in AHC/CANM's central space included weaving, grinding corn, touching artifacts and replicas, watching videos of experimental archaeology, and exploring palynology, dendrochronology, satellite imaging, and curation with microscopes and computers. The pithouse, salvage archaeology, and participatory

${ }^{18}$ The archaeology timeline occupied approximately 26.5 meters vs. the Pueblo peoples' approximately 25.5 meters) 
(Re)Presenting peoples and storied lands

displays occupied more than half of the main exhibit hall. My observation disclosed most visitors were drawn to them and held by them: a museum staff member reported most visitor engagement with weaving and grinding. Visitors interviewed in this research talked at length about the loom, the grindstones, and the reconstructed pithouse.

The museum's ancillary spaces (two smaller exhibit spaces and a large lobby housing retail, information desk, regional tourism displays, archaeologically themed computer games) may function as spaces for alternative constructions of heritage (L. Smith, 2006). In the summer of 2013, the first gallery contained works from previous artist-in-residence programs and a series of historic photos of the Southern, Ute Mountain, and Northern tribes of Ute Indians. The second gallery showed a retrospective of Colorado painter and teacher Stanton Engelhard. The hallway leading to the Engelhard show displayed "River of Sorrows: The Lower Dolores River Valley," detailing prereservoir EuroAmerican settlement, as well as panels acknowledging and picturing museum volunteers.

The use of space in the main exhibit hall suggested that the display's gravitas inheres in heritage archaeologically constructed. The use of costly and labor-intensive media in the pre-contact portion of the Pueblo peoples' timeline suggested that the museum display privileged a Native American cultural narrative that has been archaeologically constructed (as does the name of the institution). However, the rhetorical weight of first-person narrative in the historic-era and contemporary Puebloan portions suggests display privileged, or at least recognized and represented, a distinct 
emic perspective. The display of local settlement-era material tied to other groups, though relegated to ancillary spaces, legitimized other constructions of life on the landscape.

Even absent explicit construction of the land and its material culture as national patrimony, despite the inclusion of alternative constructions of the meaning and the use of significant places and objects, display practices reflect existing relations of power. Existing relations of power determine the construction of cultural heritage. As Smith $(2004,2006)$ emphasizes, the construction of heritage is inherently exclusionary: heritage privileges some peoples' stories and marginalizes others'. Multivocality in Interpretation often risks swamping alternative perspectives, if not rendering them entirely superfluous, as Atalay (2008) maintains and AHC/CANM illustrates,.

\section{CONCLUSION}

In this chapter, I presented the various components of cultural narratives in interpretive programming across the five research sites. I argued that all five cases use different rhetorical strategies to interpret natural and cultural resources for the visitor; all five elect a different balance of emic and etic knowledge, a different combination of Native and institutional voice. At the Nevada sites, the emic is absent. At Mesa Verde-flagship cultural park and World Heritage Site-- it is incorporated. At Petroglyph --where affiliated Native American tribes and pueblos are particularly numerous and heterogeneous-- insider knowledge is mediated by institutional voice. At Bandelier, knowledge and authority is shared. AHC/CANM most nearly approaches multivocality in the Interpretation and display of archaeology. The next chapter continues to examine the transparency of interpretive authority and the legibility of consultation and collaboration, 
(Re)Presenting peoples and storied lands

querying the who, where, when, and how of the stories told to visitors and examining specific examples of Interpretation in light of representation and self-representation. 
Chapter 5: Who, Where, When, How: Voice, Time, and Representation

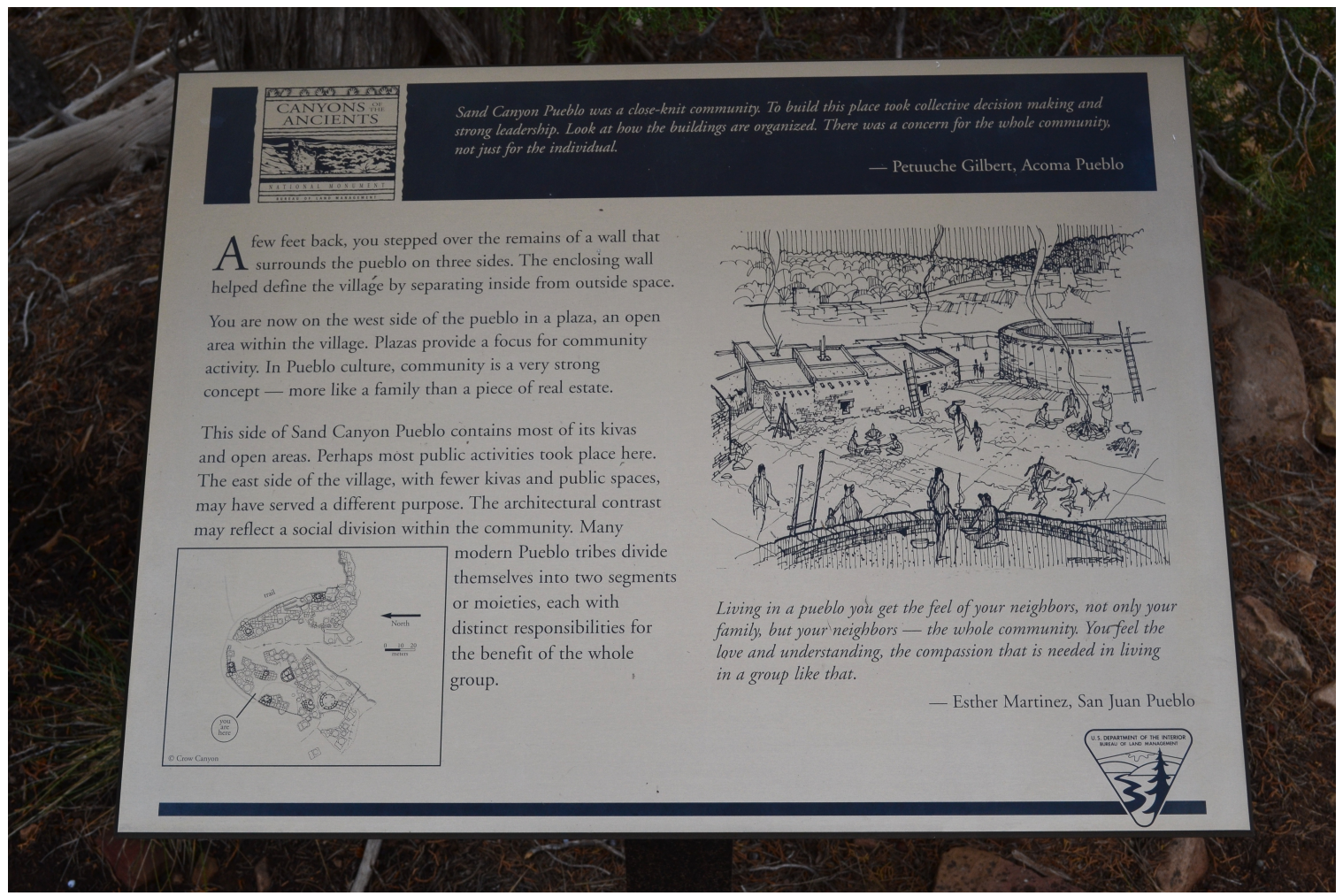

Figure 40. AHC/CANM Sand Canyon Pueblo trail minimal interpretive panel. Note evocative contemporary style of artist's rendering and graphic design elements emphasizing the parity of cultural and scientific narratives.

Some of the Interpretation sampled in this research displayed the parity of cultural and scientific narratives as in this AHC/CANM panel (Figure 40). The previous chapter examined variation in the components of cultural narratives and analyzed the relationship between emic and etic knowledge in the cultural narratives sampled in this research. I argued that the choice of rhetorical strategy reflected site-specific attitudes to emic and etic knowledge, and I characterized the research sites in terms of how they represented emic and etic knowledge: erasure/bricolage, incorporation, ethnography, autoethnography, and multivocality. This chapter continues to address the transparency 
(Re)Presenting peoples and storied lands

of authority and the visibility of Native American involvement, consultation, and collaboration in display.

This chapter frames issues of representation in the public presentation of archaeology in protected areas in terms of the who, where, when, and how of the stories told to visitors. I contend that contemporary practice in the public presentation of archaeology in the five US protected areas studied in this research occupies a continuum ranging from positivist representation of archaeology and Native American culture- the signature strategy of the NV sites - to a moderate relativist self-representation of boththe rhetorical strategy characteristic of Interpretation at AHC/CANM. This chapter considers the relative presence of narrative voice and the relative presence of narratives expressly situated in ancient time, the historic era (from 1540, the Entrada de Coronado, to 1999$)$, and the 21 st century.

In order to reveal how protected areas construct archaeology and Native Americans, I examine the grammar and narrative structure of two key types of interpretative displays — welcome statements and maps — as represented utterances. In order to disclose the rhetorical strategies at work, I query the use of active and passive voice and verb tenses, the presence of an implied or explicit narrator, of representation or self-representation, and multivalence in specific displays.

I use active and passive voice to distinguish between grammatical constructions in which the grammatical subject is the agent of the action of the verb and those in which the referent of the grammatical subject typically 'undergoes', 'experiences', or 'receives' the action of the verb: She loved him vs. He was loved by her (Oxford Dictionary of 
English Grammar, 2014b). I suggest that the use of the by-clause (the Latinate dative) functions to obscure the subject's agency. In the following discussion, implied narrators generally tell stories / deliver cultural narratives from the third-person omniscient point of view, explicit narrators from the first-person; both may or may not be identified by name, profession, or tribal affiliation; as a rule, first-person narrators are identified in some way. I use representation to mean the production and consumption of texts in any medium photos, films, language, painting — which render absent people and places present; I fully intend to foreground the partiality and selectiveness of interpretive texts. I follow scholars in anthropology like Clifford (2004), Erickson (Bowechop \& Erikson, 2005; 2003), and Nesper (2005) in using self-representation to emphasize the determining force of context (Clifford, 2001): the policies and practices of protected areas shape what it is possible for people and nations to say in them.

\section{REGIMES OF REPRESENTATION}

Who references several dimensions of who tells the story? At the largest scale, protected areas author Interpretation by funding and displaying interpretive material; they delegate authority to a number and variety of individuals and groups-employees, contractors - to create narratives and craft Interpretation. As in film and fiction, these narratives employ an implied narrator with a discernible point of view, ordinarily thirdperson (telling) or first-person (showing). At the literal level, then, who equates to narrative voice or point of view. This research found a third-person omniscient narrator appeared most frequently in the Interpretation sampled at all five research sites: thirdperson narratives appeared with a relative frequency ranging from $56 \%$ at PETR to $82 \%$ at MEVE. First-person narratives attributed to a non-Indigenous speaker did not appear at 
(Re)Presenting peoples and storied lands

MEVE, but appeared with a relative frequency ranging from $2 \%$ at the NV sites to 9\% at AHC/CANM. Third-person inclusive Indigenous speakers (e.g., "Our ancestors") appeared in Interpretation at three of the five research sites, ranging from 3\% (MEVE and AHC/CANM) to $8 \%$ (BAND). This research did not observe first-person Indigenous point of view at all in the Interpretation at the NV sites and in only two panels at PETR; at the other three sites, Interpretation credited first-person Indigenous narrators (ranging from $1 \%$ at $\mathrm{AHC} / \mathrm{CANM}$ and MEVE to $11 \%$ at Band) or attributed first-person narratives to specific, named individuals (raging from $1 \%$ at MEVE to $23 \%$ at $\mathrm{HC} / \mathrm{CANM}$ ).

Table 12. Relative presence of selected language constructions: Narrative point of view

\begin{tabular}{|c|c|c|c|c|c|c|c|}
\hline Research Site & 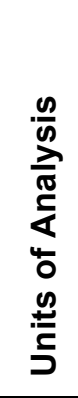 & 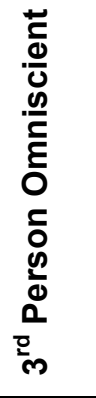 & 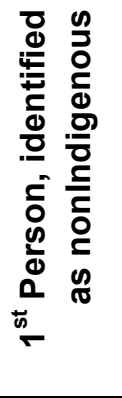 & 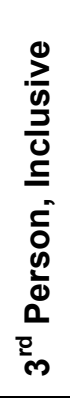 & 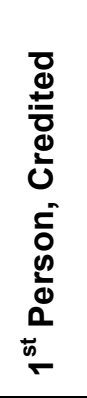 & 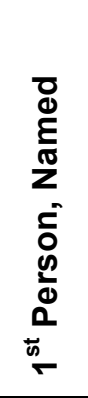 & 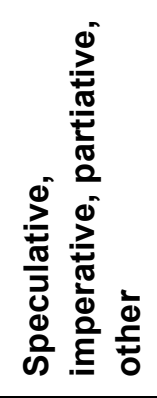 \\
\hline Petroglyph National Monument & 80 & $56 \%$ & $6 \%$ & 0 & 0 & $1 \%$ & $37 \%$ \\
\hline Bandelier National Monument & 111 & $71 \%$ & $5 \%$ & $8 \%$ & $11 \%$ & $6 \%$ & $15 \%$ \\
\hline Mesa Verde National Park & 129 & $82 \%$ & 0 & $3 \%$ & $1 \%$ & $1 \%$ & $50 \%$ \\
\hline $\begin{array}{l}\text { Anasazi Heritage Center / } \\
\text { Canyons of the Ancients } \\
\text { National Monument }\end{array}$ & 115 & $80 \%$ & $9 \%$ & $3 \%$ & $1 \%$ & $23 \%$ & $30 \%$ \\
\hline NV Sites (composite) & 98 & $72 \%$ & $2 \%$ & 0 & 0 & 0 & $26 \%$ \\
\hline
\end{tabular}

As cinematic narratives may advance via dialogue, in which characters speak, or by voiceover, in which the narrative consciousness mediates (and often summarizes) the action, interpretive narratives regularly represent voice and specialized knowledge. Therefore, in this research, who tells the story? also references who speaks? and who is 
(Re)Presenting peoples and storied lands

spoken for? When etic knowledge incorporates or appropriates emic knowledge, the outsider - author, anthropologist, interpreter, exhibit designer-represents the life and culture of the insider. Representation, whether cloaked or disclosed, remains representation, "an active process" of "constructing one culture for another" (Lidchi, 1997, p. 200). The Interpretation sampled in this research generally favors the thirdperson omniscient point of view: the all-knowing narrator speaks for Native Americans and scientists (archaeologists, geologists, biologists) far more often than they speak for themselves. For example, at Bandelier, the third-person point of view appeared with a relative frequency of $71 \%$ of the Interpretation sampled; non-Indigenous first-person narratives appeared in 5\%; and Native American first-person narratives appeared in 17\%. At AHV/CANM, the third-person point of view appeared with a relative frequency of $80 \%$ of the Interpretation sampled; non-Indigenous first-person narratives appeared in 9\%; and Native American first-person narratives appeared in 24\%.

Gough (2008) maintains that, in the context of First Nations' museum engagement, voice has political, representational, and epistemological implications. Following Gough, I use voice to uncover "whose voice is used in the construction and writing of museum texts, as well as schematic and display techniques utilized by museums" (2008, p. 222). Furthermore, the author explicitly situates the temporal dimension of voice within relations of power/knowledge:

In terms of epistemology, the notion of voice serves to challenge the social constructs that impose value and meaning on an Aboriginal voice as necessarily existing within an ethnographic and historical past ... Inherently, this "way of knowing" is very political in that it has functioned to encourage a view of Aboriginal cultures as static and unchanging (Gough, 2008, pp. 222-223). 
(Re)Presenting peoples and storied lands

Interpretation at the five research sites displayed not only variability in the use

of emic knowledge, but also in the space made for Native American self-representation. When Interpretation represents the knowledge and perspectives of cultural insiders, the particular use of language is key: Who does Interpretation represent as the grammatical subject and the object of a sentence? What people does Interpretation represent as active and what people as passive? How does the Interpretation use of verb tenses situate people in time? Additionally, does Interpretation represent different peoples in different times? Are Euro-American settlers, archaeologists, and ethnographers represented, or only Native Americans?

Table 13. Relative presence of narrative timeframes

\begin{tabular}{|c|c|c|c|c|c|}
\hline Research Site & $\begin{array}{l}\text { Units of } \\
\text { Analysis }\end{array}$ & 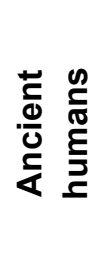 & 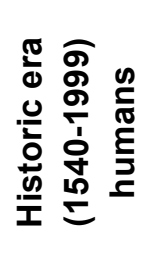 & 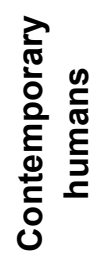 & 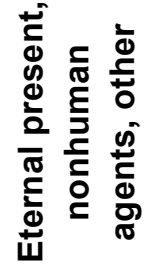 \\
\hline Petroglyph National Monument & 80 & $36 \%$ & $21 \%$ & $38 \%$ & $11 \%$ \\
\hline Bandelier National Monument & 111 & $58 \%$ & $20 \%$ & $42 \%$ & $5 \%$ \\
\hline Mesa Verde National Park & 129 & $51 \%$ & $16 \%$ & $29 \%$ & $6 \%$ \\
\hline $\begin{array}{l}\text { Anasazi Heritage Center / } \\
\text { Canyons of the Ancients } \\
\text { National Monument }\end{array}$ & 115 & $42 \%$ & $30 \%$ & $30 \%$ & $4 \%$ \\
\hline NV Sites (composite) & 98 & $15 \%$ & $6 \%$ & 0 & $79 \%$ \\
\hline
\end{tabular}

The results capture how interpretive materials situate humans in time, but not necessarily which humans. For example, historic-era narratives appeared with a relatively 
(Re)Presenting peoples and storied lands

high relative frequency $(21 \%)$ in interpretative materials at Petroglyph, but the relative frequency of non-Indigenous history was also high (21\%; see Figure 25): considerably more of Petroglyph's historic-era narratives focused on Spanish exploration and colonization than on the Pueblo Revolt, for example. In comparison, at Bandelier non-Indigenous history appeared less frequently (with a relative presence of 7\%) and historic-era narratives appeared almost as frequently $(20 \%)$ as the Interpretation sampled at Petroglyph. This difference in the two sites' results reflected, in part, the presence of Interpretation identifying (and often picturing) the archaeologists and the citizens of Santa Clara, Cochiti, and San Ildefonso Pueblos instrumental in the park's early history. In general, Interpretation observed at Bandelier represented the agency of historic Pueblo peoples in a fairly limited geographic area; Petroglyph, the agency of the colonizers on a larger scale. Entanglement may look quite different to different descendant communities.

Historic-era narratives appeared with the greatest relative frequency at AHC/CANM (30\%, and non-Indigenous history also appeared with a relatively high relative frequency there (14\%; see Figure 25$)$. In the museum, the historic era comprised the entire archaeology timeline and slightly less than half of the Pueblo People timeline (about 9.5 of 21.5 meters). In interpretive material displayed in situ (i.e. on the landscape or in the outdoors), historic-era narratives focused on archaeological practice. Archaeologists were represented more frequently than Pueblo people, and other EuroAmericans were largely absent in historic-era Interpretation sampled at AHC/CANM. (This sample excluded temporary exhibits in a gallery, a meeting room, and a corridor. In August 2013, those spaces displayed a retrospective of the work of Colorado painter 
Stanton Engelhard, works by recent artists-in residence, a collection of historic photographs of Ute Indians [sic], and an exhibit focused on local Euro-American history and architecture in the pre-McPhee Reservoir lower Dolores River valley.)

Constructing a protected area as a global monument to "the works of man [sic]" or as archaeology qua archaeology creates a durable, but not impenetrable, hegemonic discourse (see Fine, 1988, for examples) and tends to obscure the local, current, and specific (Hodder, 1999; L. Smith, 2006). At the Nevada sites, historic-era narratives appeared in $6 \%$ of the Interpretation sampled and non-Indigenous history appeared in $33 \%$ (see Figure 25): in general, Interpretation focused on middle-range theory, and represented people largely as settlers and miners. At Mesa Verde, historic-era narratives appeared with a relative frequency of $16 \%$ and non-Indigenous history with a relative frequency of 13\% (see Figure 25) in the Interpretation sampled. In general, the historicera narratives sampled at Mesa Verde focused on Euro-Americans who were key to establishing the park and the early-20th-century archaeologists who worked there. The Interpretation sampled at Mesa Verde effectively erased Native Americans from the historic era, though a visitor might learn about Ute land ownership and Navaho labor from an individual interpreter leading a tour (as this observer did).

In sharp contrast, Interpretation at all five sites generally represented flora, fauna, and geology in an eternal present, using the present tense except for discrete events. For example: "Notice how the volcanic escarpment curves around the island-like field of native plants... The lava flowed around the hill, cooled and hardened into solid basalt rock" (Petroglyph minimalist trail sign); "The fast-growing, short-lived nature of aspens 
creates a recycling system that frequently replenishes the soil" (Bandelier museum panel). Interpretation focused on the environment at these sites generally emphasized a long, continuous temporal arc; drought and fire, however, were frequently represented as cyclical. Potentially, representing lands, plants, and animals in this eternal present obscures their dynamic relationship with culture and reinforces the construction of nature as wilderness (Cronon, 1996; Escobar, 1999; Lane, 2010).

\section{Voice and (self-)representation}

Native voice.

This research found evidence of Native voice in interpretive material across the representational spectrum at four of the five sites: Petroglyph, Bandelier, Mesa Verde, and AHC/CANM; third-person inclusive and first-person Indigenous narratives appeared with a relative frequency ranging from $1 \%$ (PETR) to $27 \%$ (AHC/CANM). Some interpretive material observed in this research mediated emic knowledge by constructing an implied narrator who represented Native voice. For example, at Petroglyph, interpretive material frequently referred to contemporary Pueblo people's beliefs, understandings, and practices - Interpretation represented emic knowledge and used the third-person point of view less frequently than other sites - but very seldom quoted and identified an individual knowledge-holder. Interpretative material at Petroglyph generally acknowledged insider cultural knowledge at a very general level: "Various Pueblos have differing opinions," "Pueblo elders believe," "Some Native Americans believe." The interpretive material observed in this research both presents and represents Native voice. 
Other interpretive material attributed quotations to specific individuals or groups or identified photographic subjects by name, i.e., they employed Native Americans self-representation. At Bandelier, for example, material frequently quoted and identified individual and corporate Native American knowledge holders. Emic and etic knowledge appeared together in the exhibition hall, often within the same panel and often within the same paragraph. One panel juxtaposed "For thousands of years, huntergatherers lived on the Parajito Plateau...", "The sumac bush had many uses. Its berries are high in Vitamin C.", "Food: Say it in Keres: ooh PEH wah," "Our ancestors were given the knowledge...", and "Mule deer (above) and cottontail rabbits (right) were abundant throughout the year and were a staple of the Ancestral Pueblo diet" (Figure 13). Interpretive material at the AHC/CANM largely privileged etic knowledge in ancient time: for example, by mapping foundational archaeological sites (Hecate Strait, Kennewick, Bluefish Caves, Clovis, Meadowcroft, Topper) in a display entitled "First Americans: Controversial discoveries hint at alternative routes to the Americas." However, Interpretation at AHC/CANM generally privileged emic understandings in historic and contemporary eras, as in this panel from the contemporary portion of the Pueblo peoples' timeline:

Through the strength of the spirits, our ancestors built these dwellings here. That's what makes them so significant. We want to encourage others to preserve these dwellings for future generations to come and observe because our cultural and traditional ways bring the soul nourishment.

(Ernest M. Vallo, Sr., Eagle Clan, Pueblo of Acoma, 2004)

Additionally, both in the museum and on the landscape, AHC/CANM Interpretation regularly juxtaposed archaeological practice and current archaeological knowledge with 
contemporary insider knowledge; in general, the different partial knowledges reinforced and amplified one another (see also Figure 5).

In contrast, at Mesa Verde interpretive display generally privileged scientific knowledge of Ancestral Pueblo people over the knowledge of contemporary Pueblo people, generally used the third-person omniscient point of view, and largely veiled the input of contemporary Native American collaborators. For example, at the Visitor and Research Center, self-representation appeared most obviously in a single attributed quotation at the entry to the exhibit space; under a regional satellite map, an audio installation played Native speakers' greetings in living languages. The Nevada sites focused on etic knowledge almost exclusively.

Native voice appeared as both first- and third-person narratives (e.g., Bandelier's unattributed "Our ancestors were given the knowledge...") and with the greatest frequency at Bandelier, which I have characterized as implementing authoethnography as rhetorical strategy, and AHC/CANM, which I described as multivocal. At AHC/CANM, my research also found the greatest frequency of first-person scientific narratives: for example, quotes from named 20th-century archaeologists figured significantly on interpretive panels at Lowry Pueblo, and primary documents (collection database, site reports) were displayed in the exhibit hall. This inclusion of curatorial voice, quite distinct from citing interpretive sources as at the Nevada sites, may contribute to rendering the workings of power/knowledge in the public presentation of archaeology more visible to the visitor. Such transparency may be an emerging trend in museology (Krmpotich \& Anderson, 2005; Schultz, 2011). Potentially, Interpretation using first- 
(Re)Presenting peoples and storied lands

person narratives —Euro- and Native Americans' both — can convey the interpenetrability of scientific and cultural knowledge (Colwell-Chanthaphonh \& Ferguson, 2010).

Welcome statements.

Welcome statements, clearly indicated as such, were observed at the Bandelier museum, Sand Canyon Pueblo (AHC/CANM), and the Mesa Verde VRC. ${ }^{19}$ Located 22 miles from the AHC/CANM museum and visitor center and less than a minute's walk from a dirt parking area with weather-beaten wayside orientation serving two trails, stood a minimalist panel: "Welcome to the Sand Canyon Pueblo and Sand Canyon Trail." Beneath a hallmark graphic, the welcome, another sentence of orientation, and an archaeological site plan including village, trails, and parking, the text read: ${ }^{20}$

... Several hundred people lived at Sand Canyon Pueblo between A.D. 1245 and 1290. Some sections were excavated by archaeologists from 1983 to 1993, then reburied to preserve the site.

Today the pueblo looks like a rubble mound with few visible walls. But it remains very much alive for modern Pueblo people, whose ancestors lived in this region for centuries.

${ }^{19}$ At Lowry Pueblo (CANM) and Petroglyph, a parking wayside titled 'welcome' provided limited orientation and management information, ditto for the Falls Trail trailhead at Bandelier. At Grimes Point, the most developed of the Nevada sites, the parking/trailhead wayside admonished visitors to "Help preserve" and "Please follow the rules;" a similarly informative/admonitory wayside stood at the parking for CANM's Sand Canyon and Rock Creek trail; however, less than fifty yards away stood "Welcome to the Sand Canyon Pueblo and Sand Canyon Trail." At the entrance to the AHC museum stood life-size cut-outs, apparently reproduced from line drawings of Ancestral Pueblo people; text on the accompanying banner invited the visitor to "participate in the Anasazi story as we know it today." I exclude these from this discussion of welcome statements because they seem to me to focus on visitor compliance rather than affect, on management rather than interpretation, and so fail to reflect my understanding of welcome statement within and without this research.

20 Italics in original 
(Re)Presenting peoples and storied lands

We have a Hopi word for this area, kiiseo, it refers to ancestral place in the northeast. Hopi people do return to some of these places; in that way the connection is maintained.... Many different Pueblo people are linked to this place. --Harlan Mahle, Hopi

Modern Pueblo people always focus on mountains and water, our ancestors did too.... There were people here who called this place home.

--Vernon Lujan, Taos Pueblo

Visitors here should be aware of the relationship of this community to nature.... When you look out from this place you see the mountains, the sky, the snow. The designs of petroglyphs, pottery, and buildings are symbolic of these things.

--Petucche Gilbert, Acoma Pueblo

The panel established the tone for Interpretation throughout the site. Archaeological knowledge ("Several hundred people lived at Sand Canyon") and archaeological practice (the site plan, "Some sections were excavated") formed a vital component of the Interpretation of the site, but so did self-represented emic knowledge. Typography further emphasized the presence of Native voice.

Named knowledge-holders situated people and actions in the present: "We have," "do return," "focus;" a word "refers," visitors "should know." The first speaker's particular use of passive voice, the present tense to denote ongoing activity, and Native language_-connection is maintained," "many are linked," kiiseo—-suggested that a range of knowledges, understandings and practices exists beyond what was offered in this or any other display (Lawlor, 2006). The third-person narrator's use of the agentless passive construction with the perfect tense-"sections were excavated...reburied"—on the other hand, suggested more a lack of agency, exertion, or accountability. Compared to the other welcome statements observed in this research, the Sand Canyon welcome speaks 
(Re)Presenting peoples and storied lands

predominantly in the Native voice, ${ }^{21}$ suggesting that federal stewardship need not silence alternative constructions of protected areas' lands.

Native voice, in the form of a direct, attributed quotation, headed four of the six remaining interpretive panels at Sand Canyon: knowledge-holders described appropriate behavior, connected village structures and cultural practices with contemporary ones, and inferred past behavior from features of the surviving village. Additional quotationsdiscussing origins and meanings, community life - appeared on panels alongside thirdperson archaeological narratives situating Sand Canyon in the context of regional archaeology, archaeological practice, tradition, and oral history. Interpretive panels depicted the village both intact and peopled, circa A.D. 1250, and in archaeological site plans from recent excavations (1983 to1993).

Sand Canyon Pueblo's welcome statement stood on the land, not in a museum or visitor center. The site's Interpretation unfolded as the visitor walked, scrambled, paused, stood, and possibly sat at places along the loop. Visitor experience, then, while still mediated by sight (and reading and all the other conventions, techniques, technologies, and disciplines of display), was shaped by the land itself-the sounds of birds and rodents, the smells of dust and sage and juniper, the warmth of a midday sun. Trail and signage structured visitor experience, but failed to control it: the land and the entities inhabiting it intruded, influencing the experience moment by moment.

${ }^{21}$ The welcome statement contained 104 italicized words directly attributed to three named Native Americans in the body of the panel vs. 85 unattributed words in the orientation and introductory sections 
(Re)Presenting peoples and storied lands

While the tourist gaze may be embodied in the constructed sense-scape, it is not simply determined by it: the visitor moves back and forth between the constructed and the experienced. The tourist gaze is more than sight: it comprises "physical movement through landscapes... aesthetic sensibility... daydreaming and mind traveling...touching, smelling, and hearing objects of the gaze" (Larsen \& Urry, 2011, p. 1115). This indeterminacy may better position the visitor is to understand, possibly even experience, alternative constructions of the land and the entities that frequent it. In the case of cultural resources on the landscape, the visitor can only perform the tourist gaze with the active, experiencing body. However, many protected areas stewarding archaeological sites persist in constructing the visitor as a passive consumer. Smith (2006) links limited opportunities for independent exploration and engagement (i.e., participation in heritage as experience and identity) to the exigencies of management within the most hegemonic institutions.

At Bandelier, ancient villages and talus houses stand some 400 yards from the visitor center and museum. The monument's welcome, a large wooden panel, stood in the museum's relatively narrow entry; motion triggered a recorded greeting with music. The panel read:

People and Place

A rugged, beautiful place / with a challenging and changing climate, / home to Ancestral Pueblo people / whose culture was shaped by their life on the land.

The affiliated Pueblos of Cochiti, San Felipe, Kewa (Santo Domingo), San Ildefonso, and Zuni have ancestral ties to Bandelier.

Special thanks are extended to the Pueblos who consulted on the design of these exhibits. 
The reverse side displayed a photo-illustrated untitled poem by Cecilia Shields, identified as Park Ranger, Picuris Pueblo, Ohkay Owingeh, and Mescalero Apache. The poem and the poetic diction of both panels and soundtrack coupled with the panel's prominent placement to emphasize the importance of the interpretive content and virtually assured the visitor's attention. The panels constructed place as transcending time and the Pueblos in undisputed possession of their heritage. The panels also veiled the exhibit's implied narrator. The park and its delegates disappeared into the passive verb of the last sentence.

At the Mesa Verde VRC, two panels_-"Welcome" and "Step into the Ancient Past"—faced each other across the lobby. Iconic material culture — a duck jar and a canteen, a black-on-white bowl, sandals_-occupied display cases to one side of the park's welcome. The welcome panel read:

Welcome / Mesa Verde National Park

Mesa Verde preserves an extraordinary record of the Ancestral Pueblo people who made their home here for more than 750 years. They lived on these mesas from A.D. 550 to A.D. 1300. The park protects nearly 5,000 archaeological sites, including 600 cliff dwellings, and more than three million objects in its museum collection.

In addition, Mesa Verde preserves a stunning natural landscape that supports a wide diversity of plants and animals. The park includes 8,500 acres of protected Wilderness.

Most Southwestern Native American pueblos recognize Mesa Verde as part of their cultural heritage.

The welcome text constructed the park as the predominant active entity in the present ("Mesa Verde preserves," "The park protects," "Mesa Verde preserves," "The park includes"). The text situated Ancestral Puebloan people in a completed past ("They lived 
on these mesas from A.D. 550 to A.D.1300"), and constructed their descendants' present relationship with their heritage as a matter of cognition rather than possession.

This interpretive text foregrounded the park and its delegates and veiled the agency of the pueblos.

A facing panel displayed two distinct sections of text and two photos of cliff dwellings; the top section read:

Step into the Ancient Past

The park invites you to imagine life here as it was hundreds of years ago, in a culture so interwoven with its environment that people's homes were literally integrated into the landscape. The natural world allowed them not only to survive but to thrive, providing them raw materials for everything they needed.

These exhibits offer a glimpse of the daily life of the Ancestral pueblo people who lived here, where their descendants are today, and ways that archaeologists continue to study the enduring structures and artifacts they left behind.

The text rendered the park, its exhibits, and the natural world active (they "invite," "offer," "allowed"). Ancestral and contemporary Pueblo people appeared in predicates and subordinate clauses, and appeared, in comparison, passive. Not all the observed Interpretation, however, denied Pueblo peoples' agency and erased Native voice,

The second section of the panel, distinguished by the use of a different background color, larger font, and quotation marks, an identified Pueblo individual, quoted noted scholar Dr. Rina Swentzell from Santa Clara Pueblo: "The sky overhead, / the earth below, / the mountains around. / I stand in the middle place— / at home." The text constructed sky, earth, mountains, and speaker as equally present and active. The attribution emphasized Native voice, and the text and its typography—short, centered lines, as opposed to running paragraphs flush left (as in the first sentence of the Bandelier 
(Re)Presenting peoples and storied lands

welcome as well)—suggested an alternative epistemology, some knowledge different in kind from that which produced the rest of the text's prose narrative and exposition. As I argued in the preceding chapter, Interpretation at Mesa Verde generally represents Native knowledge via incorporation. This panel illustrates the use of Native voice as validation (Brady, 2011, p. 205). The power of the speech act in this panel-the identification of the author, the authority of poetic form-helped conceal the absence of Native voice in the exhibit as a whole, and particularly in its more political dimensions (Silberman, 2008, p. 138).

Mesa Verde and Bandelier positioned their welcomes and acknowledgments in very different locales within shaped space. The Mesa Verde welcome occupied the hightraffic lobby connecting the main entrance, the rotunda, and access to three approximately equal spaces signed "Store," "Exhibits," and "Tickets." I observed most Mesa Verde visitors hurrying through this space to reach the ticket queue or the uniformed volunteers in the exhibit space. In contrast, the Bandelier welcome was prominently located, but within the exhibit itself and at a distance from the auditorium, bookstore, and info desk. In general, I observed comparatively few Bandelier visitors entering the exhibit, but more than half those who did stopped and attended to the welcome panel.

The Mesa Verde VRC acknowledged "Native American pueblos and tribes" for their "continuing support of the park's mission" in the monumental plaza between the parking area and the VRC building; the VRC acknowledged board, foundation, and individual support in the building entry. I observed visitors attending to the monumental 
sculpture and the bronzed awards displayed in the entry but not to either acknowledgment panel. In contrast, Bandelier acknowledged consultation twice within the exhibit itself as well as in printed interpretive material. I observed most exhibit visitors (by no means the majority of the monument visitors) attended to at least the first exhibit acknowledgment, and that many monument visitors accessed at least one trail guide acknowledging consultation (for example, during one two-hour period of observation, every group touring the main ancestral village included at least one person carrying an unfolded brochure). At the VRC, the physical distance between the exhibits of cultural narratives and the explicit recognition of Native Americans' support reflects a representational regime that locates Pueblo people at the periphery of their history (see Incorporation in Chapter 3). At Bandelier, Interpretation erased that distance, reflecting a rhetoric and regime of shared authority.

Interpretive material explicitly featuring acknowledgment of supporters or consultants may simply reproduce the balance of power between agencies and their financial contributors and Native American consultants. Like donors and board members, tribes and pueblos support the park: support lacks the active political overtones of consultation. Consultation, government-to-government consultation, is potentially problematic within hegemonic structures. Furthermore, even consciously crafted exhibits and interpretive material may fail to educate visitors about consultation or collaboration.

Recent research suggests that messages about collaboration, consultation, and stakeholder involvement may not actually play into visitor experience. Benton (2011) found that people recalled consultation and preservation messages from interpretive 
programming a month after visiting NPS sites. However, even at Bandelier, where the Interpretation clearly represented Native Americans' agency from ancient time through the present, respondents' reported responses focused on consultation as an activity performed by management (2011, p. 90). In a museum setting, Krmpotich and Anderson found that visitors to a collaborative exhibit - despite the exhibit's exclusive use of firstperson narrative technique, extensive personal stories, explicit identification of individual contributors in photos, text panels, and films, an entrance panel reading "A Unique Collaboration," and a display of individual team members' photos and bios at the end of the exhibit-"rarely recognized the extent of the collaboration, and thus rarely equated Nitsitapiisinni with concepts of [Blackfoot] self-representation or self-determination" (2005, p. 377). Despite the fact that collaboration has become normative practice in archaeology and the museum, it remains virtually invisible to the public (Schultz, 2011). My research found interpretive text acknowledging collaboration, consultation, and stakeholder involvement quite regularly, but found its representation only at AHC/CANM.

\section{Representing lands and peoples}

Four of the five research sites displayed interpretive maps as well as maps orienting the visitor to trails, sites, features, etc. Historically, maps are key instruments of governmentality and they figure largely in the construction of nationhood (Anderson, 1991; Rose, 1999). The maps observed in this research differed significantly in their constructions of land (e.g., topography, rivers, highways, settlements) and political and cultural boundaries (e.g., state, reservation and pueblo; languages and language groups, 
pre-processual archaeological cultures). This research found Native lands seldom represented as such.

This research found Native voice, as an explicit expression or acknowledgment of tribal or pueblo sovereignty, conspicuous by its absence in all five research sites. Interpretive material at four of the five sites acknowledged the support of, or consultation with, Native American tribes and pueblos but generally failed to acknowledge their status as sovereign nations. For example, at the AHC, exhibit panels addressed the sovereign status of affiliated Native American tribes and Pueblos, but only implicitly and from the perspective of the dominant. One panel read "Native American consultants assist archaeologists in planning research and interpreting the findings. Many tribes manage their own cultural preservation and archaeological research programs." However, the next paragraph undermined individual agency and tribal sovereignty: "Legislation assures Native American access to sacred sites. It also requires that human remains and burial items be returned;" in another panel, AIRFA "directs the government to preserve Native Americans' inherent religious rights."

The Mesa Verde VRC prominently displayed a regional satellite map near the conventional free-standing three-dimensional representation of the park (free-standing 3D topographic maps, a feature of many parks and monuments, were also found at Bandelier and AHC/CANM; at Petroglyph, a 3-D map hung near the info desk). The satellite map not only showed topography and rivers, towns, and state and park boundaries, but also the lands of tribes and Pueblos across the Southwest; the interactive display below played greetings in five Native American languages. This map was the 


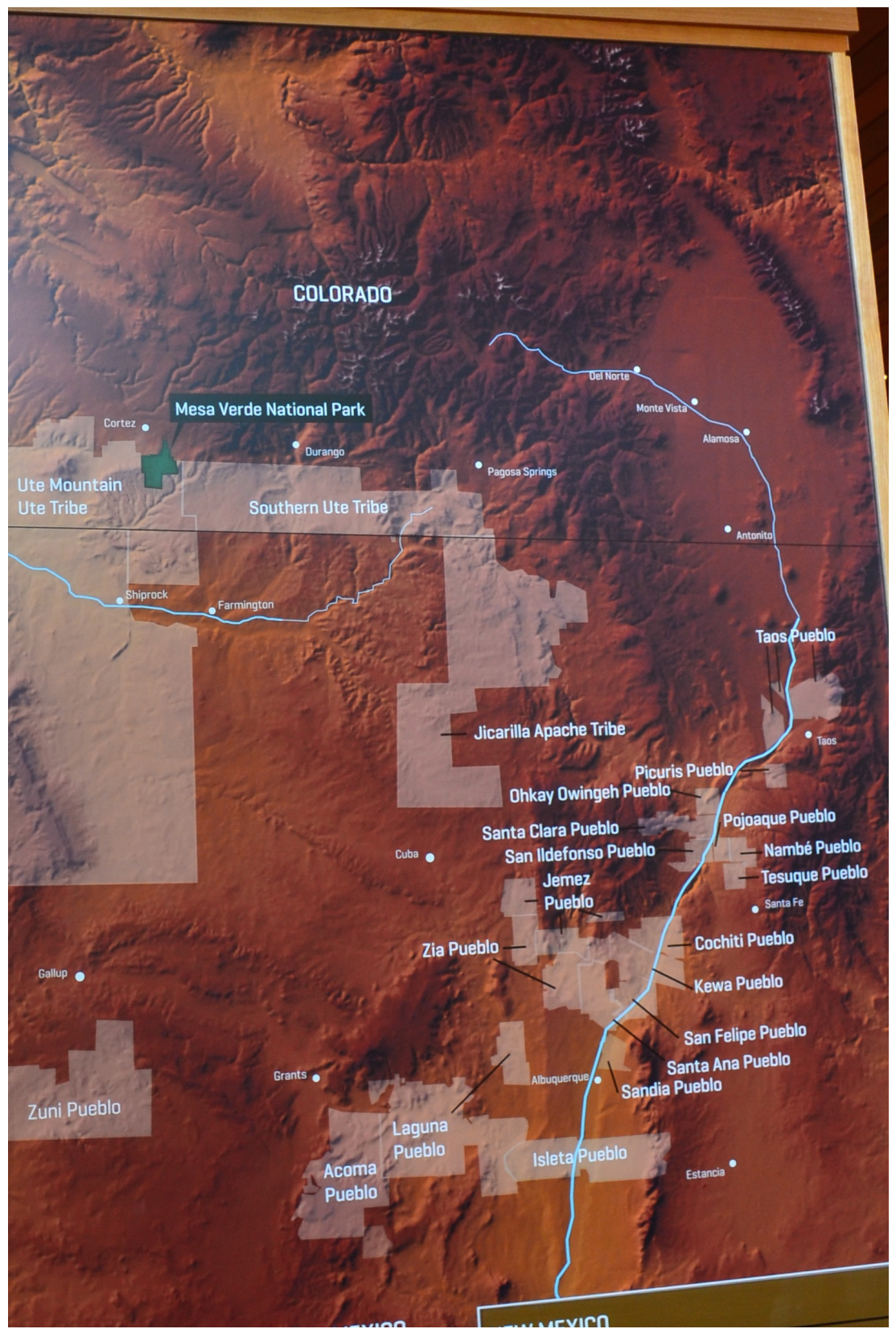

Figure 41. Mesa Verde VRC Satellite Map detail. Note representation of settlements and sovereign lands.

only visual representation of tribal sovereignty in the research. Such a representation may legitimize NPS ownership/stewardship of this land by emphasizing that descendant peoples own/possess that land. 
In sharp contrast, interpretive maps at Bandelier generally represented land in the absence of political boundaries (not necessarily the absence of political entities), and suggested an alternative construction of people, place, and land.

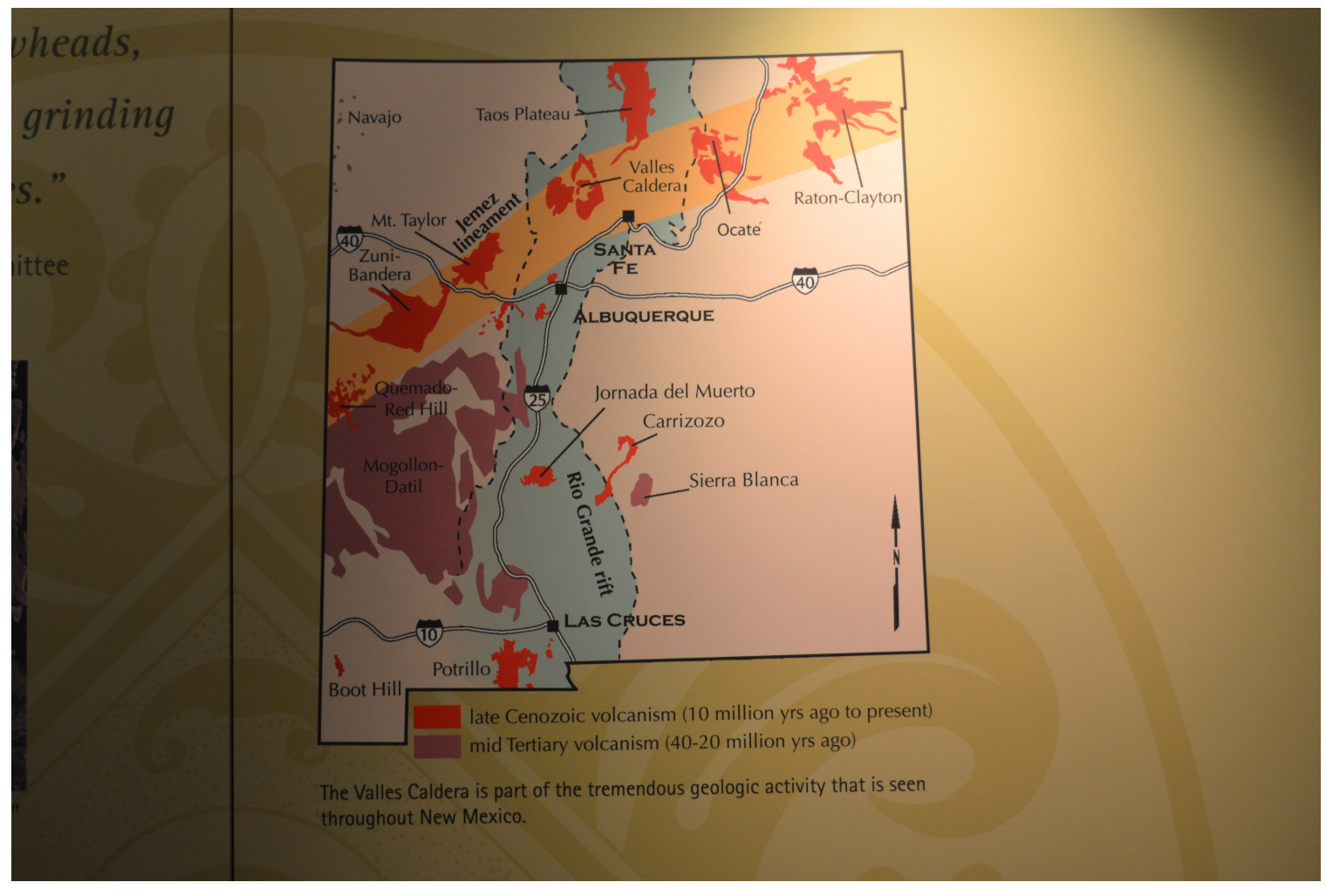

Figure 42. Bandelier museum geologic Map. Note the presence of Santa Fe, Albuquerque, Las Cruces, US Highways 30 and 40, and the absence of political boundaries and other settlements.

Such representations emphasized continuity: the land was and is; the Pueblos were and are. Furthermore, these maps represented the pueblos as settlements, as communities; the absence of boundaries suggests that people's construction of ancestral territories may have been, and may still be, fluid, negotiated, even contested. The absence of boundaries suggests a "hybrid indigenous space," one of many lived political geographies 


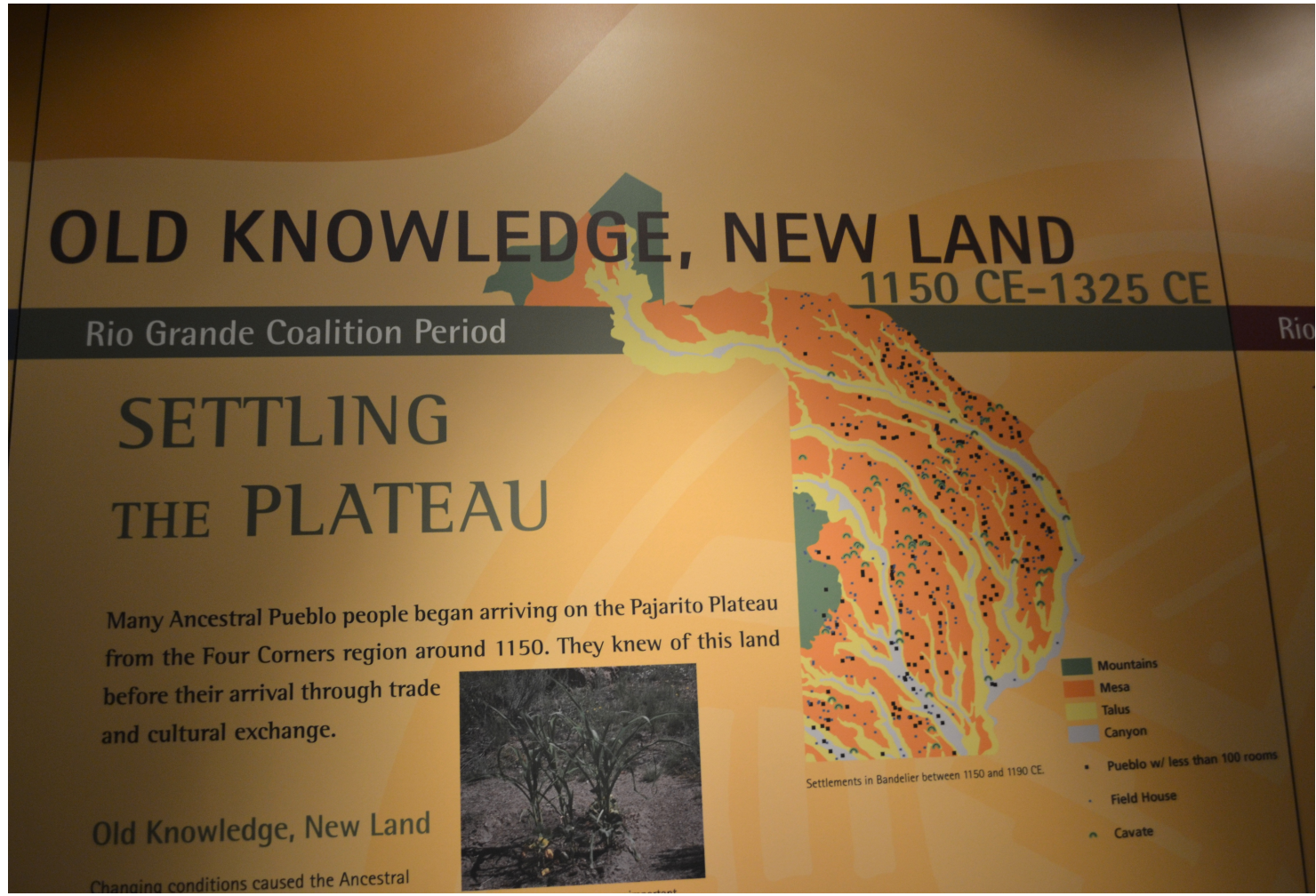

Figure 43. Bandelier museum Rio Grande Coalition Period map. Not visible in photo: pale grey lines representing state boundaries.

constructed under sovereignty (Biolsi, 2005, p. 240). In contrast, Mesa Verde represented the pueblos in terms of the boundaries established and recognized by the federal government in the recent past. Bandelier's representation of pueblo lands may reinforce the notion of the land as common ancestral territory stewarded by the NPS. Such a representation may justify NPS investment in robust consultation and collaboration by emphasizing that descendant peoples belong on this land. Shared authority may be predicated upon shared strategy. 


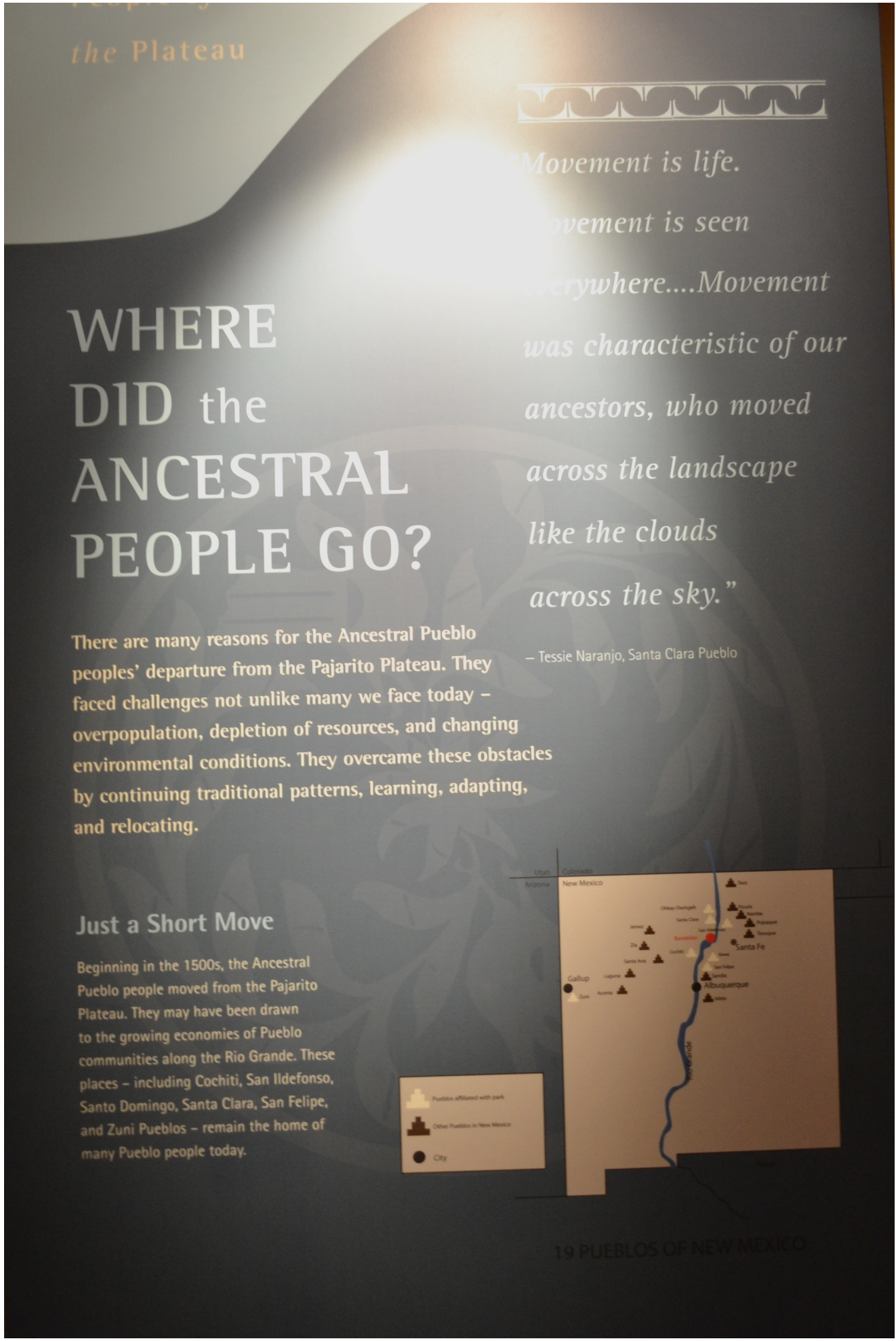

Figure 44. Bandelier museum migration Map. Note the presence of the Rio Grande and markers for the Monument, Albuquerque, Gallup, affiliated Pueblos, and other Pueblos. 
AHC/CANM's main and ancillary exhibit spaces displayed a number of archaeological site plans and historical maps as well as interpretive maps, the majority of which were constructed in terms of states, rivers, and archaeological knowledge: one represented theories of the peopling of the Americas; two used digital photo displays to represent agricultural patterns over time and languages and language groups over space.

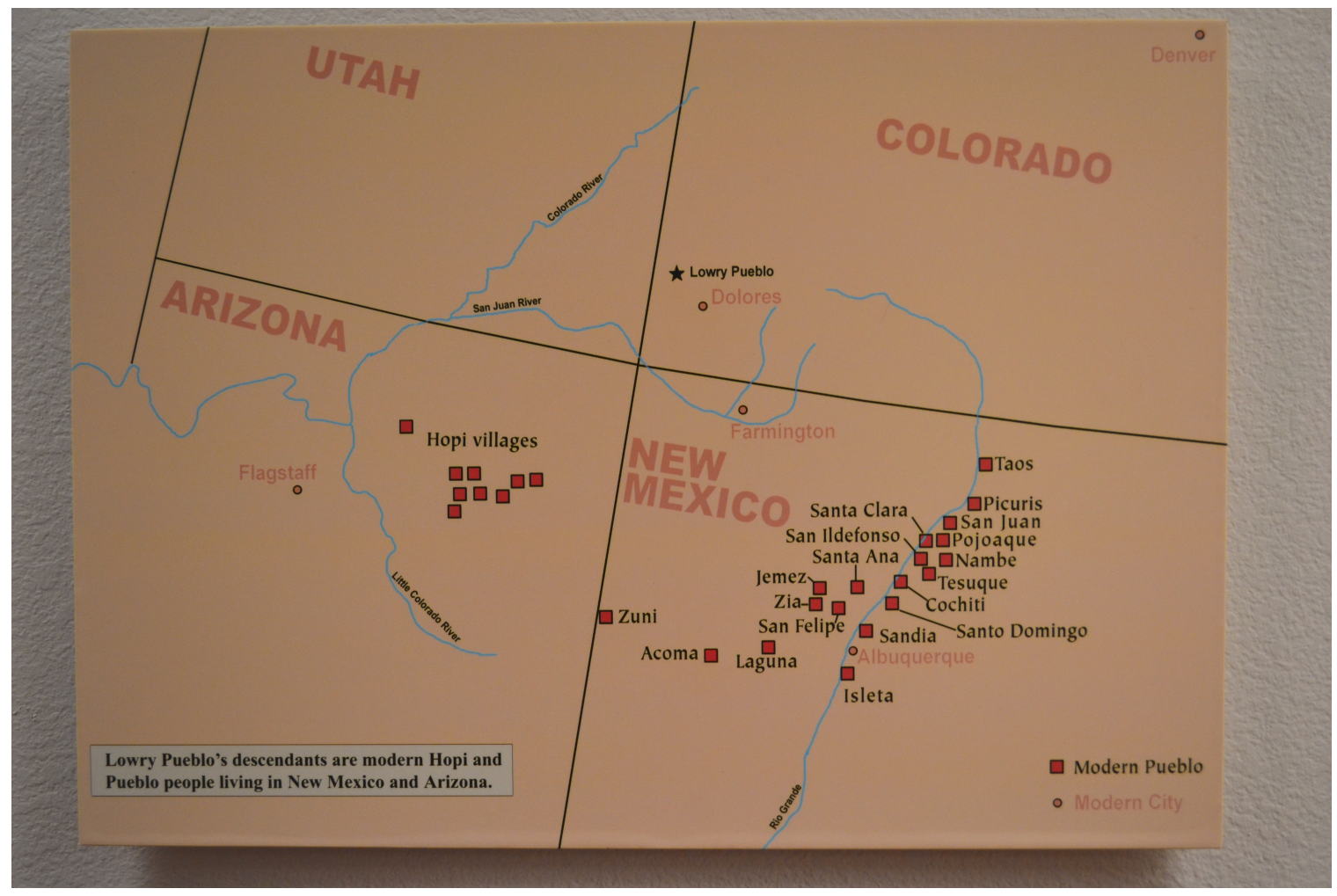

Figure 45. AHC/CANM Lowry Pueblos descendants map, detail of Figure 39, Ancestral Knowledge. Note the presence of rivers, state boundaries, and settlements.

Two others constructed land and trade in terms of Northern San Juan, Chaco, and Kayenta cultures. The wall entitled Ancestral Knowledge displayed a map of contemporary pueblos — showing river systems, pueblos, cities, and only state boundaries (therefore reminiscent of Bandelier's) — amid Native American collaborators' texts and 


\section{CULTURAL CONTINUITY}

Shortly after AD 1280, the last Puebloans left Colorado and moved to New Mexico and Arizona. Some groups founded new settlements; others may have dispersed or joined relatives in southern villages. Oral histories recount a series of migrations en route to a new homeland.

Three centuries later, Spanish explorers found the descendants living in the same regions as today-an arc stretching from the Hopi villages to the Pueblos along the upper Rio Grande.

Many changes took place between AD 1300-1600: Migrating groups settled together as clans, and

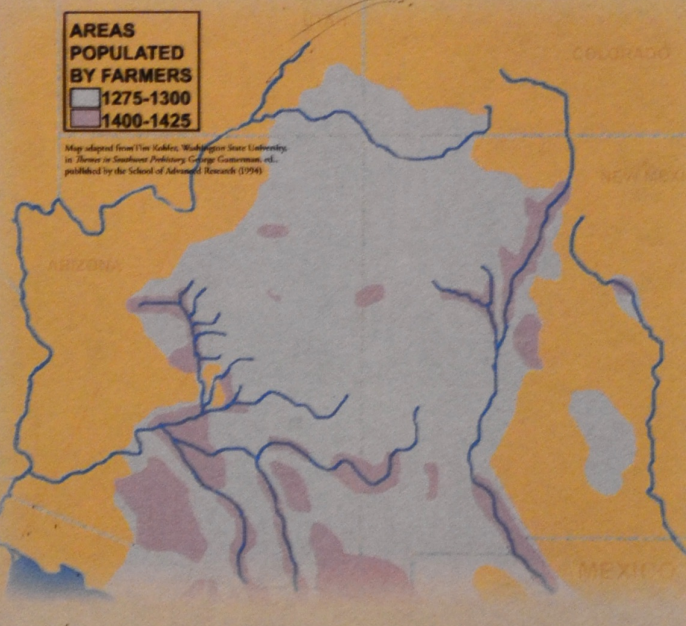
some may have adopted new languages. Villages became larger and more enclosed than they were in earlier times.

Figure 46. AHC/CANM Cultural Continuity map. Note juxtaposition of reduced maps from digital agriculture display in Figure 19 and Lowry Pueblo descendants, from Ancestral Knowledge, Figure 39. 
photos. This same map reappeared twice in the main exhibit, each time re-framed by traditional history. Such a representation privileged cultural knowledge over scientific and historical knowledge, but neither trivialized nor ignored them. The representation contextualizes topography and etic knowledge within traditional knowledge, and so presented the land as a very specific ethnographic landscape as well as a cultural one (Colwell-Chanthaphonh, 2010, p. 330; Basso, 1996, p. 43). In contrast, the archaeologically constructed maps characteristic of conventional museum display —most particularly the culture area map - represent limited, dated, or contested perspectives on Native Americans and native history (Barker, 2010, pp. 299-300; Bennett, 2005, p. 525; Dartt-Newton, 2009, p. 25)

\section{CONCLUSION}

In this final chapter, I examined regimes of representation in order to query authority and the visibility/audibility of Native Americans in the public presentation of archaeology in protected areas: the who, where, when, and how of the stories told to visitors. The overwhelming presence of third-person omniscient narratives suggests that Interpretation generally continues to privilege etic knowledge. The variability of the relative presence of narratives expressly situated in ancient time, the historic era (from 1540, the Entrada de Coronado, to 1999), and the 21 st century may suggest that Interpretation reflects local colonial history and shifting relations of power/knowledge. 


\section{Chapter 6: Conclusion}

\section{META-ANALYSIS OF NARRATIVE CONTENT}

Foucault characterizes the museum as a space of representation (1970, p. 130). Following Foucault, Lord (B. Lord, 2006) reads "representation as the space between things and the ways of conceptualizing them" (2006, p. 5). Potentially, the public presentation of archaeology represents peoples and places as well as things. According to Hall (1996), identity is strategic and political rather than essential, and we construct identity within, not without, representation (1996, pp. 3-4). As Clifford (2001, 2004) repeatedly emphasizes, representation — selected by outsider or insider authority—in museums and heritage sites has significant consequences for the people represented. Representation reflects the positioning of the agents involved, and produces and reproduces relations of power/knowledge (Lawlor, 2006; Lidchi, 1997; Li, 2000).

Following Lidchi (1997), I use discursive formation as "the systematic operation of several discourses or statements constituting a 'body of knowledge', which work together to construct a specific object/topic of knowledge in a particular way, and to limit the other ways in which that object/topic may be constituted" (1997, p. 191); discursive formations change over time (i.e., they are epistemic). First of all, the discursive formation of the museum, of display and representation, frames these five research sites. Natural history museums, anthropology museums, art museums, and science museums exist within a space of representation constructed by the interaction of the disciplines of archaeology, anthropology, art history, history, geology, biology, and education as they

are colored by popular culture, colonialism, and identity (Bennett, 2004, p. 75; Lidchi, 
1997, p. 197). Indeed, Bandelier, Mesa Verde, and AHC/CANM incorporate both physical spaces housing displays explicitly designated as museums and spaces explicitly designated as visitor centers; Petroglyph lacks a museum. At all the sites, brochures and signage mediate visitor experience of the landscape. ${ }^{22}$

Mesa Verde's Chapin Archaeological Museum, for example, displayed a nearly overwhelming number of cased artifacts collected in the region ("Who needs 36 of the same black on white vessel?" one staff member asked me) arranged, labeled, and interpreted to reflect a positivist, evolutionary construction of the site; but the museum also displays also 19th- and 20th-century Euro-American art in a variety of media, as well as artifact replicas, taxidermy, scale models, and miniature dioramas (the "park video" ran in an adjacent assembly room). The VRC displayed a similar range of material: a smaller sample of iconic pottery, contemporary sculpture and painting in the entrance plaza and rotunda, life-size dioramas, touchable replicas, maps instead of taxidermy, and no video. Both included staffed information desks, retail, limited seating, and nearby restrooms; tour tickets were sold at the VRC, and ranger-led activities were observed only at the museum.

Petroglyph, the sole research site with only a visitor center, not only dispensed park information and orientation at the info desk, but also practiced display and

${ }^{22}$ One land manager interviewed in this research characterized the difference between a visitor center and a museum as the difference between information, on one hand, and learning or experience, on the other: a visitor center provides information that enables the visitor to decide what to see, or even whether to see anything at all. I would suggest that in practice and in visitor experience, the distinction between museum and visitor center may be moot, but the distinction between indoors and outdoors on the land is key. 
Interpretation: volunteers curated and rotated a case of ancient and historic material culture and an accessible HD installation showed interpretive videos; this visitor center also included retail, limited seating, and nearby restrooms. Arguably, the mere presence of waysides and trail guides at the relatively undeveloped Nevada sites also situates them within this discursive formation. The waysides and trail guides observed in this research rarely, if ever, presented orientation alone; though they varied in rhetorical strategy, all are inherently representational.

However museum-like these sites may be, all five are located in protected areas. A discursive formation compounded of economic, tourist and recreation, natural resource, Indigenous resource use and land rights, preservation, and conservation discourses frames protected areas (Dearden, 2000; Escobar, 1999; Spence, 1999; Stevens, 2014). The nature / culture divide continues to constrain much environmental discourse. While ranging from anthrocentric to ecocentric perspectives, environmental discourse tends to privilege the physical and life sciences, and regularly construct lands and landscapes in biological, not cultural, terms (Corbett, 2006). Management and Interpretation in protected areas generally reflects the privilege science enjoys. Additionally, the relatively recent emergence of Interpretation as a discipline-itself an articulation of tourism, environmental education, history, and archaeology (Benton, 2009) — links protected area, environmental, and museum discourse.

Furthermore, all five research sites are located on lands constructed differently by different people -- archaeologists, land managers, citizens of affiliated tribes and pueblos, local residents, recreationists, and others, lands whose existence transcends the many 
ways humans may construct them. Discourses of tourism, performance studies, and geography articulate another relevant, though perhaps insufficiently theorized, discursive formation that frames these protected areas. The work of tourism providers and interpretive professionals scripts and structures visitor experience. But despite scripting and guidance, the visitor encounters material culture quite differently on the landscape than in the museum or visitor center. The body and landscape writ large mediate visitor experience possibly even more than the discipline(s) of sight/reading.

Finally, in these five sites, representation of archaeology generally emphasizes the deep time of Native American cultures over the historic time of entanglement, expansion, and Euro-American warfare. The material culture interpreted at these sites was and is Native American, but—as one interviewee emphasized-- Interpretation is generally produced and consumed by members of the dominant culture. Therefore, I situate the public presentation of archaeology within a discursive formation that articulates representation and identity (Clifford, 2001, 2004; Deloria, 1969; Hall, 1999; Mihesuah, 1996). Broad historical shifts key to the episteme of protected area Interpretation of archaeology at these five research sites include the development of reflexive anthropology, indigenous archaeology and multivocal archaeology (Atalay, 2012; Colwell-Chanthaphonh, 2010; Hodder, 2008; Silberman, 2008; Trigger, 2008; Watkins, 2011), late 20th-century Native American political activism and self-representation (e.g., the American Indian Movement and the occupation of Alcatraz, the Determination of Rights and Unity of Menominee Stockholders, the establishment of Native museums and cultural centers), and US legislation and (select) recognition of Native sovereignty. 
Indigenous scholars' significant contributions span these discourses and, to a great extent, shape their formation.

\section{FUTURE WORK}

I definitely take a critical stance in terms of looking at how I portray knowledge to visitors. I want to provide for them the most critical and ethical sort of lens for looking at this place. [I'm] not just throwing a bunch of information at them, but letting them really decide: letting the light bulbs come on, letting them think for themselves and see, yes, it is okay sometimes to question narratives, and it is sometimes okay to say 'Wait a minute. Let's stop and investigate how we have constructed this history.' Right? I think when they do this it's a powerful thing. You know, critical thinking is amazing. Totally.

Veteran interpreter

Throughout this work, I seek to mirror this interpreter's critical stance, specifically to analyze interpretive material in light of four broad themes: the exigencies of protected area management and preservation, representation vs. self-representation, the constructedness of knowledge and its relationship to power, and archaeological epistemology. I inquire into the ways these themes play out, or fail to do so, on the ground of the public presentation of archaeology, in museums and visitor centers and on the landscape. We, as anthropologists no less than as archaeologists, must continue to be mindful of the uses to which the discipline is put (Hodder, 2008; L. Smith, 2004; L. T. Smith, 1999). Given protected areas' increasingly limited capital and interpretive resources, it seems likely that practicing anthropologists and archaeologists may be positioned to forward projects that protected area staff no longer can, to facilitate communication and understanding between protected area staff and interested stakeholders, and to open space for alternative constructions of living lands in the discourse that dominates protected areas. If we can marry theory and practice, we may be 
(Re)Presenting peoples and storied lands

able to, within and because of our own disciplinary ethics, tell better stories and so reach, affect, and teach more people.

This work aims to contribute to the emerging discourse in applied anthropology about connecting heterogeneous individuals with wildly varying agendas —including Native Americans, tourists, historians, anthropologists, archaeologists, museum curators, exhibit designers, media practitioners - with an equally heterogeneous, interested public. I hope to contribute to the creation of opportunities to share knowledge that cut across conventional boundaries of class and culture and between individuals and institutions.

This research will be shared with protected area managers and staff at a state, a county, and a tribal museum. The lessons learned from this research have been directly applied to the site and interpretive development at Black Canyon Archaeological District on the Pahranagat National Wildlife Refuge in Lincoln County, Nevada and will contribute to the U.S. Fish and Wildlife Service's management of the site. By addressing the content of protected area Interpretation, what Interpretation communicates, this work fills a gap in a developing literature generally focused on how and how well Interpretation communicates (Staiff et al., 2002). Additionally, this work contributes to the very small number of qualitative studies seeking to capture visitors' and interpreters' understandings of Interpretation (Hunter, 2012).

The research I conducted indicates that the public presentation of archaeology in the selected protected areas privileged scientific narratives over cultural narratives and management messages, consistent with the privilege science enjoys in contemporary public discourse as well as in protected area Interpretation. However, this research also 
(Re)Presenting peoples and storied lands

identifies an emerging interpretive practice that emphasizes the practice of archaeology, the constructedness of the discipline, and the relevance of cultural and traditional knowledge. Potentially, archaeology is one kind of subjugated knowledge - a "meticulous, erudite, exact historical knowledge" that is "present but disguised within the body" of protected area management. Native American cultural practice may be another subjugated knowledge_- "disqualified... as inadequate ... or insufficiently elaborated ... beneath the required level of cognition or scienticity"(Foucault, 1994, p. 203). Potentially, the union of subjugated knowledges finds expression in the emergence of this multivocal interpretive practice, a practice both theoretical and tactical.

Additionally, my research disclosed that this developing trend aligns with visitors' stated interest in the stories of living peoples and in "how we know what we know" as well as with the way interpreters construct their work. Multivocal interpretive practice has the potential to ameliorate contemporary perceptions of Native Americans and increase knowledge and understanding of contemporary Native culture (Doering et al., 1999). Research strongly suggests that first-person narratives, self-representation, successfully engage the visiting public (Pekarik et al., 1996). Furthermore, selfrepresentation "allow[s] Indians some say" in shaping public discourse (Lyons, 2000, pp. $459,449)$.

My research at these five sites indicated that their Interpretation of archaeology generally favored strategies of representation over self-representation, a distinction that resonates in the literature of museum studies (Ames, 1992; Hedlund, 1994) as well as anthropology (e.g. Nesper, 2003, 2005). The research also indicated that Interpretation 
generally represented entanglement on the basis of written sources to the exclusion of oral and traditional ones, and seldom acknowledged Native American sovereignty and self-determination in Lyons' (2000) sense. Some interpretive material in this research situated Native Americans only in the ancient past; some constructed Native Americans as essentially other, primitive, or passive; and some represented Native Americans as either civilized or victimized by colonialism, rather than thriving through long entanglement. These research sites and their characteristic rhetorical strategies reflect a broad spectrum of practices.

Any study of a museum is, because of disciplinary practices of rotation and curation, an act of archaeology (Bennett, 1995, 2004; Foucault, 1970). Arguably the same is true of interpretive display: protected area staff interviewed in this research emphasized that they generally lack the economic and human capital to keep pace with changes in anthropological thought and even with changes in agency policy. In the future, the public presentation of archaeology in US protected areas may widely and explicitly acknowledge Native Americans' moral right to the ancestral lands that protected areas steward; it may explicitly acknowledge Native Americans' right to self-representation and sovereignty; and it may transcend gestural consultation (L. Smith, 2004; Spoon, Arnold, Hambelton, et al., 2012; Spoon, Arnold, Lefler, \& Milton, 2015) and minimal stakeholder involvement to embrace full collaboration in resource management and interpretive projects. In the future, protected areas may widely represent archaeology as a dynamic practice — culturally situated, contested, and contingent — that can contribute to better stories of the past. In the future, the public presentation of archaeology, adequately 
(Re)Presenting peoples and storied lands

funded and anthropologically informed, may embrace the rich complexity of interpreting storied lands. 


\section{References}

Aarts, B. (Ed.). (2014). The Oxford dictionary of English grammar (2nd ed.). Oxford: Oxford University Press. Retrieved from http://www.oxfordreference.com.proxy.lib.pdx.edu/view/10.1093/acref/97801996 58237.001.0001/acref-9780199658237-e-1051

Ames, M. M. (1992). Cannibal tours and glass boxes: the anthropology of museums. Vancouver: UBC Press.

Ames, M. M. (2003). How to decorate a house: the renegotiation of cultural representations at the University of British Columbia Museum of Anthropology. In L. Peers \& A. K. Brown (Eds.), Museums and source communities: a Routledge reader (pp. 171-180). London: Routledge.

Anderson, B. R. O. (1991). Imagined communities: reflections on the origin and spread of nationalism. London; New York: Verso.

Anschuetz, K. F., Ferguson, T. J., Francis, H., Kelley, K. B., \& Scheick, C. L. (2002). "That place people talk about": The Petroglyph National Monument ethnographic landscape report. Santa Fe: Rio Grande Foundation for Communities and Cultural Landscapes.

Atalay, S. (2006). Indigenous archaeology as decolonizing practice. American Indian Quarterly, 30(3/4), 280-310.

Atalay, S. (2008). Multivocality and Indigenous archaeologies. In J. Habu, C. P. Fawcett, \& J. M. Matsunaga (Eds.), Evaluating Multiple Narratives (pp. 29-44). New York: Springer.

Atalay, S. (2012). Community-based archaeology: research with, by, and for Indigenous and local communities. Berkeley: University of California Press.

Baldick, C. (Ed.). (2015). bricolage. The Oxford Dictionary of Literary Terms (Online version). Oxford University Press. Retrieved from http://www.oxfordreference.com.proxy.lib.pdx.edu/view/10.1093/acref/97801987 15443.001.0001/acref-9780198715443-e-148

Barber, K. (2013). Shared authority in the context of tribal sovereignty: Building capacity for partnerships with Indigenous nations. The Public Historian, 35(4), 20-39.

Barker, A. W. (2010). Exhibiting archaeology: archaeology and museums.(Report). Annual Review of Anthropology, 39, 293-308.

Basso, K. H. (1996). Wisdom sits in places : landscape and language among the Western Apache. Albuquerque: University of New Mexico Press. 
(Re)Presenting peoples and storied lands

Batten, B. (2005). A shared history? Presenting Australia's post-contact Indigenous past. Journal of Interpretation Research, 10(1), 31-48.

Beck, L., \& Cable, T. T. (2002). Interpretation for the 21st century: Fifteen guiding principles for interpreting nature and culture (2nd ed.). Champaign, IL: Sagamore Pub.

Beck, L., \& Cable, T. T. (2011). The gifts of interpretation : fifteen guiding principles for interpreting nature and culture (3rd ed.). Urbana, IL: Sagamore Publishing.

Bennett, T. (1995). The birth of the museum: history, theory, politics. London; New York: Routledge.

Bennett, T. (2004). Pasts beyond memory: Evolution, museums, colonialism. London; New York: Routledge.

Bennett, T. (2005). Civic laboratories: Museums, cultural objecthood and the governance of the social. Cultural Studies, 19(5), 521-547.

Bennett, T., Dibley, B., \& Harrison, R. (2014). Introduction: Anthropology, collecting and colonial governmentalities. History and Anthropology, 25(2), 137-149.

Benton, G. M. (2009). From principle to practice: four conceptions of interpretation. Journal of Interpretation Research, 14(1), 7.

Benton, G. M. (2011). Visitor perceptions of cultural resource management at three National Park Service sites. Visitor Studies, 14(1), 84-99.

Berkes, F., \& Turner, N. J. (2006). Knowledge, learning and the evolution of conservation practice for social-ecological system resilience. Human Ecology, 34(4), 479-494.

Bernard, H. R. (2011). Research Methods in Anthropology (5th ed.). Lanham, Md.: AltaMira Press.

Biolsi, T. (2005). Imagined geographies: Sovereignty, Indigenous space, and American Indian struggle. American Ethnologist, 32(2), 239-259.

Boast, R. (2011). Neocolonial collaboration: Museum as Contact Zone revisited. Museum Anthropology, 34(1), 56-70.

Bowechop, J., \& Erikson, P. P. (2005). Forging indigenous methodologies on Cape Flattery: The Makah Museum as a center of collaborative research. The American Indian Quarterly, 29(1), 263-273. 
(Re)Presenting peoples and storied lands

Brady, M. J. (2008). Governmentality and the National Museum of the American Indian: Understanding the Indigenous museum in a settler society. Social Identities, 14(6), 763-773.

Brady, M. J. (2011). Mediating Indigenous voice in the museum: Narratives of place, land, and environment in new exhibition practice. Environmental Communication: A Journal of Nature and Culture, 5(2), 202-220.

Bricolage, n. (2015, December). OED Online. Oxford University Press. Retrieved from http://www.oed.com.proxy.lib.pdx.edu/view/Entry/261904?redirectedFrom=brico lage ;

Bryman, A. (2012). Social research methods (4th ed.). Oxford; New York: Oxford University Press.

Buchanan, I. (2016). bricolage. A dictionary of critical theory (Online version). Oxford University Press. Retrieved from http://www.oxfordreference.com.proxy.lib.pdx.edu/view/10.1093/acref/97801995 32919.001.0001/acref-9780199532919-e-99?rskey=hcXw4T\&result=5

Bureau of Land Management. (2004, December 3). 8100-The Foundations for Managing Cultural Resources. Retrieved from http://www.blm.gov/style/medialib/blm/wo/Planning_and_Renewable_Resources/ coop_agencies/cr_publications.Par.44865.File.dat/Binder2-2.pdf

Bureau of Land Management. (2012, January 26). The Bureau of Land Management: Who We Are, What We do. Retrieved March 20, 2016, from http://www.blm.gov/wo/st/en/info/About_BLM.html

Calhoun, C. J. (2002). Incorporation, n. Dictionary of the social sciences. Oxford: Oxford University Press. Retrieved from http://www.oxfordreference.com.proxy.lib.pdx.edu/view/10.1093/acref/97801951 23715.001.0001/acref-9780195123715-e-810

Carr, A. (2004). Mountain places, cultural spaces: The interpretation of culturally significant landscapes. Journal of Sustainable Tourism, 12(5), 432-459.

Clifford, J. (1988). The predicament of culture: Twentieth-century ethnography, literature, and art. Cambridge, Mass: Harvard University Press.

Clifford, J. (1997). Museums as contact zones. In Routes: Travel and translation in the late twentieth century. Cambridge, Mass.: Harvard University Press.

Clifford, J. (2001). Indigenous articulations. Contemporary Pacific, 13(2), 468-490. 
(Re)Presenting peoples and storied lands

Clifford, J. (2004). Looking several ways: Anthropology and Native heritage in Alaska. Current Anthropology (Chicago), 45(01), 5-30.

Clifford, J., Marcus, \& Fortun, K. (2010). Writing culture: The poetics and politics of ethnography (25th anniversary ed. / with a foreword by Kim Fortun.). Berkeley, Calif: University of California Press.

Colwell-Chanthaphonh, C. (2010). Living histories: Native Americans and Southwestern archaeology. Lanham, Md.: AltaMira Press.

Colwell-Chanthaphonh, C., \& Ferguson, T. J. (2006). Memory pieces and footprints: Multivocality and the meanings of ancient times and ancestral places among the Zuni and Hopi. American Anthropologist, 108(1), 148-162.

Colwell-Chanthaphonh, C., Ferguson, T. J. (2008). Collaboration in archaeological practice: Engaging descendant communities. Lanham, Md.: AltaMira Press.

Colwell-Chanthaphonh, C., \& Ferguson, T. J. (2010). Intersecting magisteria: Bridging archaeological science and traditional knowledge. Journal of Social Archaeology, 10(3), 325-346.

Colwell-Chanthaphonh, C., Ferguson, T. J., Lippert, D., McGuire, R. H., Nicholas, G. P., Watkins, J. E., \& Zimmerman, L. J. (2010). The premise and promise of indigenous archaeology. American Antiquity, 75(2).

Conaty, G. T. (2003). Glenbow's Blackfoot gallery: working towards co-existence. In L. Peers \& A. K. Brown (Eds.), Museums and source communities: A Routledge reader (pp. 227-242). London: Routledge.

Corbett, J. B. (2006). Communicating nature: How we create and understand environmental messages. Washington, DC: Island Press.

Cronon, W. (1996). Uncommon ground: rethinking the human place in nature. New York: WWNorton \& Co.

Dartt-Newton, D. (2009). Negotiating the Master Narrative: Museums and the Indian/Californio Community of California's Central Coast. University of Oregon. Retrieved from https://scholarsbank.uoregon.edu/xmlui/handle/ $1794 / 9926$

Dartt-Newton, D. (2011). California's Sites of Conscience: An Analysis of the State's Historic Mission Museums. Museum Anthropology, 34(2), 97-108.

Darvill, T. (2007). Research frameworks for World Heritage Sites and the conceptualization of archaeological knowledge. World Archaeology, 39(3), 436457. 
(Re)Presenting peoples and storied lands

Dearden, P. (2000). Tourism, national parks and resource conflicts. In R. W. Butler \& S. W. Boyd (Eds.), Tourism and national parks: Issues and implications. (pp. 187-202). Chichester: Wiley.

Deloria, V. (1969). Custer died for your sins: An Indian manifesto. New York, NY: Macmillan Company.

Denzin, N. K. (2005). Indians in the park. Qualitative Research QR., 5(1), 9-33.

Dickinson, E. (2012). (Re)appropriating The Petroglyphs: Commercial representations of a cultural landscape. Journal of Consumer Culture, 12(2), 117-136.

Dilworth, L. (1996). Imagining Indians in the Southwest: Persistent visions of a primitive past. Washington: Smithsonian Institution Press.

Doering, Z. D. (1999). Strangers, guests, or clients? Visitor experiences in museums. Curator: The Museum Journal, 42(2), 74-87.

Doering, Z. D., DiGiacomo, K. R., \& Pekarik, A. J. (1999). Images of Naive Americans. Curator: The Museum Journal, 42(2).

Dove, M. R., Smith, D. S., Campos, M. T., Mathews, A. S., Rademacher, A., Rhee, S., \& Yoder, L. M. (2007). Globalisation and the construction of western and nonwestern knowledge. In P. Sillitoe (Ed.), Local science vs. global science: approaches to indigenous knowledge in international development. Berghahn, New York (pp. 129-154).

Duncan, G. S., \& Martin, S. R. (2002). Comparing the effectiveness of interpretive and sanction messages for influencing wilderness visitors' intended behavior. International Journal of Wilderness, 8(2), 20-25.

Dustin, D. L., Schneider, I. E., Mcavoy, L. H., \& Frakt, A. N. (2002). Cross-Cultural Claims on Devils Tower National Monument: A Case Study. Leisure Sciences, 24(1), 79-88.

Duval, M., \& Smith, B. (2013). Rock art tourism in the uKhahlamba/Drakensberg World Heritage Site: Obstacles to the development of sustainable tourism. Journal of Sustainable Tourism, 21(1), 134-153.

Ellenbogen, K. M., \& Luke, J. J. (2004). Family learning research in museums: An emerging disciplinary matrix? Science Education, 88(4), S48-S58.

Erikson, P. P. (2003). Welcome to this house: A century of Makah people honoring identity and negotiating cultural tourism. Ethnohistory, 50(3), 523-547. 
(Re)Presenting peoples and storied lands

Escobar, A. (1999). After nature: Steps to an antiessentialist political ecology. Current Anthropology, 40(1), 1-30.

Ethnography, n. (2016, March). OED Online. Oxford University Press. Retrieved from http://www.oed.com.proxy.lib.pdx.edu/view/Entry/64809;jsessionid=100EAB311 6A18EC2B998E84BBA6887AE?redirectedFrom=ethnography\#eid

Falk, J. (2004). The director's cut: Toward an improved understanding of learning from museums. Science Education, 88(4), S83-S96.

Farmer, J., \& Knapp, D. (2008). Interpretation programs at a historic preservation site A mixed methods study of long-term impact. Journal of Mixed Methods Research, 2(4), 340-361.

Fawcett, C., Habu, J., \& Matsunaga, J. M. (2008). Introduction: Evaluating multiple narratives: Beyond nationalist, colonialist, imperialist archaeologies. In Evaluating Multiple Narratives (pp. 1-11). New York: Springer.

Fine-Dare, K. S. (2002). Grave injustice: The American Indian repatriation movement and NAGPRA. Lincoln: University of Nebraska Press.

Fine, K. (1988). The politics of "Interpretation" at Mesa Verde National Park. Anthropological Quarterly, 61(4), 177-186.

Foley, D. E. (2002). Critical ethnography: The reflexive turn. International Journal of Qualitative Studies in Education, 15(4), 469-490.

Foucault, M. (1970). The order of things: An archaeology of the human sciences. London: Tavistock.

Foucault, M. (1979). Discipline and punish: The birth of the prison. New York: Vintage Books.

Foucault, M. (1980). Power/knowledge: Selected interviews and other writings, $1972-$ 1977 (C. Gordon, Ed.). (C. Gordon, Ed., C. Gordon, L. Marshall, J. Mepham, \& K. Soper, Trans.). New York: Pantheon Books.

Foucault, M. (1994). Two Lectures. In N. B. Dirks, G. Eley, \& S. B. Ortner (Eds.), Culture/Power/History: A reader in contemporary social theory (pp. 200-221). Princeton: Princeton University Press.

Garibaldi, A., \& Turner, N. (2004). Cultural Keystone Species: Implications for Ecological Conservation and Restoration. Ecology and Society, 9(3), 1. 
(Re)Presenting peoples and storied lands

Glass, A. (2009). A cannibal in the archive: Performance, materiality, and (in)visibility in unpublished Edward Curtis photographs of the Kwakw a k a “wakw Hamat"sa. Visual Anthropology Review, 25(2), 128-149.

Goffman, E. (1959). The presentation of self in everyday life. Garden City, NY: Doubleday.

Gonzalez, S. L., Modzelewski, D., Panich, L. M., \& Schneider, T. D. (2006). Archaeology for the seventh generation. American Indian Quarterly, 30(3-4), $388-415$.

Gough, M. (2008). The changing relationship between First Nations people and

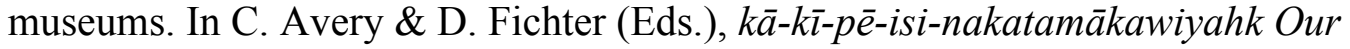
Legacy: Essays (pp. 205-231). Saskatoon: University of Saskatchewan.

Graburn, N. H. (1983). The anthropology of tourism. Annals of Tourism Research, 10(1), 9-33.

Habu, J., Fawcett, C. P., \& Matsunaga, J. M. (2008). Evaluating multiple narratives: Beyond nationalist, colonialist, imperialist archaeologies. New York: Springer.

Hall, S. (1996). Modernity: An introduction to modern societies. Cambridge, Mass.: Blackwell.

Hall, S. (1999). Un-settling "the heritage", re-imagining the post-nation: Whose heritage? Third Text, 13(49), 3-13.

Hall, S., Critcher, C., Jefferson, T., Clarke, J., \& Roberts, B. (1978). Policing the crisis: Mugging, the state, and law and order. London and Basingstoke: Macmillan.

Hall, S., \& Gieben, B. (1992). Formations of modernity. Oxford: Polity; Open University.

Hall, S., Held, D., \& McGrew, A. G. (1992). Modernity and its futures. Cambridge: Polity; Open University.

Ham, S. H. (1992). Environmental interpretation: A practical guide for people with big ideas and small budgets. Golden, Colorado: North American Press.

Ham, S. H. (2009). From interpretation to protection: Is there a theoretical basis? Journal of Interpretation Research, 14(2), 49.

Hedlund, A. L. (1994). Speaking for or about others? Evolving ethnological perspectives. Museum Anthropology, 18(3), 32-43. 
(Re)Presenting peoples and storied lands

Hibbard, M., Lane, M. B., \& Rasmussen, K. (2008). The split personality of planning: Indigenous peoples and planning for land and resource management. Journal of Planning Literature, 23(2), 136-151.

Hodder, I. (1999). The archaeological process: An introduction. Wiley-Blackwell.

Hodder, I. (2008). Multivocality and social archaeology. In J. Habu, C. P. Fawcett, \& J. M. Matsunaga (Eds.), Evaluating multiple narratives (pp. 196-200). New York: Springer.

Hughes, M., \& Saunders, A. M. (2005). Interpretation, activity participation, and environmental attitudes of visitors to Penguin Island, Western Australia. Society and Natural Resources, 18(7), 611-624.

Hunter, J. E. (2012). Towards a cultural analysis: The need for ethnography in interpretation research. Journal of Interpretation Research, 17(2), 47.

Incorporation, n. (2015, December). OED Online. Oxford: Oxford University Press. Retrieved from http://www.oed.com.proxy.lib.pdx.edu/view/Entry/93966?redirectedFrom=incorp oration

Jamal, T., \& Hill, S. (2004). Developing a framework for indicators of authenticity: The place and space of cultural and heritage tourism. Asia Pacific Journal of Tourism Research, 9(4), 353-372.

King, L. (2011). Speaking sovereignty and communicating change: Rhetorical sovereignty and the inaugural exhibits at the NMAI. American Indian Quarterly, 35(1), 75-103.

Knudson, D. M., Cable, T. T., \& Beck, L. (2003). Interpretation for the 21 st century. State College, PA: Venture.

Krmpotich, C., \& Anderson, D. (2005). Collaborative exhibitions and visitor reactions: The case of Nitsitapiisinni: Our way of life. Curator: The Museum Journal, 48(4), 377-405.

Lahoff, R. E. (2013). The search for interpretation sovereignty: Accommodating Nuwuvi (Southern Paiute) voice in protected area Interpretation (MA). Portland State University, Portland, Oregon. Retrieved from http://pdxscholar.library.pdx.edu/ cgi/viewcontent.cgi?article $=1005 \&$ context $=$ anth_grad

Lane, M. B. (2010). Affirming new directions in planning theory: Comanagement of protected areas. Society and Natural Resources, 14, 657-671. 
(Re)Presenting peoples and storied lands

Larsen, J., \& Urry, J. (2011). Gazing and performing. Environment \& Planning D: Society \& Space, 29(6), 1110-1125.

Lassiter, L. E. (2000). Authoritative texts, collaborative ethnography, and Native American studies. The American Indian Quarterly, 24(4), 601.

Lassiter, L. E. (2005). Collaborative ethnography and public anthropology. Current Anthropology, 46(1), 83-106.

Lawlor, M. (2006). Public Native America: Tribal self-representations in casinos, museums, and powwows. New Brunswick, NJ: Rutgers University Press.

Lidchi, H. (1997). The poetics and politics of representing other cultures. In S. Hall (Ed.), Representation: Cultural Representation and Signifying Practices (pp. 151-222). London: Sage Publications.

Li, T. M. (2000). Articulating Indigenous Identity in Indonesia: Resource Politics and the Tribal Slot. Comparative Studies in Society and History, 42(1), 149-179.

Little, B. J., \& Amdur-Clark, N. (2008). 23. Archeology and civic engagement. Retrieved March 1, 2016, from http://digitalcommons.unl.edu/natlpark/100/

Littlefair, C., \& Buckley, R. (2008). Interpretation reduces ecological impacts of visitors to world heritage site. AMBIO: A Journal of the Human Environment, 37(5), 338341.

Lonetree, A. (2007). Missed opportunities: Reflections on the NMAI. American Indian Quarterly, 30, 632-4), p.632-645.

Lonetree, A. (2012). Decolonizing museums Representing Native America in national and tribal Museums. Chapel Hill: The University of North Carolina Press.

Longacre, W. A. (2000). Exploring Prehistoric Social and Political Organization in the American Southwest. Journal of Anthropological Research, 56(3), 287-300.

Lord, A. B. (1960). The singer of tales. Cambridge, Harvard University Press.

Lord, B. (2006). Foucault s museum: difference, representation, and genealogy. Museum and Society, 4(1), 1-14.

Lyons, S. R. (2000). Rhetorical sovereignty: What do American Indians want from writing? College Composition and Communication, 51(3), 447-468.

MacCannell, D. (1973). Staged authenticity: Arrangements of social space in tourist settings. American Journal of Sociology, 589-603. 
(Re)Presenting peoples and storied lands

MacCannell, D. (1976). The tourist: A new theory of the leisure class. Schocken Books.

MacCannell, D. (2001). Tourist agency. Tourist Studies, 1(1), 23-37.

Martindale, A., \& Marsden, S. (2003). Defining the Middle Period (3500 BP to 1500 BP) in Tsimshian history through a comparison of archaeological and oral records. $B C$ Studies, 2003(138/139).

Martindale, A., \& Nicholas, G. P. (2014). Archaeology as Federated Knowledge. Canadian Journal of Archaeology, 38(2), 434-465.

Maziarski, A. (2012). A city, asleep: Revisiting and reevaluating history and Interpretation at Mesa Verde National Park. Columbia University in the City of New York. Retrieved from http://academiccommons.columbia.edu/ catalog/ac: 174674

Meyer, J. L. (1996). The spirit of Yellowstone: The cultural evolution of a national park. Lanham, Md: Rowman \& Littlefield.

Mihesuah, D. A. (1996). American Indians: Stereotypes and realities. Atlanta, Georgia: Clarity Press, Inc.

Miles, M. B., \& Huberman, A. M. (1994). Qualitative data analysis: An expanded sourcebook. Thousand Oaks: Sage.

Miller, M. (2008). The Timbisha Shoshone and the national park idea: Building toward accommodation and acknowledgment at Death Valley National Park, 1933-2000. Journal of the Southwest, 50(4), 415-445.

Morse, J. M., \& Niehaus, L. (2009). Mixed method design: Principles and procedures. Walnut Creek, Calif: Left Coast Press.

Nabokov, P. (2002). A forest of time: American Indian ways of history. New York: Cambridge University Press.

National Association for Interpretation. (n.d.). What is Interpretation? Retrieved March 20, 2016, from http://www.interpnet.com/NAI/interp/About/ About_Interpretation/nai/_About/what_is_interp.aspx?hkey=53b0bfb4-74a6-4cfc8379-1d55847c2cb9

National Park Service. (2006). Management Policies 2006. U.S. Government Printing Office. Retrieved from http://www.nps.gov/policy/mp2006.pdf

National Park Service. (n.d.-a). Mesa Verde National Park, Colarado. Retrieved March 20, 2016, from http://www.nps.gov/meve/index.htm 
(Re)Presenting peoples and storied lands

National Park Service. (n.d.-b). Our Mission. Retrieved March 27, 2016, from http://www.nps.gov/aboutus/index.htm

National Park Service, I. D. P. (2007, March 1). Foundations of Interpretation Curriculum Content Narrative: Types of Interpretation. Retrieved March 20, 2016, from http://www.nps.gov/idp/interp/101/FoundationsCurriculum.pdf

National Park Service, I. D. P. (n.d.-c). Interpretive Talk: Themes, Goals, and Objectives (Module 103). Retrieved March 20, 2016, from http://www.nps.gov/ idp/interp/103/tgos.htm

National Park Service Visitor Use Statistics. (2016, January 27). Retrieved March 20, 2016, from https://irma.nps.gov/Stats/

National Register Bulletin: Guidelines for Evaluating and Documenting Traditional Cultural Properties. (1998). Retrieved March 25, 2016, from https://www.nps.gov/nr/publications/bulletins/pdfs/nrb38.pdf

Nesper, L. (2003). Simulating culture: Being Indian for the tourists in Lac du Flambeau's Wa-Swa-Gon Indian Bowl. Ethnohistory, 50(3), 447-472.

Nesper, L. (2005). Historical ambivalence in a tribal museum. Museum Anthropology, $28(2), 1-16$.

Ortiz, A. (1969). The Tewa world: space, time, being, and becoming in a Pueblo society. Chicago: The University of Chicago Press.

Peers, L. (2007). Playing ourselves: interpreting Native histories at historic reconstructions. Lanham, MD: AltaMira Press.

Peers, L., \& Brown, A. K. (2003). Museums and source communities: A Routledge reader. London: Routledge.

Pekarik, A. J., \& Mogel, B. (2010). Ideas, objects, or people? A Smithsonian exhibition team views visitors anew. Curator: The Museum Journal, 53(4), 465-482.

Pekarik, A. J., Ziebarth, E. K., \& Doering, Z. D. (1996). Connecting with Native voices: Visitor Impressions of the George Gustav Heye Center, Nation Museum of the American Indian (Institutional Studies No. 96-1) (p. 92). Washington DC: Smithsonian Institution.

Phillips, R. B. (2003). Community collaboration in exhibitions: Toward a dialogic paradigm: Introduction. In L. Peers \& A. K. Brown (Eds.), Museums and source communities: A Routledge reader (pp. 155-170). London: Routledge. 
(Re)Presenting peoples and storied lands

Phillips, R. B. (2005). Re-placing objects: Historical practices for the second museum age. The Canadian Historical Review, 86(1), 83-110.

Pike, K. L. (1967). Language in relation to a unified theory of the structure of human behavior, $(2 \mathrm{~d}$, rev. ed.). The Hague, Mouton.

Powell, R. B., \& Ham, S. H. (2008). Can ecotourism interpretation really lead to proconservation knowledge, attitudes and behaviour? Evidence from the Galapagos Islands. Journal of Sustainable Tourism, 16(4), 467-489.

Powell, R. B., \& Stern, M. J. (2013). Is it the program or the interpreter? Modeling the influence of program characteristics and interpreter attributes on visitor outcomes. Journal of Interpretation Research, 18(2), 9-43.

Pratt, M. L. (1991). Arts of the contact zone. Profession, 33-40.

Preucel, R. W., \& Mrozoski (Eds.). (2010). Contemporary archaeology in theory: The new pragmatism (2nd ed.). Chichester: Wiley-Blackwell.

Raheja, M. H. (2007). Reading Nanook's smile: Visual sovereignty, Indigenous revisions of ethnography, and Atanarjuat (The Fast Runner). American Quarterly, 59(4), 1159-85.

Raheja, M. H. (2011). Reservation reelism redfacing, Visual sovereignty, and representations of Native Americans in film. Lincoln: University of Nebraska Press.

Rose, N. S. (1996). Identity, genealogy, history. In S. Hall \& P. Du Gay (Eds.), Questions of cultural identity (pp. 128-150). London; Thousand Oaks: Sage Publications.

Rose, N. S. (1999). Powers of freedom: Reframing political thought. Cambridge, United Kingdom ; New York, NY: Cambridge University Press.

Schelhas, J. (2010). The U.S. national parks in international perspective: The Yellowstone Model or conservation syncretism? In G. Polisciano \& O. Farina (Eds.), National parks: Vegetation, wildlife and threats. New York: Nova Science Publishers.

Schultz, L. (2011). Collaborative museology and the visitor. Museum Anthropology, $34(1), 1-12$.

Silberman, N. A. (2008). Virtual Viewpoints: Multivocality in the Marketed Past? In J. Habu, C. P. Fawcett, \& J. M. Matsunaga (Eds.), Evaluating Multiple Narratives (pp. 138-143). New York: Springer.

Simon, N. (2010). The participatory museum. Santa Cruz, Calif: Museum 20. 
(Re)Presenting peoples and storied lands

Skibins, J. C., Powell, R. B., \& Stern, M. J. (2012). Exploring empirical support for interpretation's best practices. Journal of Interpretation Research, 17(1), 25-44.

Smith, L. (2004). Archaeological theory and the politics of cultural heritage. London; New York: Routledge.

Smith, L. (2006). Uses of heritage. London; New York: Routledge.

Smith, L. T. (1999). Decolonizing methodologies: Research and Indigenous peoples. London; New York: Zed Books; Dunedin, NZ.

Smith, L., \& Waterton, E. (2009). Heritage, communities and archaeology. London: Duckworth.

Spence, M. D. (1999). Dispossessing the wilderness: Indian removal and the making of the national parks. New York: Oxford University Press.

Spoon, J. (2014). Quantitative, qualitative, and collaborative methods: approaching indigenous ecological knowledge heterogeneity. Ecology and Society, 19(3).

Spoon, J., \& Arnold, R. (2012). Collaborative research and co-learning: Integrating Nuwuvi (Southern Paiute) ecological knowledge and spirituality to revitalize a fragmented land. Journal for the Study of Religion, Nature \& Culture, 6(4), 477500 .

Spoon, J., Arnold, R., Hambelton, K., \& Nuwuvi Working Group. (2012). Consultation handbook: Nuwuvi (Southern Paiute), the Spring Mountains National Recreation Area and the Desert National Wildlife Refuge Complex. Portland, Oregon: The Mountain Institute and Portland State University.

Spoon, J., Arnold, R., Lefler, B., \& Milton, C. (2015). Nuwuvi (Southern Paiute), shifting fire regimes, and the Carpenter One Fire in the Spring Mountains National Recreation Area, Nevada. Journal of Ethnobiology, 35(1), 85-110.

Spoon, J., Arnold, R., \& Nuwuvi Working Group. (2011). Nuwu Kanee, Nuwu Tooveenup (Our home, our story): Nuwuvi (Southern Paiute) and the Spring Mountains. Portland, Oregon: Portland State University and the Mountain Institute.

Spoon, J., Arnold, R., \& Nuwuvi Working Group. (2012). Nuwu-vots (Our footprints): Nuwuvi (Southern Paiute) and the Pahranagat Valley. Portland, Oregon: The Mountain Institute and Portland State University.

Spoon, J., Arnold, R., \& Nuwuvi Working Group. (2014). The voices of the rocks sing through us: Nuwuvi (Southern Paiute) and Black Canyon. Portland, Oregon: The Mountain Institute and Portland State University. 
(Re)Presenting peoples and storied lands

Spoon, Jeremy. (2013). Different ways of knowing, shared goals: Applied sustainability projects in the Himalyas and Great Basin. In V. Dujon, J. Dillard, \& E. M. Brennan (Eds.), Social sustainability: A multilevel approach to social inclusion. Routledge.

Spoon, J., Melham, J., \& Arnold, R. (2015). Interpretive and public use site plan for the Black Canyon Archaeological District, Pahranagat National Wildlife Refuge, Desert National Wildlife Refuge Complex, Nevada. Portland, Oregon: The Mountain Institute, Portland State University, and Alta Planning and Design.

Staiff, R., Bushell, R., \& Kennedy, P. (2002). Interpretation in national parks: Some critical questions. Journal of Sustainable Tourism, 10(2), 97-113.

Stern, M. J., \& Powell, R. B. (2013). What Leads to Better Visitor Outcomes in Live Interpretation? Journal of Interpretation Research, 18(2), 9-43.

Stern, M. J., Powell, R. B., McLean, K. D., Martin, E., Thomsen, J. M., \& Mutchler, B. A. (2013). The Difference Between Good Enough and Great: Bringing Interpretive Best Practices to Life. Journal of Interpretation Research, 18(2), 79100.

Stevens, S. (2014). Indigenous peoples, national parks, and protected areas: A new paradigm linking conservation, culture, and rights. University of Arizona Press.

Strickland-Munro, J., \& Moore, S. (2013). Indigenous involvement and benefits from tourism in protected areas: a study of Purnululu National Park and Warmun Community, Australia. Journal of Sustainable Tourism, 21(1), 26-41.

Survant, C., \& Spoon, J. (2015). Comparative Study of Similar Sites. In Interpretive and public use site plan for the Black Canyon Archaeological District, Pahranagat National Wildlife Refuge, Desert National Wildlife Refuge Complex, Nevada. Portland, Oregon: The Mountain Institute, Portland State University, and Alta Planning and Design.

Thomas, D. H. (1985). The archaeology of Hidden Cave, Nevada. New York: American Museum of Natural History.

Tilden, F. (2007). Interpreting our heritage. (R. B. Craig, Ed.) (4th ed., expanded and updated.). Chapel Hill: University of North Carolina Press.

Trigger, B. G. (1984). Alternative archaeologies: Nationalist, colonialist, imperialist. Man, 19(3), 355-370.

Trigger, B. G. (2006). A history of archaeological thought (2nd ed.). Cambridge England; New York: Cambridge University Press. 
(Re)Presenting peoples and storied lands

Trigger, B. G. (2008). “Alternative Archaeologies” in historical perspective. In J. Habu, C. P. Fawcett, \& J. M. Matsunaga (Eds.), Evaluating Multiple Narratives (pp. 187-195). New York: Springer.

Tschauner, H. (1996). Middle-range theory, behavioral archaeology, and postempiricist philosophy of science in archaeology. Journal of Archaeological Method and Theory, 3(1), 1-30.

Turner, N. J., \& Berkes, F. (2006). Developing resource management and conservation. Human Ecology, 34(4), 475-478.

Urry, J. (1992). The Tourist Gaze 'revisited.’. American Behavioral Scientist, 36(2), 172186.

Urry, J. (2003, December 6). Globalising the tourist gaze. Retrieved February 26, 2016, from http://www.comp.lancs.ac.uk/sociology/papers/Urry-Globalising-theTourist-Gaze.pdf

U.S. Department of the Interior, B. of L. M. (2015, June 12). Grimes Point Archaeological Area. Retrieved March 25, 2016, from http://www.blm.gov/nv/ st/en/fo/carson_city_field/blm_programs/recreation/grimes_point.html

Vansina, J. (1985). Oral tradition as history. Madison, Wis: University of Wisconsin Press.

Watkins, J. (2011). Indigenous archaeology as complement to, not separate from, scientific archaeology. Jangwa Pana, 10(1), 46-62.

Wendel, K. L. (2014). Lifeblood of the earth: Nuwuvi (Southern Paiute) hydrological knowledge and perceptions of restoration in two Southern Nevada protected areas (MS). ProQuest Dissertations Publishing.

West, P., \& Brockington, D. (2006). An anthropological perspective on some unexpected consequences of protected areas. Conservation Biology, 20(3), 609-616.

White, D. D., Virden, R. J., \& Cahill, K. L. (2005). Visitor experiences in National Park Service cultural sites in Arizona: Implications for interpretive planning and management. Journal of Park and Recreation Administration, 23(3). 


\section{Appendix A: Recommendations and Lessons Learned}

This research was undertaken as part of the Interpretive and Public Use Site Plan for the Black Canyon Archaeological District (Spoon, Melham, et al., 2015) on the Pahranagat National Wildlife Refuge, Desert National Wildlife Refuge Complex, Nevada, produced by principal investigators Dr. Jeremy Spoon of Portland State University and The Mountain Institute and Richard Arnold of the Pahrump Paiute Tribe and The Mountain Institute for the U.S. Fish and Wildlife Service (FWS). The following material represents an expanded treatment of the recommendations presented to the U.S. Fish \& Wildlife Service and stakeholders in December of 2103 and included in Spoon, Melham et al 2015.

\section{RECOMMENDATIONS}

Presenting Information

- Update interpretive signage and brochures regularly

- Keep trail guides readily available and free

- Use technology to layer and reiterate interpretive content

Stewarding Sites

- Utilize personal Interpretation as fully as possible

- Explore electronic media as a stand-in for personal Interpretation

- Appropriately repair or restore damaged cultural resources

- Put a human face on losses due to looting and vandalism

- Minimize Interpretation featuring outdated practices in archaeology

\section{Engaging Visitors}

- Encourage independent discovery on the land

- Present contemporary people in color photographs, video, and audio

- Design exhibits that elicit visitors' intellectual, imaginative, and embodied participation, in addition to visitor choice in display and touchable objects

- Consider implementing display that constructs knowledge, poses questions, and incorporates visitor feedback; possible media include post-it notes, bulletin boards, card readers or copiers for uploading or duplicating visitors' photos, social media

- Explore innovative solutions to accessibility challenges, especially those that do not require the visitor to ask for, or wait for staff to offer, accommodations

- Commission three-dimensional art and installations, music, and poetry

- Engage cultural demonstrators as often as possible 
- Consider challenging representational convention: incorporate evocative, contemporary illustration styles

- If iconic artists' renderings are used as site signatures, update them regularly to reflect changes in archaeological and ethnographic knowledge; illustrate traditional lifeways with line drawings

- When early ethnographic images must be used, clearly label them as such and disclose the circumstances of the photo's making

- Consider carefully the featured resource, the image of it, and the uses to which it will be put: determine which resources and images are culturally appropriate for Interpretation and publication; negotiate intellectual property rights and educate partners to do the same

- Seek visual equivalents for alternative constructions of time and historic events

- Emphasize the age and cross-cultural significance of resources

- Display only actual, current, and accurate images of Native Americans; identify individuals and events

\section{Ending Erasure and Resituating Archaeology}

- Acknowledge and illustrate individual and collective involvement and collaboration with stakeholders and consultation with Native American tribes; document contributions to the knowledge base of Interpretation even when individual attribution is inappropriate

- Display disparate viewpoints side by side

- Be transparent about how we know what we know

- Accept ambiguity and contradiction

- Allow visitors to discover their own understanding

\section{LESSONS LEARNED}

\section{Presenting Information}

Visitors come to see iconic cultural resources; both visitor experience and safety demand that a certain amount of interpretive resources be devoted to orientation, as several interviewees noted. Ideally, staff and volunteers provide visitors with both orientation and Interpretation. Observation at the four staffed sites indicated that signage, even at trailheads, generally duplicated information volunteered by visitor center staff and was frequently less detailed and less accurate; signage at all five sites, to varying degrees, needed maintenance. Many visitors take advantage of buy or borrow boxes of 
(Re)Presenting peoples and storied lands

trail guides; at unstaffed sites, the trail guides are a vital interpretive tool, sometimes the only one.

De-emphasizing costly wayside panels and trailhead signage in favor of less visually obtrusive minimalist signs, key signs, and trail guides may encourage both visitors' interactions with staff and their individual encounters with the land. As one interviewee noted, revising, updating, and producing trail guides is easier, cheaper, and faster than maintaining, revising, and updating signage, and therefore signage often lingers, worn and outdated. Additionally, as another interviewee emphasized, protected area staff may be able to fabricate smaller, simpler signage in-house or obtain it from local sources, thereby serving return visitors better and keeping current with changing knowledge; updating information this way may also foster connections in and with the community. Furthermore, at sites with cell phone coverage or where it is feasible for a protected area to provide a local intranet, motivated visitors can use QR codes to access specific web pages for orientation, park history, agency mission, and more; one interviewee stressed the importance of using technology to balance best practices in museology (in object display, less is more in labeling) and Interpretation (offering visitors multiple avenues to individual meaning-making).

\section{Stewarding Sites}

Iconic sites are regularly in danger of being loved to death, in the words of several interviewees. I interviewed several protected area land managers and archaeologists who maintained that the more well-known a cultural resource is, especially in the local community, the more vital that it be featured prominently in Interpretation. In general, 
staff expressed the belief that personal Interpretation is the best — but not infalliblestrategy for minimizing both human and environmental threats to cultural resources. Technology may provide a reasonable proxy for ranger-led tours when human capital is scarce. Protected areas may be able to charge visitor fees for formal personal Interpretation and retain that income to support current or additional interpretive programming.

Only one case in the study used cellphone audio and video tours. Staff there characterized the medium as inexpensive, easy to use, and producing unexpectedly frequent and positive visitor feedback. Cellphone tours may provide an opportunity to provide high-quality interpretive content across multiple platforms and encourage visitor retention of important messages. Additionally, they may encourage visitors to report human and environmental threats to natural and cultural resources, and enable timely management response. In areas without cell service, protected areas could conceivably load interpretive material on electronic tablets and lend them to visitors. Further research on feasibility, visitor response, and management satisfaction is needed.

My observation indicated that preservation/conservation messages tended to be admonitory rather than informative or provocative. In interviews, protected area staff maintained that increased visitation correlates with decreased vandalism and increased environmental threats to resources; that unrepaired/unrestored vandalism attracts vandalism, and that encouraging visitors to touch, carve, mark, climb, etc. in a designated, limited area fails to reduce damage to resources. I observed visible repair/restoration at three sites but found no interpretive displays that showed visitors 
evidence of increasing damage over time or vandalism, nor any that documented repair. restoration, or (un)satisfactory results. ${ }^{23}$ An additional low-cost visitor center video focusing on individuals' personal experiences—a restorer's frustration over unpredictable results, or an interview with a long-time visitor, perhaps even the one I encountered weeping, literally weeping, over the damage to the Grimes Point petroglyphs since her last visit—might well provoke visitors' visceral reaction.

One of the five sites made interpreted, preserved, and abandoned excavations generally accessible to unaccompanied visitors during park hours. Another offered fortnightly volunteer-led tours of an abandoned excavation. At the first one, the only visitors I observed at the excavations were archaeology students on organized tours. In contrast, a small but steady stream of visitors in small groups explored the nearby stabilized village and water catchment sites during multiple observations.

On the excavation tour, visitors displayed little enthusiasm, regularly wandered off, and asked few questions, despite the fact that taking the tour involved considerable time, planning, and effort. Their disengagement might be attributed to the interpreter's insufficient competence, charisma, and command of logistics (for established standards and best practices in personal Interpretation, see Powell \& Stern, 2013; Stern et al., 2013; Stern \& Powell, 2013); however, visitors' disengagement might equally be attributed to

${ }^{23}$ At Bandelier, roving rangers and temporary signage on construction barriers interpreted ongoing stabilization work; panels elsewhere at Bandelier detailed changing practices in the reconstruction of archaeological sites over time. Interpretation at AHC/CANM and Baker, sites biased toward archaeological practice, discussed stabilization and backfill. 
qualities inherent in the site. ${ }^{24}$ Such sites represent the discipline of archaeology as excavation and looting rather than study and science. This research suggests that interpreted, preserved, and abandoned excavations generally fail to engage visitors, and that the interpretive resources devoted to them might be diverted to other projects.

\section{Engaging Visitors}

Visitors come to protected areas that present archaeology not only to see iconic resources, but also to learn about other times, other peoples, other places (White et al., 2005). My research seldom observed visitors attending to historic photographs of Native Americans, adventurers, or archaeologists, even dramatic enlargements; however, this research did observe visitors drawn to and held by color photos of people, even small ones on text panels. Audios and videos in which Native Americans or archaeologists were represented as contemporary people engaged in contemporary activities - telling a story, answering a reporter's questions, dancing, saying hello in a Native language — drew visitors and held them longer. Potentially, representations like these may contribute to visitor experience by emphasizing personal or phenomenological authenticity (Jamal \& Hill, 2004), and may manifest another way of knowing.

Participatory displays (Simon, 2010) drew visitors of all ages, but panels and displays offering touchable replicas were observed to attract visitors ${ }^{25}$ less than those that required an action (for example, pressing a button to light a section of a 3-D topographic

\footnotetext{
${ }^{24}$ On purely subjective grounds, I suggest that such sites may evoke a profoundly alienating and negative emotional response in some visitors: stripped, raped, and dead come to mind. In contrast, stabilized or stabilized-and-backfilled sites may evoke curiosity and excitement.

${ }^{25}$ I observed no visitors with evident visual impairments in this research.
} 
map), and considerably less than those that required both action and choice (for example choosing a projectile point to put under a microscope). The AHC/CANM museum - which staff at other protected areas praised for both its participatory design and its focus on archaeological practice — enabled visitors to weave, grind corn, and use tools of paleobotany, archaeology, and curation, as well as to choose from a variety of videos on experimental archaeology and drawers of artifacts and replicas (the interactives in the discussion above). ${ }^{26}$ Tactile and kinesthetic engagement like this may also heighten personal authenticity and potentially provoke the personal meaning-making that Interpretation seeks. Further qualitative research into visitor experience in participatory museums focused on archaeology is needed.

The nature of archaeological sites often renders access difficult. Buildings and facilities at all five research sites appeared to comply with ADA requirements, but access to cultural sites on the landscape varied widely and perhaps necessarily. Four of the five sites' webpages featured interpretive text, photos and/or videos; potentially online media may serve as a virtual visit or a virtual tour for those unable to access archaeological sites in person. At Petroglyph, the visitor center placed interpretive videos-complete with headphones and closed-caption controls - within reach of a seated visitor. Bandelier's museum and the Mesa Verde VRC displayed bronze maquettes of key ancestral villages

\footnotetext{
${ }^{26}$ I also observed participatory displays at Bandelier, Petroglyph, and Mesa Verde, primarily interactive drawers of artifacts and replicas but also visitor-choice audio and video and displays requiring the visitor to flip, slide, or otherwise manipulate the display to reveal an answer. The difference is not merely a matter of degree, but also in offering the visitor embodied experience and, at least theoretically, empathy-producing engagement.
} 
that not only provided an opportunity for tactile exploration, but were objects of beauty in and of themselves.

I observed that visitors engaged with sculpture and installation pieces in ways that reinforce key tenets of Interpretation, namely that social interaction and provocation support meaning-making (Ellenbogen \& Luke, 2004; Falk, 2004). I regularly observed visitors encountering sculpture, collecting other members of their social group, and bringing them back to the work to talk about what resonated in their own lives; installations in particular drew and held social groups that included school-age children. Two examples from the Mesa Verde VRC: "Look, Grampaw, he can tell me a story just like you" (preschool boy to older man); "Look at how she's sitting. Could you do that? I couldn't make pots if I had to do that" (middle-aged woman to one female and two male peers). I observed no similar social engagement occasioned by prints, paintings, or object cases. Commissioning art—as, for example, the paintings and sculptures by established mid-career artists, the majority of whom are Native Americans, displayed at the VRCmay potentially further an interpretive strategy based in self-representation.

My research found a paucity of cultural demonstrations, possibly because my visits occurred at the end of tourist season. However, even limited observation testified to the attractive and holding power of art and of artists engaged in their work. Not a single visitor was observed to ignore the two potters at work in a shaded corridor outside the Bandelier visitor center: several social groups, in fact, returned later in the day to see the potters' work progress and continue earlier conversations; one group returned repeatedly to watch the work take shape. Further research — particularly extended observation of 
visitors' engagement with artists and different art forms, and especially sculpture and installation-is needed.

\section{Representing Visually}

Overall, the Interpretation viewed at four of these five sites situated adventurers, settlers, and archaeologists in the historic era, and situated archaeologists and Native Americans in the present. In most cases, Interpretation used exquisitely detailed artists' renderings to represent people in ancient time; first-person accounts and period drawings and photographs to represent people in the historic era; and first-person narratives and color photos to represent contemporary people. The images used in Interpretation may be problematic for several reasons. First, the kind of four-color artists' renderings associated with NPS site bulletins and National Geographic archaeology cover stories are likely to carry the weight of those institutions' authority in the minds of many dominant-culture visitors; thus, Interpretation using elegant reconstructions based on current archaeological inference may lead viewers to a belief that the representation is authoritative and definitive, objective truth rather than contingent knowledge. Some of the newest renderings, for example at Mesa Verde's VRC and AHC/CANM's Sand Canyon Pueblo, tend to the more abstract and evocative: this may be a positive trend, and merits further study.

Second, while historic photos of Native Americans may have been staged by white photographers, they may also evidence subjects' agency and active selfrepresentation (Glass, 2009). In many cases, it is impossible to obtain the photographic subjects' informed consent for their display. To complicate matters further, descendants 
and descendant communities may value the photos quite highly: some may wish to see such vital documents displayed, others may not; according to one interviewee, even tribal cultural centers and museums sometimes experience difficulty negotiating permission for photographic display. When permission is granted to display such images, visitors could be informed of their provenance by QR codes, website hyperlinks, even by a small and simple brochure printed in-house and held at the info desk; at the very least, staff could be trained to answer the occasional question and provide additional information.

Furthermore, different peoples' constructions of living lands, even different people's understandings of cultural resources, determine what they consider appropriate use of imagery. One person may experience a landscape as a favorite place for early morning exercise, and another as a place of pilgrimage (Anschuetz, Ferguson, Francis, Kelley, \& Scheick, 2002). One person may find rock art or petroglyphs where another encounters rock writing or sentient beings (Spoon et al., 2014). Petroglyphs are particularly vulnerable to appropriation for "logoization" and commercial use (Dickinson, 2012), and petroglyph photographs and drawings often appear in protected area interpretive material. The ethical mandate to seek informed consent holds in this case, too: in the absence of an interpretive delegate able to obtain informed consent from a nonhuman entity, decisions about the appropriate use of Native American intellectual property in Interpretation should only be made in light of robust consultation with affiliated peoples. 
Differing constructions of time and history also have implications for representation. Timelines were observed in three of these five case studies. Two represented events solely as constructed by science and written history. Increasingly, Euro-American culture and archaeology recognize the durability of oral tradition (A. B. Lord, 1960; Martindale \& Marsden, 2003; Martindale \& Nicholas, 2014; Vansina, 1985). At one site I observed a timeline that juxtaposed archaeological/written and traditional narratives of events in time and history (see Barber, 2013 for another example); this attention to oral tradition may mark another positive trend in display and also merits further research.

\section{Ending Erasure and Resituating Archaeology}

While any study of the practices of museum display is necessarily a sort of archaeology (Bennett, 1995, 2004; Foucault, 1970), a study of protected area Interpretation of archaeology is acutely time-bound. A museum may only need to rotate objects and create new labels to reflect changing thought and safeguard material culture, but a protected area may need to interpret new resources (to reduce human threats to familiar resources, to shape visitor behavior at interpreted sites, or to provide new experiences for regular visitors, for example). Protected areas also tend to invest their resources in producing print and signage that reflects current knowledge. As a result, Interpretation on the land may lag behind changes in archaeological knowledge even more so than Interpretation in visitor centers and museums, as one interviewee noted repeatedly. Interested visitors may be able to discern clues to the age of the Interpretation on the land (degree of wear and tear, graphic style, copyright, etc.), but with the 
(Re)Presenting peoples and storied lands

exception of Sand Canyon and Lowry Pueblos, the Interpretation observed in this research generally failed to situate itself in time. Visitor-historians—avocational, amateur, professional, or scholarly — may be particularly interested in this information (Maziarski, 2012). As with historic photographs, the interpretive history of protected areas could be disclosed relatively easily.

Furthermore, Interpretation could potentially disclose its authorship and increase its credibility by showing visitors that individuals, professions, and disciplines interact to construct themes, narratives, and content. Predominant interpretive practice does not credit photographers, illustrators, designers, etc. for their work, nor does current practice disclose the sources of the knowledge that the final exhibits represent. When display represents the knowledge of Native Americans, archaeologists, anthropologists, and other specialists -the rhetorical strategies of ethnography, autoethnography, and multivocality-exhibit panels might picture the specialists involved with interpretive development teams as well as naming them.

My observation indicated that Interpretation generally did not emphasize Native American involvement, collaboration, or consultation in resource management or interpretative development. This research found that protected area staff perspectives on consultation varied from "cultural sensitivity should play more into Interpretation, but the tribes are not very engaged in this part of the country... Basically all we do is Section 106 [letters] and do our best to follow up with them" to "our relationship far transcends NAGPRA or Section 106." Legally mandated consultation may necessarily be opaque to the visitor-by definition, consultation occurs at the government-to-government level-- 
(Re)Presenting peoples and storied lands

but Interpretation could foreground Native American involvement, consultation, and collaboration. The nexus of archaeological resources, development and/or maintenance, and visitation in protected areas creates an unrivaled opportunity—a missed opportunity — to educate the public about tribal sovereignty.

Rhetorical sovereignty, "the inherent right and ability of peoples to...decide for themselves the goals, modes, styles, and languages of public discourse" (Lyons, 2000, p. 449 , italics in original), may encourage self-representation and collaborative development in protected area Interpretation of archaeology in some cases and may discourage it in others. Some Native American peoples may conduct ethnographic study and prepare interpretive resources for a protected area to use (for example, Spoon, Arnold, \& Nuwuvi Working Group, 2012; Spoon et al., 2014); others may focus on identifying given material culture as appropriate or inappropriate for Interpretation (e.g. Anschuetz et al., 2002); while others approve or reject proposed display. The range of engagement in interpretive projects may reflect the heterogeneity of Native American peoples, their particular circumstances, and their historical and ongoing relationships with protected area staff. But surely collaboration allows room for negotiation over disclosure of the processes involved in collaborative interpretive display and resource co-management where they exist.

The extensive use of Native voice in two, possibly three, of these case studies suggests the sites' Interpretation was developed collaboratively and implies a degree of involvement that merits significant acknowledgment. In one case, Interpretation attributed knowledge to cultural insiders in a very general way; in two other cases, it 
(Re)Presenting peoples and storied lands

acknowledged contributions from named individuals and a specific group.

Transparency may contribute to meaningful visitor experience: while general attribution is essential to convey a sense of Native or curatorial voice; individual attribution is preferable (e.g., "Native Elder, Las Vegas Band of Paiute Indians," Fish and Wildlife Service Archaeologist," "Rancher and Life-long Caliente Resident); named individuals may speak to visitors. Recent museum visitor research suggests that—in keeping with the entrance narrative model (Doering, 1999)—most visitors to explicitly collaborative exhibits retain their pre-existing belief that institutions and curators, not collaborators, hold authoritative knowledge, assert power over its dissemination, and develop displays (Krmpotich \& Anderson, 2005; Schultz, 2011). Even so, the historic erasure of living Native Americans from protected area Interpretation may be countered, in part, by making the extent of their participation in exhibit development transparent. 


\section{Appendix B: Sample Questions}

Sample Questions for Protected Area Staff

I gave interviewees an index card prompting them to fill in the following blanks: job title, time associated with protected areas, time associated with this protected area, age, gender, and ethnic identity.

Tell me about your day today: what interpretive activities have you been involved in?

- What is interpretation? What does interpretation do?

- What is interpretation in the context of archaeology?

- What are your goals for interpretation? How do you measure success?

Tell me about the site:

- Why is it important or meaningful?

- What have you learned here?

- How does archaeology teach us about the past? about our present?

- What do you want visitors to take away?

For all staff, but particularly for interpreters:

- Of all your interpretive activities, what do you think is most effective?

- What is successful interpretation?

- What do you enjoy the most?

- What do you perceive visitors are getting from the experience?

- How do you try to influence visitor behavior?

- What do you want visitors to take away?

For all staff, but particularly for land managers:

- What kinds of problems do you have with damage to the resources?

- What makes people want to protect the site?

- What encourages different kinds of damage?

- What works best to preserve archaeological resources?

- Are there times the different aspects of your mission collide? Please tell me about that

- What advice would you offer to someone developing a new visitor center at an archaeological site? 
Sample Questions for Visitors

I briefly described the project to potential interviewees, solicited their participation, and asked for permission to record the conversation.

Your age?

Where do you live?

What brought you to $?$

Please tell me about the things you most enjoyed about

Would you do again?

What would you like to have more of?

Please tell me what kinds of thing you learned from [Probe for human-environment dynamics] [Probe for Native American culture]

What could the ranger/guide/interpreter talk more about?

What originally interested you about ?

What do you think is most interesting now?

What do you expect to see and do when you visit a national park / tribal park / national monument? 


\section{Appendix C: Codebook}

\begin{tabular}{|c|c|c|c|c|}
\hline Category & Group & Code & Includes & $\begin{array}{l}\text { Exclusions/ } \\
\text { comments }\end{array}$ \\
\hline \multirow[t]{11}{*}{$\begin{array}{l}\text { Narrative } \\
\text { Content } \\
\end{array}$} & $\begin{array}{l}\text { Management } \\
\text { Messages }\end{array}$ & orientation & regulation, law, penalty, safety & \\
\hline & & conservation & $\begin{array}{l}\text { preservation, multiple use, } \\
\text { stabilization, vandalism, } \\
\text { collecting/collections, curation }\end{array}$ & \\
\hline & & mission & $\begin{array}{l}\text { management structure, } \\
\text { administration, institutional } \\
\text { history, } 19^{\text {th }}-21^{\text {st }} \mathrm{C} \text { development } \\
\text { as PA; donors, awards; academic } \\
\text { and private partnerships; thanks to } \\
\text { named collaborators }\end{array}$ & \\
\hline & $\begin{array}{l}\text { Scientific } \\
\text { Narratives }\end{array}$ & $\begin{array}{l}\text { archaeological } \\
\text { practice }\end{array}$ & $\begin{array}{l}\text { everything that shows } \\
\text { constructedness, reasoning, } \\
\text { discusses technique and } \\
\text { technology (radiocarbon or } \\
\text { obsidian dating, stratigraphy), } \\
\text { how we know what we know } \\
\end{array}$ & \\
\hline & & archaeology & $\begin{array}{l}\text { inference, interpretation, } \\
\text { conventional explanations derived } \\
\text { from material culture study: } \\
\text { migration, subsistence (hunting } \\
\text { gathering, seasonal round), tool } \\
\text { use, architecture, technology, } \\
\text { agriculture, trade }\end{array}$ & \\
\hline & & natural history & $\begin{array}{l}\text { flora, fauna, environment, climate, } \\
\text { fire, flood }\end{array}$ & \\
\hline & & geology & soil, rock, volcano & \\
\hline & $\begin{array}{l}\text { Cultural } \\
\text { Narratives }\end{array}$ & $\begin{array}{l}\text { non-Indigenous } \\
\text { history }\end{array}$ & $\begin{array}{l}\text { contact and other cultures, } \\
\text { Spanish, new Mexican, explorers, } \\
\text { collectors, archaeologists; } \\
\text { contemporary cultural interaction, } \\
\text { understanding; contact, } \\
\text { entanglement, exploration, } \\
\text { discovery, settlement; captures } \\
\text { specific references to peoples } \\
\text { other than those whose material } \\
\text { culture is showcased in the site }\end{array}$ & \\
\hline & & $\begin{array}{l}\text { connection to } \\
\text { place, place- } \\
\text { based } \\
\text { spirituality }\end{array}$ & & $\begin{array}{l}\text { other or } \\
\text { unspecified } \\
\text { religion/spiritual } \\
\text { practice }\end{array}$ \\
\hline & & $\begin{array}{l}\text { cultural } \\
\text { continuity }\end{array}$ & & $\begin{array}{l}\text { contemporary } \\
\text { art, photographs, } \\
\text { material culture }\end{array}$ \\
\hline & & other & $\begin{array}{l}\text { meaning, significance, } \\
\text { timelessness, escape city, } \\
\text { consultation, language, pottery, } \\
\text { market economy/integration, }\end{array}$ & $\begin{array}{l}\text { explicitly stated } \\
\text { above }\end{array}$ \\
\hline
\end{tabular}




\begin{tabular}{|c|c|c|c|c|}
\hline & & & $\begin{array}{l}\text { gender roles, cultural exchange, } \\
\text { culture change, oral history, } \\
\text { water, resource use, defense, } \\
\text { communication, medicine }\end{array}$ & \\
\hline \multirow[t]{5}{*}{ Voice: } & $\begin{array}{l}\text { POV } \\
\text { Management } \\
\text { Messages, } \\
\text { Scientific } \\
\text { Narratives }\end{array}$ & $\begin{array}{l}3^{\text {rd }} \text { person } \\
\text { omniscient }\end{array}$ & & $\begin{array}{l}\text { voice of } \\
\text { orientation }\end{array}$ \\
\hline & & $1^{\text {st }}$ person & archaeologists, Franciscans & \\
\hline & $\begin{array}{l}\text { POV Cultural } \\
\text { Narratives }\end{array}$ & $\begin{array}{l}3^{\text {rd }} \text { person } \\
\text { inclusive }\end{array}$ & $\begin{array}{l}\text { Our ancestors...they } \\
\text { Our ancestors...we }\end{array}$ & \\
\hline & & $\begin{array}{l}1^{\text {st }} \text { person, } \\
\text { credited }\end{array}$ & & \\
\hline & & $\begin{array}{l}1^{\text {st }} \text { person } \\
\text { named }\end{array}$ & & \\
\hline \multirow[t]{3}{*}{ Timeframe } & & Ancient time & & $\begin{array}{l}\text { how narrative } \\
\text { situates people: } \\
\text { people can be } \\
\text { absent from } \\
\text { narrative }\end{array}$ \\
\hline & & Historic era & Entrada de Coronado - 1999 & \\
\hline & & Contemporary & & $\begin{array}{l}\text { unless otherwise } \\
\text { noted in } \\
\text { comments, } \\
\text { natural history } \\
\text { and geological } \\
\text { narratives are } \\
\text { contemporary }\end{array}$ \\
\hline
\end{tabular}




\section{Appendix D: Informed Consent}

\section{Protected Area Staff Informed Consent - Written}

You are invited to participate in a research study conducted by Cerinda Survant from Portland State University, Department of Anthropology. The researcher hopes to learn the full range of ways that archaeology is presented to the public. This research is in partial fulfillment of the requirements of a master's degree and is supervised by Dr. Jeremy Spoon.

You were selected as a possible participant in this study because of your involvement in the interpretation of archaeological resources in a protected area. If you decide to participate, you will be asked to participate in an hour-long interview; the interview will be recorded on a digital audio recorder.

You may not receive any direct benefit from taking part in this study, but the study may help to increase knowledge which may help others in the future.

Any information that is obtained in connection with this study and that can be linked to you or identify you will be kept confidential.

- Digital audio recordings will contain no identifying information and will be kept on

- the researcher's password-protected computer. Recordings will be transcribed for analysis.

- Interview transcripts will contain no identifying information. During the research phase,

- transcripts will be held on the researcher's password-protected computer and secure servers

- maintained by the university and SCRC (qualitative analysis software).

- After the research phase, transcripts will be held in a locked office at the university and

- $\quad$ on the researcher's password-protected computer. Digital audio files will be erased.

This research is a chance to share your experience, and while every attempt will be made to keep your identity confidential, your story could be identified and your confidentiality cannot be guaranteed.

Your participation is voluntary. You may withdraw from participation at any time.

If you have questions or concerns about your participation in this study, please contact Cerinda Survant at 5039976589 or cerinda@pdx.edu or Dr. Spoon at 5037259729 or jspoon@pdx.edu. If you have concerns about your rights as a research subject, please contact Research and Strategic Partnerships, Market Center Building 6th floor, Portland State University, PO Box 751, Portland, OR 97207-0751, 5037254288.

Your signature indicates that you have read and understand the above information and agree to take part in this study. The researcher should provide you with a copy of this form for your own records. 


\section{Visitor Informed Consent - Verbal}

In accordance with NPS research protocols, I solicited only those visitors I observed engaged in interpretive activities. I collected basic demographic information and no identifying information from each interviewee: the interviews were and are anonymous.

For participants who appeared potentially under the age of eighteen, I requested verbal consent from the parent or guardian prior to approaching the child or children.

Immediately after introducing myself and my research, I recorded each interviewee's permission to record the interview. I ended each conversation by thanking my interviewee and giving him or her a written acknowledgement and contact information.

Acknowledgement

Thank you very much for participating in a research study conducted by Cerinda Survant from Portland State University, Department of Anthropology.

The researcher hopes to learn why people visit archaeological sites in parks and monuments, what people most enjoy about their visits, and what they find meaningful or memorable. This research is in partial fulfillment of the requirements of a master's degree and is supervised by Dr. Jeremy Spoon.

You were selected as a possible participant in this study because of your visit to such an archaeological site, visitor center, or museum. You may not receive any direct benefit from taking part in this study, but the study may help to increase knowledge which may help other visitors in the future.

If you have questions or concerns about your participation in this study, please contact Cerinda Survant at 5039976589 or cerinda@pdx.edu or Dr. Spoon at 5037259729 or jspoon@pdx.edu. If you have concerns about your rights as a research subject, please contact Research and Strategic Partnerships, Market Center Building 6th floor, Portland State University, PO Box 751, Portland, OR 97207-0751, 5037254288. 


\section{Appendix E: Demographic statistics}

\begin{tabular}{|l|c|c|c|c|}
\hline Total Interviewees & & & & 31 \\
\hline Total Staff Interviewees & & & & $\mathbf{1 6}$ \\
\hline Number of Staff Interviews & & & 15 & \\
\hline Age of Youngest Staff Interviewee & 25 & & & \\
\hline Age of Oldest Staff Interviewee & 67 & & & \\
\hline Mean Age of Staff Interviewees & & 49 & & \\
\hline Median Age of Staff Interviewees & & 51 & & \\
\hline Range of Experience in Protected Areas & $6-43$ years & & & \\
\hline Mean Years Working in Protected Areas & 21 years & & & \\
\hline Total Visitor Interviewees & & & & 15 \\
\hline Total Visitor Interviews & & & & \\
\hline Age of Youngest Visitor Interviewee & 7 & & & \\
\hline Age of Oldest Visitor Interviewee & 74 & & & \\
\hline Mean Age of Visitor Interviewees* & & 35 & & \\
\hline Median Age of Visitor Interviewees* & & 40 & & \\
\hline
\end{tabular}

* Four visitors declined to state age 


\section{Appendix F: NPS Permits}

\begin{tabular}{|c|c|}
\hline $\begin{array}{c}\text { SCIENTIFIC RESEARCH AND } \\
\text { COLLECTING PERMIT } \\
\text { Grants permission in acoondance with the attached } \\
\text { general and special conditions } \\
\text { United States Department of the Interior } \\
\text { National Park Service } \\
\text { Mesa Yerde NP }\end{array}$ & $\begin{array}{l}\text { Studyf̈: MEVE-20150 } \\
\text { l'ermito: MEVE-2013-SC1-0005 } \\
\text { Start Date: Jun 05, 2013 } \\
\text { Rexplration Date: Aug 31, } 2013 \\
\text { Coop Agreemento: n/a } \\
\text { Optional Park Code: n/a }\end{array}$ \\
\hline
\end{tabular}

Name of principal investigator:

Name: Jeremy Spoon Phone: 503-725-9729 Email: jspoon@iptix.eL̂u

Name of institution represented:

Portland State University

Co-Investigators:

Name: Ceriada Survant

Phone: 5039976589

Emall: cerinda@pdx edu

Projeet title:

The Interpretation of Archacology in Protected Areas: Toward a Best Practices Appronch

Purpose of study:

Reconciliag conservation and recreational use of public lands is probjematic, particularly when archacological or spiritunl significance is involved (Dustin, Schneider, McAvoy, \& Frakt, 2002). Protected area land managers adopt many strategies to safeguard cultural resorarces including installing exhibits that detail a resource's vulnenability or signage thas explains sanctions, and placing trails and barriers to mannge visitor access (Duncan \& Martin, 2002: Hughes 8 Saunders. 2005; White, Virden, \& Cahill, 2005). Of these strutegies, personal interoretotion a 2 the informal informational and inspirational communication with visitors - is often favored bectuse it is believed to foster visitors emotional connection to the resources and so guide behavior (Beck, \& Cable, 2002; Ham \& Krumpe, 1996; Ham, 2009; Tilden, 2007). This proposed fesenrch compares the interpretation of five archacological sites in protected arens in the American west, examining visitot experience and querying protected aren staff members' understanding of interpretation: the primary rescarch is supplemented by site visits to four archaeological sites in Lincola County, Nevada.

My research aims to contribute to the developing literature on the evaluation of interpretation in protected areas, to aderess a comparable lack of evaluative researeh oa public archacology, and increase the scant literature on the interpsetation of archacology.

SubjectDiscipline:

Social Science

Locations authorized:

Research will occur in areas developed for the interuretation of historic and pre-historic archaeology and the eavircament (e.p. visitor cersers and museums, an signposted trails, stenic drives, guided tours), not in wildemess areas. Research includes participant observation in regulatly seheduled interpretive activities and programs at Mesa Verde Nationsl Park (MEVA):

Visilur and Resesarch Center: Chapin Mesa Archoological Museum, Spruce Tree House, Mesan Top Loop Road, Far View Sites Complex, Cedar Tree Tower, Cliff Palace, liviag history proprams: Wetherill Mesa, Step House, Long House, Badper House Trail; San Temple; Mocefield ranger talks

Transportation method to research site(s):

personaj vehicle, Oregon plate CU $390 ! 9$

Collectlon of the following specimens or muterials, quantities, and any limitations on collecting:

Collection only of data.

Name of repository for specimens or sample materials if applieable: 


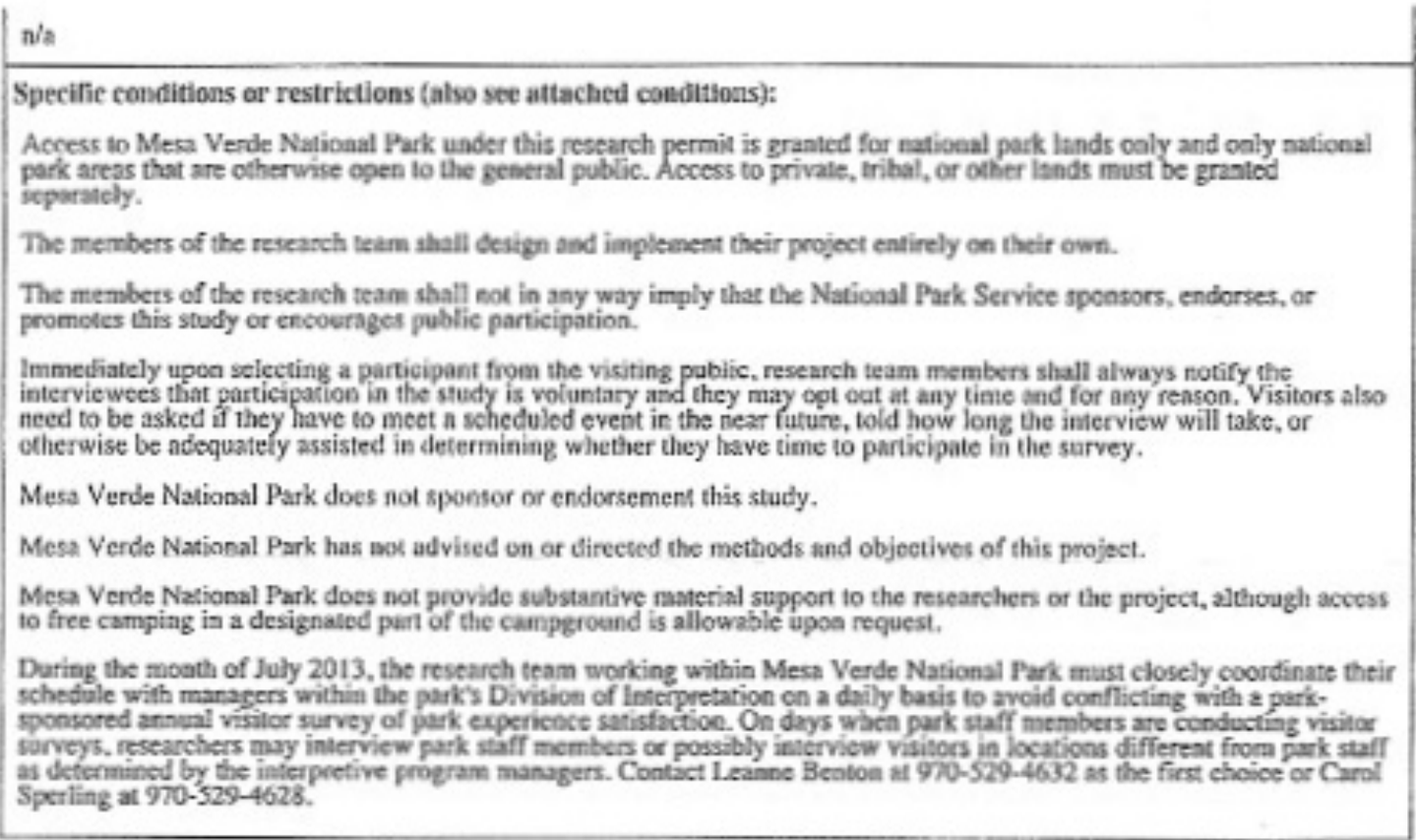

Recommended by park staff(name and title):

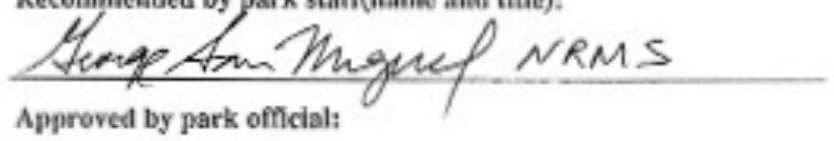

Approved by park official:

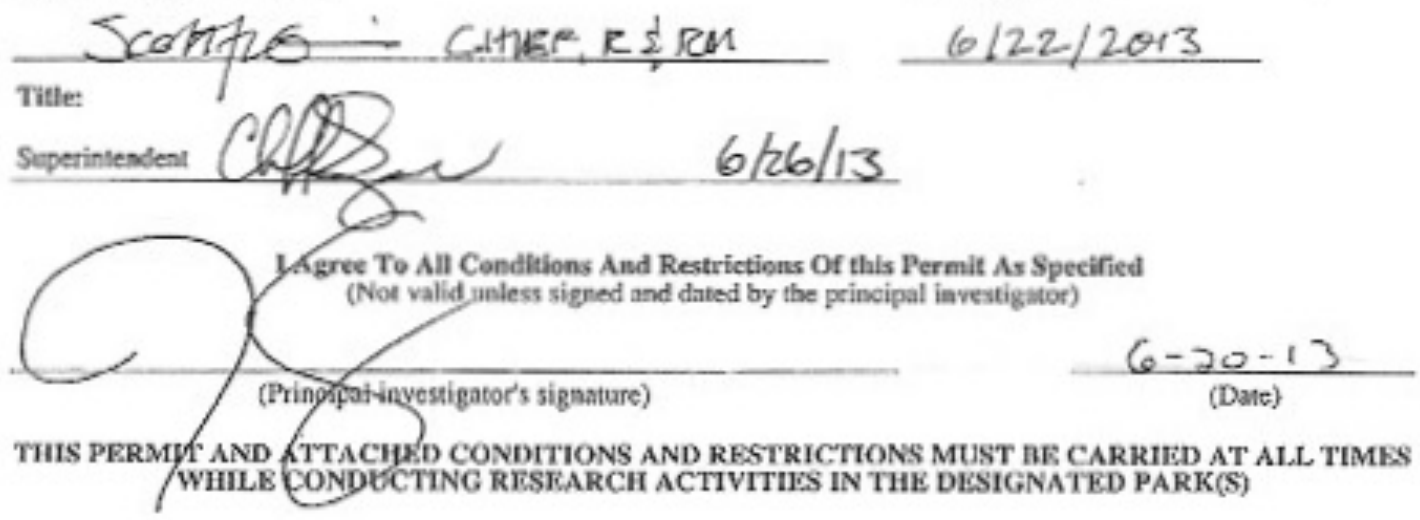

Reviewed by Collections Manager;

$$
\text { Yes } X \quad \text { No }
$$

Date Approved: 


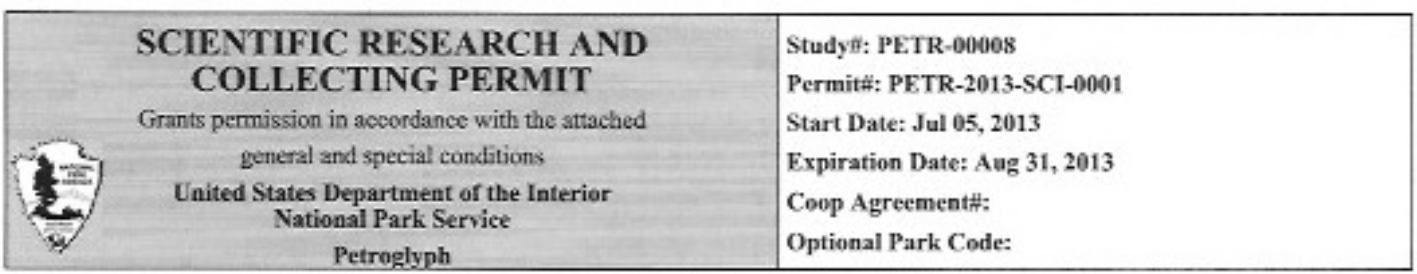

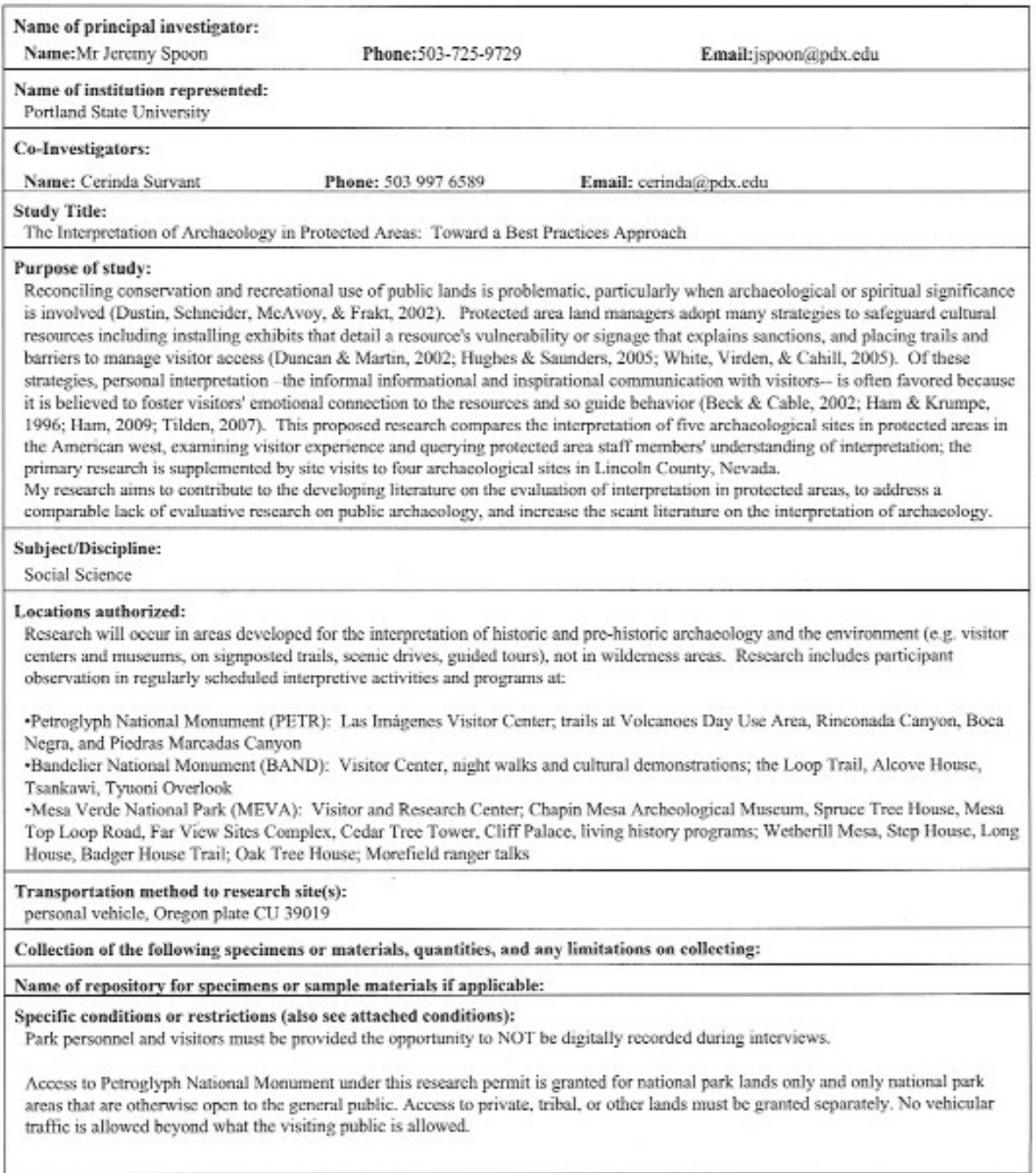


The members of the research team shall design and implement their project entirely on their own.

The members of the research team shall not in any way imply that the National Park Service sponsors, endorses, or promotes this study or encourages public participation

Immediately upon selecting a participant from the visiting public, research team members shall always notify the interviewees that participation in the study is voluntary and they may opt out at any time and for any reason. Visitors also need to be asked if they have to meet a scheduled event in the near future, told how long the interview will take, of otherwise be adequately assisted in determining whether they have time to participate in the survey.

Petroglyph National Monument does not sponsor or endorsement this study.

Petroglyph National Monument bas not advised on or directed the methods and objectives of this project

Petroglyph National Monument does not provide substantive material support to the researchers or the project.

During the moath of July 2013, the research team working within Petroglyph National Monument must closely coordinate their schetule with the Chief of Resource Management to avoid conflicting with a park-sponsored annual visitor survey of park experience satisfaction. On days when park staff members are conducting visitor surveys, rescarchers maly interview park staff members or possibly interview visitors in locations different from park staff as detenmined by park managers. Contact Mike Medrano at (505) 899. $0205 \mathrm{ext} 334$ for scheduling

Recommended by park staff(name and title): $(/ 2)$

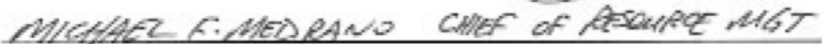

Approved by park official:

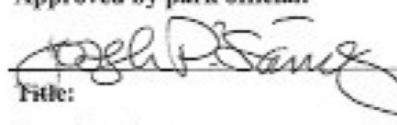

Superintendent

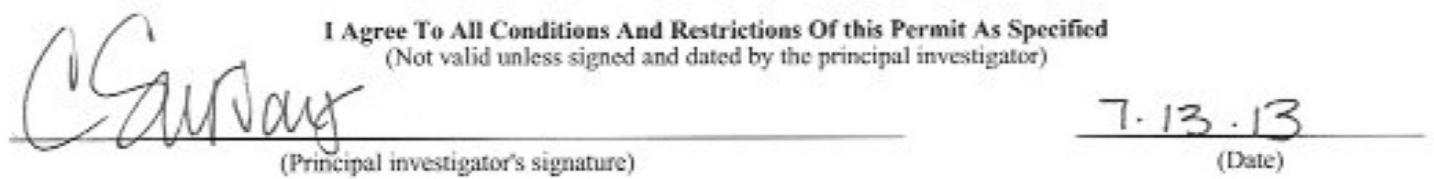

(Principal investigator's signature)

Reviewed by Collections Manager:

$$
\operatorname{Yes} X
$$

No

Date Approved:

$1 / 41 / 20 / 3$

THIS PERMIT AND ATTACHED CONDITIONS AND RESTRICTIONS MUST BE CARRIED AT ALL TIMES WHILE CONDUCTING RESEARCH ACTTVITIES IN THE DESIGNATED PARK(S) 


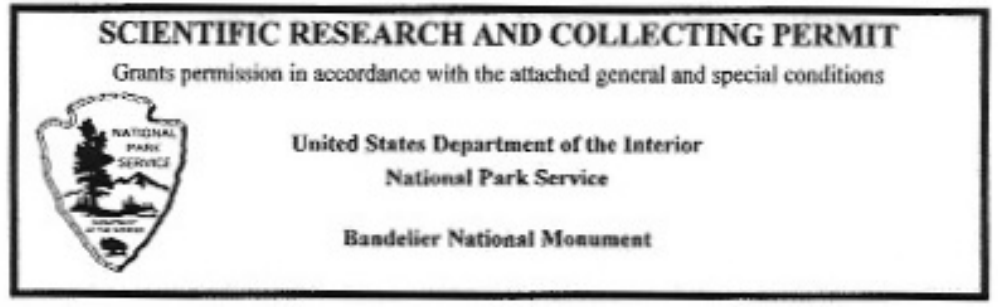

\begin{tabular}{|l|}
\hline Study H: 13996 \\
\hline Permit N: BAND-2013-SC1-0009 \\
\hline Start date: July 5, 2013 \\
\hline Expiration date: December 31, 2013 \\
\hline Coop. Agreement it: \\
\hline Optional Park Code: \\
\hline
\end{tabular}

Name of principal investigator: Cerinda Survant, Graduate Researcher, Office of Applied Anthropological Research, Portland State University, 2129 NE Couch Street clo Rachel Lahoff, Portand, OR 97232 USA. Phone: 503-997-6589; e-mail: cerinda@pdx edu Name of institution represented: Portland State University Additional investigator(s): Jeremy Spoon; 503-725-9729; ispoon(aipdx.edu

Project title: A Public Survey of Interpretation of Archaeology in Protected Areas

Purpose of study: Evaluation of interpretation of archaeology on public lands

Locations authorized: Outside of the Visitor Center, the Main Loop Trail, Alcove House, Tsankawi, and Tyuoni Overlook Transportation method to research site(s): By vehicle when on the park's paved roads.

Collection of the following specimens or materials, quantities authorized, and any limitations on collecting:

No collecting is permitted.

Name of repository for specimens or sample materials, if applicable: N/A

Specific conditions or restrictions (also see attached conditions)

DECLARATIONS

The members of the research team shall design and implement their project entirely on their own; Bandelier National Monument does not sponsor or endorse this study; Bandelier National Monument has not advised on or directed the methods and objectives of this project; Bandelier National Monument does not provide substantive material support to the researchers or the project. PERMIT CONDITIONS

1. Access to Bandelier National Monument under this research permit is granted only for national park areas that are open to the general public.

2. The members of the research team shall not in any way imply that the National Park Service sponsors, endorses, or promotes this study or encourages public participation.

3. Immediately upon selecting a participant from the visiting public, research team members shall always notify the interviewees that participation in the study is voluntary and they may opt out at any time and for any reason. Visitors also need to be asked if they have to meet a seheduled event in the near future, told how long the interview will take, or otherwise be adequately assisted in determining whether they have time to participate in the survey.

4. During the month of July 2013, the research team working within Bandelier National Monument must closely coordinate their schedule with managers within the park's Division of Interpretation on a daily basis to avoid conflicting with a park-sponsored annual visitor survey of park experience satisfaction. On days when park staff members are conducting visitor surveys, researchers may interview park staff members or possibly interview visitors in locations different from park staff as determined by the interpretive program managers. Contaet Tom Betts at 505-672-3861 x401 as the first choice or Sally King at 505-672-3861 x514. 3. An abstract of study's preliminary accompiishments and results is due by January 31, 2014. This abstract should be submitted using the web-based Investigator's Annual Report (IAR) using the web site found at <http://science.nature.nps.gov/research>. 6. A copy of all published papers resulting from this work shall be provided to the park.

7. A copy of this permit must be carried with field crew at all times during work within Bandelier National Monument.

Recommended by park sygfi (print mane and title)
Approved by park official:
Trtle:

I Agree To AlKConditions And Restrictions Of This Permit As Specified.

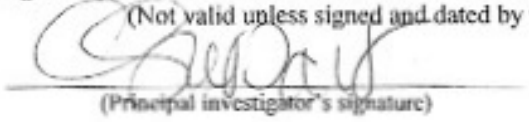

